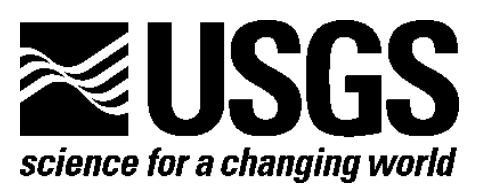

\title{
Proceedings of the 11th United States-Japan Natural Resources Panel for Earthquake Research, Napa Valley, California, November 16-18, 2016
}

Edited By Shane Detweiler and Fred Pollitz

Open-File Report 2017-1133

U.S. Department of the Interior

U.S. Geological Survey 


\section{U.S. Department of the Interior \\ RYAN K. ZINKE, Secretary}

\section{U.S. Geological Survey \\ William H. Werkheiser, Acting Director}

U.S. Geological Survey, Reston, Virginia: 2017

For more information on the USGS—-the Federal source for science about the Earth, its natural and living resources, natural hazards, and the environment-visit https://www.usgs.gov/ or call 1-888-ASK-USGS (1-888-275-8747).

For an overview of USGS information products, including maps, imagery, and publications, visit https://store.usgs.gov.

Any use of trade, firm, or product names is for descriptive purposes only and does not imply endorsement by the U.S. Government.

Although this information product, for the most part, is in the public domain, it also may contain copyrighted materials as noted in the text. Permission to reproduce copyrighted items must be secured from the copyright owner.

The abstracts by non-U.S. Geological Survey (USGS) authors in this volume are published as they were submitted. Abstracts authored entirely by non-USGS authors do not represent the views or position of the USGS or the U.S. Government and are published solely as part of this volume.

Suggested citation:

Detweiler, S., and Pollitz, F., eds., 2017, Proceedings of the 11th United States-Japan natural resources panel for earthquake research, Napa Valley, California, November 16-18, 2016: U.S. Geological Survey Open-File Report 2017-1133, 147 p.,

https://doi.org/10.3133/ofr20171133. 


\section{Contents}

Resolution of the Eleventh Joint Meeting of the United States-Japan Panel on Earthquake Research

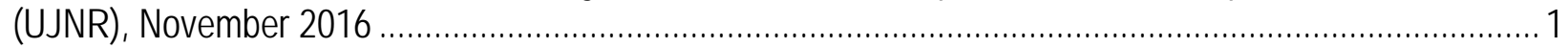

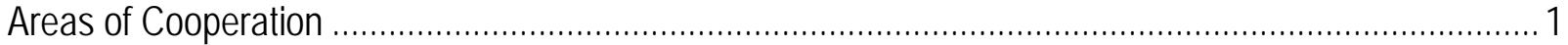

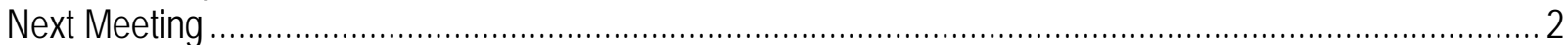

Agenda 2016 UJNR Meeting, Napa Valley, California: Oral and Poster Sessions (Presenter in Bold).......... 3

Session 1: National Policies, Strategies Programs, Networks, and Ongoing/Upcoming Projects................. 8

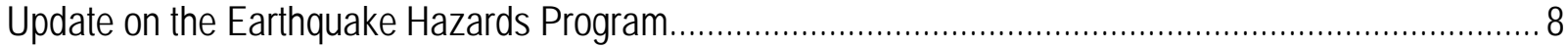

Overview of the Earthquake Hazards Program ............................................................................ 8

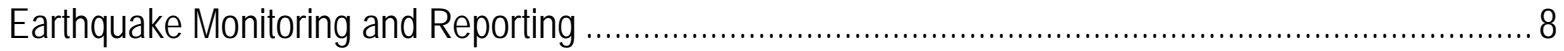

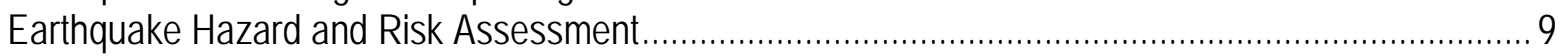

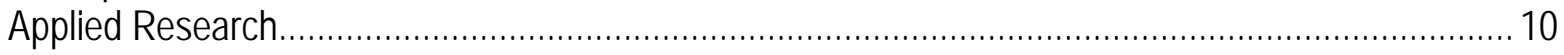

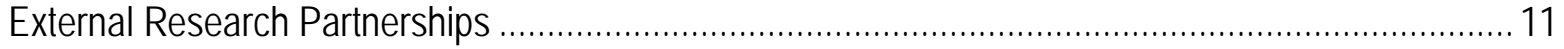

Communication, Outreach and Science Collaboration................................................................ 11

Japanese Earthquake Researches for Seismic and Tsunami Disaster Resilience................................. 13

The Path Towards Public Earthquake Early Warning for the Western United States............................. 14

Toward Incorporation of Real-time GNSS Data in the West Coast Earthquake Early Warning System ... 15

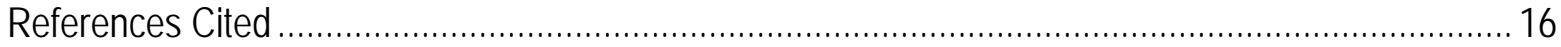

The 2014 Update to the U.S. National Seismic Hazard Model ............................................................ 17

Recent Advances in Earthquake Response and Research at the USGS NEIC ................................... 19

Session 2: The 2016 Kumamoto Earthquake Sequence .................................................................... 21

The 2016 Kumamoto Earthquake - Overview of the Seismic Activity and New Guidelines for the Seismic

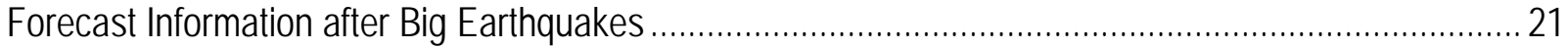

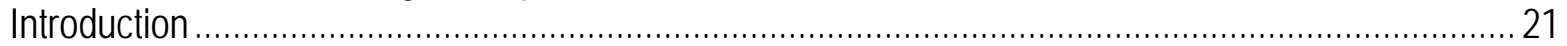

Distribution of Hypocenters and Mechanisms of the Earthquakes .............................................. 21

Analysis of Source Process and Source Scanning Algorithm .................................................. 22

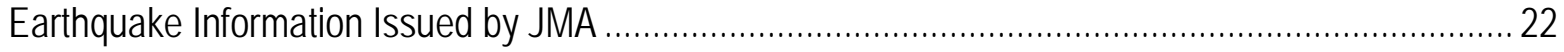

New Guidelines for the Seismic Forecast Information after Big Earthquakes ............................... 22

Strong Ground Motion of the 2016 Kumamoto Earthquake Observed in the Midst of Severely Damaged

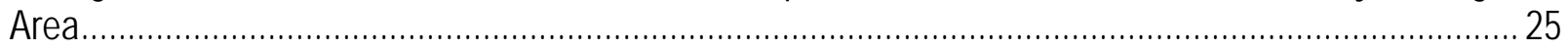

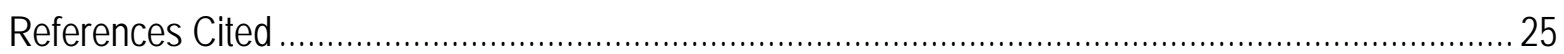

Seismicity and Structure Responses Following the 2016 Kumamoto Earthquake ................................ 27

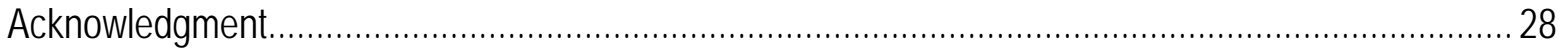

Fault Model of the 2016 Kumamoto Earthquake Inferred from Hypocenter Distribution and Strong-motion

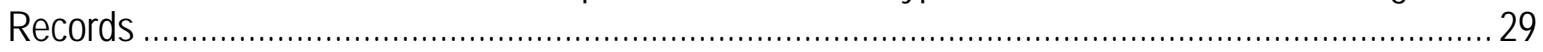

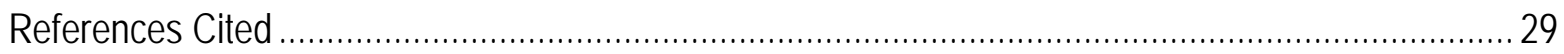

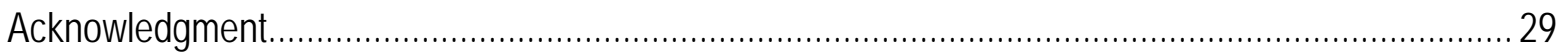

Detailed Ground Surface Displacement and Fault Ruptures of the 2016 Kumamoto Earthquake

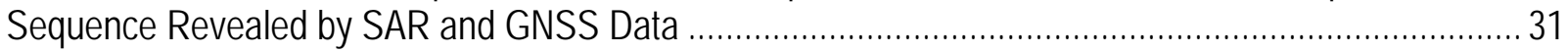

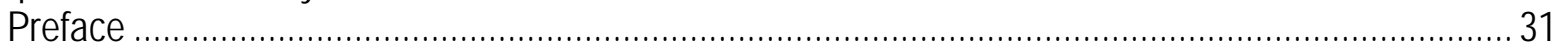

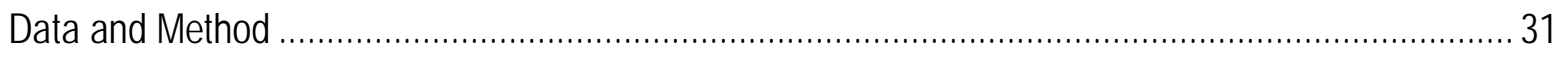

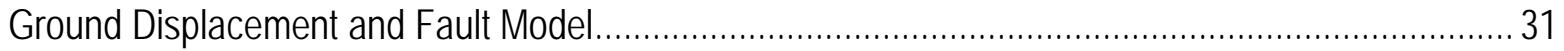

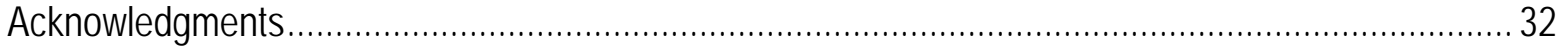

Small Displacement Surface Linear Ruptures of the 2016 Kumamoto Earthquake Sequence Detected by

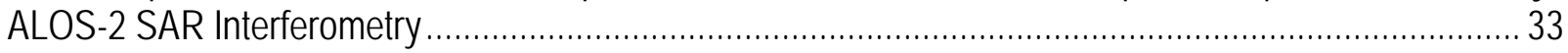

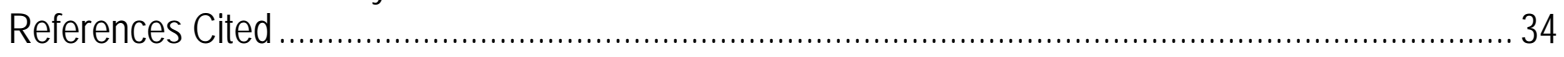


Earthquake Early Warning for the 2016 Kumamoto Earthquake: Performance Evaluation of the Current System and the Next-Generation Methods of the Japan Meteorological Agency ..................................... 35

Session 3: Earthquake Hazards Studies, Recurrence, and Mapping ..................................................... 37

A Spatiotemporal Clustering Model for the Third Uniform California Earthquake Rupture Forecast (UCERF3-ETAS) - Toward an Operational Earthquake Forecast........................................................ 37

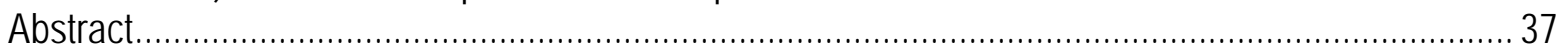

Operational Aftershock Forecasting for the United States and Globally ............................................ 38

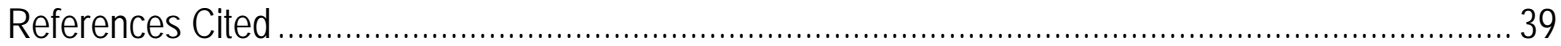

Incorporating ground motions from 3-D earthquake simulations into the U.S. National Seismic Hazard

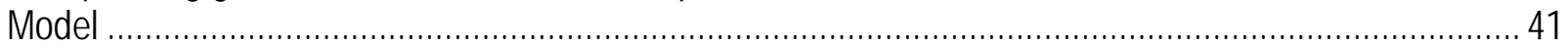

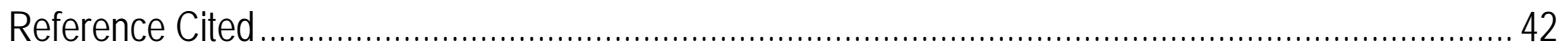

Supercycles and Synchronization Signatures in Synthetic Seismic Sequences................................. 43

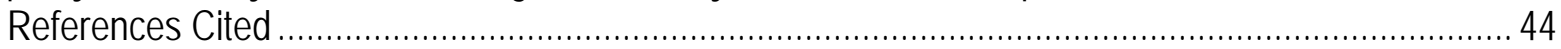

Possibility of Large Seismic Slip on Creeping Fault Segments and Deeper Creeping Fault Extensions.. 45

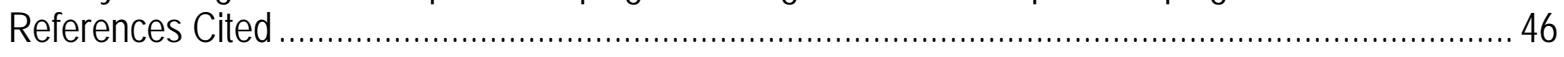

Correlations Between Fault Zone and Earthquake Properties in the Southern California Plate-boundary

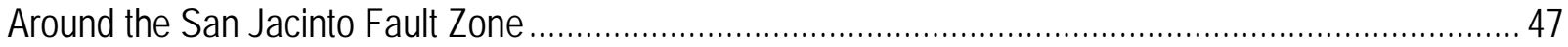

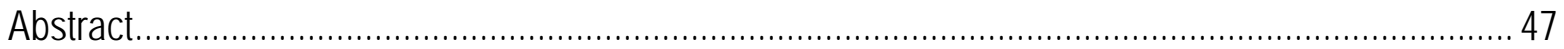

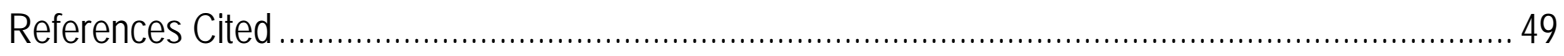

Evidence for Distributed Clockwise Rotation of the Crust in the Northwestern United States from Fault

Geometries and Earthquake Focal Mechanisms ……………............................................5

Shallow Surface Deformation Observed with UAVSAR. What Are the Implications for Earthquake

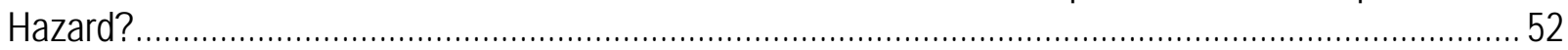

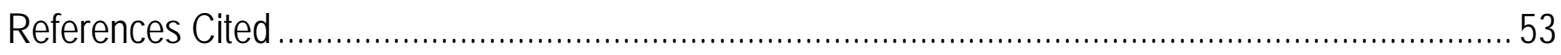

Session 4: Induced Seismicity ............................................................................................. 54

Statistics and Risk Associated with Induced Seismicity at The Geysers Geothermal Area, California and

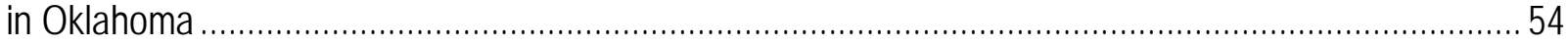

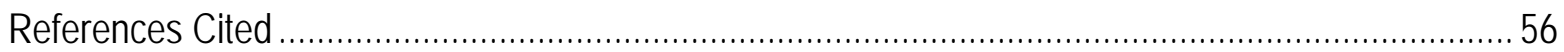

Managing the Hazard of Induced Earthquakes: Insights from InSAR and Geology ........................... 57

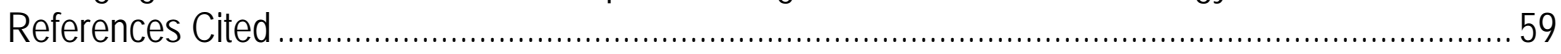

LArge-n Seismic Survey in Oklahoma (LASSO): Probing Injection-induced Seismicity with a Dense

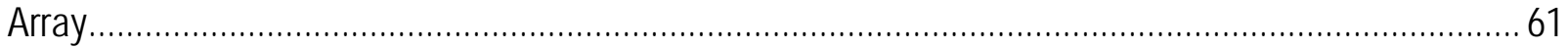

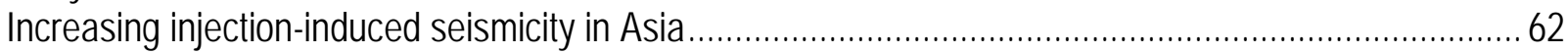

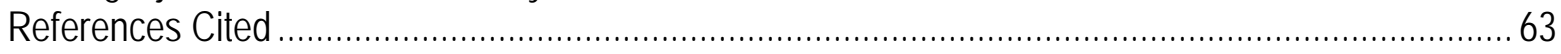

Induced Seismicity Insights from the Decatur, IL, $\mathrm{CO}_{2}$ Sequestration Project........................................ 64

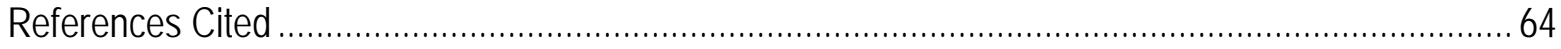

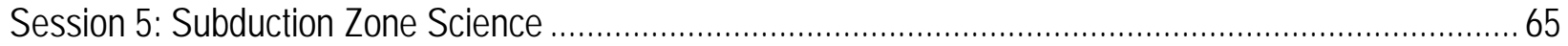

Recent Initiatives (S-Net, DONET, 'Ring of Fire', Subduction Zone Observatory) …….............................. 65

Estimation of Seismic Velocity Structure Beneath the Ocean Using Seismic Stations Offshore and on

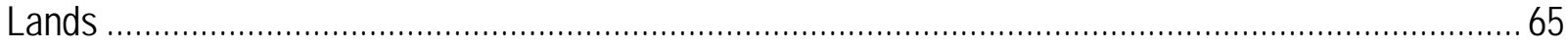

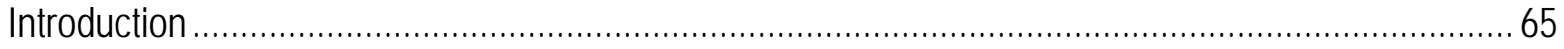

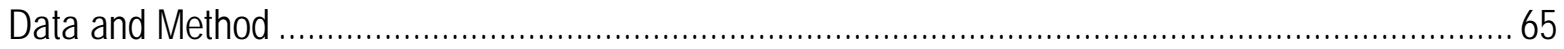

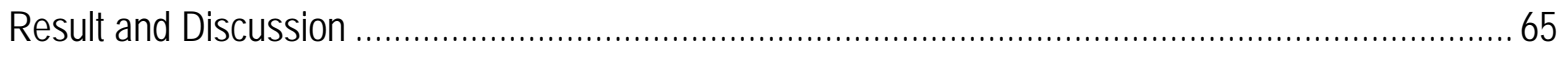

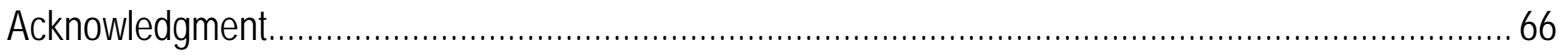

GRACE and Follow-on Gravity Missions: Contributions to Subduction Zone Science and Prospects for

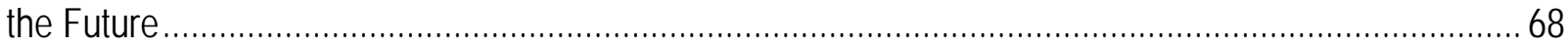

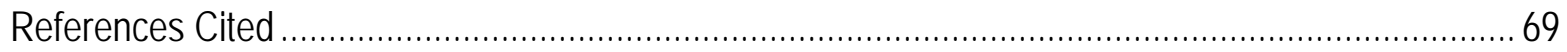


Real-Time Tsunami Inundation Forecast System using S-net Data ……........................................... 70

Recent Progress of Seafloor Geodetic Monitoring in Japan ......................................................... 71

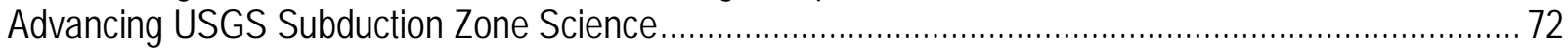

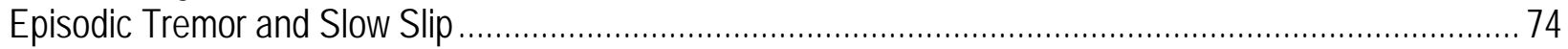

Shallow Slow Slip Event Off Kii Peninsula, Japan ......................................................................... 74

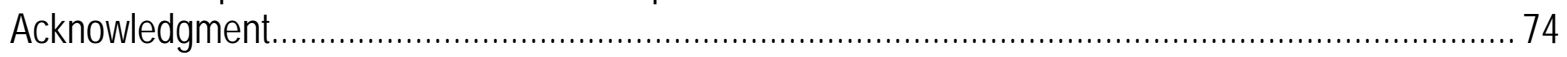

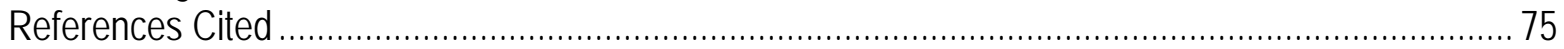

Fluid-faulting Evolution in High Definition: Connecting Fault Structure and Frequency-magnitude

Variations During the 2014 Long Valley Caldera, California Earthquake Swarm ....................................76

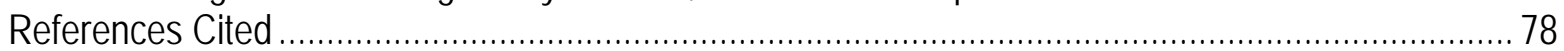

Interaction of SSE and Brittle Nucleation in Simulated Preseismic Slip ............................................. 79

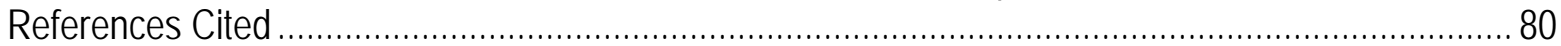

Operational Forecasting and Early Warning Systems of Earthquakes and Tsunamis .............................. 81

Global Navigation Satellite System Tsunami Early Warning Project .................................................... 81

Real-time Prediction of Ground Shaking Without Source Information: Data Assimilation and Simulation

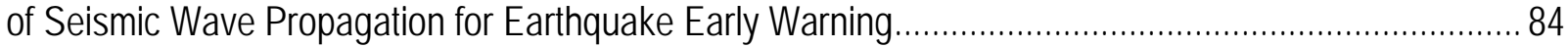

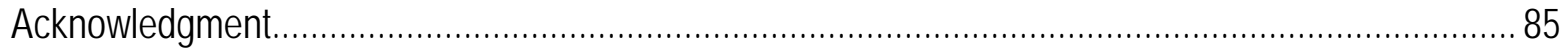

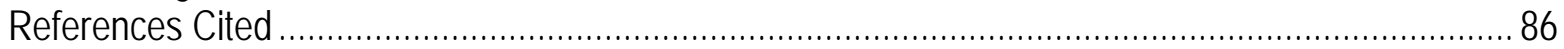

Constructing Better Communication for Operational Earthquake Forecasting of Aftershocks................. 87

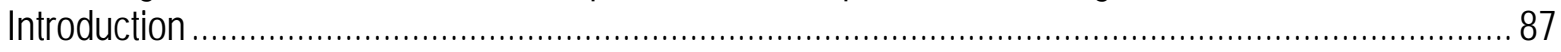

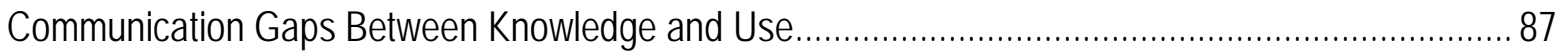

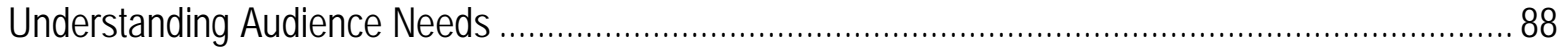

Diverse Preferences for Aftershock Forecast Content and Format.................................................. 88

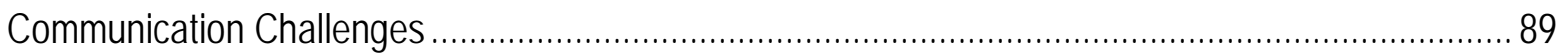

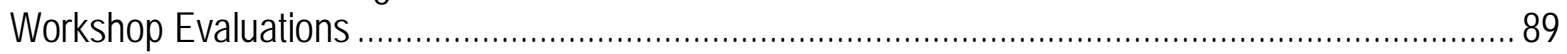

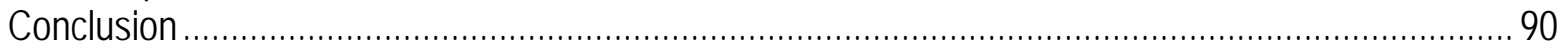

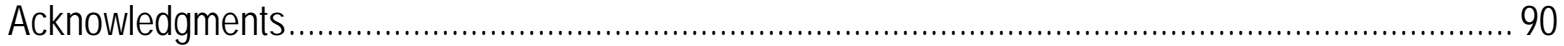

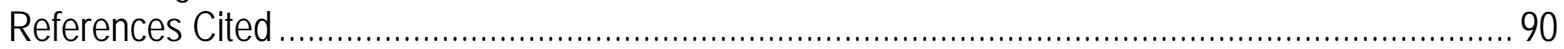

Warning When it Matters: Earthquakes and Tsunamis Around the Globe.......................................... 91

The Theoretical and Observational Limits of Earthquake Early Warning ............................................. 92

Probabilistic Earthquake and Tsunami Hazard Estimation .................................................................... 93

Inferring seafloor displacements during the 2011 Tohoku-Oki earthquake with minimal prior information 93

Abstract............................................................................................................. 93

Self-consistent Source Model for the 2011 Tohoku Earthquake and Tsunami: Evaluating the Northern

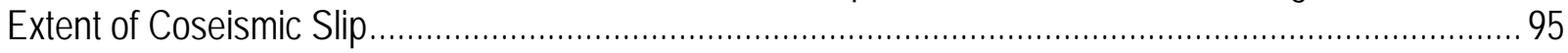

Modeling Deformation Processes of the Island Arc Crust and Mantle During the Interseismic and

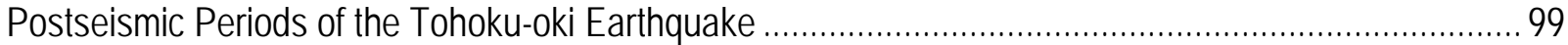

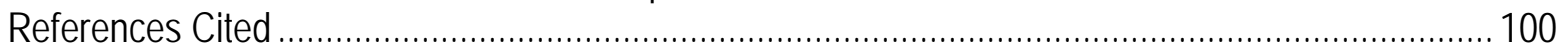

Using Tsunami Deposits to Interpret Tsunami Wave and Seafloor Rupture Characteristics: Lessons from

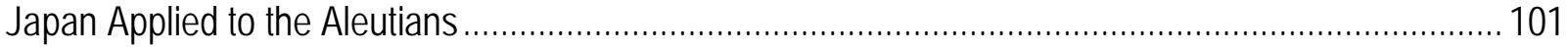

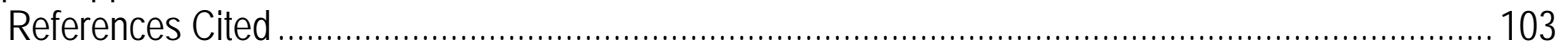

Evaluation of Variety in Earthquake Rupture Along the Nankai Trough Deduced from Paleoseismological

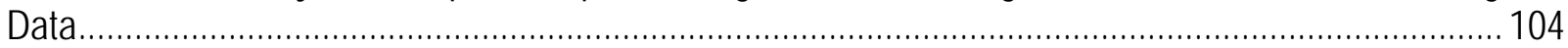

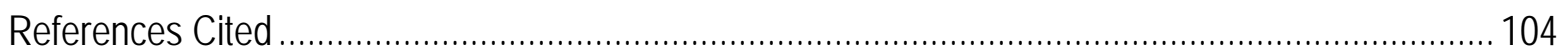

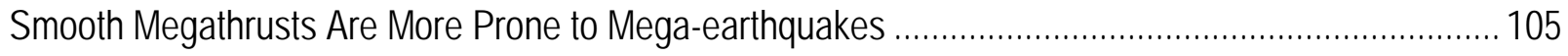

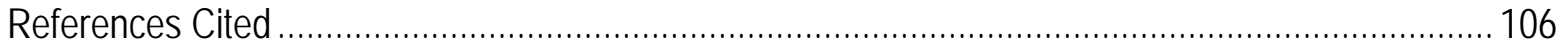

Modeling Researches Toward Earthquake Disaster Mitigation by using Japanese High Performance 


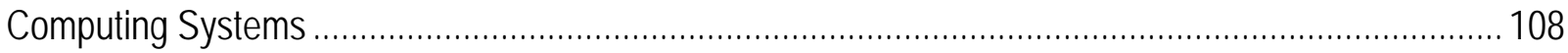

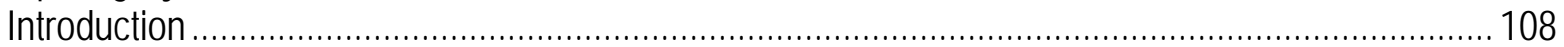

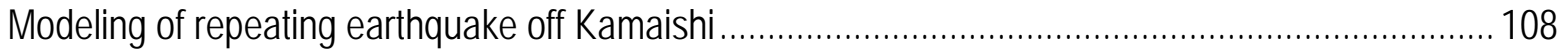

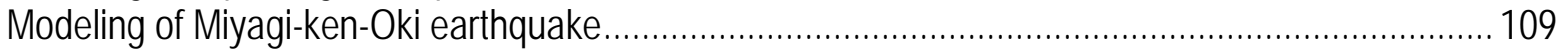

Modeling of megathrust earthquakes along Nankai Trough ....................................................... 110

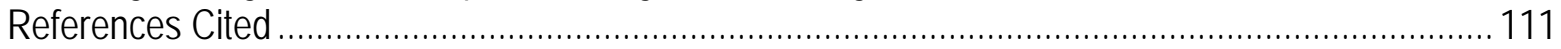

Real-time Seismic and Geodetic Monitoring and Seafloor Observations............................................ 112

Transient Deformation and Stress From Enduring Postseismic Deformation of the 2011 Tohoku-Oki

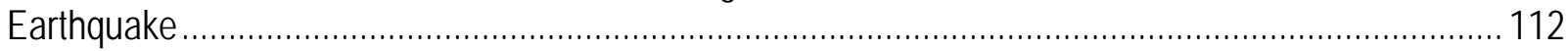

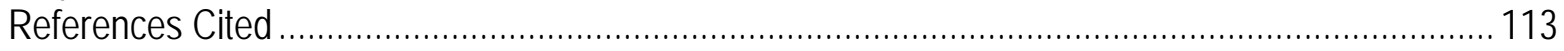

Subduction Zone Geodesy and UNAVCO Community Science Results ..........................................115

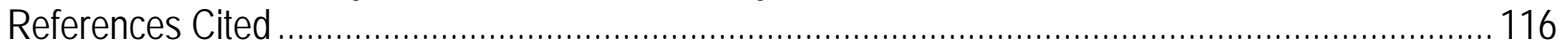

New Ways to Look at Active Tectonic Deformation of the Western United States ..............................117

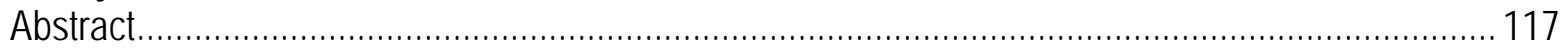

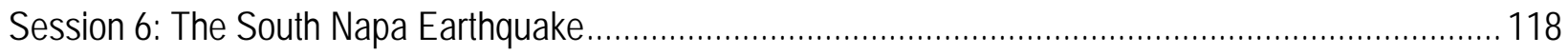

Fault Afterslip Forecast for the August 24, 2014, South Napa Earthquake ........................................ 118

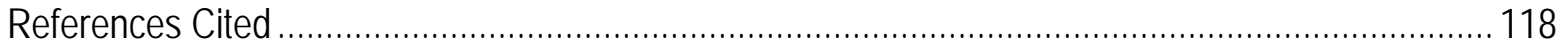

Ground-Motion Attenuation in the Sacramento-San Joaquin Delta, California from Seven Bay Area

Earthquakes, Including the 2014 M6.0 South Napa Earthquake .................................................. 119

References Cited ...................................................................................................... 119

Regional Attenuation Parameters in Ground-motion Predictions: An Example from the 2014 South Napa

Earthquake

121

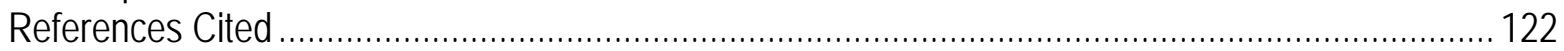

Using Numerical Models to Investigate Distributed Deformation - The South Napa Earthquake as a

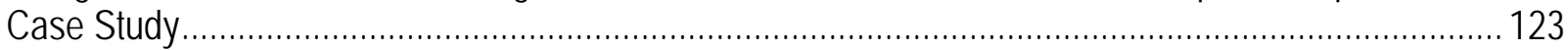

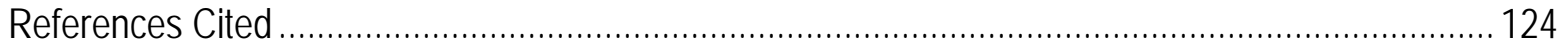

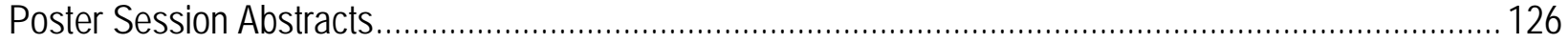

Low Frequency Tremor Near the Nankai Trough Axis, Japan........................................................ 126

Bayesian Combination of Models for a Data-driven Approach to Earthquake Recurrence, for Crustal or

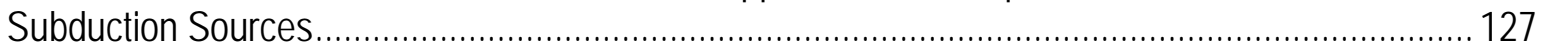

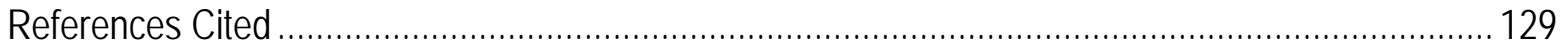

The GEONET Real-time Analysis System for Rapid Finite Fault Modeling ....................................... 130

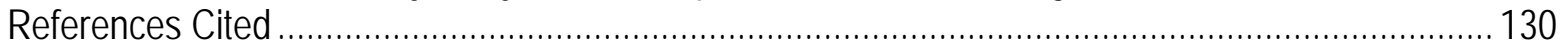

Earthquake Rupture Properties of the 2016 Kumamoto Earthquake Foreshocks (Mj 6.5 and Mj 6.4)

Revealed by Conventional and Multiple-aperture InSAR ............................................................ 131

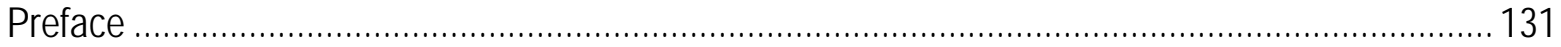

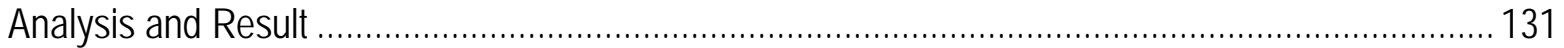

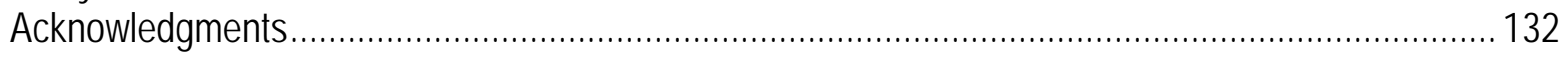

Estimation of Fluid Volumes Necessary for the Fracturing Around the Seismogenic Zone: Insights from

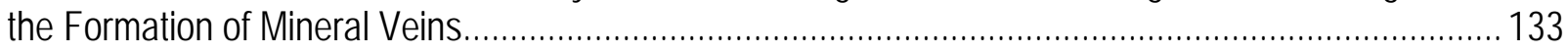

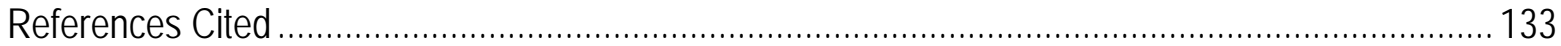

Alternative Segmentation Methods for Subduction Zones: An Alaskan-Aleutian Megathrust Model...... 135

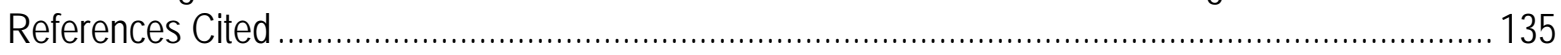

Regional and Stress Drop Effects on Aftershock Productivity of Large Megathrust Earthquakes .......... 136

Basin Edge And Depth Effects On Ground Motion Amplifications In The Kanto Basin, Japan............... 139

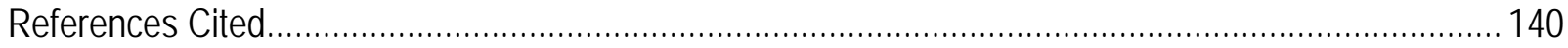

Surface ruptures associated with the 2016 Kumamoto earthquake sequence, central Kyushu, Japan.. 141 
Abstracts of the following presentations were not received for inclusion in this report: Gerald Bawden "NISAR-NASA and ISRO Synthetic Aperture Radar Mission Overview of the mission and science objectives"

Gerald Bawden "Development of a GNSS-Enhanced Tsunami Early Warning System" Tom Jordan "CISM earthquake forecasting activities"

Ben Brooks "Internet of Things Earthquake Early Warning" 


\section{Resolution of the Eleventh Joint Meeting of the United States-Japan Panel on Earthquake Research (UJNR), November 2016}

The UJNR Panel on Earthquake Research promotes advanced research toward a more fundamental understanding of the earthquake process and hazard estimation. The Eleventh Joint meeting was extremely beneficial in furthering cooperation and deepening understanding of problems common to both Japan and the United States.

The meeting included productive exchanges of information on approaches to systematic observation and modeling of earthquake processes. Regarding the earthquake and tsunami of March 2011 off the Pacific coast of Tohoku and the 2016 Kumamoto earthquake sequence, the Panel recognizes that further efforts are necessary to achieve our common goal of reducing earthquake risk through close collaboration and focused discussions at the 12th UJNR meeting. We look forward to continued cooperation on issues involving the densification of observation networks and the open exchange of data among scientific communities. We recognize the importance of making information publicly available in a timely manner. We also recognize the importance of information exchange on research policy and strategies, including the frameworks of research organizations.

\section{Areas of Cooperation}

Specific areas of earthquake research where cooperative research between Japan and the United States may lead to significant advancement include, but are not limited to:

- Probabilistic earthquake and tsunami hazard estimation, including extraordinarily large earthquakes, both in our respective countries and worldwide, incorporating knowledge of current and past behavior, and physics based computational models;

- Real-time information from seismic, geodetic and strain measurements, including borehole strainmeters and seafloor observations using offshore cabled networks;

- Technologies for measuring crustal deformation including GNSS, GPS-acoustic, InSAR, LiDAR, VLBI, and SLR;

- Early warning technologies for earthquakes and tsunamis;

- Studies of recurrence of large and extraordinary large earthquakes using paleoseismic, paleotsunami, geodetic and seismic methods;

- Studies of earthquake sources and fault-zone processes using observational, experimental, theoretical, and in situ methods;

- Studies of episodic tremor and slow slip events using seismic, geodetic, and borehole strain measurements, and simulation techniques;

- Systematic studies of earthquake predictability through rigorously evaluated scientific prediction experiments and robust databases;

- Studies of strong ground motions, geological effects and the response of engineered structures.

The Panel strongly urges that the appropriate agencies in Japan and the U.S., which are represented on this panel, work together with the academic sector to support and coordinate scientific work in these areas of cooperation.

The Panel recognizes the importance of promoting the exchange of scientific personnel, exchange of data, and fundamental studies to advance progress in earthquake research. Japan and 
the United States should promote these exchanges throughout the world. The Panel endorses continuation of these activities.

\section{Next Meeting}

The next meeting will be held in Japan in the autumn of 2018 . 


\section{Proceedings of the 11th United States-Japan Natural Resources Panel for Earthquake Research, Napa Valley, California, November 16-18, 2016}

Edited By Shane Detweiler and Fred Pollitz

Agenda 2016 UJNR Meeting, Napa Valley, California: Oral and Poster Sessions (Presenter in Bold)

Wednesday, 16 November 2016

Session 1: National Policies, Strategies Programs, Networks, and ongoing/upcoming Projects

08:30 Welcoming Remarks (Dr. William Leith, Mr. Masato Kano)

Co-conveners: Naoshi Hirata and Morgan Moschetti

08:45 William Leith "Update on the Earthquake Hazards Program" resilience"

09:00 Naoshi Hirata "Japanese earthquake researches for seismic and tsunami disaster

09:15 Gerald Bawden "NISAR-NASA and ISRO Synthetic Aperture Radar Mission Overview of the mission and science objectives"

09:30 Elizabeth Cochran "The Path Towards Public Earthquake Early Warning for the Western United States"

09:45 Jessica Murray "Toward incorporation of real-time GNSS data in the West Coast Earthquake Early Warning system"

10:00 Morgan Moschetti "The 2014 Update of the U.S. National Seismic Hazard Model" NEIC"

10:15 Gavin Hayes "Recent advances in earthquake response and research at the USGS

10:30-10:45 Break

Session 2: The 2016 Kumamoto Earthquake Sequence

Co-conveners: Noriko Kamaya and Tomokazu Kobayashi

10:45 Noriko Kamaya "The 2016 Kumamoto Earthquake - Overview of the Seismic Activity and New Guidelines for the Seismic Forecast Information after Big Earthquakes"

11:00 Masayuki Yoshimi "Strong ground motion of the 2016 Kumamoto earthquake observed in the midst of severely damaged area"

11:15 Norimitsu Nakata "Seismicity and structure responses following the 2016 Kumamoto earthquake"

11:30 Takahiko Uchide "Fault model of the 2016 Kumamoto earthquake inferred from hypocenter distribution and strong-motion records"

11:45 Tomokazu Kobayashi "Detailed ground surface displacement and fault ruptures of the 2016 Kumamoto Earthquake Sequence revealed by SAR and GNSS data” 
12:00 Hiroshe Une "Small displacement surface linear ruptures of the 2016 Kumamoto earthquake sequence detected by ALOS-2 SAR interferometry"

12:15 Yuki Kodera "Earthquake Early Warning for the 2016 Kumamoto Earthquake: Performance Evaluation of the Current System and the Next-Generation Methods of the Japan Meteorological Agency"

12:30-13:30 lunch

Session 3: Earthquake Hazard Studies, Recurrence, and Mapping

Co-conveners: Jeanne Hardebeck and Tom Brocher

13:30 Ned Field "A Spatiotemporal Clustering Model for the Third Uniform California Earthquake Rupture Forecast (UCERF3-ETAS) - Toward an Operational Earthquake Forecast"

13:45 Jeanne Hardebeck "Operational Aftershock Forecasting for the United States and Globally"

14:00 Morgan Moschetti “Incorporating ground motions from 3-D earthquake simulations into the U.S. National Seismic Hazard Model"

14:15 Kevin Milner "Supercycles and Synchronization Signatures in Synthetic Seismic Sequences"

14:30 Nadia Lapusta "Possibility of large seismic slip on creeping fault segments and deeper creeping fault extensions"

14:45 Yehuda Ben-Zion "Correlations between fault zone and earthquake properties in the Southern California plate-boundary around the San Jacinto Fault Zone"

15:00 Tom Brocher "Evidence for Distributed Clockwise Rotation of the Crust in the Northwestern United States from Fault Geometries and Earthquake Focal Mechanisms"

15:15 Andrea Donellan "Shallow surface deformation observed with UAVSAR. What are the implications for earthquake hazard?"

15:30-15:45 Break

Session 4: Induced Seismicity

Co-conveners: Xinglin Lei and William Ellsworth

15:45 Donald Turcotte "Statistics and risk associated with induced seismicity at The Geysers geothermal area, California and in Oklahoma"

16:00 Greg Beroza "Efficient Similarity-Based Earthquake Detection Applied to the Onset of the Guy-Greenbrier, Arkansas Sequence"

16:15 William Ellsworth "Managing the Hazard of Induced Earthquakes: Insights from InSAR and Geology"

16:30 Sara Dougherty "LArge-n Seismic Survey in Oklahoma (LASSO): Probing injectioninduced seismicity with a dense array"

16:45 Xinglin Lei "Increasing injection-induced seismicity in Asia"

17:15 Joern (Ole) Kaven "Induced seismicity insights from the Decatur, $\mathrm{IL}, \mathrm{CO}_{2}$ sequestration project"

17:30-18:00 Poster session preview (2-3 minutes each)

18:00 Adjourn

18:30 Reception

Thursday 17 November, 2016

Session 5: Subduction Zone Science (note earlier start time)

Recent Initiatives (S-Net, DONET, 'Ring of Fire', Subduction Zone Observatory)

Co-conveners: Joan Gomberg and Shin Aoi 
08:00 Makoto Matsubara "Estimation of seismic velocity structure beneath the ocean using seismic stations offshore and on lands"

08:15 Jeanne Sauber "GRACE and follow-on gravity missions: Contributions to subduction zone science and prospects for the future"

08:30 Shin Aoi "Real-Time Tsunami Inundation Forecast System using S-net Data"

08:45 Ryota Hino "Recent progress of seafloor geodetic monitoring in Japan"

09:00 Joan Gomberg "Advancing USGS Subduction Zone sciences”

\section{Episodic Tremor and Slow Slip}

Co-conveners: Makiko Ohtani and David Shelly

09:15 Satoshi Itaba "Shallow Slow Slip Event Off Kii Peninsula, Japan"

09:30 David Shelly "Fluid-faulting evolution in high definition: connecting fault structure and frequency-magnitude variations during the 2014 Long Valley Caldera, California earthquake swarm"

09:45 Makiko Ohtani "Interaction of SSE and brittle nucleation in simulated pre-seismic slip"

10:00-10:15 break

\section{Session 5: Subduction Zone Science (continued)} Operational Forecasting and Early Warning Systems of Earthquakes and Tsunamis

Co-conveners: Sarah Minson and Mitsuyuki Hoshiba

10:15 John Rundle “GNSS Tsunami Early Warning: Status and Plans

10:30 Gerald Bawden "Development of a GNSS-Enhanced Tsunami Early Warning System"

10:45 Mitsuyuki Hoshiba "'Real-time prediction of ground shaking without source information: "Data assimilation and simulation of seismic wave propagation for Earthquake Early Warning"

11:00 Tom Jordan "CISM earthquake forecasting activities"

11:15 Anne Wein "Communication of aftershock information"

11:30 Richard Allen "Warning when it matters: Earthquakes and tsunamis around the globe" Warning"

11:45 Sarah Minson "The Theoretical and Observational Limits of Earthquake Early

12:00 Ben Brooks "Internet of Things Earthquake Early Warning”

12:15-13:15 lunch

13:15-14:15 Poster Session

Satoshi Annoura "Low frequency tremor near the Nankai trough axis, Japan"

Delphine Fitzenz "Bayesian combination of models for a data-driven approach to earthquake recurrence, for crustal or subduction sources"

Satoshi Kawamoto "The GEONET real-time analysis system for rapid finite fault modeling"

Tomokazu Kobayashi "Earthquake rupture properties of the 2016 Kumamoto Earthquake foreshocks (Mj 6.5 and Mj 6.4) revealed by conventional and multiple-aperture InSAR"

Makoto Otsubo "Estimation of fluid volumes necessary for the fracturing around the seismogenic zone: Insights from the formation of mineral veins"

Natanya Porto "Alternative Segmentation Methods for Subduction Zones: An Alaskan Megathrust Model" 
Susan Schwartz "Regional and stress drop effects on aftershock productivity of large megathrust earthquakes"

Emel Seyhan "Basin edge and depth effects on ground motion amplifications in the Kanto Basin, Japan"

Yoshiki Shirahama "Surface ruptures associated with the 2016 Kumamoto earthquake sequence, central Kyushu, Japan"

Masayuki Yoshimi "Earthquake Fatalities Mapping for the Eastern Asia Earthquake and Volcanic Hazards Information Map"

Probabilistic Earthquake and Tsunami Hazard Estimation

Co-conveners: Bunichiro Shibazaki and Guy Gelfenbaum

14:15 Mark Simons "Inferring seafloor displacements during the 2011 Tohoku-Oki earthquake with minimal prior information"

14:30 Thorne Lay "Northern Limit of Shallow Slip for 2011 Tohoku: Re-rupture of 1896 Tsunami Earthquake Zone"

Session 5: Subduction Zone Science (continued)

14:45 Bunichiro Shibazaki "Modeling deformation processes of the island arc crust and mantle during the interseismic and postseismic periods of the Tohoku-oki earthquake"

15:00 Guy Gelfenbaum "Using tsunami deposits to interpret tsunami wave and seafloor rupture characteristics: lessons from Japan applied to the Aleutians"

15:15 Masanobu Shishikura "Evaluation of variety in earthquake rupture along the Nankai Trough deduced from paleoseismological data"

15:30 Quentin Bletery "Smooth megathrusts are more prone to mega-earthquakes"

15:45 Keisuke Ariyoshi "Modeling Research toward Earthquake Disaster Mitigation by using Japanese High Performance Computing Systems"

Real-time Seismic and Geodetic Monitoring and Seafloor Observations Co-conveners: Wayne Thatcher and Meghan Miller

16:00 Roland Burgmann "Transient Deformation and Stress From Enduring Postseismic Deformation of the 2011 Tohoku-Oki Earthquake" Results"

16:15 Meghan Miller "Subduction Zone Geodesy and UNAVCO Community Science

16:30 Wayne Thatcher "New ways to look at active tectonic deformation of the western United States"

16:45 Group Photo

17:10 For those interested in group dinner, meet in hotel lobby

17:15 Depart hotel

17:30 Arrive at restaurant Morimoto for dinner

$\sim 20: 30$ Return to hotel

Friday 18 November, 2016

Session 6: The South Napa Earthquake

Co-conveners: Annemarie Baltay and Margaret Glasscoe Earthquake"

09:00 Ken Hudnut "Fault Afterslip Forecast for the August 24, 2014, South Napa

09:15 Jem Erdem "Ground-Motion Attenuation for the South Napa earthquake in the Sacramento-San Joaquin Delta, California"

09:30 Annemarie Baltay "Regional attenuation parameters in ground-motion predictions: An example from the 2014 South Napa earthquake" 
09:45 Margaret Glasscoe "Using Numerical Models to Investigate Distributed Deformation - The South Napa Earthquake as a Case Study"

10:00 Presentation of the 11th UJNR Resolution

10:15 Concluding Remarks (Dr. William Leith, and Mr. Masato Kano)

Field Trip to the 2014 M6.0 South Napa Earthquake Rupture Area

$\sim 10: 45$ Departure

$\sim 12: 00$ Lunch

$\sim 17: 00$ Return to hotel 


\title{
List of Abstracts
}

\section{Session 1: National Policies, Strategies Programs, Networks, and Ongoing/Upcoming Projects}

\author{
Update on the Earthquake Hazards Program
}

\author{
By William Leith ${ }^{1}$
}

Overview of the Earthquake Hazards Program

The Earthquake Hazards Program (EHP) is the applied Earth science component of the National Earthquake Hazards Reduction Program (NEHRP). Through NEHRP, the U.S. Geological Survey (USGS) partners with the Federal Emergency Management Agency (FEMA), the National Science Foundation (NSF), and the National Institute of Standards and Technology (NIST) to reduce earthquake losses in the United States. The USGS is the only federal agency that routinely and continuously reports on current domestic and worldwide earthquake activity.

The EHP is structured in four program components: Monitoring and Reporting Earthquake Activity and Crustal Deformation; Assessment and Characterization of Earthquake Hazards; Research into Earthquake Causes and Effects; and Earthquake and Safety Information for Loss Reduction.

\section{Earthquake Monitoring and Reporting}

The Advanced National Seismic System (ANSS) is a cooperative effort to collect and analyze data on earthquakes, issue timely reliable notifications of their occurrence and impacts, and provide data for earthquake research, hazard, and risk assessment as a foundation for building an earthquake resilient nation. Deployment of the ANSS is focused on expanding and improving the performance and integration of monitoring networks in the United States. The system includes a national "backbone" seismic network, the National Earthquake Information Center (NEIC), 11 partner-operated regional seismic networks, and a Strong Motion Project for monitoring earthquake shaking in the free field and in structures. The ANSS is capable of detecting almost all felt earthquakes in the United States, except in remote areas of Alaska. The ANSS typically reports on domestic earthquakes within minutes of their occurrence.

The NEIC provides information on potentially damaging earthquakes to several federal agencies; State offices for emergency services, numerous public and private infrastructure management centers (for example, highways, railroads and pipelines), the news media, and the public. Rapid earthquake notifications are delivered electronically to over 400,000 subscribers, and a suite of earthquake information products such as ShakeMaps, and Did You Feel It? Prompt

1U.S. Geological Survey. 
Assessment of Global Earthquakes for Response (PAGER) estimates of financial and human impacts, and scientific data are rapidly made available on the EHP's web site, which receives more than two million page-views daily.

Regional earthquake monitoring-The USGS and cooperating universities operate regional seismic networks in areas of higher seismic risk. Each region has appropriate local data processing capabilities. ANSS regional seismic networks also serve as State or local distribution points for information about earthquakes to the public, local and State agencies, and other regional interests. In 2017, USGS seeks to permanently improve earthquake monitoring in the Central and Eastern United States by assuming long-term operation of 158 stations in the Central and Eastern U.S. Seismic Network.

Recent Federal, State, and private investments have resulted in a prototype Earthquake Early Warning (EEW) system called ShakeAlert, which has been sending live alerts to selected test users since January of 2012. Before reliable public alerts can be sent, the system requires more seismic and geodetic stations and additional development to maximize its speed, reliability and accuracy. In 2017, USGS will work with the states of California, Washington, and Oregon toward implementing a limited earthquake early warning system. Efforts will include expanding seismometer coverage outward around major urban areas, integrating geodetic data into the system, and continued development and testing to improve reliability.

\section{Earthquake Hazard and Risk Assessment}

The USGS contributes to earthquake risk mitigation strategies by developing seismic hazard maps that describe the likelihood and potential effects of earthquakes Nationwide, especially in the urban areas of highest risk. Federal, State, tribal, and local government agencies, architects and engineers, utility and lifeline operators, insurance companies and other private businesses, land use planners, emergency response officials, and the general public rely on the USGS for earthquake hazard information to refine building codes, develop land-use strategies, safeguard lifelines and critical facilities, develop emergency response plans, and take other precautionary actions to reduce losses from future earthquakes.

The USGS National Seismic Hazard Maps are used to develop new national building codes

for the United States These digital maps integrate a wide range of geological and geophysical information to estimate the severity of ground shaking that each given location is expected to experience in the coming decades. The USGS works closely with earthquake researchers, engineers, and State and local government representatives across the Nation to ensure the maps represent the most current and accurate information available. USGS science underlies the International Building Code (IBC), the code that has been adopted throughout most of the United States as the standard for building design. USGS updates the National Seismic Hazard Maps on a 6year cycle aligned with the processes that lead to updates to the IBC. The California source model for the 2008 and 2014 updates were derived from Uniform California Earthquake Rupture Forecasts.

Because the scale of the National Seismic Hazard Maps precludes taking into account local variations in the size and duration of seismic shaking caused by small-scale geologic structures and soil conditions, the USGS also partners with State and local experts to produce more detailed urban seismic hazard maps for high- to moderate-risk areas. These products make it possible for local officials to make precise and informed zoning and building code decisions. Modeling of ground motion is also provided for engineering applications. In conjunction with release of these 
targeted products, the USGS conducts workshops to assure the proper transfer of knowledge and to help design effective mitigation strategies.

In 2015, the USGS released a report showing that many more Americans may be at risk from damaging earthquakes than previously estimated. The study looked at changes in both the characterization of the earthquake hazard and the total population since 1996. More than 143 million Americans living in the 48 contiguous states are exposed to potentially damaging ground shaking from earthquakes. When the people living in the earthquake-prone areas of Alaska, Hawaii and U.S. territories are added, this number rises to nearly half of all Americans. The new exposure estimate is nearly double the previous estimate; that doubling because of significant growth of populations in areas prone to earthquakes, and to improved scientific methods that allow for more accurate estimates of earthquake hazards and ground shaking.

In 2016 and 2017, USGS is partnering with FEMA-funded engineering groups in a two-year project to improve methods for development of future building codes.

\section{Applied Research}

USGS conducts a broad suite of research on the causes, characteristics, and effects of earthquakes. This research has direct application in increasing the accuracy and precision of USGS earthquake hazards assessments, earthquake forecasts, earthquake monitoring products, and earthquake mitigation practices.

Induced Seismicity - The development of underground oil and gas resources has the potential to induce earthquakes. Researchers have long known that human actions can cause earthquake activity, from petroleum extraction to water reservoir impoundments, and fluid injection into the subsurface. Although small magnitude (microseismic) events are commonly produced by hydraulic fracturing operations and are occasionally felt, current understanding suggests that the potential risk of damaging earthquakes is greatest from high-volume wastewater disposal. The risk of inducing felt earthquakes directly stemming from hydraulic fracturing operations is low, but damaging earthquakes can be induced through disposal of wastewater in deep wells. Extensive sets of empirical observations could demonstrate that operations to date are consistent with predictive models over a range of geologic conditions and operational parameters.

In recent years, the USGS has responded to significant increases in earthquake rates in Oklahoma, Kansas and Texas, accompanied by many moderate-magnitude, lightly damaging earthquakes. We are working to develop methods to forecast what types of wastewater injections in which geologic setting would be likely to induce or trigger earthquakes, to perform comprehensive studies at carefully-selected field sites, and to establish procedures to adapt the National Seismic Hazard Maps to account for potential hazards from earthquakes induced in association with the production of oil and gas.

Forecasting Hazards from Earthquake Sequences - The USGS conducts research to quantify changes in earthquake likelihoods with time, in response to observations of the earthquake generation process from data such as earthquake catalogs and geodetic deformation. Currently, we have begun the process of integrating the aftershock forecasting methodology within the software systems of the NEIC, and institute procedures for issuing aftershock warning advisories following large earthquakes striking anywhere within the United States. Improved methods will be developed and integrated into the operational system after appropriate testing. The USGS is also developing a suite of new earthquake forecast products useful to society, ranging from one- 
time earthquake forecasts, to new hazard assessment maps, continuously updated online releases, and user-customized estimates for decision support and situational awareness.

\section{External Research Partnerships}

Partnerships are crucial to the EHP's success. Approximately one-quarter of the EHP budget is directed toward research grants and cooperative agreements with universities, State agencies, and private technical firms to support research and monitoring activities. Collaboration advances targeted research, and addresses specific needs of the USGS by using the experience and knowledge of world experts. EHP provides competitive, peer-reviewed, external research support through competitive grants and cooperative agreements that enlist the talents and expertise of the academic community, State government, and the private sector. Funded work includes: mapping seismic hazards in urban areas, developing credible earthquake planning scenarios including loss estimates, defining the prehistoric record of large earthquakes, investigating the origins of earthquakes, improving methods for predicting earthquake effects, support of monitoring networks, and development of an earthquake early warning system.

\section{Communication, Outreach and Science Collaboration}

The EHP produces a large and growing quantity of data and information on earthquakes and related hazards. For this science information to be effectively used to mitigate risk and limit losses, the USGS takes a proactive role with various user communities in the application and interpretation of program results. Active engagement with users provides opportunities for dialogue on modifications to existing products and advice on new products that make USGS science more relevant and applicable. Opportunities for engaging users take place at both national and regional levels.

The EHP strives to create and refine a variety of earthquake information products that accurately and effectively communicate earthquake science to key audiences, including decision makers. In 2017, the USGS will release a major earthquake scenario involving a magnitude-7 earthquake rupturing the Hayward Fault in the San Francisco Bay Area; the USGS estimates there to be a 1-in-3 chance that the Hayward Fault will produce a major earthquake within the coming decades. The scenario earthquake triggers fires, liquefaction and landslides that cause further damage to buildings and lifeline infrastructure. The scenario's name, HayWired, speaks to the chaos caused by impacts to an urban environment in which communities, culture and economy are all entwined with the Internet. Stakeholders will use the scenario to understand the "ripple effects" of damages and disruption, and to prioritize mitigation actions to increase resilience.

Through NEHRP, the USGS partners with FEMA to develop and update building codes, based on USGS hazard maps. The ShakeMap product, which provides rapid situational awareness of earthquake ground motions, is imported directly into FEMA's Hazus software for detailed estimation of earthquake impacts. USGS also participates in FEMA-led National-level earthquake disaster response exercises.

The USGS and NSF's Earth Sciences Division jointly fund the Global Seismographic Network (GSN) and the Southern California Earthquake Center, a high-leveraged research consortium that is making significant advances in the fields of seismic hazards assessment, seismic-resistant engineering, public risk communication, paleoseismology, and the modeling of earthquake ground motions via high-performance computing. Data from the GSN flow directly to the two Tsunami Warning Centers maintained by the National Oceanic and Atmospheric Administration (NOAA). 
The warning centers use those data to provide early estimates of the magnitudes, locations and depths of large earthquakes and to send rapid warnings of potential tsunami arrivals. 


\title{
Japanese Earthquake Researches for Seismic and Tsunami Disaster Resilience
}

\author{
By Naoshi Hirata 1
}

It is 21 years since the Headquarters for Earthquake Research Promotion (HERP), Japan, was established after the 1995 Hyogoken-Nanbu earthquake, which is internationally known as the Kobe earthquake. The Headquarters consists of two committees; Policy Committee and Earthquake Research Committee.

The Policy Committee formulated and the HERP released its earthquake research policy every 10 years. The first policy was published in 1999. The committee formulated the current policy, which was titled as New Promotion of Earthquake Research - Comprehensive Basic Policies for the Promotion of Seismic Research through the Observation, Measurement, and Survey -. This policy is a guideline of earthquake research for the next 10 years, and was released in 2009. The policy was revised in September 2012 to enhance researches related to Tsunami hazards according to the 2011 Tohoku-oki earthquake, which brought severer damages in Japanese society particularly by extraordinary tsunami. One of the examples is implementation of the Seafloor Observation Networks for Earthquakes and Tsunamis along the Japan Trench (S-net) by National Research Institute for Earth Science and Disaster Resilience (NIED).

The Earthquake Research Committee holds regular meetings once every month and classifies and analyzes research and observation results, as well as study outcomes. It does this in order to evaluate seismic activity in a comprehensive manner and to publish evaluation results. In addition, special meetings are held in response to damaging earthquakes or marked seismic activity.

Immediately after the 2016 Kumamoto earthquake, we have two special meetings, one on April 15th, next day of the largest foreshock, M6.5, and the other on April 17th, the next day of the main shock, M7.3. We could not forecast the main shock in the 15 th meeting, but those earthquakes occurred in the known active fault zone: Hinagu active fault zone and Futagawa active fault zone. The occurrence probabilities of earthquakes on active faults are evaluated in 2013.

I will discuss some recent results published by the Earthquake Research Committee to address how we can improve risk communication to public and risk managers in local and national governments.

\footnotetext{
1Earthquake Research Institute, the University of Tokyo, Chair of Earthquake Research Committee, the Headquarters for Earthquake Research Promotion.
} 


\title{
The Path Towards Public Earthquake Early Warning for the Western United States
}

\author{
By Elizabeth S. Cochran ${ }^{1}$
}

Seconds of advanced warning of imminent strong shaking from an earthquake underway can be used to trigger a range of automated responses to reduce losses and warn the public to take protective action. A prototype earthquake early warning (EEW) system has been in operation for the west coast of the United States since February 2016. Alerts produced by the EEW system, known as ShakeAlert, will be an additional product of the Advanced National Seismic System regional networks in California and the Pacific Northwest. ShakeAlert is managed by the U.S. Geological Survey and has been developed in close collaboration with partners at several universities, including Caltech, University of Washington, and University of California, Berkeley. The system is currently based on a set of algorithms that determine point source information (magnitude, location, and origin time) from real-time seismic data. This point source information can then be used to estimate expected ground shaking at a user's location and issue a warning or trigger an action if expected ground shaking exceeds a user-defined threshold (fig. 1). In this presentation, I describe the current system as well as ongoing developments, including seismicand geodetic-based finite fault algorithms, an improved aggregator of alerts, and improvements to estimate expected ground-shaking levels. Additionally, I describe efforts to assess the performance of the system both in terms of how closely alerts match to catalog information and whether an appropriate action would have been initiated by an end user at a defined shaking threshold. Finally, I briefly describe issues related to alert distribution, as well as outcomes from pilot projects that are employing ShakeAlert messages and helping to define best practices for use of EEW in various sectors, for example, emergency management, transportation, education, and others.
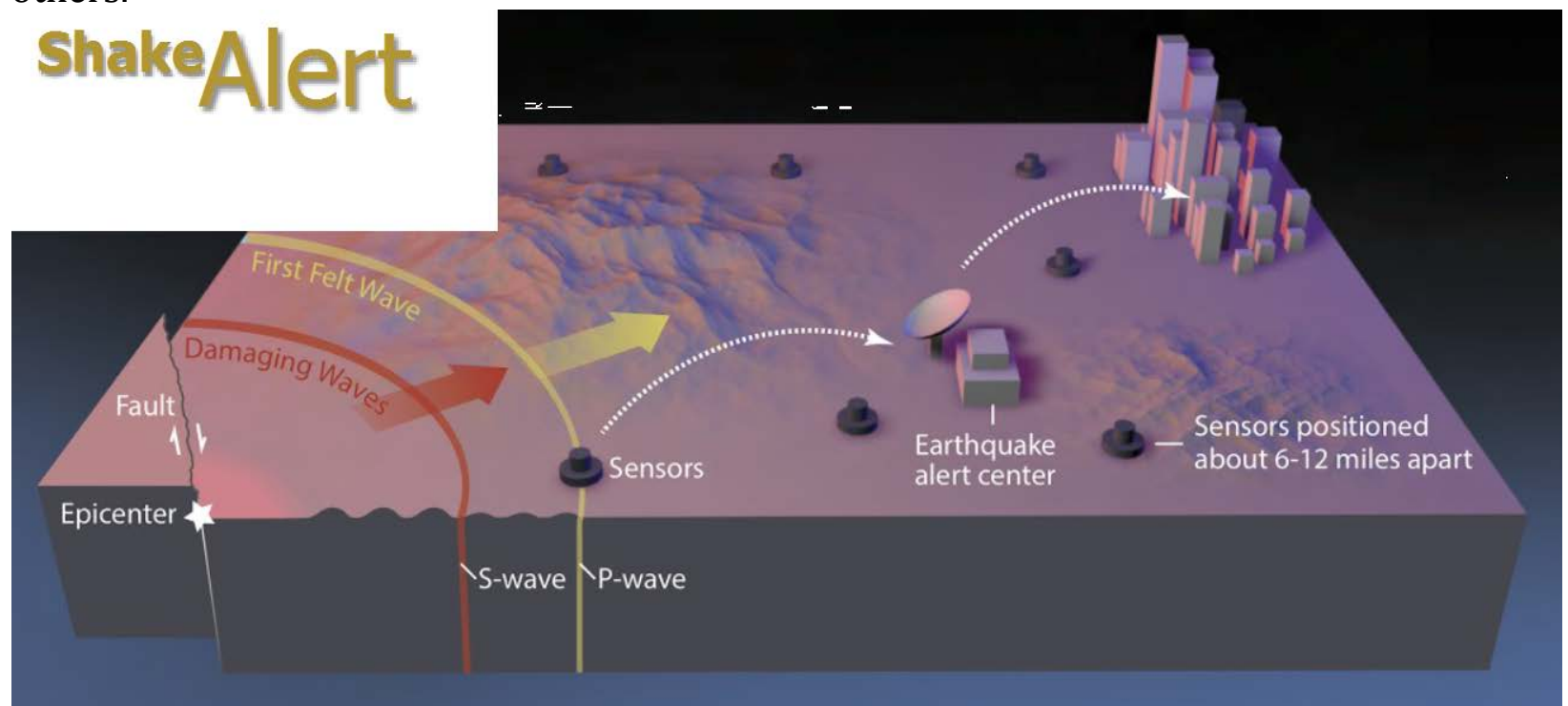

Figure 1. Conceptual image of the ShakeAlert earthquake early warning system.

\footnotetext{
${ }^{1}$ U.S. Geological Survey.
} 


\section{Toward Incorporation of Real-time GNSS Data in the West Coast Earthquake Early Warning System}

By Jessica R. Murray ${ }^{1}$, Brendan Crowell, ${ }^{2}$ Ronni Grapenthin, ${ }^{3}$ Kathleen Hodgkinson, ${ }^{4}$ John Langbein, ${ }^{1}$ Tim Melbourne, ${ }^{5}$ Diego Melgar, ${ }^{6}$ Sarah Minson, ${ }^{1}$ and David Schmidt 2

Development of an earthquake early warning (EEW) system for the west coast of the contiguous United States is underway. Currently the prototype system, named ShakeAlert, incorporates multiple algorithms that use seismic data to rapidly estimate the point source location, origin time, and magnitude of an earthquake, which may still be in progress. While seismic instruments are sensitive to small ground motions such as signals from moderate earthquakes that may be damaging, magnitude estimates based on these data may saturate for large earthquakes (for example, $>M 7$ ). In addition, use of a point source representation may lead to underprediction of anticipated ground motion.

The Global Navigation Satellite System (GNSS) is not sensitive enough to independently resolve small signals such as $\mathrm{P}$-wave ground motion or offsets $<\sim 1$ centimeter. However, these data complement seismic observations by providing a direct measure of large coseismic displacements and dynamic motions that stays on scale. This enables use of real-time GNSS data to rapidly infer an earthquake's magnitude, moment tensor, and finite fault model for regional events $>$ M7.5; for the largest events, this information is potentially available even as the rupture evolves. Several studies have demonstrated the potential value that this added information could provide for EEW (for example, Crowell and others, 2016; Grapenthin and others, 2014; Melgar and others, 2015; Minson and others, 2014, Ohta and others, 2012).

For inclusion in ShakeAlert, all algorithms (seismic and geodetic) must first undergo rigorous testing in a development system that mirrors the production system's infrastructure. We are currently working on several fronts to realize testing and possible certification of geodetic algorithms.

On the operational side, we have defined a framework for transmitting real-time position streams to algorithms that will be running at multiple alerting centers and have established standardized data formats and protocols for ingesting the geodetic position streams into the same data distribution infrastructure as used by the seismic data. Multiple real-time GNSS data processing strategies exist, and we are comparing their respective solutions to identify approaches that result in the highest precision and lowest latency. We are also developing and testing methods for merging solutions from multiple processing centers, including the combination of baseline lengths with absolute positions, to more efficiently provide robust geodetic data streams for alerting systems. Finally, we are working to fully characterize the GNSS station distribution for optimal contribution to ShakeAlert performance, the noise characteristics

\footnotetext{
1U.S. Geological Survey.

2University of Washington.

${ }^{3} \mathrm{New}$ Mexico Institute of Mining and Technology.

4UNAVCO, Inc.

${ }^{5}$ Central Washington University.

6University of California, Berkeley.
} 
of data from diverse monument types including less expensive designs, which might allow for greater spatial coverage, and the value of co-located seismic and geodetic instrumentation.

In parallel, algorithm developers are working to further refine their methodology, for instance to enhance performance for the range of earthquake sources that might occur throughout the ShakeAlert region. They are also working to create production-ready versions of software prototypes. Any algorithm testing requires a suite of test data. While ideally test data sets would be composed of observations from real earthquakes, the number of earthquakes in the magnitude range observable with real-time GNSS positioning for which such observations exist is very limited. Therefore, testing will largely rely on simulated observations for hypothetical events. Development of synthetic position waveforms with the proper frequency content for simultaneously testing algorithms that use seismic and geodetic data, or that make joint use of both data types, is an area of active research.

\section{References Cited}

Crowell, B.W., Schmidt, D.A., Bodin, P., Vidale, J.E., Gomberg, J., Hartog, J.R., Kress, V.C., Melbourne, T.I., Santillan, M., Minson, S.E., and Jamison D.G., 2016, Demonstration of the Cascadia G-FAST geodetic earthquake early warning system for the Nisqually, Washington earthquake: Seismological Research Letters, v. 87, no. 4, p. 930-943, https://doi.org/10.1785/0220150255.

Grapenthin, R., Johanson, I.A., and Allen, R.M., 2014, Operational real-time GPS-enhanced earthquake early warning: Journal of Geophysical Research—Solid Earth, v. 119, no. 10, p. 7944-7965, https://doi.org/10.1002/2014JB011400.

Melgar, D., Crowell, B.W., Geng, J., Allen, R.M., Bock, Y., Riquelme, S., Hill, E., Protti, M., and Ganas, A., 2015, Earthquake magnitude calculations without saturation from the scaling of peak ground displacement: Geophysical Research Letters, v. 42, no. 13, p. 5197-5205, https://doi.org/10.1002/2015GL064278.

Minson, S.E., Murray, J.R., Langbein, J.O., and Gomberg, J.S., 2014, Real-time inversions for finite fault slip models and rupture geometry based on high-rate GPS data: Journal of Geophysical Research-Solid Earth, v. 119, no. 4, p. 3201-3231, https://doi.org/10.1002/2013JB010622. Ohta, Y., Kobayashi, T., Tsushima, H., Miura, S., Hino, R., Takasu, T., Fujimoto, H., Iinuma, T., Tachibana, K., Demachi, T., and Sato, T., 2012, Quasi real-time fault model estimation for nearfield tsunami forecasting based on RTK-GPS analysis-Application to the 2011 Tohoku-Oki earthquake ( $M_{\mathrm{w}}$ 9.0): Journal of Geophysical Research—Solid Earth, v. 117, no. B2, https://doi.org/10.1029/2011JB008750. 


\section{The 2014 Update to the U.S. National Seismic Hazard Model}

By M.P. Moschetti, ${ }^{1}$ M.D. Petersen, ${ }^{1}$ P.M. Powers,${ }^{1}$ C.S. Mueller, ${ }^{1}$ K.M. Haller, ${ }^{1}$ A.D. Frankel, ${ }^{1}$ Y. Zeng,,${ }^{1}$ S. Rezaeian, ${ }^{1}$ S.C. Harmsen, ${ }^{1}$ O.S. Boyd,${ }^{1}$ and N. Field ${ }^{1}$

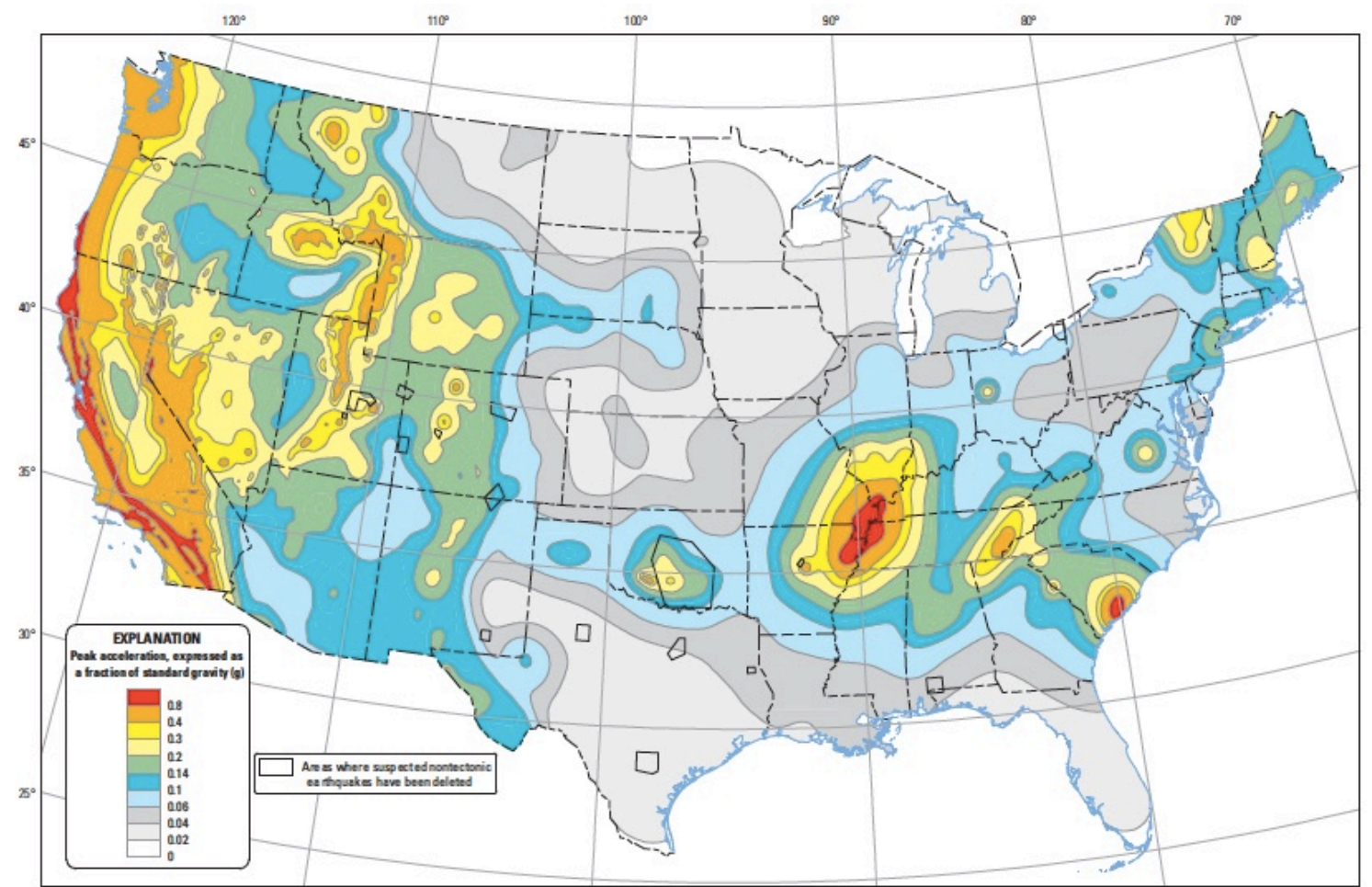

Figure 1. Peak horizontal ground acceleration (PGA) with a 2 percent probability of exceedance in 50 years from the 2014 U.S. National Seismic Hazard Model.

In 2014 the U.S. Geological Survey updated the U.S. National Seismic Hazard Model (NSHM) with new data, models, and methods to characterize earthquake sources and ground shaking (fig. 1). Development of the NSHM followed the process established for the 1996 NSHM and employed in intervening updates $(2002,2008)$ : Regional (central and eastern United States, intermountainwest United States, Pacific Northwest, California) and topical (ground-motion prediction) workshops were held in the years leading up to the update to solicit new research results for potential incorporation into the NSHM and to vet modifications and additions; a preliminary model was made available for public comment, and modeling choices were vetted by a Steering Committee. The 2014 update to the NSHM produced a time-independent probabilistic seismic hazard assessment for the conterminous United States The source model for California (Uniform California Earthquake Rupture Forecast, version 3) was independently developed by the Working Group on California Earthquake Probabilities (WGCEP) and coordinated for incorporation into the NSHM. The NSHM provides the probabilistic and deterministic seismic hazard assessments that underlie the seismic provisions governing design standards for buildings, highways, bridges,

1U.S. Geological Survey. 
railways, and other structures. They are also used in determining earthquake insurance rate structures, risk assessments, governmental disaster management and mitigation strategies, seismic safety applications, and site-specific engineering analyses.

The seismic source and ground motion characterizations follow the methodology developed in previous NSHM updates, but with new data and data types, and with new methods. The seismic source model comprises seismicity- and fault-based models to forecast the locations, frequency and magnitudes of earthquakes. Important additions to the seismic source model for the 2014-update included the use of geodetic-based models to constrain fault slip-rates, incorporation of updated seismic source models for fault-sources in the central and eastern United States from analysis of paleoseismic and geologic data, modified recurrence rates and magnitudes for earthquakes in the Cascadia subduction zone (CSZ) - primarily suggested by analyses of turbidite data-and the use of adaptive smoothed seismicity methods. We attempted to exclude transient effects, such as the induced seismicity that is a prominent contributor to seismicity in parts of the central and eastern United States and prompted a separate, short-term seismic hazard assessment. Updated ground motion models for active, shallow earthquakes in the western United States and for interface and intraslab earthquakes in the CSZ were incorporated from individual developers and from groups of developers (for example, NGA-West-2, BCHydro). In the central and eastern United States (CEUS), changes to the ground motion models (GMMs) logic tree weights resulted in a greater logic-tree weighting on models with faster stronger geometric attenuation and smaller medians, causing reductions in the probabilistic ground motions of about 10-20 percent. For shallow crustal earthquakes in active tectonic regions of western United States (WUS,) the five GMMs of the NGA-West-2 project replaced previous models. In general, the medians are lower and the standard deviations are higher, causing increases of about 5-15 percent. For the CSZ, new models and modified weights caused increases as much as 15 percent and decreases as much as 10 percent; differential attenuation in the forearc and backarc regions caused varying spatial patterns. 


\title{
Recent Advances in Earthquake Response and Research at the USGS NEIC
}

\author{
By Gavin P. Hayes, ${ }^{1}$ Harley M. Benz,,${ }^{1}$ Jennifer L. Nealy, ${ }^{1}$ David J. Wald, ${ }^{1}$ William L. Yeck, ${ }^{1}$ and Paul S. Earle ${ }^{1}$
}

The U.S. Geological Survey (USGS) National Earthquake Information Center (NEIC) is now well known for the suite of response products it provides to the community after major global earthquakes. These include tectonic summaries, moment tensors, ShakeMaps, finite-fault models, and Prompt Assessment of Global Earthquakes for Response (PAGER) reports, all targeted at placing a recent event into a more understandable context from a seismotectonic and earthquake impact perspective. Following the immediate aftermath of a major earthquake, the NEIC also often provides value-added content to help understand such events in more detail including educational slide sets, multiple-event relocation of aftershocks and more complete seismotectonic characterizations of earthquake sequences. Over the past several years, all of these products have evolved. In this presentation, we provide an update on each and describe some of the current research pursuits of the NEIC group.

Recently, a compilation of tectonic summaries for all $M 7+$ earthquakes of the 21st century (2000-2015) has been published and is available for download as an interactive Google Earth KML. USGS W-phase moment tensors are now routinely available for all M5+ earthquakes in both the United States and Japan, and other well-instrumented regional networks like Chile and New Zealand. Finite fault models for all M7.5+ earthquakes since 1990 are also available for viewing and download, from USGS event pages and the USGS NEIC Comprehensive Catalog (ComCat http://earthquake.usgs.gov/earthquakes/search/).

ShakeMap, PAGER, ShakeCast and Did You Feel It? are all undergoing a systematic overhaul of underlying software and associated products. This software migration into a uniform, opensource, and continuously integrated software development environment includes standard Python, Github, and apiDocs platforms. As part of the ShakeMap overhaul we are also taking advantage of-and participating in-the open-source, cooperative development framework highlighted by the OpenQuake hazard library. Research and development advances on these systems include the exploration of incorporating spatial correlation into ground shaking and loss estimates, and a characterization of the spatial probability of secondary hazard (for example, landslides, liquefaction) in association with ground shaking. Impact estimates via the PAGER system directly benefit from these improvements to ShakeMap, and from a parallel update of the underlying ShakeMap Atlas of historical earthquakes back through 1973. We are also producing a systematic suite of scenario earthquakes for the United States consistent with the rupture and ground motion models underlying the U.S. national seismic hazard maps.

Seismotectonic studies of earthquakes conducted by the NEIC generally include improved event detection and relocations of mainshock-aftershock sequences, and more detailed finite-fault modeling (including the use of geodetic data) than is possible in real time. As part of these efforts, NEIC researchers have made significant advances in using subspace detection for the identification of small $(M<4.5)$ aftershocks, and a variety of earthquake relocation codes (for example, mloc, a Joint Hypocentroidal Decomposition approach, and BayesLoc, a large-scale probabilistic relocation package routed in a Bayesian framework) to improve knowledge of the

1U.S. Geological Survey. 
absolute locations of aftershocks, including location uncertainties. Recent efforts from work on the 2014 Iquique, and 2015 Illapel earthquake sequences in Chile highlight what we can learn from such studies, including intriguing correlations between seismicity and slab structure in northern Chile, which may hint at structural control on the megathrust earthquake cycle (fig. 1).
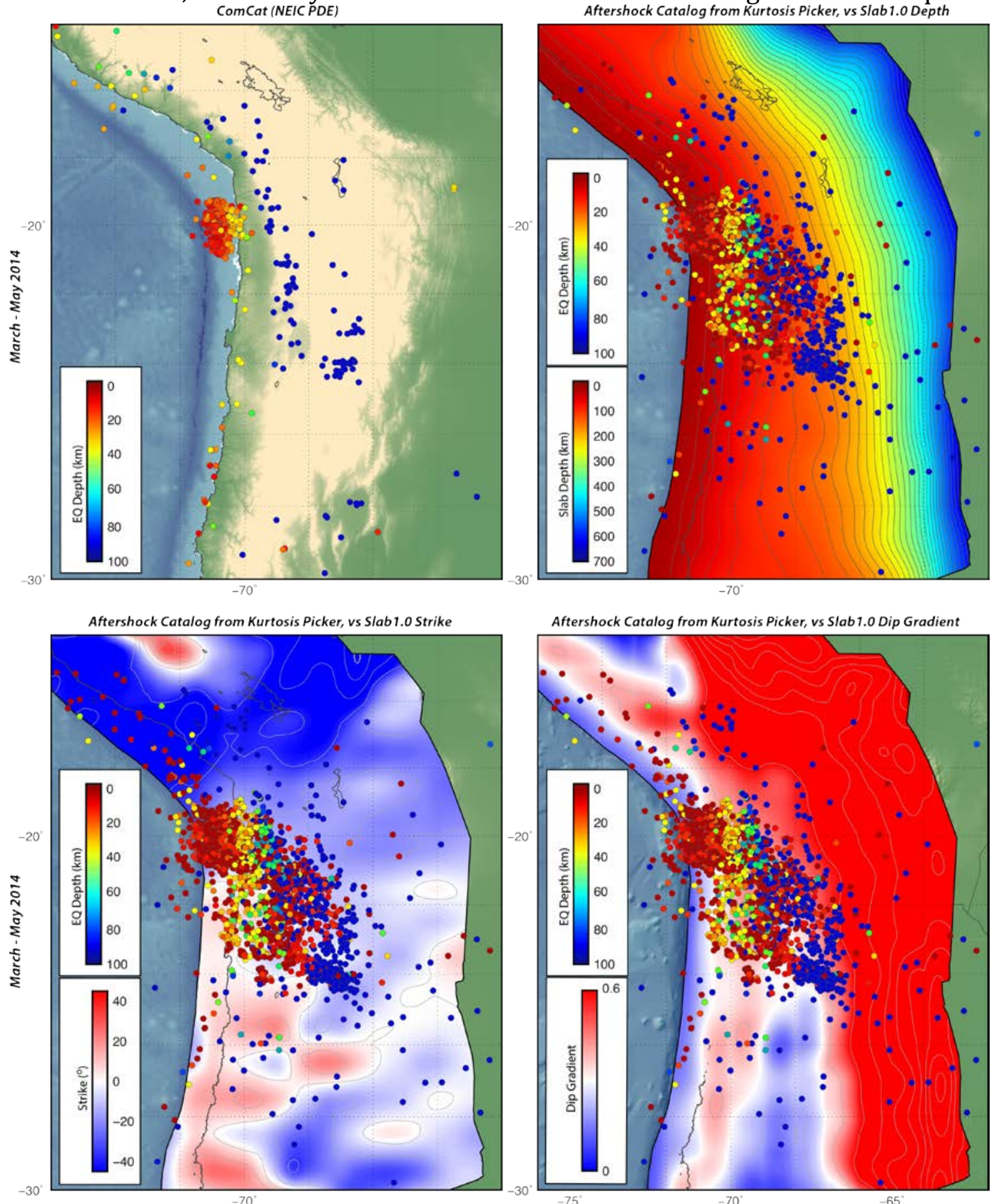

Figure 1. A comparison of events in the lquique, Chile earthquake sequence (March-May 2014) as recorded $(A)$ in ComCat, and $(B-D)$ using a kurtosis-based picker. The latter catalog improves our magnitude of completeness and allows us to compare sequence seismicity to slab structure - slab depth in $(B)$, slab strike in $(C)$, and slab dip gradient in $(D)$. In each $(B-D)$, slab structure appears to exert a control on the southern limit of seismicity. 


\section{Session 2: The 2016 Kumamoto Earthquake Sequence}

\section{The 2016 Kumamoto Earthquake - Overview of the Seismic Activity and New Guidelines for the Seismic Forecast Information after Big Earthquakes}

By Noriko Kamaya, ${ }^{1}$ Naoyuki Yamada, ${ }^{1}$ Yuzo Ishigaki, ${ }^{1}$ Kiyoshi Takeda, ${ }^{1}$ Hidekuni Kuroki, ${ }^{1}$ Satoshi Takahama, ${ }^{1}$ Ken Moriwaki, ${ }^{1}$ Mugi Yamamoto, ${ }^{1}$ Mitsuharu Ueda, ${ }^{1}$ Takahiko Yamauchi, ${ }^{1}$ Miho Tanaka, ${ }^{1}$ Youko Komatsu, ${ }^{1}$ Kouji Sakoda, ${ }^{1}$ Nobuyuki Hirota, ${ }^{1}$ Jun-ichi Suganomata, ${ }^{1}$ Akio Kawai, ${ }^{1}$ Yuki Morita, ${ }^{1}$ Satoshi Annoura, ${ }^{1}$ Yuji Nishimae, ${ }^{1}$ Shigeki Aoki, ${ }^{1}$ Naoto Koja, ${ }^{1}$ Koji Nakamura, ${ }^{1}$ Gen Aoki, ${ }^{1}$ and Tetsuo Hashimoto ${ }^{1}$

Introduction

A big earthquake of M6.5 occurred at 21:26 on 14 April, 2016 (JST) in Kumamoto region of Kumamoto Prefecture. Its focal depth was estimated at $11 \mathrm{~km}$, and the maximum JMA seismic intensity scale was 7, which is the strongest of the scale. After 28 hours of the earthquake, a bigger earthquake of $M 7.3$ occurred in the same region, and the seismically active area was spread up to about $150 \mathrm{~km}$ long, from Kumamoto Prefecture to Oita Prefecture. Just after the latter biggest earthquake (M7.3), triggered earthquake of M5.7 occurred in the central region of Oita Prefecture. The magnitude of this earthquake (M5.7) is a reference value and the JMA Seismic intensity is unknown because of overlaps of seismic waves from $M 7.3$ event. One and a half hour after the biggest earthquake (M7.3), another big earthquake of M5.9 occurred in Aso region of Kumamoto Prefecture which is $40 \mathrm{~km}$ northeast of the hypocenter of $M 7.3$ event. The maximum JMA seismic intensity of this earthquake was 5+. As described above, many big earthquakes occurred and the number of earthquakes which JMA seismic intensities over 5- reached 24 (as of 10 October). JMA named the sequence of this seismic activity "The 2016 Kumamoto Earthquake".

This seismic activity occurred in crust, and the Earthquake Research Committee of Headquarters of Earthquake Research Promotion (HERP) evaluated that this seismic activity is caused by activities of parts of Futagawa Fault Zone and Hinagu Fault Zone.

Distribution of Hypocenters and Mechanisms of the Earthquakes

Hypocenters of the 2016 Kumamoto Earthquake are distributed along a belt area from northeast to southwest direction within Beppu-Shimabara Graben in central Kyushu. Detailed analysis of the distribution of hypocenters by using Double-Difference method suggests vertical and steeply dipping fault planes inclining toward northwest and north northwest. In addition, it shows that there are complex planes around the junction of the Futagawa Fault Zone and the Hinagu Fault Zone. In the central Oita Prefecture, the hypocenters of the new seismic activity are distributed in the areas where seismicity had been inactive.

The mechanisms of the earthquakes are mainly strike slip type with North-South Tension axis. Some Normal fault type earthquakes occur around Futagawa Fault Zone.

1Seismology and Volcanology Department, Japan Meteorological Agency (JMA). 
Analysis of Source Process and Source Scanning Algorithm

Source process analysis on the biggest earthquake (M7.3) in Kumamoto region of Kumamoto Prefecture by using strong-motion seismic records of near seismometers on the assumption that only one fault in Futagawa Fault Zone slips shows that the fault slip was propagated from the hypocenter toward northeast. Area of high slip is estimated between several to $20 \mathrm{~km}$ northeast of the hypocenter.

Source Scanning Algorithm on the same earthquake (M7.3) shows that emission of energy started around the Futagawa Fault Zone, and spread to the Hinagu Fault Zone.

Earthquake Information Issued by JMA

JMA issued a lot of press releases on the 2016 Kumamoto Earthquake and held press conferences frequently.

JMA issued Early Earthquake Warning (EEW) for 19 earthquakes in the sequence of the 2016 Kumamoto Earthquake.

As regards the Intensity Scale for Long-period Ground Motion of JMA, intensity 3 and 4 were observed at the following earthquakes. Intensity 3 means the maximum value of absolute velocity response spectrum (Sva) is $50 \mathrm{~cm} / \mathrm{s} \leq \mathrm{Sva}<100 \mathrm{~cm} / \mathrm{s}$ in the periods between $1.6 \mathrm{~s}$ and $7.8 \mathrm{~s}$ with dumping ratio 5.0 percent. Intensity 4 is the strongest intensity on the scale, and it means the maximum value of Sva is $100 \mathrm{~cm} / \mathrm{s} \leq \mathrm{Sva}$.

- M6.5 on 14 April: Intensity 3 in Kumamoto region of Kumamoto Prefecture (the maximum Sva was $93 \mathrm{~cm} / \mathrm{s}$ in the period $1.6 \mathrm{~s})$.

- M6.4 on 15 April: Intensity 4 in Kumamoto region of Kumamoto Prefecture (the maximum Sva was $109 \mathrm{~cm} / \mathrm{s}$ in the period $1.6 \mathrm{~s}$ ).

- M7.3 on 16 April: Intensity 4 in Kumamoto region and Aso region of Kumamoto Prefecture (the maximum Sva was $212 \mathrm{~cm} / \mathrm{s}$ in the period $1.6 \mathrm{~s}$ ).

It was the first time to observe the intensity 4 since the start of issuance of this information by JMA in March 2013.

New Guidelines for the Seismic Forecast Information after Big Earthquakes

JMA issued information about aftershock probability after the first big earthquake of $M 6.5$ on 14 April. The information was based on guidelines determined by the HERP in 1998. However, bigger earthquake (M7.3) occurred on 16 April and this seismic activity was revealed that it was not a simple mainshock - aftershock patterns. Therefore, JMA stopped issuance of the following information. Instead of issuance of information about aftershock probability, JMA called attention to people to high seismic activity and strong motion by big earthquakes.

With lessons learned from the 2016 Kumamoto earthquake, seismologists and JMA discussed under a framework of the HERP, and the Earthquake Research Committee of HERP published new guidelines for the seismic forecast information after big earthquakes in August 2016. The points of the guidelines are followings.

1. JMA calls attention to strong motion which is similar level to the first big earthquake for about one week after big earthquakes.

2. If there were prior cases of foreshock - mainshock - aftershock series or earthquakes with similar magnitude which occurred in short period near the big earthquakes, JMA calls attention to such cases. 
3. If active faults and source regions of thrust-type big earthquakes at subduction zones existed near the big earthquakes, JMA explains the characteristics and calls attention to them.

4. After one week, if the active seismic activity continues, JMA issues aftershock probability. The probability is shown by magnification ratio which compares to the probability just after the biggest earthquake and before the big earthquakes.

5. When JMA calls to attention to strong motion by aftershocks, JMA uses a word "earthquake" instead of "aftershock", because the word of "aftershock" gave some impression to people that bigger earthquakes would not occur.
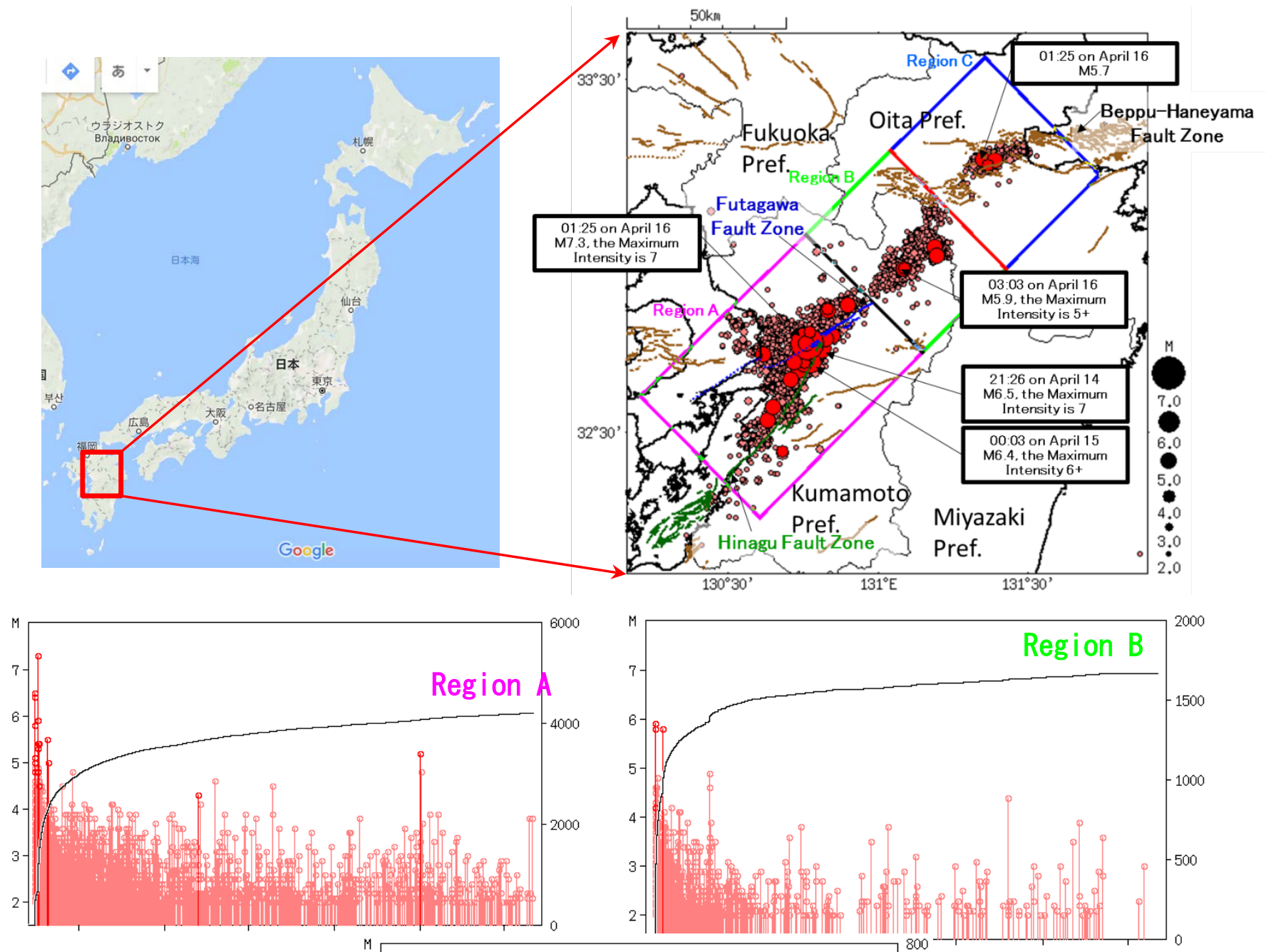

Figure 1. Epicenter

of the 2016

21:00 on April 14 $M \geq 2.0,0 \mathrm{~km} \leq$

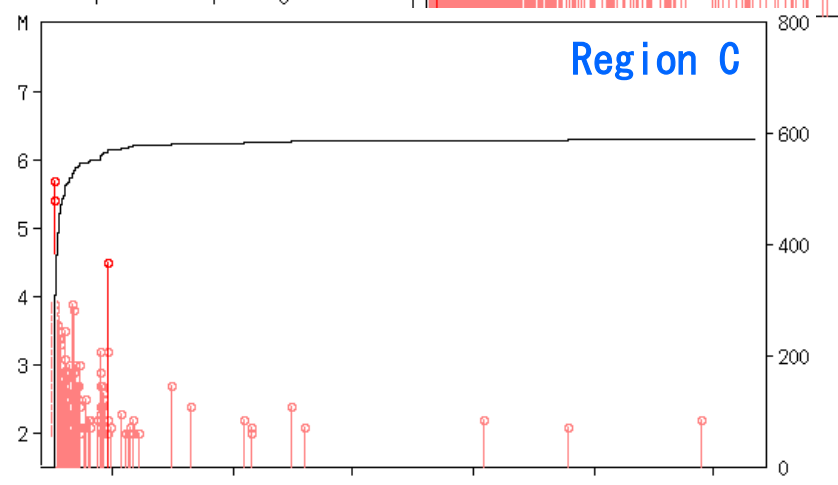

distribution and $\mathrm{M}-\mathrm{T}$ diagrams Kumamoto Earthquake (from to $09: 00$ on October 11, depth $\leq 20 \mathrm{~km}$ ). 

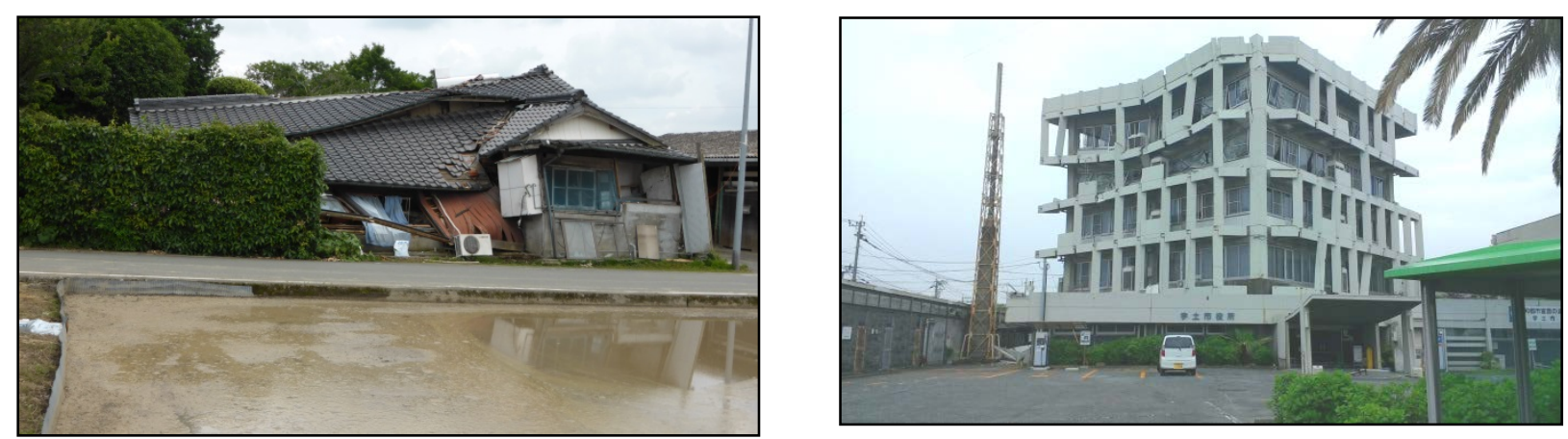

Figure 2. A damaged house and a town hall of Uto city in Kumamoto Prefecture (Photographs taken by Fukuoka Regional Headquarters, JMA). 


\title{
Strong Ground Motion of the 2016 Kumamoto Earthquake Observed in the Midst of Severely Damaged Area
}

\author{
By Masayuki Yoshimi, ${ }^{1}$ Hiroyuki Goto, ${ }^{2}$ Yoshiya Hata, ${ }^{3}$ and Nozomu Yoshida ${ }^{4}$
}

Near-field strong ground motions have been observed during the 2016 Kumamoto earthquake. Peak ground velocity exceeded $100 \mathrm{~cm} / \mathrm{s}$ at many stations, some of them scored VII in the JMA intensity scale, which is the maximum score. There observed very near-fault ground motions, with in one kilometer from the surface fault (Shirahama and others, 2016), in Nishihara village and Mashiki town. Observed ground motion in Nishihara town office is characterized by large (PGV $250 \mathrm{~cm} / \mathrm{s}$ ) and long velocity pulse, which is resulted from permanent displacement by faulting (over $2 \mathrm{~m}$ ). In Mashiki town, Hata and others, (2016) succeeded in recording ground motions in the midst of the damaged area during main shock (16th Apr., $M_{\mathrm{w}} 7.0$ ) by temporally installed seismometers aiming at aftershock observation. Those observed in the Mashiki town show amplified ground motion especially around $1 \mathrm{~s}$ period that might have caused severe damage to wooden houses.

We analyzed ground motion in Mashiki town. Firstly, the soil non-linearity is analyzed by using the surface and borehole records at KiK-net KMMH16 (Mashiki) station. Optimal S-wave velocity models to explain amplification spectra clearly show a dependence of input levels of ground motions. Relations of shear stiffness and damping ratio to shear strain were estimated, and modeled as $\mathrm{G}-\gamma$ and $\mathrm{h}-\gamma$ curves. Then, equivalent linear analyses are conducted for KMMH16 site on the basis of the non-linear model. The synthetic surface ground motions agreed well with the observed ones, especially at S-wave amplitude and phase for the first and main shocks. In addition, we also conducted the same analyses for TMP3 site of Hata and others, (2016), where was located in the heavily damaged zones. The synthetic motions well represented the observed ones, and difference of spectral accelerations was well explained by the analyses. The results indicated that the soil non-linearity played a big role to cause the difference of ground motions in the downtown of Mashiki town.

\section{References Cited}

Goto H., Hata Y., Yoshimi M., and Yoshida N.: Non-linear Site Response at KiK-net KMMH16 (Mashiki) and Heavily Damaged Sites, during the 2016 Kumamoto Earthquake ( $M_{\mathrm{w}}$ 7.1), Japan, Bulletin of the Seismological Society of America (submitted).

Hata Y., Goto H., and Yoshimi M.: Preliminary analysis of strong ground motions in the heavily damaged zone in Mashiki town, Kumamoto, Japan, during the main shock of the 2016 Kumamoto earthquake $\left(M_{\mathrm{w}} 7.0\right)$ observed by a dense seismic array, Seismological Research Letters, Vol.87, No.5, pp.1044-1049, 2016.

Shirahama Y, Yoshimi M., Awata Y., Maruyama T., Azuma T., Miyashita Y., Mori H., Imanishi K.,

Takeda N., Ochi T., Otsubo M., Asahina D., and Miyakawa A.: Characteristics of the surface

${ }^{1}$ Geological Survey of Japan/AIST.

${ }^{2}$ DPRI Kyoto University.

${ }^{3}$ Osaka University.

${ }^{4}$ Tohoku Gakuin University. 
ruptures associated with the 2016 Kumamoto earthquake sequence, central Kyushu, Japan, Earth. Planets and Space, (submitted). 


\section{Seismicity and Structure Responses Following the 2016 Kumamoto Earthquake}

\section{By Norimitsu Nakata ${ }^{1}$}

The 2016 Kumamoto earthquake sequence has a complex character including three earthquakes of magnitude greater than 6 that occurred within 30 hours (April 14-16) that ruptured two major active faults (Hinagu and Futagawa). Due to these large earthquakes, seismicity was remotely triggered at the Aso volcano and Beppu areas, which are both to the east of the mainshock epicenter. I analyze continuous seismic records observed by NIED, JMA, and universities in Kyushu to understand the increase in seismicity and estimate changes in the seismic structure caused by the Kumamoto earthquakes (fig. 1). For the seismicity, I find about 200,000 new events based on the template matching technique, in which I use 200+ events cataloged by JMA. Among the newly detected earthquakes, I find small events that appear to be triggered by the foreshock. For the change in the structure, I use ambient seismic field correlations of all 9 components, and KiK-net data for near-surface changes, and find some areas have a significant decrease in seismic velocity after the largest foreshock (April 14), and other areas only change after the mainshock (April 16). I also observe a larger velocity change at the Aso area than vicinities.

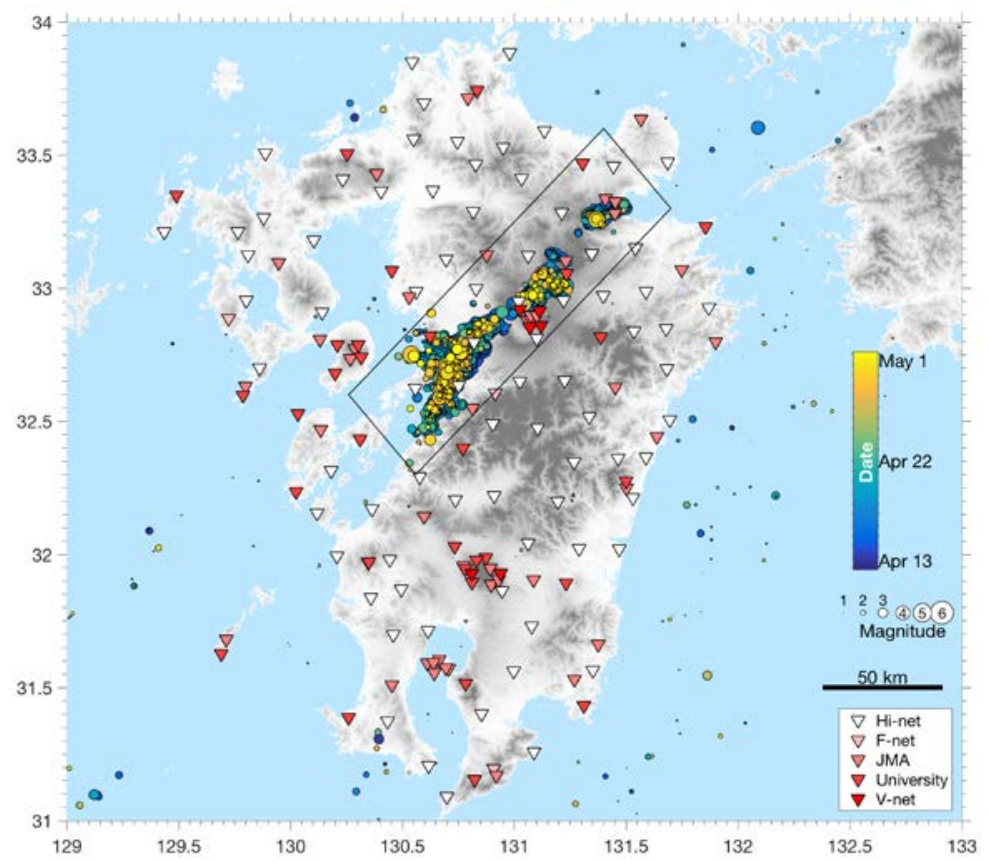

Figure 1. The geometry of stations and epicenters used in this study. The earthquakes are recorded in April 2016.

1University of Oklahoma. 


\section{Acknowledgment}

I am grateful to the National Research Institute for Earth Science and Disaster Resilience, Japan Meteorological Agency, Universities of Tokyo, Kagoshima, and Kyushu for maintaining and providing seismic data. 


\title{
Fault Model of the 2016 Kumamoto Earthquake Inferred from Hypocenter Distribution and Strong- motion Records
}

\author{
By Takahiko Uchide ${ }^{1}$
}

The 2016 Kumamoto earthquake $\left(M_{\mathrm{w}} 7.0\right)$ occurred in central Kyushu, Japan on April 16, 2016 (Japan Standard Time), following two M6-class events on April 14 and 15. These events mainly ruptured well-documented surface traces of faults (the Futagawa and Hinagu fault systems), while the geometry of the buried faults was less clear. Aiming a better description of the earthquake rupture process and the fault geometry, we conducted a hypocenter relocation analysis for fore- and aftershocks and a slip inversion analysis for the mainshock.

We relocated the hypocenters of aftershocks and foreshocks by hypoDD code [Waldhauser and Ellsworth, 2000] using the Japan Meteorological Agency (JMA) phase data. The result indicates that the faults ruptured by foreshocks and those by aftershocks are different at depth, though locations of some of surface ruptures are common. In addition, we also found minor buried faults.

Following the relocated hypocenter distribution, we set two fault planes of the mainshock corresponding to the Futagawa and Hinagu fault systems and conducted a slip inversion analysis using the code of Uchide and Ide [2007]. We detected a large slip up to $6 \mathrm{~m}$ on the Futagawa fault system and the large slip area penetrating into the large caldera of Mt. Aso. The absence of aftershocks in the western part of the Aso caldera is probably due to this large slip. The relationship between this fault behavior and the structure of Mt. Aso should be investigated in future.

\section{References Cited}

Uchide, T., and S. Ide (2007), Development of multiscale slip inversion method and its application to the 2004 mid-Niigata Prefecture earthquake, J. Geophys. Res., 112, B06313, doi:10.1029/2006JB004528.

Waldhauser, F., and W. L. Ellsworth (2000), A double-difference earthquake location algorithm: Method and application to the northern Hayward fault, California, Bull. Seismol. Soc. Am., 90, 1353-1368, doi:10.1785/0120000006

\section{Acknowledgment}

We used the hypocenter locations from the JMA Unified Earthquake Catalog and seismograms from Hi-net, KiK-net and K-NET of National Research Institute for Earth Science and Disaster Resilience (NIED).

\footnotetext{
${ }^{1}$ Geological Survey of Japan, AIST.
} 

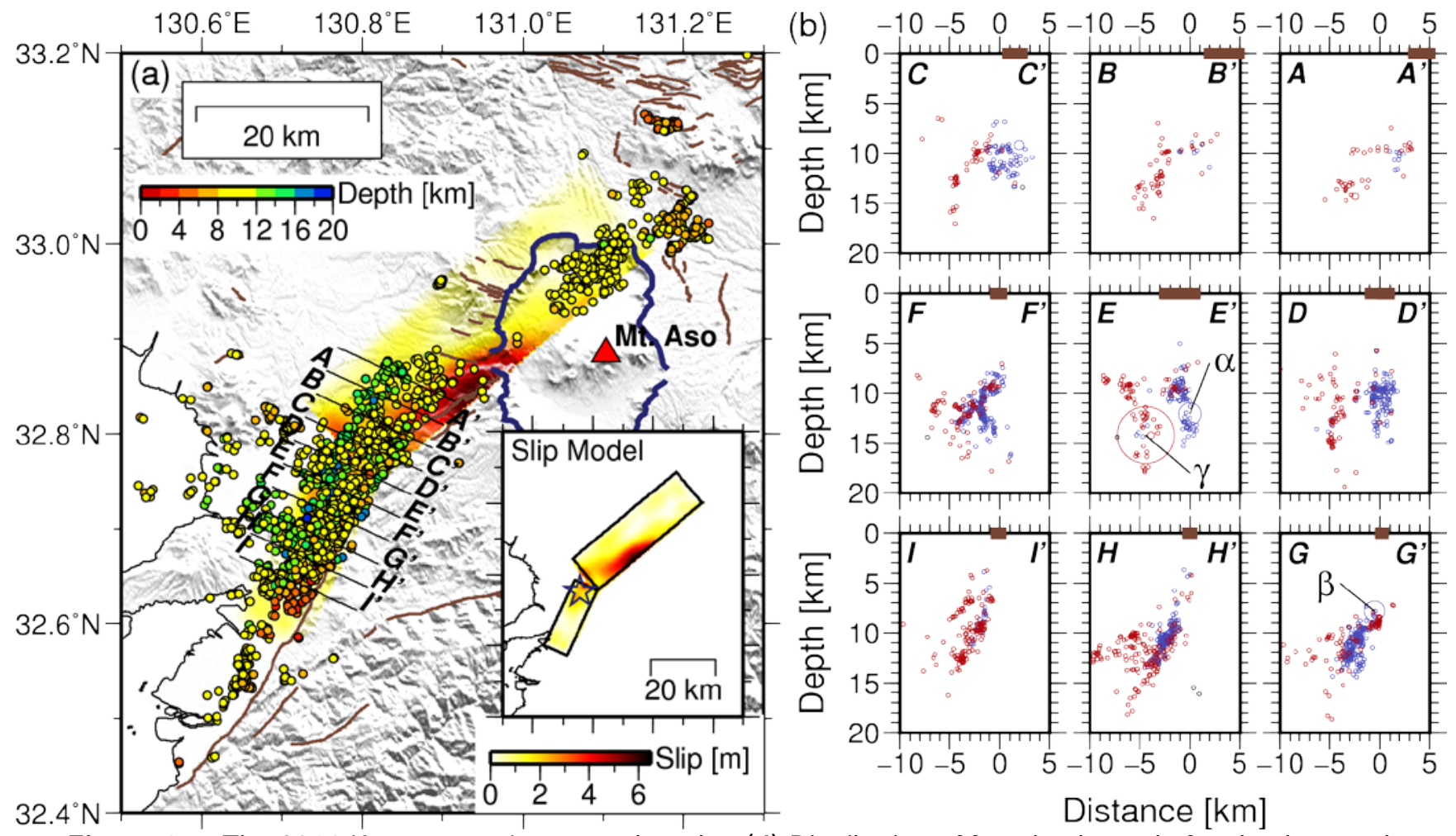

Figure 1. The 2016 Kumamoto, Japan earthquake. (A) Distribution of foreshocks and aftershocks together with the fault slip of the mainshock. (B) Cross sections of hypocenter distribution of foreshock (blue) and aftershocks (red). $\alpha$ and $\beta$ are the M6-class foreshocks and $\gamma$ is the mainshock. 


\title{
Detailed Ground Surface Displacement and Fault Ruptures of the 2016 Kumamoto Earthquake Sequence Revealed by SAR and GNSS Data
}

\author{
By Tomokazu Kobayashi, ${ }^{1}$ Hiroshi Yarai, ${ }^{1}$ Yu Morishita, ${ }^{1}$ Satoshi Kawamoto, ${ }^{1}$ Satoshi Fujiwara, ${ }^{1}$ and Takayuki \\ Nakano ${ }^{1}$
}

Preface

The 2016 Kumamoto earthquake sequence started with a JMA (Japan Meteorological Agency) magnitude (Mj) of 6.5 on April 14, 2016, and is followed by a larger earthquake of Mj 7.3 which occurred on April 15, 2016. The former is thought to occur in the Hinagu Fault, while the latter occur in the Futagawa fault. An L-band synthetic aperture radar (SAR) satellite, known as the Advanced Land Observing Satellite 2 (ALOS-2), and continuous GNSS observation sites (GEONET) which are operated by GSI of Japan have successfully detected the crustal deformation associated with these earthquakes. In particular, SAR data have unveiled the whole and the detailed picture of the ground surface displacement even in the proximity of the faults. In this presentation, we report the displacement field and the rupture location and style of the main shock obtained from these geodetic data.

Data and Method

We used ALOS-2 data observed from the east and the west, both of which were acquired on April 15, 2016 for master image and on April 29, 2016 for slave image. The effect of foreshocks is not included. We applied a pixel offset method in addition to InSAR to retrieve the displacement even in the incoherent area and to measure the along-track displacement component. With these four-component displacements, we estimated the 3D-displamcent field by a least squared approach (fig. 1).

\section{Ground Displacement and Fault Model}

The obtained displacement field shows clear displacement boundaries linearly along the Futagawa, the Hinagu, and the Denokuchi faults across which the sign of displacement component turns to be opposite, suggesting that the fault ruptures occurred there. The fault motion is a rightlateral for the Futagawa and the Hinagu faults, while along the Denokuchi fault a normal faulting with a left-lateral component is recognized. The ground in the northern side of the Futagawa fault subsides with $2.5 \mathrm{~m}$ at maximum, suggesting that the slip on the Futagawa fault has significantly include not only right-lateral slip but also normal dip-slip. The displacement boundary with rightlateral motion extends further eastward from the eastern edge of the known Futagawa fault trace, suggesting the rupture propagated into the Aso caldera. It is noted that the subsidence area shiftes to the southern side of the displacement boundary, suggesting the change of the fault motion and/or the fault plane. Our fault model shows that the main rupture occurred on the Futagawa fault with a right-lateral motion including a slight normal fault motion with a moment magnitude $\left(M_{\mathrm{w}}\right)$ of 6.9. The rupture on the Futagawa fault extends into the Aso caldera with a right-lateral

\footnotetext{
${ }^{1}$ Geospatial Information Authority of Japan.
} 
motion. Of note, the fault plane oppositely dips toward southeast, maybe suggesting that it is a conjugate fault against the main fault. In the west, the rupture branches southward along the Hinagu Fault in which a right lateral motion is predominant. The $M_{\mathrm{w}}$ is estimated to be 6.7, suggesting that the Hinagu Fault in which the foreshocks $\left(M_{\mathrm{w}} 6.2\right.$ and $\left.M_{\mathrm{w}} 6.0\right)$ occurred is also intimately involved with the main shock.

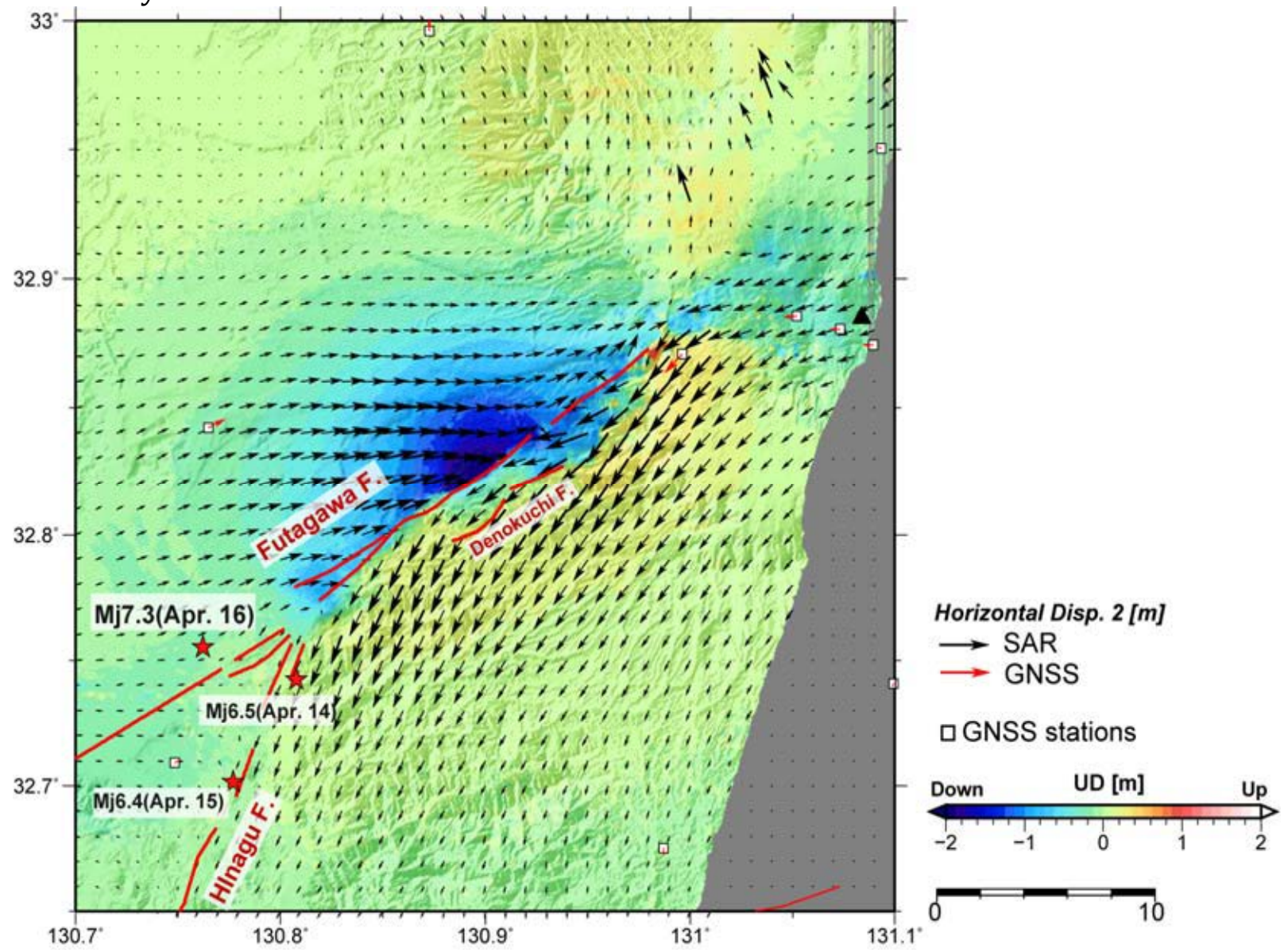

Figure 1. 3D-displacement field obtained from ALOS-2 data. Vertical component with horizontal displacement vectors. The master and slave dates are Apr. 15, 2016 and Apr. 29, 2016, respectively. Clear displacement boundaries can be identified along the Futagawa fault and the Hinagu fault. The ground motion clearly shows that the seismic event had a right lateral motion with normal fault motion.

Acknowledgments

ALOS-2 data were provided from the Earthquake Working Group under a cooperative research contract with JAXA (Japan Aerospace Exploration Agency). The ownership of ALOS-2 data belongs to JAXA. 


\section{Small Displacement Surface Linear Ruptures of the 2016 Kumamoto Earthquake Sequence Detected by ALOS-2 SAR Interferometry}

By Satoshi Fujiwara, ${ }^{1}$ Hiroshi Yarai, ${ }^{1}$ Tomokazu Kobayashi, ${ }^{1}$ Yu Morishita, ${ }^{1}$ Takayuki Nakano, ${ }^{1}$ Basara Miyahara, ${ }^{1}$ Hiroyuki Nakai, ${ }^{1}$ Yuji Miura, ${ }^{1}$ Haruka Ueshiba, ${ }^{1}$ Yasuaki Kakiageand, ${ }^{1}$ and Hiroshi Une ${ }^{1}$

We constructed and analyzed the ground surface displacement associated with the 2016 Kumamoto earthquake sequence using satellite radar interferometry images of the Advanced Land Observing Satellite 2. The radar interferogram generally shows elastic deformation caused by the main earthquakes but many other linear discontinuities showing displacement are also found. About 230 lineaments are identified and the position of some of these coincides with known active faults, such as the main earthquake faults belonging to the Futagawa and Hinagu fault zones and other minor faults, however, there are much fewer known active faults than lineaments. In each area, the lineaments have a similar direction and displacement to each other, therefore, they can be divided into several groups of faults based on location and major features. Since the direction of the lineaments coincides with that of known active faults or their conjugate faults, the cause of the lineaments must be related to the tectonic stress field of this region. The lineaments are classified into the following two categories: (1) main earthquake faults and their branched sub-faults; and (2) secondary faults that are not directly related to the main earthquake but whose slip was probably triggered by the main earthquake or aftershocks.

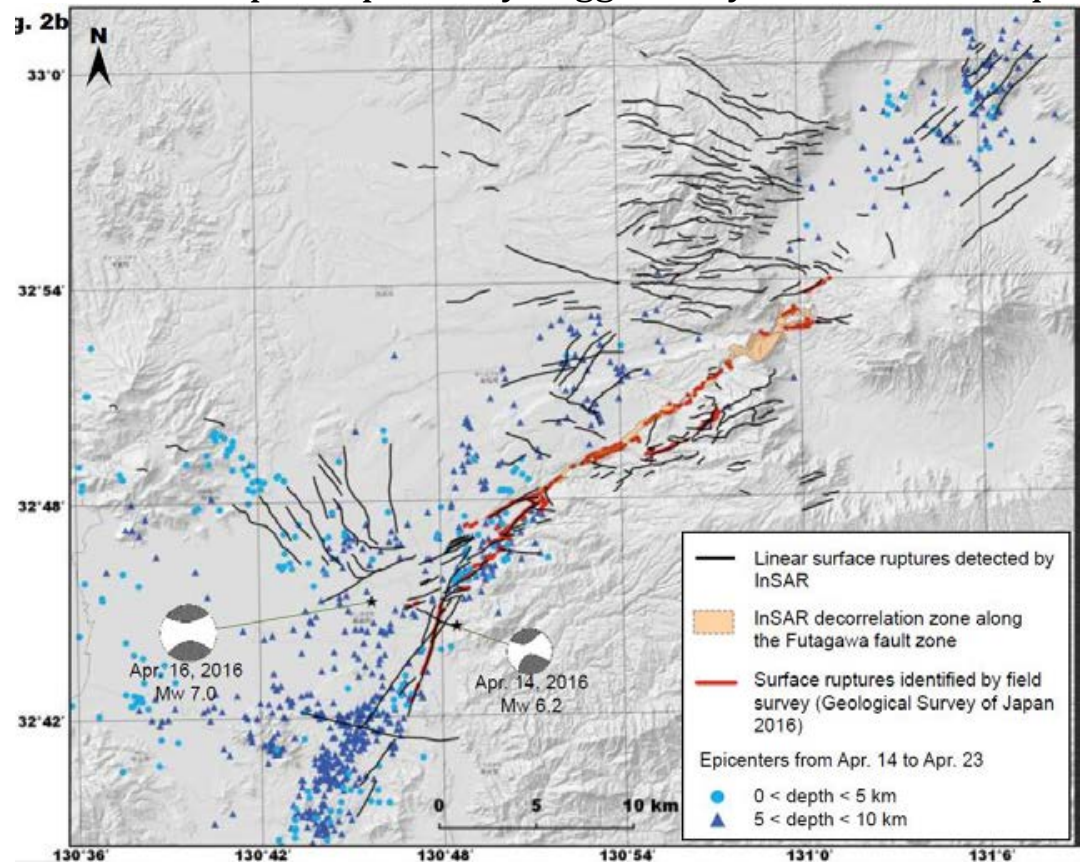

Figure 1. Small solid lines show identified linear surface ruptures. Long, narrow orange area shows the InSAR decorrelation zone along the Futagawa fault zone. Small circles and triangles show epicenters from April 14 to April 23, and beach ball diagrams are from JMA (2016a, b). Red lines show surface ruptures identified by field survey (Geological Survey of Japan 2016).

${ }^{1}$ Geospatial Information Authority of Japan. 

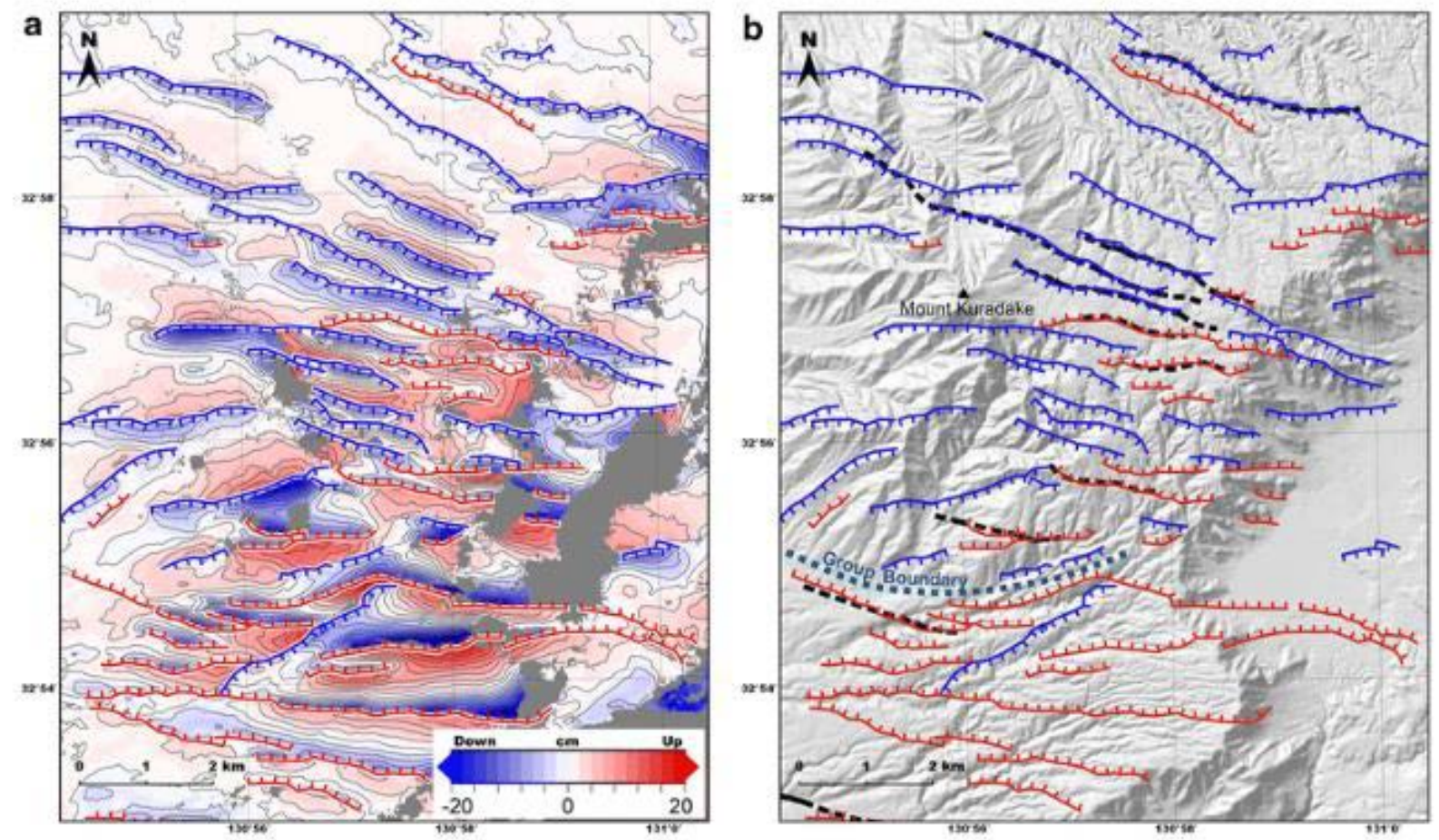

Figure 2. Linear surface ruptures northwest of the outer rim of Aso caldera. A., A high-pass-filtered up-down displacement map made by three-dimensional (3-D) analysis (Morishita and others, 2016) using ALOS-2 image pairs. Red and blue areas represent up and down, respectively. The contour interval is $2 \mathrm{~cm}$. Red solid lines show the identified linear surface ruptures with dip slip where the north side moving down, and blue solid lines show the identified linear surface ruptures with dip slip where the south side moving down. Ticks of the lines show the lower side of each displacement. Red solid lines show the identified linear surface ruptures with dip slip where the north side moving down, and blue solid lines show the identified linear surface ruptures with dip slip where the south side moving down. Ticks of the lines show the lower side of each displacement. Black dashed lines show known active faults (Nakata and Imaizumi 2002; Research group for active tectonics in Kyushu 1989).

\section{References Cited}

Geological Survey of Japan (2016) Surface earthquake faults associated with the 2016 Kumamoto earthquake.

Japan Meteorological Agency (2016a) CMT solution (April 2016). Japan Meteorological Agency (2016b) Hypocenter map (2016 Kumamoto earthquake).

Morishita Y, Kobayashi T, Yarai H (2016) Three-dimensional deformation mapping of a dike intrusion event in Sakurajima in 2015 by exploiting the right-and left-looking ALOS-2 InSAR. Geophys Res Lett 43:4197-4204. doi:10.1002/2016GL068293 Nakata T, Imaizumi T (eds) (2002) Digital active fault map of Japan. Research group for active tectonics in Kyushu (1989) Active tectonics in Kyushu. 


\title{
Earthquake Early Warning for the 2016 Kumamoto Earthquake: Performance Evaluation of the Current System and the Next-Generation Methods of the Japan Meteorological Agency
}

\author{
By Yuki Kodera, ${ }^{1}$ Jun Saitou, ${ }^{2}$ Naoki Hayashimoto, ${ }^{2}$ Shimpei Adachi, ${ }^{2}$ Masahiko Morimoto, ${ }^{2}$ Yuji Nishimae, ${ }^{2}$ and \\ Mitsuyuki Hoshiba ${ }^{1}$
}

The 2016 Kumamoto earthquake (the Kumamoto earthquake sequence) is high-seismicity event that has continuously occurred in Kumamoto Prefecture and its surrounding areas in Japan since April 14, 2016, at 21:26 (JST). The earthquake early warning (EEW) system operated by the Japan Meteorological Agency (JMA) disseminated warnings for 19 cases during the Kumamoto earthquake sequence. The sequence generated numerous earthquakes within a short time and distance, which required the EEW system to continuously operate under some of the heaviest workload conditions yet observed.

We evaluated the system performance for the 19 cases where warnings were issued. We calculated (1) prediction scores that represent an accuracy of predicted seismic intensities at the time of warning issuance and (2) lapse times from detection to the time of warning issuance. Results showed that the system issued warnings with a high accuracy without lengthy delays for most of the large earthquakes in the Kumamoto earthquake sequence. This indicates that the EEW system successfully contributed to mitigation of earthquake damage even under the severe conditions. On the other hand, there were four cases of warnings with a particularly low prediction score due to hypocenter mislocations caused by multiple simultaneous earthquakes within a short distance and time. This reveals that the trigger-data classification algorithm adopted in the current EEW system has a fundamental obstacle.

In addition, we simulated new techniques that JMA plans to implement in the EEW system and evaluated their performance for the Kumamoto earthquake sequence. One of the new techniques is the integrated particle filter (IPF) method. The IPF method is hypocenter estimation algorithm that uses a Bayesian estimation framework and a particle filter technique. The IPF method is expected to distinguish and separately process multiple simultaneous earthquakes more robustly than the current method. The other new technique is the propagation of local undamped motion (PLUM) method. The PLUM method is a simple wavefield estimation algorithm that predicts strong motion using real-time seismic intensities, without hypocenter estimation. The PLUM method is expected to stably estimate strong motion when massive earthquake with a wide rupture zone and multiple simultaneous earthquakes occur. Additionally, the PLUM method has an advantage on rapid detection of strong motion compared with the current method since the PLUM method can operate with a denser seismic network.

The simulation results of the IPF method showed that the IPF method minimized the effect of over-prediction due to hypocenter mislocations caused by multiple simultaneous earthquakes within a short distance. This resulted from its own trigger-data classification algorithm using velocity amplitude and hypocenter determination algorithm using not-yet-arrived data. The simulation results of the PLUM method indicated that the PLUM method issued warnings more

\footnotetext{
${ }^{1}$ Meteorological Research Institute, Japan Meteorological Agency.

2Seismology and Volcanology Department, Japan Meteorological Agency.
} 
rapidly for many destructive inland earthquakes than the current system. This was due to the use of additional seismometers that only the PLUM method can incorporate. 


\section{Session 3: Earthquake Hazards Studies, Recurrence, and Mapping}

\section{A Spatiotemporal Clustering Model for the Third Uniform California Earthquake Rupture Forecast (UCERF3-ETAS) - Toward an Operational Earthquake Forecast}

By Edward H. Field, ${ }^{1}$ Kevin R. Milner, ${ }^{1}$ Jeanne L. Hardebeck, ${ }^{1}$ Morgan T. Page, ${ }^{1}$ Nicholas van der Elst, ${ }^{1}$ Thomas H. Jordan, ${ }^{1}$ Andrew J. Michael, ${ }^{1}$ Bruce E. Shaw,${ }^{1}$ and Maximilian J. Werner ${ }^{1}$

\section{Abstract}

We present a spatiotemporal clustering model for the third Uniform California Earthquake Rupture Forecast (UCERF3), with the goal being to represent aftershocks and otherwise triggered events as a potential basis for operational earthquake forecasting (OEF). Specifically, we add an epidemic-type aftershock sequence (ETAS) component to the previously published timeindependent and long-term time-dependent forecasts. This combined model, referred to as UCERF3-ETAS, collectively represents a relaxation of segmentation assumptions, the inclusion of multi-fault ruptures, an elastic-rebound model for fault-based ruptures, and a state-of-the-art spatiotemporal clustering component. It also represents an attempt to merge fault-based forecasts with statistical seismology models, such that information on fault proximity, activity rate, and time since last event are considered in OEF. We describe several unanticipated challenges that were encountered, including a need for elastic rebound and characteristic magnitude-frequency distributions on faults, both of which are required to get realistic triggering behavior. UCERF3-ETAS produces synthetic catalogs of $M \geq 2.5$ events, conditioned on any prior $M \geq 2.5$ events that are input to the model. We evaluate results with respect to both long-term (1,000 year) simulations, as well as for 10 year time periods following a variety of hypothetical scenario main shocks. While the results are very plausible, they are not always consistent with the simple notion that triggering probabilities should be greater if a main shock is located near a fault. Important factors include whether the magnitude-frequency distributions near faults includes a significant characteristic earthquake component, as well as whether large triggered events can nucleate from within the rupture zone of the main shock. Because UCERF3-ETAS has many sources of uncertainty, as will any subsequent version or competing model, potential usefulness needs to be considered in the context of actual applications.

1U.S. Geological Survey. 


\section{Operational Aftershock Forecasting for the United States and Globally}

By Jeanne L. Hardebeck, ${ }^{1}$ Morgan T. Page, ${ }^{1}$ Nicholas van der Elst, ${ }^{1}$ Andrew J. Michael, ${ }^{1}$ Edward H. Field, ${ }^{1}$ Kevin R. Milner, ${ }^{2}$ Anne Wein, ${ }^{1}$ Clark Jeria, ${ }^{3}$ Shivani Singhal, ${ }^{3}$ and Daniel Chen ${ }^{3}$

The U.S. Geological Survey (USGS) currently publicly issues probabilistic aftershock forecasts following $M \geq 5$ earthquakes in the state of California, based on the method of Reasenberg and Jones (1989) and model parameters developed specifically for California. We are working to expand USGS capabilities to routinely publicly issue forecasts for $M \geq 5$ earthquakes within the rest of the United States, to generate forecasts for significant global earthquakes when called upon by other U.S. Government agencies or international partners, and to transfer this capability to other countries. We are also working to improve various aspects of the forecast calculations and products.

Major improvements to the Reasenberg and Jones methodology were recently published by Page and others, (2016). The improvements include model parameters for events outside California, based on the Garcia and others, (2012) tectonic regionalization of the earth, and a timedependent magnitude of completeness model for global earthquakes to account for the evolving catalog completeness following large earthquakes. As an aftershock sequence progresses, the model parameters can be updated using Bayes Rule, with the distribution of parameters from the Garcia region as the prior. We find that updating only the productivity parameter is often adequate, avoids over-fitting, and allows for timely parameter updates even for low-productivity sequences. The forecasts include both the epistemic uncertainty represented by the prior distribution, and the uncertainty due to aleatory variability in the non-stationary Poisson model. The inclusion of epistemic uncertainty addresses criticisms of the Reasenberg and Jones method by Rydelek and others (1990).

The improvements to the Reasenberg and Jones methodology are implemented in Java (www.OpenSHA.org), with a graphical user interface (GUI) to aid in exploring the data and model parameters. The code module that computes the Reasenberg and Jones forecasts can be replaced in the future with modules based on other forecast models, and we plan to implement a temporal epidemic-type aftershock sequence (ETAS) model (Ogata, JASA, 1988). The GUI and the underlying code has been used by USGS to generate publicly-issued aftershock forecasts for events such as the $M_{\mathrm{w}} 5.8$ Pawnee, Oklahoma, earthquake of September 3, 2016. Currently the code must be run by hand, and the forecasts uploaded manually. We are working to automate this process, so that forecasts based on the regional parameters automatically appear on the USGS website within minutes following a $M \geq 5$ event in the United States ( $M \geq 6$ in Alaska). Updated forecasts would be issued at regular intervals either automatically or with minimal human intervention.

For significant earthquakes outside the United States, the USGS will have the ability to generate aftershock forecasts if requested inside the U.S. Government or by an international partner. We are working to build aftershock-forecasting capability in other counties by

1U.S. Geological Survey.

2University of Southern California.

${ }^{3}$ Carnegie Mellon University Silicon Valley. 
developing and sharing stand-alone software that can be used directly by the appropriate agencies in partner countries. This will promote the use of consistent, authoritative methods across political and tectonic borders, while at the same time relieving the USGS of the somewhat problematic role of issuing international aftershock forecasts. For example, when the U.S. Embassy in Kathmandu requested aftershock forecasts following the 2015 Nepal earthquake, a difficult decision had to be made whether to publicly release the forecasts without coordination with the Nepalese government. The USGS and the Embassy decided to publicly share the forecast so that it was available to all governments and non-government organizations (NGO)s involved in the response efforts, as well as the public. Challenges included how to balance simple messaging with forecasts over a variety of time periods, whether to characterize probabilities with words such as those suggested by the Intergovernmental Panel on Climate Change (IPCC; Mastrandrea and others, 2010), and how to word the messages in a way that would translate accurately into Nepali and not alarm the public. Cross-cultural communication difficulties did arise, for example from differences in understanding a "forecast" as a probabilistic versus a deterministic statement.

We have developed a template for the advisory message to accompany the aftershock forecasts, using findings from a study of the communication of aftershock information in New Zealand, and guidance from crisis and risk communication experts. The template was revised based on feedback from an emergency manager user group, and a contingent of social science experts. The template is organized as a progression of information: forecasts begin with a concise statement about what has occurred and the increased seismic hazard, and then connects to other related messages about what people can do and how they can cope. This is followed by more detail about the forecast for the coming week (or month), and interpretation about what the hazard means for vulnerable buildings and landslides (as applicable). It is a challenge to communicate the small probabilities for the rare but potentially damaging large aftershocks. The template includes context for the probabilities by reporting the increase in earthquake probability compared to background, if the background is known. The template uses alternative descriptions of probability, as percentages and in the form of " 1 in X", and reports ranges for the expected number of earthquakes to represent the uncertainties in the calculations. A technical appendix provides the expected rate of earthquakes and probabilities for various magnitudes and time windows to support a broad range of decision-making.

Current forecasts specify the expected number of aftershocks in a given time frame, magnitude range, and spatial area. However, feedback from users of the forecasts shows substantial demand for forecasts of the likely ground motions (see abstract by Wein and others, this volume). Users studies also show a need for multiple formats of forecast information (text, tables, figures, and maps.) Therefore, we plan to implement a spatial-temporal ETAS model in order to build map-based products similar to ShakeMap and Prompt Assessment of Global Earthquakes for Response (PAGER), but for anticipated, rather than observed, earthquake shaking. We also plan to build a simple graphical user interface through which expert users can generate custom products based on the aftershock forecasts.

\section{References Cited}

Garcia, Daniel, Wald, D.J., and Hearne, M.G., 2012, A global earthquake discrimination scheme to optimize ground-motion prediction equation selection: Bulletin of the Seismological Society of America, v. 102, no. 1, p. 185-203. 
Mastrandrea, M.D., Field, C.B., Stocker, T.F., Edenhofer, O., Ebi, K.L., Frame, D.J., Held, H., Kriegler, E., Mach, K.J., Matschoss, P.R., Plattner, G.-K., Yohe, G.W., and Zwiers, F.W., 2010, Guidance note for lead authors of the IPCC fifth assessment report on consistent treatment of uncertainties: Intergovernmental Panel on Climate Change (IPCC), Available at http://pubman.mpdl.mpg.de/pubman/item/escidoc:2147184/component/escidoc:2147185/u ncertainty-guidance-note.pdf.

Ogata, Yosihiko, 1988, Statistical models for earthquake occurrences and residual analysis for point processes: Journal of the American Statistical Association, v. 83, no. 401, p. 9-27.

Page, M.T., Van Der Elst, N., Hardebeck, J., Felzer, K., and Michael, A.J., 2016, Three Ingredients for Improved Global Aftershock Forecasts-Tectonic Region, Time-Dependent Catalog Incompleteness, and Intersequence Variability: Bulletin of the Seismological Society of America, v. 106 , no. 5 , p. $2290-2301$.

Reasenberg, P.A., and Jones, L.M., 1989, Earthquake hazard after a mainshock in California: Science, v. 243, no. 4895, p. 1173-1176.

Rydelek, P.A., Reasenberg, P.A., and Matthews, M.V., 1990, California aftershock model uncertainties: Science, v. 247, no. 4940, p. 343-343. 


\section{Incorporating ground motions from 3-D earthquake simulations into the U.S. National Seismic Hazard Model}

\section{By Morgan Moschetti ${ }^{1}$}

The increasing accuracy of 3-D earthquake ground motion simulations has motivated our investigation of methods to incorporate simulated ground motions into the U.S. National Seismic Hazard Model. We present a preliminary investigation of an amplification-based approach for introducing simulated ground motions into probabilistic seismic hazard analysis (PSHA). There are unique requirements for incorporating simulated ground motions into a national-scale seismic hazard model that forms the basis for seismic provisions in building codes. These requirements include continuity with the empirically based ground motions at surrounding sites and use of only the most robust features of the ground motion simulations. The initial use of the amplification-based method meets these criteria, as (1) it enforces a matching of the simulated and empirically based median ground motions at rock sites, where we expect that the empirically based ground motion prediction equations (GMPEs) provide greater accuracy than is expected at sites overlying deep sediments, and (2) the absolute ground motion level is prescribed by the empirically based GMPEs. However, the 3-D simulations control the spatial patterns and relative amplitudes of the ground motion amplifications, which result from wave-propagation and finitefault features.

In this presentation, we describe a potential framework for using 3-D ground motion simulations to modify the median ground motions for probabilistic seismic hazard analysis and perform initial sensitivity testing with one seismic source. A U.S. Geological Survey working group on urban hazards has recommended that initial tests of the incorporation of simulated ground motions into PSHA focus on modifying the median values of the ground motion distribution. Preliminary calculations employ simulations of M7.9 earthquakes on the southern San Andreas Fault from the Southern California Earthquake Center's (SCEC) CyberShake 15.4 project (Figure 1). Data from past small- to moderate-sized earthquakes are used to identify sites where the ground motion response is well predicted by GMPEs, and these sites are used as reference sites in the amplification calculations. The amplified ground motions, computed from the 3-D simulations, indicate stronger ground motions within the deep sedimentary basins of southern California than are predicted by the current GMPEs. We find a strong sensitivity of the amplified ground motions to the rupture realization and to the reference site. We interpret the variability to largely arise from finite-fault effects, primarily rupture directivity.

1U.S. Geological Survey. 


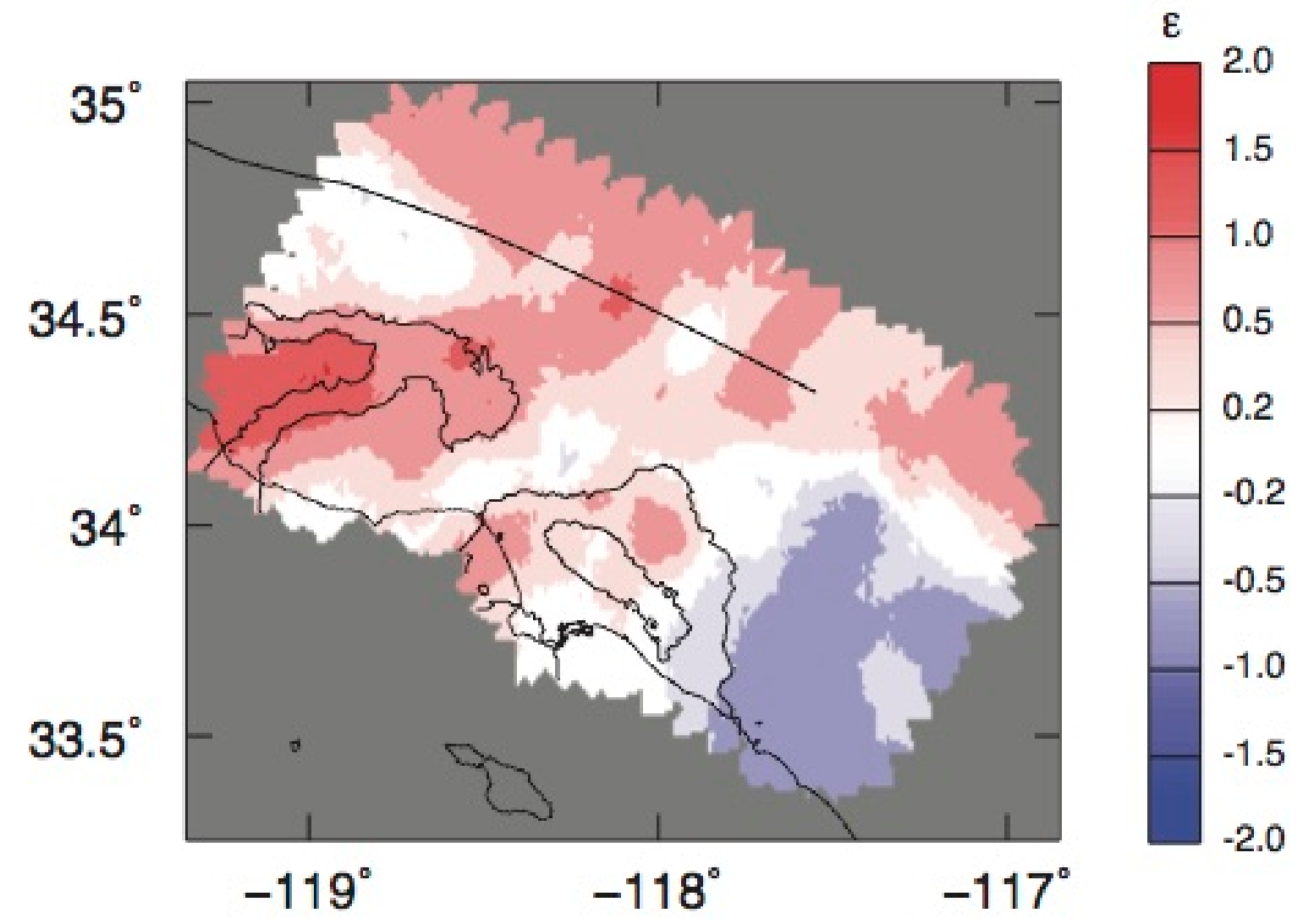

Figure 1. Ground motion residuals $(\varepsilon)$ from the average of all amplified ground motions computed from all reference sites, for $M 7.9$ earthquakes on the southern San Andreas Fault. Residuals are computed relative to the GMPE of Abrahamson and others (2014) and indicate the difference in the median ground motions in units of the standard deviation of the GMPE.

\section{Reference Cited}

Abrahamson, N.A., Silva, W.J., and Kamai, R., 2014 Summary of the ASK14 ground motion relation for active crustal regions: Earthquake Spectra, v. 30, no. 3, p. 1025-1055. 


\section{Supercycles and Synchronization Signatures in Synthetic Seismic Sequences}

By K.R. Milner ${ }^{1}$ and T.H. Jordan

Synchronization is a key concept in nonlinear dynamics. Owing to the paucity and uncertainty of paleoseismic data, we can't say much about the synchronization of large earthquakes in complex fault systems such as the San Andreas, but we know that substantial elastic strain has accumulated in the southern part of this system since its last major earthquake in 1857. One question is whether the distribution of long open intervals is consistent with the recently published Third Uniform California Earthquake Rupture Forecast (UCERF3: Field and others, 2015), which assumes that time-dependent event probabilities can be modeled by Reid renewal processes correlated across faults only by co-rupture. In a UCERF3 world, the probability of observing an open-interval distribution as extreme as the present day would be low, less than 1 percent according to one estimate (Jackson, 2016). An alternate hypothesis is that we are in a period of low overall energy release; for example, near the minimum of a "seismic supercycle." UCERF3 does not explicitly model supercycles, but they emerge from long runs of physics-based rupture simulators, such as the RSQSim model of Dieterich \& Richards-Dinger $(2010,2012)$ and the ALLCAL model of Ward (2012). In these models, the synchronization of large events on different fault sections leads to variations in seismic energy release of \pm 50 percent on time scales of about 200 years. Spectral analysis of a million-year RSQSim catalog shows synchronization harmonics with a fundamental period of 200 years and a corresponding depletion at longer event periods (fig. 1). This synchronization signature is absent in UCERF3 and randomized versions of the RSQSim catalog. We further investigate synchronization and its time dependence using twodimensional "recurrence plots" (Eckmann and others, 1987) to map the temporal recurrence of proximate RSQSim states. We use the results to speculate on the hazard implications of the supercycle hypothesis.

1University of Southern California. 


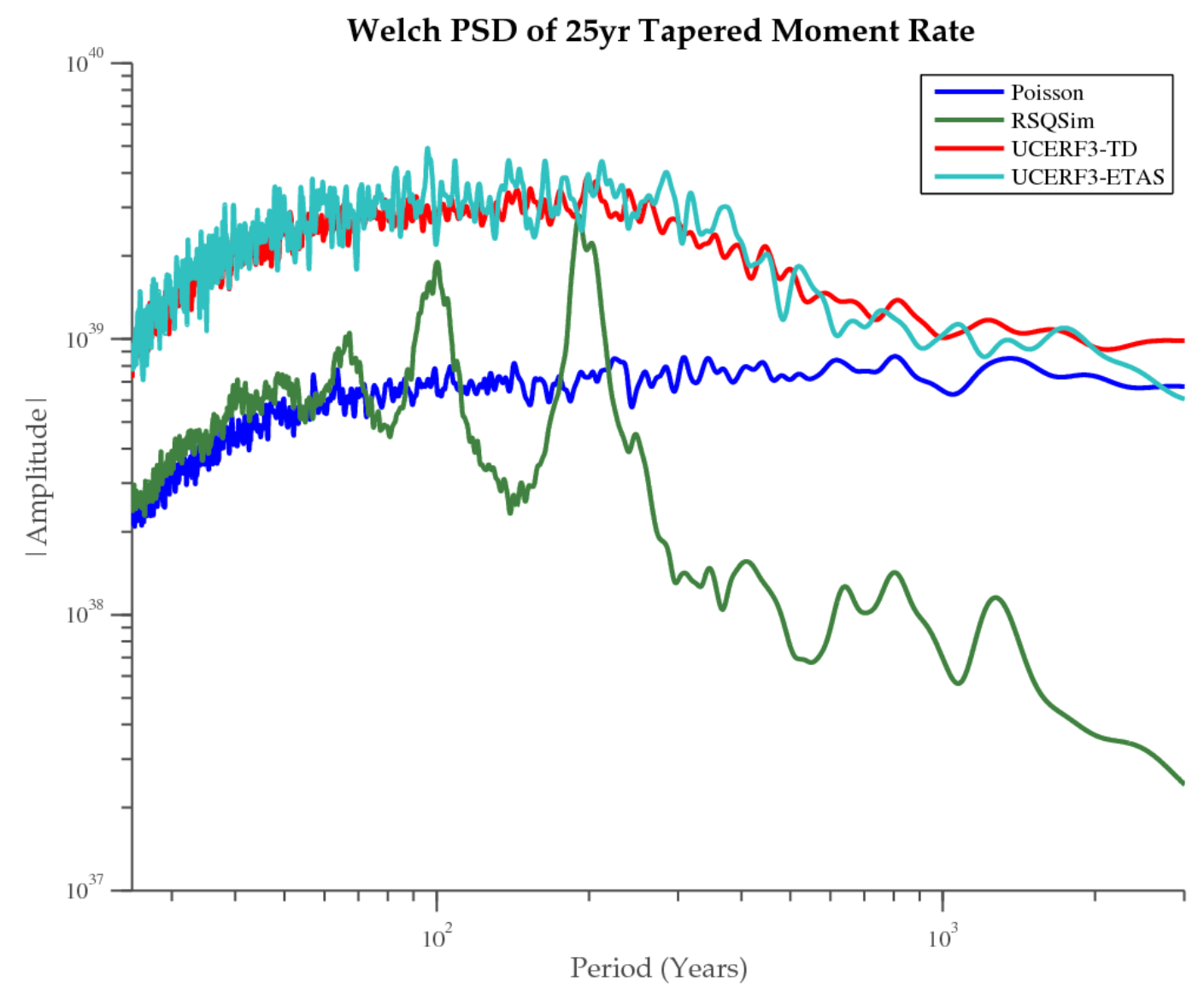

Figure 1. Power spectral density estimate of seismic moment release from RSQSim catalogs (randomized in blue, actual in green), UCERF3-TD (red), and UCERF3-ETAS (cyan). RSQSim catalogs show strong synchronization at periods of 100 and 200 years which are absent from randomized RSQSim and both UCERF3 catalogs.

\section{References Cited}

Dieterich, J.H., \& Richards-Dinger, K.B. (2010), Earthquake recurrence in simulated fault systems. Pure and applied geophysics,167(8-9), 1087-1104

Eckmann, J.P., Kamphorst, S.O., \& Ruelle, D. (1987), Recurrence plots of dynamical systems. EPL (Europhysics Letters),4(9),973.

Field, E.H., Biasi, G.P., Bird, P., Dawson, T., Felzer, K.R., Jackson, D.D., Johnson, K.M., Jordan, T.H., Madden, C.L., Michael, A.J., Milner, K.R., Page, M.T., Parsons, T., Powers, P.M., Shaw, B.E.,

Thatcher, W.R., Weldon, R.J., \& Zeng, Y. (2015), Long-Term Time-Dependent Probabilities for the Third Uniform California Earthquake Rupture Forecast (UCERF3), Bulletin of the Seismological Society of America, 105(2A), 511-543. doi: 10.1785/0120140093.

Jackson, D.D. $(2016,09)$, The bridge from earthquake geology to earthquake seismology. Oral Presentation at 2016 SCEC Annual Meeting.

Richards-Dinger, Keith, and James H. Dieterich. "RSQSim earthquake simulator." Seismological

Research Letters 83.6 (2012): 983-990.

Ward, S.N. (2012), ALLCAL earthquake simulator. Seismological Research Letters, 83(6), 964-972. 


\section{Possibility of Large Seismic Slip on Creeping Fault Segments and Deeper Creeping Fault Extensions}

\section{By Nadia Lapusta ${ }^{1}$}

Rate-and-state fault models associate creeping regions with velocity-strengthening (VS) friction, suggesting that they act as barriers to earthquakes since their strength increases with their slip velocity (also called slip rate). Indeed, earthquakes often arrest at the boundaries of creeping regions. However, experimental and theoretical studies reveal that several weakening mechanisms, such as thermal pressurization of pore fluids, can be activated at high seismic slip rates. As earthquake rupture penetrates into the VS fault areas, it significantly increases slip rates there, potentially activating the additional co-seismic weakening and turning the stable fault areas into seismogenic ones. We have explored such behavior in a numerical model with fault properties measured using rock samples obtained from the Chelungpu fault, the site of the 1999 Chi-Chi earthquake (Noda and Lapusta, Nature, 2013). The model reproduces a number of both long-term and coseismic observations about faults that hosted the 2011 Tohoku-Oki and 1999 Chi-Chi earthquakes. Moreover, only models in which the largest earthquake events rupture a shallow creeping region can reproduce the 1000-year recurrence interval proposed for the Tohoku-Oki-like events (Cubas and others, EPSL, 2015).

In short, it is physically plausible for a creeping fault region to sustain dramatic seismic slip, and this may have occurred in the 2011 Tohoku-Oki and 1999 Chi-Chi earthquakes. After seismic slip, such regions would stay locked for a while, but eventually accumulate enough stress to start creeping again, obscuring the evidence of their violent past.

The possibility that seismic rupture can be sustained in a creep-prone, VS region due to coseismic weakening implies that earthquake ruptures can potentially penetrate below the locked seismogenic zone, into the deeper creeping fault extensions (Jiang and Lapusta, Science, 2016). Our strike-slip fault models mimicking segments of the San Andreas Fault (SAF) show that the depth extent of the largest events is determined by the boundary where enhanced coseismic weakening stops being efficient. The depth extent of coseismic rupture influences the seismicity pattern throughout the post-seismic and inter-seismic period. When large events are confined in the traditionally defined seismogenic region, with velocity-weakening (VW) rate-and-state friction properties, streaks of microseismicity are seen at and above the VS/VW transition due to stress concentration between the locked and creeping regions being in the VW area. In the cases with deeper penetration due to the enhanced dynamic weakening, the microseismicity streaks disappear. These characteristic behaviors resemble the observed seismicity activity on the Parkfield and Carrizo segments on SAF, respectively.

The much larger occasional extent of earthquake ruptures in these models than what would be inferred based on currently locked fault areas highlights the potential for extreme, unexpected events. We need to study the structure, properties, and past behavior of creeping regions, such as the one on the San Andreas Fault, to evaluate their propensity for coseismic weakening, and hence their ability to sustain seismic slip, so that we can better assess the range of physically plausible fault behaviors.

${ }^{1}$ Mechanical \& Civil Engineering and Seismological Laboratory, California Institute of Technology. 


\section{References Cited}

Noda, H. and Lapusta, N. 2013. "Stable creeping fault segments can become destructive as a result of dynamic weakening," Nature, 493 518-521, doi:10.1038/nature11703

Cubas et al, 2015 "Numerical modeling of long-term earthquake sequences on the NE Japan megathrust: Comparison with observations and implications for fault friction," Earth Planet Sci. Lett., 419, 187-198.

Jiang, J. and Lapusta, N. 2016 "Deeper penetration of large earthquakes on seismically quiescent faults," Science, 352, 6291, 1293-1297. 


\title{
Correlations Between Fault Zone and Earthquake Properties in the Southern California Plate- boundary Around the San Jacinto Fault Zone
}

\author{
By Yehuda Ben-Zion ${ }^{1}$
}

\section{Abstract}

I review multi-scale/signal seismological results on structure and earthquake source properties in San Jacinto Fault Zone (SJFZ) in southern California, with a focus on developing deterministic correlations between fault zone and earthquake properties. In particular I examine (1) relations between velocity contrast across fault sections and earthquake directivity, and (2) geometrical fault complexity and source tensor terms. The results are based on data (fig.1) of the southern California and Anza networks, over 70 additional near-fault seismometers including six linear arrays with instrument spacing 25-50 m that cross the SJFZ at several locations, and a rectangular array with $>1100$ vertical-component sensors separated by 10-30 m centered on the fault south of Anza. The structural studies utilize earthquake data to image the seismogenic sections and ambient noise to image the shallower structures. The earthquake studies use waveform inversions and additional time domain and spectral methods. Pronounced damage regions with low seismic velocities are observed at several scales [Allam and Ben-Zion 2012; Allam and others, 2014; Zigone and others, 2015]. The damage zones follow a flower-shape with depth (fig. 2); in places with velocity contrast they are offset to the stiffer side of the seismogenic section as expected for bimaterial ruptures with persistent propagation direction [for example, Ben-Zion and Shi 2005]. Analyses of PGV/PGA, source spectra of body waves and second seismic moments indicate persistent directivity of earthquake ruptures on given fault sections [Kurzon and others, 2014; Ross and Ben-Zion 2016; Meng and others, 2016]. Persistent directivity is also indicated by along-strike-asymmetry of stacked aftershock sequences [Zaliapin and Ben-Zion 2011]. The results are consistent with expectations of bimaterial ruptures associated with the local velocity contrasts [for example, Andrews and Ben-Zion 1997; Ampuero and Ben-Zion 2008; Shlomai and Fineberg, 2016]. Full source tensor properties of $M>4$ earthquakes in the complex trifurcation area of the SJFZ include statistically-robust small isotropic component [Ross and others, 2015]. The results are consistent with expectation for damage-related-radiation generated by rock fracturing in the source volumes [Ben-Zion and Ampuero 2009].

1University of Southern California. 


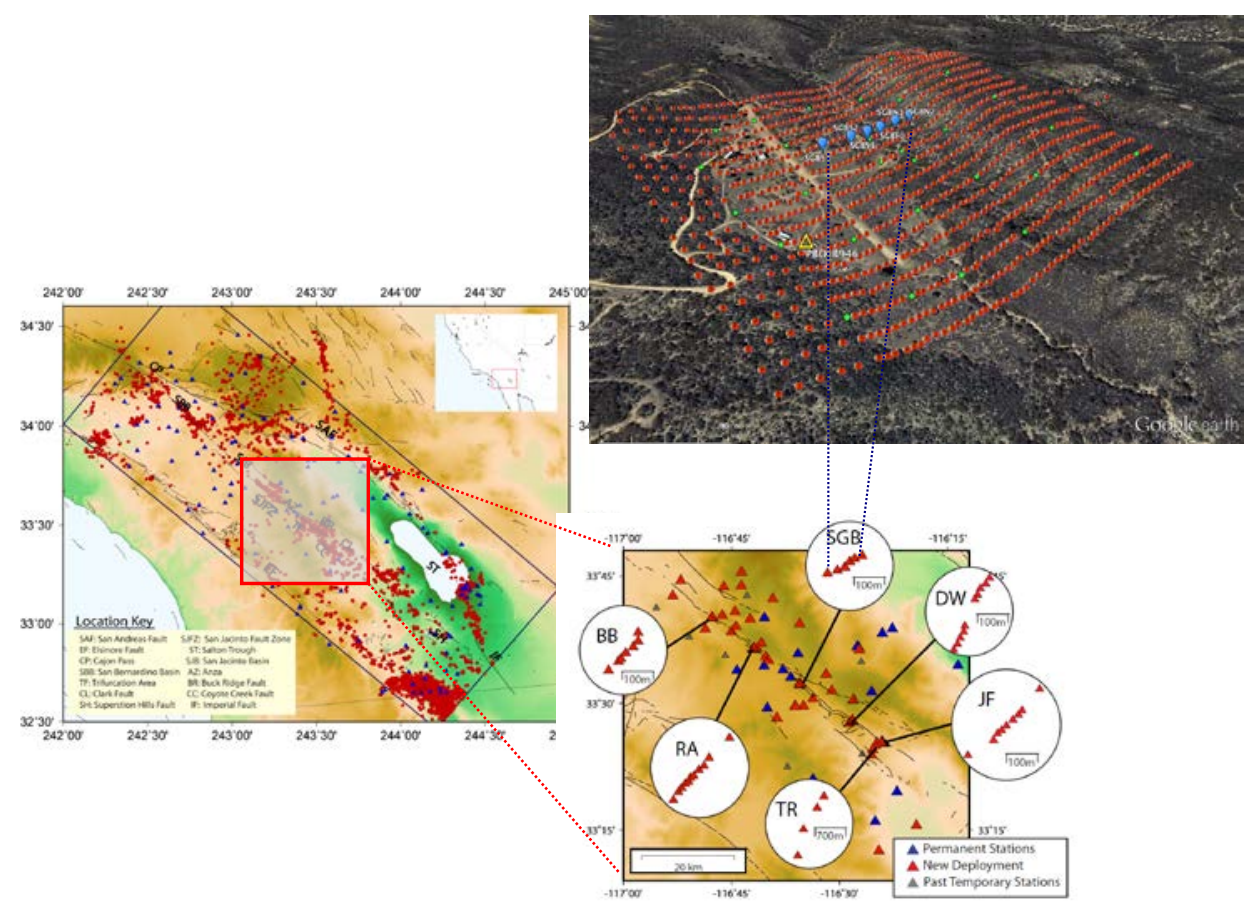

Figure 1. (Left) Regional seismic stations (blue triangles) and seismicity (red circles). (Bottom right) Zoom in showing $>70$ additional near-fault stations (red triangles) and dense across-fault linear arrays. (Top right) Further zoom showing a spatially-dense N array with 1108 vertical-component sensors at site SGB (blue symbols). From Ben-Zion and others, [2015].
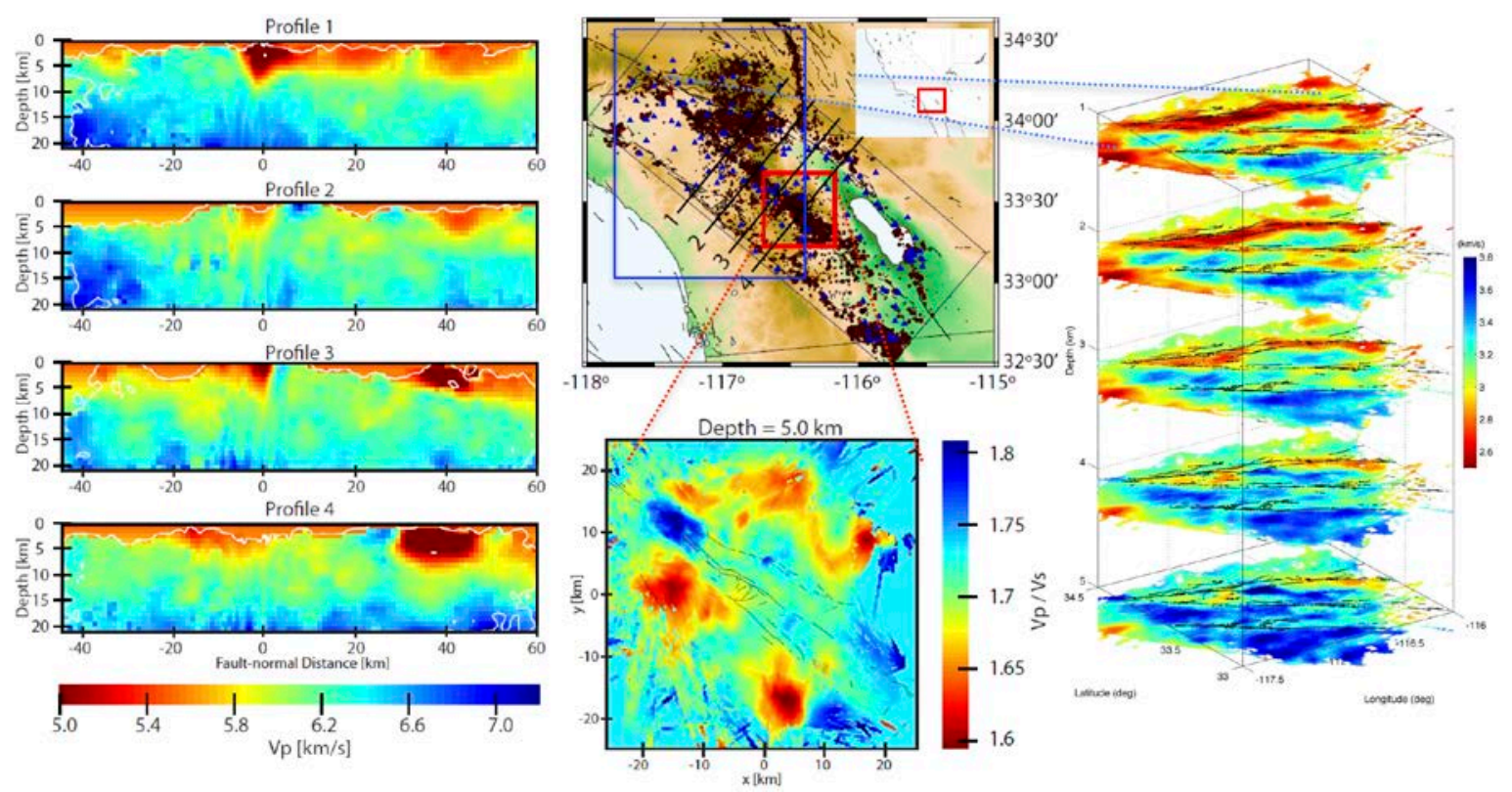

Figure 2. Fault-normal cross-section views of P-wave velocities (left) and VP/VS ratios (bottom middle) from double-difference earthquake tomography at locations indicated on top middle [Allam and Ben-Zion, 2012; Allam and others, 2014]. The results have good resolution over the depth section 3-15 km. Noise-based tomography with frequencies up to $1 \mathrm{~Hz}$ (right) provide imaging results over the depth section $0.5-7 \mathrm{~km}$ [Zigone and others, 2015]. 


\section{References Cited}

Allam, A.A. and Y. Ben-Zion, 2012, Seismic velocity structures in the Southern California plateboundary environment from double-difference tomography, Geophys. J. Int., 190, 1181-1196, doi: 10.1111/j.1365-246X.2012.05544.x.

Allam, A.A., Y. Ben-Zion, I. Kurzon and F.L. Vernon, 2014, Seismic velocity structure in the Hot Springs and Trifurcation Areas of the San Jacinto Fault Zone, California, from double-difference tomography, Geophys. J. Int., 198, 978-999, doi: 10.1093/gji/ggu176.

Ampuero, J.P., and Y. Ben-Zion (2008), Cracks, pulses and macroscopic asymmetry of dynamic rupture on a bimaterial interface with velocity-weakening friction, Geophys. J. Int., 173(2), 674692.

Andrews, D.J. and Y. Ben-Zion, 1997, Wrinkle-like Slip Pulse on a Fault Between Different Materials, J. Geophys. Res., 102, 553-571.

Ben-Zion, Y. and Z. Shi, 2005, Dynamic rupture on a material interface with spontaneous generation of plastic strain in the bulk, Earth Planet. Sci. Lett., 236, 486-496, DOI: 10.1016/j.epsl.2005.03.025.

Ben-Zion, Y. and J.-P. Ampuero, 2009, Seismic radiation from regions sustaining material damage, Geophys. J. Int., 178, 1351-1356, doi: 10.1111/j.1365-246X.2009.04285.X.

Ben-Zion, Y., F.L. Vernon, Y. Ozakin, D. Zigone, Z. E. Ross, H. Meng, M. White, J. Reyes, D. Hollis and M. Barklage, 2015, Basic data features and results from a spatially-dense seismic array on the San Jacinto fault zone, Geophys. J. Int., 202, 370-380, doi:10.1093/gji/ggv14.

Kurzon, I., F.L. Vernon, Y. Ben-Zion and G. Atkinson, 2014. Ground Motion Prediction Equations in the San Jacinto Fault Zone - Significant Effects of Rupture Directivity and Fault Zone Amplification, Pure Appl. Geophys., 171, 3045-3081, doi: 10.1007/s00024-014-0855-2.

Meng, H., Y. Ben-Zion and J. McGuire, 2016, Towards automated estimates of directivity and related source properties of small to moderate earthquakes in Southern California with second seismic moments, Proc. of Annual meeting, Southern California Earthquake Center.

Ross, Z.E., Y. Ben-Zion and L. Zhu, 2015. Isotropic source terms of San Jacinto fault zone earthquakes based on waveform inversions with a generalized CAP method, Geophys. J. Int., 200, 1269-1280, doi: 10.1093/gji/ggu460.

Ross, Z.E. and Y. Ben-Zion, 2016, Towards reliable automated estimates of earthquake source properties from body wave spectra, J. Geophys. Res., 121, doi:10.1002/2016JB013003.

Shlomai, H., and J. Fineberg, 2016, The structure of slip-pulses and supershear ruptures driving slip in bi-material friction, Nat. Comm., 7. Article Number 11787, doi:10.1038/ncomms11787.

Zaliapin, I. and Y. Ben-Zion, 2011, Asymmetric distribution of aftershocks on large faults in California, Geophys. J. Int., 185, 1288-1304, doi: 10.1111/j.1365-246X.2011.04995.x. Zigone, D., Y. Ben-Zion, M. Campillo and P. Roux, 2015. Seismic Tomography of the Southern California plate boundary region from noise-based Rayleigh and Love Waves, Pure Appl. Geophys., 172, 1007-1032, doi: 10.1007/s00024-014-0872-1. 


\title{
Evidence for Distributed Clockwise Rotation of the Crust in the Northwestern United States from Fault Geometries and Earthquake Focal Mechanisms
}

\author{
By Thomas M. Brocher, ${ }^{1}$ Ray E. Wells, ${ }^{1}$ and Andrew P. Lamb ${ }^{1}$
}

Paleomagnetic and GPS data indicate that Washington and Oregon have rotated clockwise for at least 16 million years (Myr). Neogene and Quaternary fault geometries, seismicity lineaments, and earthquake focal mechanisms provide evidence that in the west this rotation is accommodated by north-south shortening along thrust faults and north-northwest-trending strike-slip faults, and in the east by west- to southwest-directed extension accommodated by normal faults and west- to southwest-trending strike-slip faults. Curvilinear northwest- to northnorthwest-trending high-angle strike-slip faults and seismicity lineaments in western Washington and northwestern Oregon define an approximate Euler pole of rotation relative to North America near Spokane, Washington $\left(117.7^{\circ} \mathrm{W}, 47.9^{\circ} \mathrm{N}\right)$. Many late Cenozoic faults and earthquake focal mechanisms throughout northwestern United States and southwestern British Columbia have orientations consistent with this Euler pole. Large active normal faults radial to the Euler pole, that may accommodate crustal rotation via crustal extension, are widespread to the southeast, and can be found along the Lewis and Clark zone in Montana, within the Centennial fault system north of the Snake River Plain in Idaho and Montana, to the west of the Wasatch Front in Utah, and within the northern Basin and Range in Oregon and Nevada. Distributed strike slip faults may help transfer slip between thrust and normal faults throughout the northwestern United States, but are most prominent in Washington and Oregon where they transfer slip between convergent structures (fig. 1). Potential drivers of the clockwise crustal rotation include oblique plate convergence, westward rollback of the Juan de Fuca slab, and a mega-gravity slide down the Yellowstone geoid high. The current surface velocity field may integrate the motion of rotating blocks and distributed deformation between and within them. Geoid highs to the west, representing the western end of the mega-gravity slide, may explain the transition between regions undergoing contraction and extension in Washington and Oregon.

1U.S. Geological Survey. 


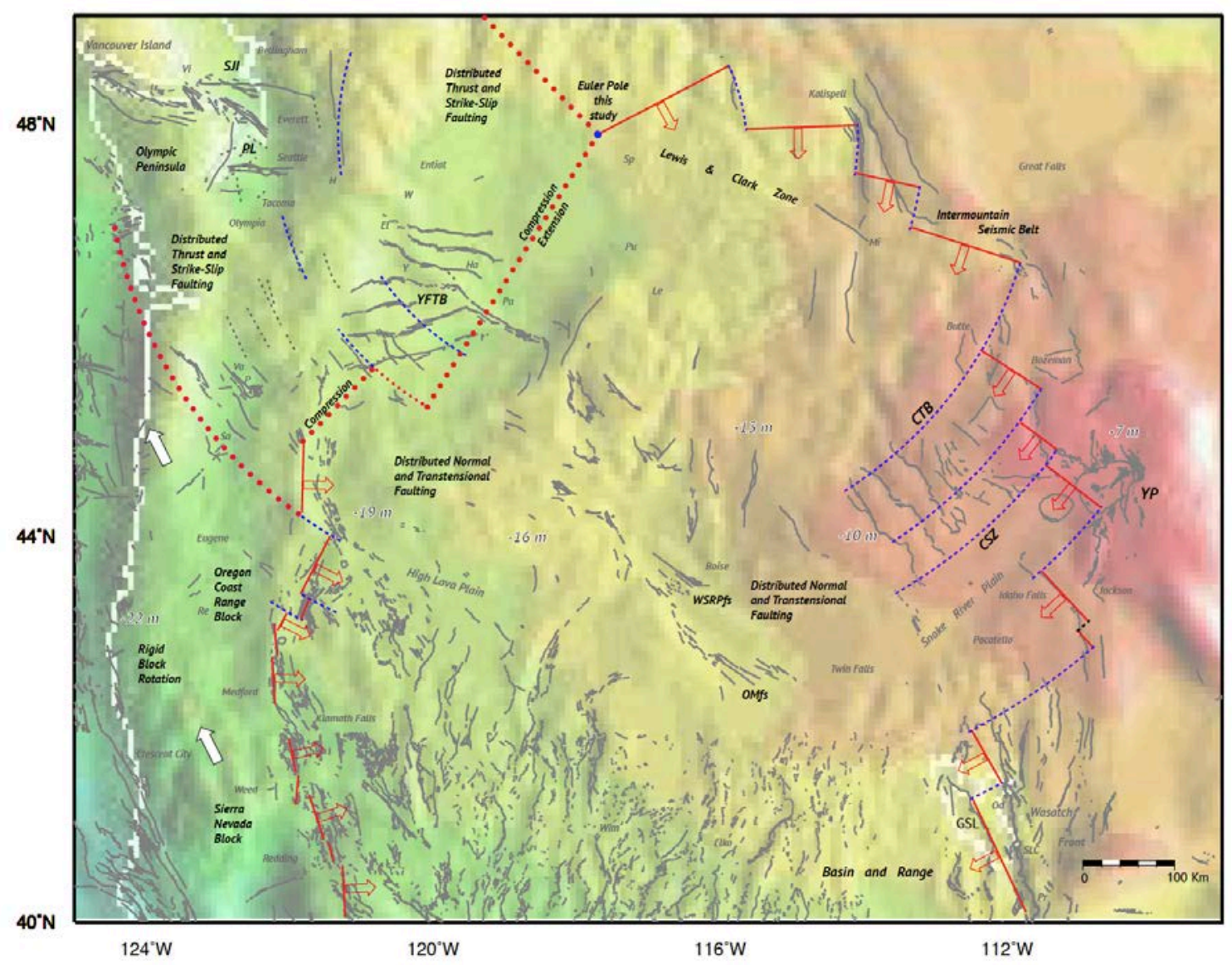

Figure 1. Seismotectonic model, Quaternary faults, and seismicity lineations in the northwestern United States superimposed on geoid heights for model Geoid 96 . Dashed blue arcs show segments of small circles about the Euler Pole in eastern Washington. Thick red lines show normal faults: along the eastern margin of the Basin and Range these faults are radial to the pole of rotation. Clockwise rotation of the crust in the Basin and Range is accommodated by distributed normal faulting with little evidence for major strikeslip faults apart from the Centennial Shear Zone (CSZ) in the Centennial Tectonic Belt (CTB). Bold dotted red lines delineate areas undergoing distributed extension and compression. Geoid high at Yellowstone Plateau is $-7 \mathrm{~m}$, geoid heights along the Oregon coast are $-22 \mathrm{~m}$ : each color represents a $3 \mathrm{~m}$ difference. Regions exhibiting compressional and extensional faulting are bounded by a local geoid anomaly minima (red dotted line). Abbreviations: GSL, Great Salt Lake; OMfs, Owyhee Mountains fault system; PL Puget Lowland; SJI, San Juan Islands; WSRPfs, Western Snake River Plain fault system; YFTB, Yakima Fold and Thrust Belt; YP, Yellowstone Plateau. 


\section{Shallow Surface Deformation Observed with UAVSAR. What Are the Implications for Earthquake Hazard?}

By Andrea Donnellan, ${ }^{1}$ Jay Parker, ${ }^{1}$ Gregory Lyzenga, ${ }^{1}$ Margaret Glasscoe,,${ }^{1}$ Michael Heflin, ${ }^{1}$, John Rundle,${ }^{2}$ Lisa Grand Ludwig ${ }^{3}$

UAVSAR and GPS observations of several recent earthquakes show shallow triggered slip on structures up to more than a fault dimension away from the mainshock rupture. How well does the surface slip indicate processes going on deeper in the crust? Fused geodetic observations from GPS and UAVSAR provides insight into these processes but the results are mixed. In some cases, triggered slip appears to be the due dynamic response to seismic wave propagation in the unconsolidated upper crustal layer. In other cases, the shallow slip seems to propagate to deeper slip during the postseismic phase following an earthquake.

UAVSAR is NASA's L-band airborne interferometric synthetic aperture radar (InSAR) instrument that is flown on a Gulfstream-III. The instrument provides line of sight differences for pairs of images. Data products are typically for swaths $90 \mathrm{~km}$ long and $15 \mathrm{~km}$ wide. Pixel spacing is about $7 \mathrm{~m}$ for unwrapped products. Short wavelength scatter of the data is about $1 \mathrm{~cm}$. Long wavelength error of a few $\mathrm{cm}$ over several $\mathrm{km}$ is due do tropospheric water vapor and unmodeled aircraft motion. Typically, in California observations have been collected every 6-12 months in east-west trending lines that are sensitive to north-south motion across the swath.

The continuous GPS network has a station spacing of about $10 \mathrm{~km}$ but produces daily position time series from which displacements, velocities, and transient motion can be detected. The GPS data provide horizontal and vertical motions that can be used to properly project the UAVSAR line of sight data into horizontal and vertical motions. Flights from multiple directions with UAVSAR also aid in separating vertical from horizontal motions.

Surface displacements were observed with UAVSAR for the following earthquakes: 2010 M7.2 El Mayor - Cucapah earthquake, 2010 M5.7 Ocotillo aftershock, 2014 M5.1 La Habra earthquake, and the 2014 M6.0 South Napa earthquake. The displacements observed with UAVSAR were consistent with the mainshock magnitude and rupture dimensions for each earthquake. The 2010 El Mayor - Cucapah earthquake triggered extensive slip on networks of conjugate faults in the Salton Trough (Donnellan and others, 2014). Surface deformation was also observed from the buried M5.7 aftershock. Both UAVSAR and GPS show continued deformation for several years following the earthquake. Triggered slip on the Imperial and Superstition Hills fault was inferred to be shallow, but GPS data can constrain whether the faults slipped at depth postseismically. The location of the Ocotillo aftershock shows continued postseismic motion until at least 2014.

UAVSAR observations show that the La Habra earthquake caused shallow northward motion of the West Coyote Hills. The $0.5 \mathrm{~km}$ depth of the modeled structure is consistent with slip on an unconformity. The earthquake triggered subtle slip northwest in Pasadena, to the east in the Chino Hills, as determined by GPS measurements, and southwest at the Trojan Way anticline

\footnotetext{
1Jet Propulsion Laboratory, California Institute of Technology.

2University of California, Davis.

3 University of California, Irvine.
} 
(Donnellan and others, 2015). The triggered slip from this event is shallow and inferred to be due to shaking from propagation of the seismic waves. It may reflect release of elastic strain accumulation still stored at depth.

The South Napa earthquake ruptured a fault parallel to and west of the main mapped fault (DeLong and others, 2016). This event triggered slip on the mapped fault, but overall on fewer structures than we've observed for southern California. A well-developed postseismic line of deformation occurred along the main rupture plane. We have not yet modeled the depth range of the postseismic slip.

\section{References Cited}

Donnellan, A., L. Grant Ludwig, J.W. Parker, J.B. Rundle, J. Wang, M. Pierce, G. Blewitt, S. Hensley, 2015, Potential for a large earthquake near Los Angeles inferred from the 2014 La Habra earthquake, Earth and Space Sci, 2, 378-385, DOI: 10.1002/2015EA000113.

Donnellan, A., J. Parker, S. Hensley, M. Pierce, J. Wang, J. Rundle, 2014, UAVSAR Observations of Triggered Slip on the Imperial, Superstition Hills, and East Elmore Ranch Faults Associated with the 2010 M7.2 El Mayor - Cucapah Earthquake, Geochemistry, Geophysics, Geosystems, 15, doi: 10.1002/2013GC005120.

DeLong, S.B., A. Donnellan, D.J. Ponti, R.S. Rubin, G. Seitz, D.P. Schwartz, C.S. Prentice, T.E. Dawson, J.J. Lienkaemper, K.W. Hudnut, C. Rosa, A. Pickering, J.W. Parker, in press, Tearing the terroir: Details and implications of surface rupture and deformation from the 24 August 2014 M6.0 South Napa earthquake, California, Earth and Space Science. 


\section{Session 4: Induced Seismicity}

\section{Statistics and Risk Associated with Induced Seismicity at The Geysers Geothermal Area, California and in Oklahoma}

By Donald L. Turcotte, ${ }^{1}$ Molly Luginbuhl, ${ }^{1}$ and John B. Rundle ${ }^{1}$

In this paper, we consider a new statistical approach to quantifying seismicity. We apply this approach to better understand induced seismicity at The Geysers geothermal area, California and in Oklahoma. An important aspect of induced seismicity is a strong time dependence related to rates of fluid injection. Our nowcasting methodology replaces clock time with "natural time". In the case of regional seismicity, our natural time measure is an event count of small earthquakes. Using this measure, it is not necessary to decluster a catalog of events, our results do not depend on the time dependence of the seismicity. We scale small earthquake behavior to large earthquake behavior using accepted Gutenberg-Richter frequency- magnitude scaling.

We will study seismicity using nowcasting at two sites of induced seismicity. The first is induced seismicity at The Geysers geothermal field, California. This seismicity is associated with enhanced geothermal extraction. Water is injected in order to continue to produce steam.

Geothermal power is considered a renewable energy source, but induced seismicity has led to serious safety concerns and terminations of some geothermal projects. The second site is the state of Oklahoma. The recent increase in seismicity, Oklahoma now has more earthquakes than California, is attributed to saline waste water injections. The fluids are primarily water separated during oil and gas production. On 9/3/2016 an earthquake near Pawnee, Oklahoma had a magnitude $M=5.6$.

The Geysers geothermal field is situated near the southern edge of Clear Lake, approximately $120 \mathrm{~km}$ north of San Francisco, CA. The Geysers is a steam-dominated geothermal field. There was little localized seismicity in The Geysers region prior to the extraction of steam for geothermal power generation that began in 1960. Beginning in 1980 the water recovered from the extracted steam was reinjected into the reservoir. This injection produced a relatively low level of induced seismicity. Beginning in 1997, large quantities of wastewater were injected in order to increase energy production. The large-scale injection of wastewater led to a large increase in seismicity.

The state of Oklahoma now has a higher rate of seismicity than California. The number of $M \geq 3$ earthquakes in Oklahoma per year. The increase from $35 M \geq 3$ earthquakes in 2012 to 109 in 2013 to 584 in 2014, and to 907 in 2015 is quite remarkable. Oklahoma is in the interior of the North American plate and prior to 2009, the level of seismicity was typical of a plate interior. The recent increase in seismicity cannot be associated with tectonics. It is accepted that the increase in seismicity is caused by the saline waste water injection. The fluids are primarily water separated directly from oil and gas production, fracking fluids play a relatively minor role. Although the annual injected volumes have increased during this period, the increases in seismicity are much

1'University of California, Davis. 
greater. Thus the increases in the seismicity cannot be directly tied to increased rates of injection or to a few new wells with higher injection volumes.

As in the case of The Geysers, the fundamental question is the origin of the energy being dissipated by the induced seismicity. As discussed above, we associate the induced earthquakes at The Geysers with active tectonic shearing that is occurring in the region. This cannot be the case in Oklahoma since the state lies in the interior of a tectonic plate. Earthquakes can certainly occur in such regions, but the accumulating tectonic shears are negligible in Oklahoma. The alternative explanation that we favor is the release of stored tectonic energy in the plate. Tectonic plates act as stress guides and thus have relatively high tectonic stresses. High fluid pressures allow earthquakes to occur on preexisting faults, dropping the regional stress.

The approach to nowcasting seismic risk given in this paper depends on the use of "natural" time in place of clock time. "Natural" time is an event count, in our case it is the number of small earthquakes, $N_{\sigma}$, that have occurred. The best statistics are obtained if the small earthquake magnitude, $M_{\sigma}$, is taken to be as small as possible, in our examples the catalog completeness level. The use of natural time has several advantages over clock time when applied to the earthquakes in a specified region. First, it is not necessary to decluster aftershocks. The natural time count is uniformly valid when aftershocks dominate, when background seismicity dominates, and when both contribute. Second, it can also be used when the background rate of seismicity is variable. Risk increases when the background rate in clock time increases and risk decreases when the background rate in clock time decreases.

The object of nowcasting seismic risk is to utilize the relationship between the number of small earthquakes, $N_{\sigma}$, with magnitude greater than $M_{\sigma}$ to the number of large earthquakes, $N_{\lambda}$, with magnitudes greater than $M_{\lambda}$. This association can be obtained directly from GutenbergRichter scaling. The cumulative number of small earthquakes is given by

$$
N_{c \sigma}=10^{a} 10^{-b M_{\sigma}}
$$

and the cumulative number of large earthquakes is given by

Dividing Eq. (2) by Eq. (1), we obtain

$$
N_{c \lambda}=10^{a} 10^{-b M_{\lambda}}
$$

$$
N_{c \lambda}=10^{-b\left(M_{\lambda}-M_{\sigma}\right)} N_{c \sigma}
$$

By definition, $N_{c \sigma}$ is natural time so that we have a prediction of the number of large earthquakes that occur in natural time.

We will utilize several approaches to nowcasting induced earthquakes. We will first plot the cumulative number of large earthquakes, $N_{c \lambda}$, versus the cumulative number of small earthquakes, $N_{c \sigma}$ (natural time). A linear dependence as shown in Eq. (3) is expected. We will then plot the cumulative number of small earthquakes, $N_{c \sigma}$ (natural time), against t clock time. If the rate of seismicity is constant, this will be well approximated by the constant rate $\frac{d N_{c \sigma}}{d t}$. However, for induced seismicity this rate can be quite variable. Since there are a large number of small earthquakes, the rate of occurrence will be quite accurately determined. This rate will be used to nowcast the rate of occurrence of large earthquakes using the relation

obtained from Eq. (3).

$$
N_{c \lambda} \text { (nowcast) }=N_{c \sigma} 10^{-b\left(M_{\lambda}-M_{\sigma}\right)}
$$

We will also utilize our nowcasting approach to assign a number to characterize the current potential for a "large" earthquake to occur in the study region. The average number $n_{\lambda}$ of small earthquakes between large earthquakes will be called the mean interevent count, $\bar{n}_{\lambda}$. 
Mathematically, we can express the potential for a large earthquake to occur having magnitude larger than $M_{\lambda}$ by computing the cumulative distribution function (CDF) of $n_{\lambda}$.

To compute the CDF, we tabulate the number of small earthquakes for each large earthquake cycle from an appropriate catalog. Once we have the CDF, we can then use the current count of small earthquakes $n(t)$ at time $t$ to compute the current value of the CDF, $P\{n \leq n(t)\}$. Note that $t$ is the (calendar) time since the last large earthquake, and $n(t)$ is the number of small earthquakes since the last large earthquake. This value is defined to be the earthquake potential score (EPS) at time $t$ :

$$
E P S \equiv P\{n \leq n(t)\}
$$

We interpret the EPS as the potential for the occurrence of the next large earthquake having magnitude larger than $M_{\lambda}$ within the defined geographic region. By construction, EPS will increase monotonically with time since the last large earthquake. It will reset to $E P S=0$ immediately after the next large earthquake, and then again begin to increase monotonically until the next large earthquake occurs. We will also give examples of this approach to nowcasting for induced seismicity at The Geysers and in Oklahoma.

\section{References Cited}

Nowcasting earthquakes: J.B. Rundle, D.L. Turcotte, A. Donnellan, L. Grant-Ludwig, M. Luginbuhl and G. Gong, Nowcasting Earthquakes, Earth and Space Science, in press 2017.

Natural time: P.A. Varotsos, N.V. Sarlis, and E.S. Skordas, Natural Time Analysis: The New View of Time, Springer-Verlag, Berlin 2011. 
Managing the Hazard of Induced Earthquakes: Insights from InSAR and Geology

\section{By William L. Ellsworth ${ }^{1}$}

Industrial activities have the potential to induce earthquakes as an unintended consequence of a wide range of actions including impoundment of water, creation of voids, and the extraction or injection of fluids into the subsurface. They cause earthquakes by disrupting the balance between the natural forces that promote and resist fault slip.

Earthquake activity in the central United States increased dramatically since 2009 as a result of changing practices for the production of oil and gas (Ellsworth, 2003). Although hydraulic fracturing has been widely discussed as a cause and triggers some earthquakes, it does not appear to be a significant contributor to the increased seismic hazard (Rubinstein and Mahani, 2015). Rather, these induced earthquakes are principally caused by disposal of unprecedented volumes of wastewater by injection into deep, undepleted formations (Walsh and Zoback, 2015).

The earthquake hazard in portions of the central United States, where tectonic earthquakes are extremely rare, is now comparable to that in California (Petersen and others, 2016). Unlike the hazard of natural earthquakes, the hazard of induced earthquakes and the risk they pose has the potential to be managed (McGarr and others, 2015). A key challenge is to develop forecasting ability to anticipate where activity may either initiate or shut-off in response to changing industrial drivers, principally injection rate for the central United States This requires a deeper understanding of the physical processes and conditions that link industrial perturbations to the Earth system to its response in seismic events.

Here, we examine sequence of moderate-magnitude earthquakes in east Texas and their relationship to wastewater disposal. The $M_{\mathrm{w}} 4.8$ Timpson, Texas, earthquake of May 17, 2012 was the largest recorded in the region and was followed by three additional $M_{\mathrm{w}} 4$ earthquakes in 2013. All of the earthquakes occurred at relatively shallow depth, between 3 and $6 \mathrm{~km}$, and all have strike slip mechanisms. An earlier study of the earthquake sequence concluded that two highvolume wastewater disposal wells located a few kilometers from the earthquakes were probably responsible for the earthquakes (Frohlich and others, 2014) based upon the spatial and temporal association of injection activities and the earthquakes. However, questions remained about the timing of the earthquakes, the location and magnitude of the pore pressure changes created by injection, and the absence of earthquakes associated with other nearby disposal wells.

These questions were investigated in greater detail in a recently published paper by Shirzaei and others, (2016). In this study, we used InSAR to measure surface deformation associated with injection and poroelastic modeling to model the spatial and temporal evolution of pore pressure in the subsurface. Surface uplift was detected and determined to be associated with two shallow $(\sim 900 \mathrm{~m})$, high volume, wastewater disposal wells that were located about $20 \mathrm{~km}$ from the earthquakes, but not with the two deeper $(\sim 1.8 \mathrm{~km})$ disposal wells identified by Frohlich and others, (2014) as responsible for the earthquakes. The uplift extended for over $8 \mathrm{~km}$ from the shallow injection wells, showing that the spatial extent of the region affected by injection can be substantial.

${ }^{1}$ Department of Geophysics, Stanford University. 
The uplift data and well injection volumes were used as input to a poroelastic model to track the evolution of volume strain and pore pressure from the start of injection in 2006 to the present time. The poroelastic model includes a layer of very low permeability (hydraulic conductivity $10^{-11} \mathrm{~m} / \mathrm{s}$ and diffusivity $0.01 \mathrm{~m}^{2} / \mathrm{s}$ ) between 1.4 and $1.6 \mathrm{~km}$ corresponding to the regionally extensive Ferry Lake anhydrite formation.

The shallow wells injected at a depth of about $900 \mathrm{~m}$, which is likely too shallow a depth to induce seismic failure through the effective stress mechanism. The pore pressure increase from these wells was also blocked from moving to greater depth by the anhydrite. Consequently, the pressure change from the shallow wells could only migrate laterally while slightly uplift the surface (rate $<3 \mathrm{~mm} / \mathrm{yr}$ ).

The situation was different at the deeper wells, where injection was at a depth of about 1.8 $\mathrm{km}$, below the anhydrite. Uplift was not observed around these wells despite injection of a slightly greater volume of wastewater. A combination of greater weight of the overlying formations, increasing stiffness of the rocks with depth and the presence of the anhydrite formation above the injection interval all acted to limit any uplift to below the detection limits of InSAR $(<0.5 \mathrm{~mm} / \mathrm{yr}$ ) while allowing the pressure to migrate to greater depth. According to the model, a pore pressure increase in excess of $1 \mathrm{MPa}$ reached the hypocentral zone when the earthquake activity initiated.

Injection into the deeper wells was significantly reduced following the 2012 earthquake, which resulted in a decline in pressure at the depth of the earthquakes. However, this pressure took about 1 year to reach the hypocentral zone, in agreement with the decline in seismicity after September 2013.

Several key results from this study include:

- Uplift caused by wastewater injection at shallow depth ( 900 m) was detected at distances of at least $8 \mathrm{~km}$ from the shallow injection wells.

- The pressure disturbance from the shallower wells was blocked from reaching greater depth by a geologic barrier, suggesting that siting injection wells with sealing formations below the injection interval may be an effective means of reducing the earthquake hazard.

- Uplift was not observed at the deeper wells injecting at twice the depth $(\sim 1.8 \mathrm{~km})$ and should not necessarily be expected to be observed in many cases.

Declining pore pressure in the hypocentral zone coincided with the end of the earthquake sequence, suggesting that pressure management may be an effective means of reducing the earthquake hazard. 


\section{Pore pressure (2006-2012)}

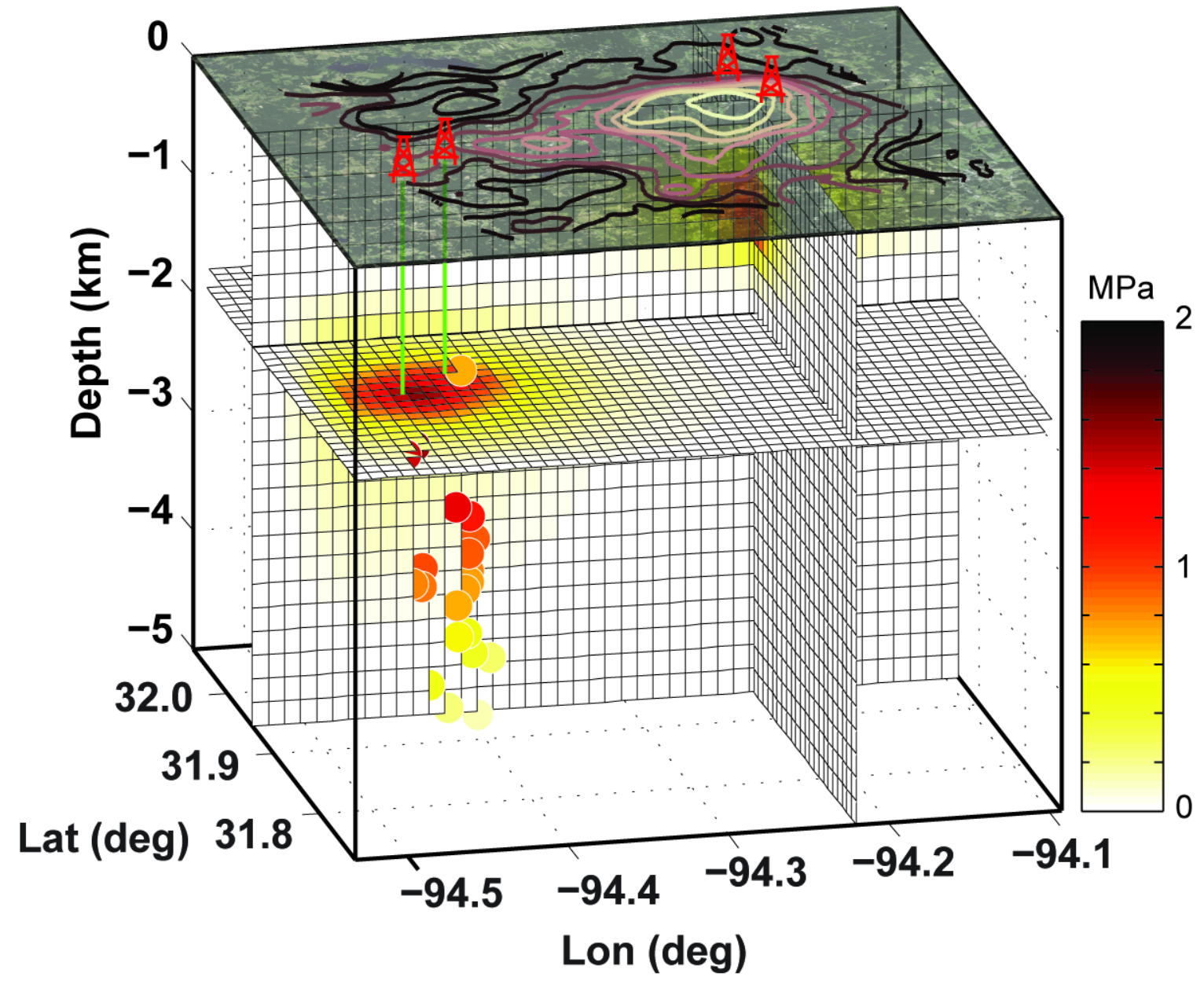

Figure 1. Distribution of the cumulative pore pressure (shaded grid cells) between 2006 and 2013. Colored circles show the pore pressure increase at the location of the earthquakes. Contours of the Line of Sight deformation rate obtained from multitemporal processing of overlapping ALOS SAR data are shown. Maximum uplift rate centered near the shallow injection wells exceeds $2 \mathrm{~mm} / \mathrm{yr}$.

\section{References Cited}

Ellsworth, W.L., 2013, Injection-induced earthquakes. Science, 341(6142), p. 1225942.

Frohlich, C., Ellsworth, W., Brown, W.A., Brunt, M., Luetgert, J., MacDonald, T. and Walter, S., 2014, The 17 May 2012 M4.8 earthquake near Timpson, East Texas: An event possibly triggered by fluid injection. Journal of Geophysical Research: Solid Earth, 119(1), pp.581-593.

McGarr, A., Bekins, B., Burkardt, N., Dewey, J., Earle, P., Ellsworth, W., Ge, S., Hickman, S., Holland, A., Majer, E. and Rubinstein, J., 2015, Coping with earthquakes induced by fluid injection. Science, 347(6224), pp. 830-831.

Petersen, M.D., Mueller, C.S., Moschetti, M.P., Hoover, S.M., Llenos, A.L., Ellsworth, W.L., Michael, A.J., Rubinstein, J.L., McGarr, A.F. and Rukstales, K.S., 2016, 2016 One-Year Seismic Hazard Forecast for the Central and Eastern United States from Induced and Natural Earthquakes (No. 2016-1035). U.S. Geological Survey. 
Rubinstein, J.L. and Mahani, A.B., 2015, Myths and facts on wastewater injection, hydraulic fracturing, enhanced oil recovery, and induced seismicity. Seismological Research Letters, 86(4), pp. 1060-1067.

Shirzaei, M., Ellsworth, W.L., Tiampo, K.F., Gonzales P.J. and Manga, M., 2016. Surface uplift and time-dependent seismic hazard due to fluid injection in eastern Texas. Science, 353(6303), pp 1416-1419.

Walsh, F.R. and Zoback, M.D., 2015, Oklahoma's recent earthquakes and saltwater disposal. Science advances, 1(5), p.e1500195. 


\section{LArge-n Seismic Survey in Oklahoma (LASSO): Probing Injection-induced Seismicity with a Dense Array}

By Sara L. Dougherty, ${ }^{1}$ Elizabeth S. Cochran,${ }^{1}$ and Rebecca M. Harrington ${ }^{2}$

Injection-induced seismicity has a significant impact on seismic hazard, particularly in regions with low rates of natural seismicity; however, further understanding of the predictability of these events based on injection practices and geological structure is necessary before hazard can be quantified reliably. In Oklahoma, the rapid increase in wastewater disposal volumes since 2008 is coincident with a drastic increase in seismicity, which has resulted in a significant increase in seismic hazard in this region. To enhance monitoring of potential injection-induced seismicity (including microseismicity) and elucidate any links between seismic observations and operational injection parameters and/or geologic structure, a seismic dataset with denser station coverage than is commonly available is needed. We deployed a large- $\mathrm{N}$ array of more than 1,800 vertical-component nodal seismometers over an 1,800 square kilometer region in northern Oklahoma for a period of 30 days in spring 2016, targeting sequences of likely induced seismicity in a region of active injection. We will use this LArge-n Seismic Survey in Oklahoma (LASSO) dense array to assess the locations, frequency, magnitudes, source properties, and spatiotemporal evolution of micro- to minor earthquakes in an effort to improve our understanding of the relation(s) between injection parameters and induced seismicity, potentially leading to more accurate seismic hazard assessment and improved hazard mitigation. We will also identify the locations and orientations of subsurface faults to provide insights into where future locations of injection-induced seismicity may occur and perform tomographic imaging of the shallow crust to provide additional details on the geologic structure and any potential preferential location of seismicity in or along a particular unit or fault. We will present preliminary results from the identification and location of events recorded by the LASSO array.

\footnotetext{
1U.S. Geological Survey.

2McGill University.
} 


\section{Increasing injection-induced seismicity in Asia}

\section{By Xinglin Lei ${ }^{1}$}

Geological Survey Japan/AIST has been conducting laboratory and field studies on induced seismicity occurred in Asia, especially in China mainland and Japan Island. On one hand, several typical cases of seismicity in geothermal areas triggered by distant earthquakes have been observed and extensively studied (for example, Lei and others, 2013, Terakawa and others, 2013). On the other hand, increasing injection-induced seismicity with sizable magnitude up to $4 \sim 5$ has been observed in both sites of long-term injection for unwanted water disposal and in sites of short-term injection for shale gas fracking in Sichuan Basin, China.

In the long-term injection sites, during the past decades, a number of seismic sequences have been observed with sizable earthquakes ranging up to M5. Their timing, location and occurrence pattern involved in statistical models, convincingly suggest that these sequences were induced by injections of unwanted water in deep wells in some depleted gas reservoirs. All sequences were initiated in days after water injection under high pressure begun. Event rate fluctuates following change of injection pressure and tapered after shut down (fig. 1).

In some short-term injection sties, multiple lines of evidence convincingly suggest that a series of earthquakes with magnitudes of up to $M 4$ were potentially induced by shale gas fracking at depths of $2.5-3 \mathrm{~km}$ (fig. 2).

In both long-term injection sites and short-term injection sites, precisely located hypocenters and the mechanism solution of moderate size events indicate that these earthquakes occurred along mapped/unmapped faults that are favorably/unfavorably oriented with respect to the tectonic stress in the region, indicating injection-induced fault reactivation. Major earthquakes, especially these of a magnitude greater than 3, occurred along pre-existing faults or other kind of interfaces in sedimentary formations form Pre-Cambrian to Mesozoic. Statistical study using the epidemic-type aftershock sequence (ETAS) approach shows that typical cases of injection-induced seismicity in the Sichuan Basin are more swarm-like characterized by very low level of aftershock productivity. Thus, it is possible to distinguish the injection-induced seismicity from tectonic activities. A uniform regional stress field is insufficient to interpret all mechanisms observed which demonstrates the local stress filed at reservoir scale significantly inhomogeneous.

Laboratory study shows that major Pre-Triassic sedimentary rocks, including dolomite, shale, and dolomitic limestone are strong and demonstrating brittle fracturing behaviors. Such properties are necessary conditions for maintaining high level of reservoir stress and leading to seismic fracturing (Lei and others, 2014).

${ }^{1}$ Geological Survey of Japan/AIST. 

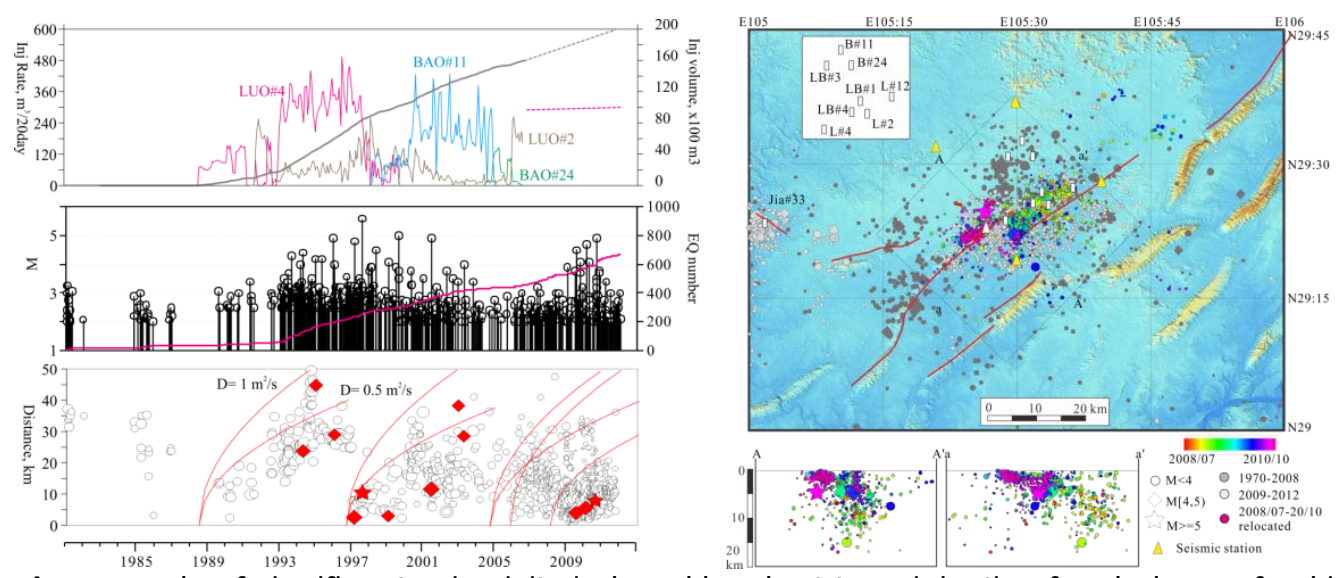

Figure 1. An example of significant seismicity induced by short-term injection for shale gas fracking in Sichuan Basin (Lei and others, in preparation).

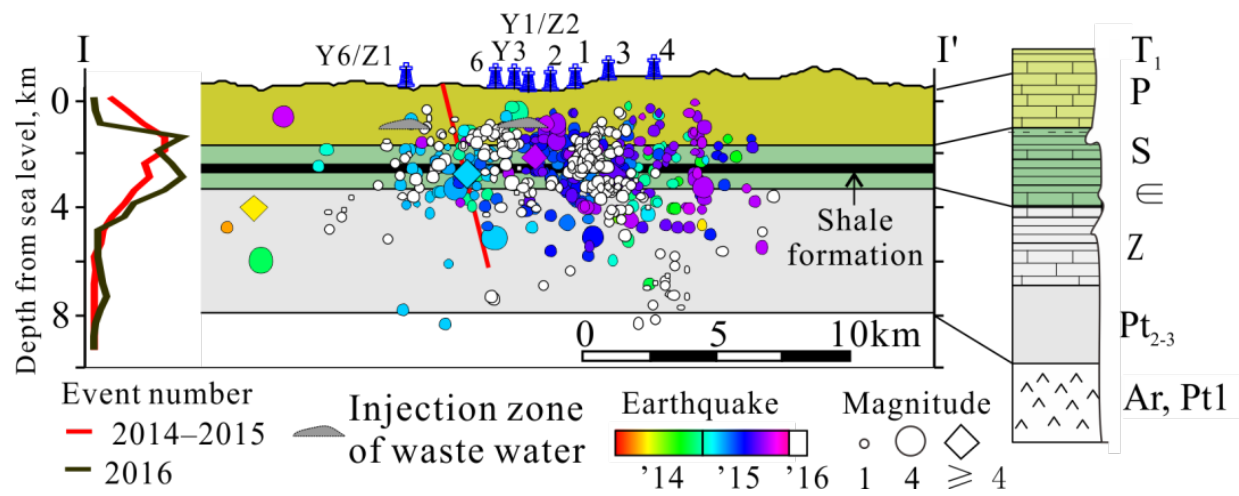

Figure 2. An example of significant seismicity induced by short-term injection for shale gas fracking in Sichuan Basin (Lei and others, in preparation).

\section{References Cited}

Lei, X.-L., Li, X.-Y., Li, Q., Ma, S.-L., Fu, B.-H. \& Cui, Y.-X. (2014), Role of immature faults in injectioninduced seismicity in oil/gas reservoirs-a case study of the Sichuan Basin, China. Geology and Seismology (in Chinese) 36, 625-643.

Lei, X., Ma, S., Chen, W., Pang, C., Zeng, J. \& Jiang, B. (2013), A detailed view of the injection-induced seismicity in a natural gas reservoir in Zigong, southwestern Sichuan Basin, China. Journal of Geophysical Research: Solid Earth 118, 4296-4311.

Lei, X., Wang, X., Su, J., Fu, H., Jiang, G. \& Wang, H. (in preparation), Fault reactivation and earthquakes with magnitudes of up to ML4.6 induced by shale gas fracking in the Sichuan Basin, China.

Lei, X., Yu, G., Ma, S., Wen, X. \& Wang, Q. (2008), Earthquakes induced by water injection at 3 km depth within the Rongchang gas field, Chongqing, China. Journal of Geophysical Research 113.

Terakawa, T., Hashimoto, C. \& Matsu'ura, M. (2013), Changes in seismic activity following the 2011 Tohoku-oki earthquake: Effects of pore fluid pressure. Earth and Planetary Science Letters 365, 17-24. 


\title{
Induced Seismicity Insights from the Decatur, $\mathrm{IL}, \mathrm{CO}_{2}$ Sequestration Project
}

\author{
By J. Ole Kaven, ${ }^{1}$ Robert Skoumal, ${ }^{1}$ and Ezer Patlan ${ }^{1}$
}

Industrial-scale carbon capture and storage (CCS) will require the injection of large volumes of $\mathrm{CO}_{2}$ into extensive undisturbed brine aquifers. Large-volume injection has the potential to induce earthquake activity (Zoback and Gorelick, 2012). To assess the seismic hazard posed by one such operation, the USGS has been monitoring seismic activity at a CCS demonstration site in Decatur, IL, where supercritical $\mathrm{CO}_{2}$ is injected into the Mount Simon Sandstone, a basal brine formation, at a depth of about 2 kilometers, several 10s of meters above granitic basement. During the first phase of injection, supercritical $\mathrm{CO}_{2}$ was injected at a rate of about 1,000 metric tons/day from November, 2011 until November, 2014. Microseismicity occurs in the Mount Simon Sandstone injection interval and, to a lesser degree, in the pre-Mount Simon and the Precambrian basement. Microseismicity occurs in distinct clusters at varying distances from the injection well and distance from the well does not increase systematically with time. Double difference relocations of these events reveal that these clusters tend to form linear features in both the Mount Simon Sandstone and the basement, suggesting the microseismicity involves reactivation of preexisting fractures and faults. This finding is corroborated by composite focal mechanisms for individual clusters that are consistent with the regional horizontal principal stress orientations and right-lateral slip across the reactivated faults and fractures. Despite the total injection of nearly one million tons of $\mathrm{CO}_{2}$ the largest microearthquake magnitudes barely exceeded $M 1$ and, thus, none of these events could be felt at the surface. During the second phase, injection down a second borehole will be at a rate of about 3,000 metric tons/day starting in early 2017 and continue for three years. To augment our monitoring capability, the deep borehole network deployed by Archer Daniels Midland will be combined with the U.S. Geological Survey network. We anticipate the addition of the new stations will substantially improve our event detection and location capabilities.

References Cited

Zoback, M.D., and Gorelick, S.M., 2012, Earthquake triggering and large-scale geologic storage of carbon dioxide: Proceedings of the National Academy of Sciences, v. 109, no. 26, p. 1016410168.

1U.S. Geological Survey. 


\title{
Session 5: Subduction Zone Science
}

\section{Recent Initiatives (S-Net, DONET, 'Ring of Fire', Subduction Zone Observatory)}

\author{
Estimation of Seismic Velocity Structure Beneath the Ocean Using Seismic Stations Offshore and \\ on Lands
}

By Makoto Matsubara, ${ }^{1}$ Kenji Uehira, Masashi Mochizuki, ${ }^{1}$ and Toshihiko Kanazawa ${ }^{1}$

Introduction

We investigate the three-dimensional (3D) seismic velocity structure beneath the ocean as well as beneath the Japanese Islands, using offshore events as well as events beneath the Japanese Islands within the seismic observation network using seismic tomographic method with arrival time data of body waves picked by NIED Hi-net. Offshore events have a large uncertainty for focal depth determined by the high-sensitivity seismograph observation network (Hi-net) operated by the National Research Institute for Earth Science and Disaster Resilience (NIED), however, broadband seismograph network (F-net) operated by NIED determined the focal depth with moment tensor inversion. NIED also determined the centroid depth with accelerometers of NIED Hi-net with moment tensor inversion (Asano and others, 2011). We also investigate the effect of 125 seismic stations of seafloor observation network for earthquake and tsunamis along the Japan Trench (S-net) operated by NIED. We do not obtain the enough data for seismic tomography yet since the NIED started the operation of S-net from March 2016, however, we conduct the checkerboard test with the assumption of data at S-net stations.

Data and Method

The target region, $20-48^{\circ} \mathrm{N}$ and $120-148^{\circ} \mathrm{E}$, covers the Japanese Islands from Hokkaido to Okinawa. A total of manually picked $4693781 \mathrm{P}$-wave and $2342621 \mathrm{~S}$-wave arrival times for 796779 earthquakes recorded at approximately 1300 stations from October 2000 to December 2014 is available for use in the tomographic method. The inversion reduces the root mean square of the P-wave traveltime residual from $0.507 \mathrm{~s}$ to $0.193 \mathrm{~s}$ and that of the S-wave data from $0.609 \mathrm{~s}$ to $0.238 \mathrm{~s}$ after eight iterations.

We assume the body waves from the earthquake beneath the Pacific Ocean with magnitude larger than 3.5 are detected at $125 \mathrm{~S}$-net stations. We conducted the checkerboard resolution test with the synthetic data.

Result and Discussion

Our new analysis revealed the failed rift structures, marked by higher Vp at lower crust and lower Vp at the upper crust, along the Japan Sea cost of central Honshu. Judging the age of the rift fill, they were produced during the formation of the Japan Sea. Similar, rifting structure also

\footnotetext{
${ }^{1}$ Earthquake and Tsunami Research Division, National Research Institute for Earth Science and Disaster Resilience.
} 
detected along the Pacific coast of Northern Honshu (fig. 1). It is marked by uplifted Moho surface, trending NS to NNW-SSE direction. Geologically, it is interpreted as a rift structure formed in the late Mesozoic. However, the tectonic meaning of this structure is still poorly understood. The new tomographic result using S-net data, makes us possible to understand the tectonic framework of the Mesozoic rifting off Tohoku.

The checkerboard resolution test with the assumed S-net data has a well-resolved at depths of 10-20 km beneath the Pacific Ocean between Honshu and Japan Trench (fig. 2). Ray paths from offshore events and land station take off downward and do not pass through the upper crust between the Japan Trench and Honshu, however, those from offshore events and S-net stations pass there. We may obtain the fine 3D structure after the accumulation of the data at Snet stations and proceed to obtain the configuration of the subducting Pacific plate in fine scale for the verification of the plate model used for the construction of the tsunami scenarios.
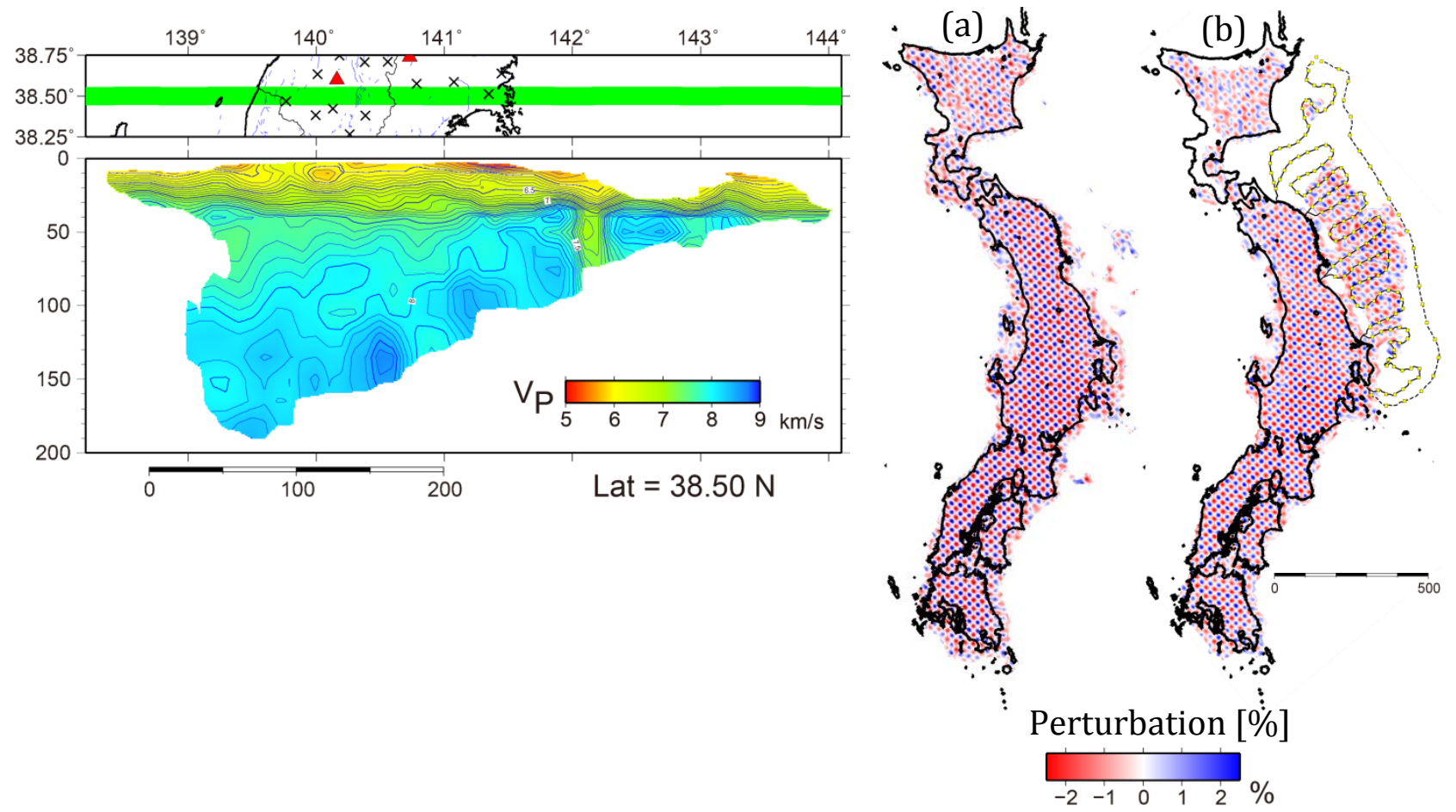

Figure 1. P-wave velocity structure at a latitude of $38.5^{\circ}$

Figure 2. Checkerboard resolution test at a depth of $10 \mathrm{~km}$. (A) Data at only land stations. (B) Data at both land and S-net stations. Yellow circles denote the S-net stations.

Acknowledgment

Our tomography is based on data from the National Research Institute for Earth Science and Disaster Resilience (NIED), the Japan Meteorological Agency, Hokkaido University, Hirosaki University, Tohoku University, the University of Tokyo, Nagoya University, Kyoto University, Kochi University, Kyushu University, Kagoshima University, the National Institute of Advanced Industrial Science and Technology (AST), the Geographical Survey Institute, Tokyo Metropolis, Shizuoka Prefecture, Hot Springs Research Institute of Kanagawa Prefecture, Yokohama City, and Japan Agency for Marine-Earth Science and Technology. This work was supported in part by the Council for Science, Technology and Innovation (CSTI) through the Cross-ministerial Strategic 
Innovation Promotion Program (SIP), entitled "Enhancement of societal resiliency against natural disasters" (Funding agency: JST).

Asano, Y., T. Saito, Y. Ito, K. Shiomi, H. Hirose, T. Matsumoto, S. Aoi, S. Hori, and S. Sekiguchi (2011) Spatial distribution and focal mechanisms of aftershocks of the 2011 off the Pacific coast of Tohoku Earthquake, Earth Planets Space, 63, 669-673, doi:10.5047/eps.2011.06.016.

Matsubara, M. and K. Obara (2011) The 2011 Off the Pacific Coast of Tohoku earthquake related to a strong velocity gradient with the Pacific plate, Earth Planets Space, 63, 663-667, doi:10.5047/eps.2011.05.018.

Matsubara M., H. Sato, T. Ishiyama, and A. D. Van Horne (2017) Configuration of the Moho discontinuity beneath the Japanese Islands derived from three-dimensional seismic tomography, Tectonophysics, 710-711, 97-107, doi:10.1016/j.tecto.2016.11.025. 


\title{
GRACE and Follow-on Gravity Missions: Contributions to Subduction Zone Science and Prospects for the Future
}

\author{
By Jeanne Sauber, ${ }^{1}$ Shin-Chan Han, ${ }^{2}$ and Fred Pollitz ${ }^{3}$
}

Since launch in 2002, data from the Gravity Recovery and Climate Experiment (GRACE) have provided a synoptic view of mass change associated seismic cycle processes. Most published results have reported coseismic and post-seismic mass change associated with great subduction zone earthquakes; however, strike-slip, normal faulting and deep focus events have produced discernible gravity changes as well. Although many GRACE studies use monthly spherical harmonic coefficients provided by the GRACE project, we have used as well individual arcs of GRACE inter-satellite tracking data to invert for earthquake source parameters (scalar seismic moment, Mo, dip, rake, and strike; [Han and others, JGR, 2013]). Also, we have tested early, varied distributions of coseismic finite-fault slip derived from seismic data against the GRACE range-rate and range-acceleration data [Han, Sauber, \& Pollitz, GRL, 2010, 2011] for earthquakes with $M_{\mathrm{w}}$ 28.4. Thus, low-latency GRACE inter-satellite range data now available following earthquakes, and eventually for the GRACE-Follow-on (GRACE-FO; launch 2017) satellite, could provide timely, relevant coseismic source information reflective of the long-wavelength mass change on time scales of days to weeks. Based on the performance simulations of the Laser Ranging Instrument (LRI) on GRACE-FO [Flechtner and others, 2014] and our earthquake simulations, we anticipate the improvements in inter-satellite range data will enable researchers to estimate coseismic source parameters for $M_{\mathrm{w}} \geq 8.0$ earthquakes particularly with the GRACE-FO test Laser Ranging Instrument (GRACE-FO-LRI).

Probably the most unique contribution to seismic cycle studies is using the longwavelength viscoelastic response to great earthquakes, as estimated by GRACE, to further constrain Earth's rheological structure. Even the 2006 Kuril megathrust earthquake $\left(M_{\mathrm{w}} 8.3\right.$, $\left.3.5 \times 10^{21} \mathrm{~N} \mathrm{~m}\right)$ and the 2007 Kuril normal faulting earthquake $\left(M_{\mathrm{w}} 8.1,1.8 \times 10^{21} \mathrm{~N} \mathrm{~m}\right)$ of the central Kuril Islands resulted in significant long-wavelength postseismic gravity change ( $\sim 4$ gal between 2007-2015) [Han, Sauber, \& Pollitz, GRL, 2016]. The GRACE data were best fit with a model of 25$35 \mathrm{~km}$ for the elastic thickness and $10^{18} \mathrm{~Pa}$ s for the Maxwell viscosity of the asthenosphere. Following larger events such as the 2004 Sumatra-Andaman earthquake, the GRACE data continues to show ongoing gravity change and may suggest multiple relaxation times including deeper relaxation processes. While we have, so far, attributed the short-term postseismic gravity change to the asthenosphere (depth $<220 \mathrm{~km}$ ), the deeper upper mantle is expected to undergo a substantial coseismic stress perturbation and hence relax following such a long rupture. The time series of GRACE, and anticipated GRACE-FO, data will provide complementary information to the individual land-based GPS sites.

Longer-term prospects for discerning gravity change associated with the seismic cycle from satellite data have been explored in performance scenarios for future gravity missions beyond GRACE-FO. For example, for the mass change due to coseismic slip in earthquakes, Pail

\footnotetext{
${ }^{1}$ NASA Goddard Space Flight Center.

2University of Newcastle, Australia.

3 U.S. Geological Survey.
} 
and others, [Surv. Geophys., 2015] considered earthquakes $M_{\mathrm{w}} 7.8$ for the Threshold scenario (minimum mission requirement) and $M_{\mathrm{w}} 7.0$ for the Target scenario (desired mission requirement). Additionally, the longer times series anticipated for the GRACE and GRACE-FO combination of data could enable us to constrain other components of the subduction zone seismic cycle such as short-term transients and long-term strain accumulation.

\section{References Cited}

Flechtner, F., P. Morton, M. Watkins, and F. Webb, 2014, Status of the GRACE follow-on mission, In Gravity, geoid and height systems, pp117-221, Springer International Publishing.

Han, S., J. Sauber, and S. Luthcke, 2010, Regional gravity decrease after the 2010 Maule (Chile) earthquake indicates large-scale mass redistribution, Geophys. Res. Lett., 37, L23307, doi:10.1029/2010GL045449.

Han, S., J. Sauber and R. Riva, 2011, Contribution of satellite gravimetry to understanding seismic source processes of the 2011 Tohoku-Oki earthquake, Geophys. Res. Lett., 38, L24312, doi:10.1029/2011GL049975

Han, S., R. Riva, J. Sauber, and E. Okal, 2013, Source parameter inversion for recent great earthquakes from a decade-long observation of global gravity fields", J. Geophys. Res. Solid Earth, 118, 1240-1267, doi:10.1002/jgrb.50116

Han, S., J. Sauber and F. Pollitz, 2016, Postseismic gravity change after the 2006-2007 great earthquake doublet and constraints on the asthenosphere structure in the central Kuril Islands, Geophys. Res. Lett., 42, doi: 10.1002/2016GL068167.

Pail et al., 2015, Science and User Needs for Observing Global Mass Transport to Understand Global Change and to Benefit Society, Surv Geophys., 36:743-772 DOI 10.1007/s10712-0159348-9 


\section{Real-Time Tsunami Inundation Forecast System using S-net Data}

By Shin Aoi, ${ }^{1}$ Naotaka Yamamoto, ${ }^{1}$ Wataru Suzuki, ${ }^{1}$ Kenji Hirata, ${ }^{1}$ Hiromitsu Nakamura, ${ }^{1}$ Takashi Kunugi, ${ }^{1}$ and Tomohiro Kubo ${ }^{1}$

At the time of the 2011 Tohoku earthquake, offshore observations were insufficient. Consequently, the underestimated tsunami heights of the initial tsunami warning issued by the Japan Meteorological Agency (JMA) three minutes after the earthquake caused enormous fatalities and significant damages for the eastern Pacific coast of Japan. The insufficient dissemination of the tsunami information to the public due to power failures also affected enormous fatalities. Considering the above, it is essentially important to deliver prompt and accurate forecast to the on-shore residences. Japanese government has decided to construct the Seafloor Observation Network for Earthquakes and Tsunamis along the Japan Trench (S-net) that is operated by National Research Institute for Earth Science and Disaster Resilience (NIED). S-net is expected to obtain additional lead time for earthquake and tsunami early warning. We develop a new methodology of real-time tsunami inundation forecast system using S-net data. In our system, several appropriate tsunami scenarios that can explain offshore tsunami observations are quickly selected by using multiple indices from the Tsunami Scenario Bank (TSB), which contains offshore tsunami pre-calculated waveforms, coastal tsunami heights, inundation depth maps, etc. One of the key features of our system is that tsunami inundations are estimated explicitly without any source information, which can contain large estimation error. Many calculations are performed to investigate the sensitivities of the source models to coastal tsunami heights along the Pacific coast of Chiba prefecture in the Kanto region. We also evaluate and improve our system through the demonstration experiments with local governments.

${ }^{1}$ National Research Institute for Earth Science and Disaster Resilience. 


\section{Recent Progress of Seafloor Geodetic Monitoring in Japan}

\section{By Ryota Hino ${ }^{1}$}

A number of important discoveries regarding mechanical processes along subduction plate boundary faults have been brought about by extensive seafloor geodetic observations. Efforts to monitor the seafloor deformation rate using GPS/Acoustic observations have been made for more than a decade in Japan. As of 2016, more than 40 seafloor benchmarks are maintained by Japan Coastal Guard and national universities (fig. 1), to yield deformation time series with frequencies of twice a year or more. The GPS/A network along Nankai Trough successfully clarify the remarkable spatial variation of the plate coupling coefficient along the megathrust to assist evaluating rupture sizes and scenario of future massive earthquakes in this subduction margin. The observation along the Japan Trench provides strong constraints on postseismic deformation processes following the 2011 Tohoku Earthquake; namely, prevalence of viscoelastic relaxation near the area with extremely large coseismic slip and occurrence of extensive afterslip in the area surrounding the zone ruptured in 2011. The spatial distribution of aseismic slip or slip deficit is expected to have strong correlation with activity of episodic slow slip events. As demonstrated by the studies on the aseismic events preceding the 2011 earthquake, continuous pressure records have great potential to detect transient seafloor deformation. Real-time bottom pressure data for tsunami monitoring obtained by the cabled seafloor observation networks deployed along Nankai Trough and Japan Trench can also be applied to monitor the slow slip activities.

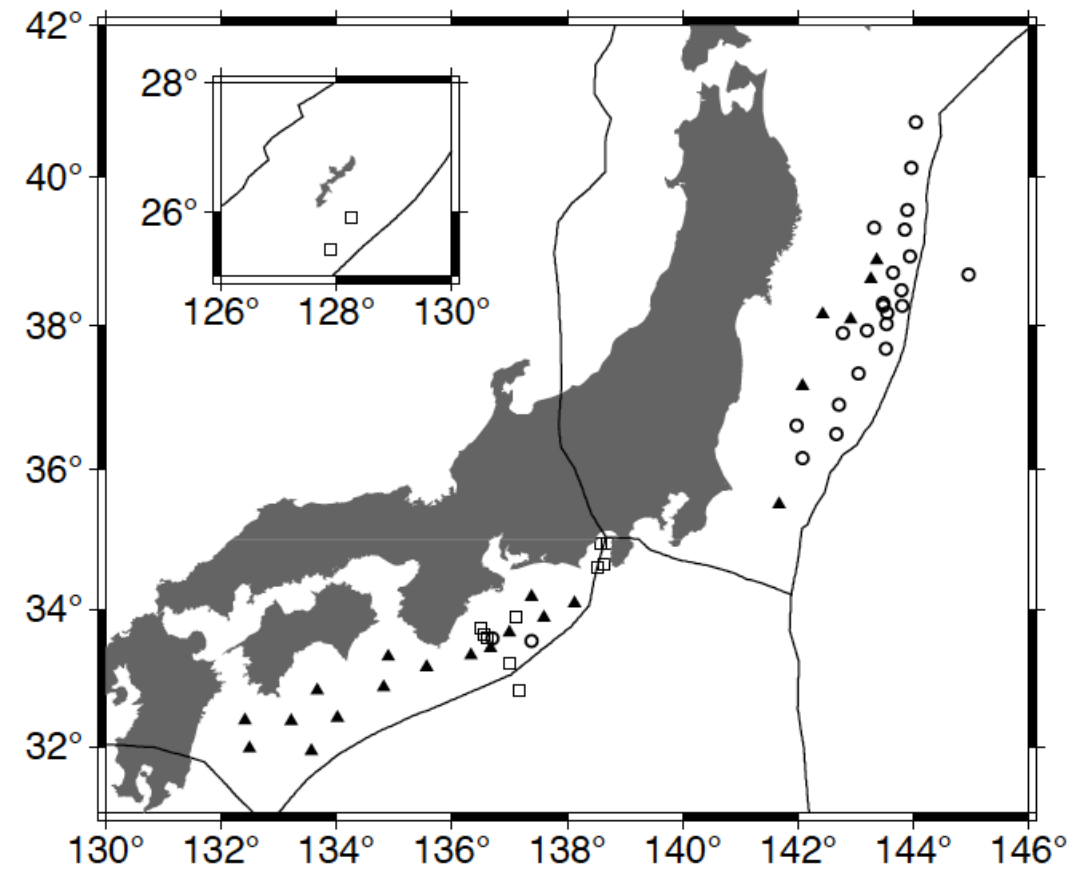

Figure 1. Distribution of seafloor benchmarks for GPS/Acoustic seafloor geodetic observation around Japan. Triangles: operated by Japan Coastal Guard, circles: by Tohoku University, squares: by Nagoya University.

\footnotetext{
${ }^{1}$ Graduate School of Science, Tohoku University.
} 


\section{Advancing USGS Subduction Zone Science}

By Joan Gomberg ${ }^{1}$ and the Subduction Zone Science Plan Writing Team

The geologic processes in subduction zones create the world's largest earthquakes, tsunamis, volcanic eruptions, and conditions highly conducive to landsliding. The inexorable nature of these processes makes all these events inevitable, with high probabilities of occurring in the next 50 years and potentially enormous impacts for the significant populations and infrastructure located near subduction zones and affected by their far-reaching outcomes. Numerous events have conspired to make this an ideal time to promote a focused effort to increase U.S. Geological Survey (USGS) activities in subduction zones. These events include: (1) the occurrence of catastrophic subduction zone earthquakes, tsunamis, and landslides in the United States and globally since 2004, (2) a cascade of popular publications and public interest in Cascadia, (3) growing momentum in the broad scientific community for a Subduction Zone Observatory sponsored by the U.S. National Science Foundation and perhaps other agencies, and (4) technologic advances and tantalizing new discoveries (for example, new seafloor instrumentation that have possibly detected precursory deformation). Over the last year and a half, a grass roots movement among USGS scientists has grown into a more official effort, involving USGS scientists, managers and directors. The primary focus of this effort is to advance USGS subduction zone science in support of its mission to assess, warn, and provide situational awareness for geologic hazards unique to, or most prevalent in subduction zones. The linkages between subduction zone geologic hazards themselves (for example, related to earthquakes, landslides, volcanic eruptions, tsunamis, widespread land level changes, etc.), and the foci of other USGS missions (for example, climate and land use change) have led to the involvement of participants from multiple disciplines and programs, and offer the potential to engage many others.

At present, a team of 18 USGS scientists are writing a formal USGS Subduction Zone Science plan, meant to serve as a 'shovel-ready' proposal that would permit us to respond immediately to new funding opportunities, and to facilitate coordination with other activities with complementary goals (for example, those aimed at creating a Subduction Zone Observatory within the broader geoscience community). Ideally the plan will serve as a tool to promote an official initiative, which would yield new resources added to the USGS budget to accomplish the goals laid out in the plan. Here we summarize the current contents of the plan, as a way of explaining our vision of subduction zone science. The Subduction Zone Science plan outlines priorities for USGS science in subduction zones, motivated by the needs of stakeholders concerned with protecting the environment, improving community resilience, mitigating risk, and responding to destructive events in subduction zone regions and elsewhere. It describes four Science Themes focused on understanding subduction zone processes, quantifying natural hazards, quantifying risk, and forecasting and situational awareness. For each theme we identify the scientific needs of stakeholders, describe relevant USGS accomplishments and current capabilities, and discusses specific gaps and frontier activities that would fill them. The section Synergistic Breadth describes the opportunities our envisioned subduction zone science offers to

1U.S. Geological Survey. 
leverage investments made by other organizations and to build new partnerships and capabilities. New investments that build on USGS's unique strengths would ensure new discoveries and rapid progress, translated into innovative and effective products; the latter are described in the section Product Innovation, Validation \& Distribution.

In the short-term, we aim to submit the plan by January 2017 for publication by the USGS. Concurrently and going forward, USGS scientists, managers and directors will continue to work with their partners in the academic community who seek to build complementary programs and research, as we recognize that such collaboration enhances the likelihood of success for all. In this new fiscal year, a number of pilot projects will commence, in which we hope to jump-start some of the frontier studies identified in the Plan with existing resources; some of these set new precedence by involving scientists from multiple programs and offices across the country. Finally, we will continue to work with stakeholders, to hone our plans so they best meet their needs. 


\section{Episodic Tremor and Slow Slip}

\section{Shallow Slow Slip Event Off Kii Peninsula, Japan}

By Satoshi Itaba, ${ }^{1}$ and Demian Saffer ${ }^{2}$

On 1April 2016, an earthquake ( $M_{\mathrm{w}}=5.9$, hereafter mainshock, USGS) occurred off the Kii Peninsula, Japan. The mainshock occurred around the expected focal region of the so-called Tonankai earthquake. After the mainshock, strain and pore-pressure changes caused by the slow slip event (SSE) were observed by the three borehole strainmeters of AIST and pressure sensor of IODP Site C0002. The source region of this SSE is located on the plate interface at southeast side of the mainshock. An equivalent magnitude of this SSE is $M_{\mathrm{w}} 6.0$, and duration is about 7 days. From after just a few days from the mainshock, in and around this SSE source region, intensive activity of shallow very low frequency earthquakes (VLF) has been observed for about ten days, it is assumed that these shallow VLF events were induced by this SSE.

In off the Kii Peninsula, VLF and Low Frequency Earthquake has been often observed, but SSE had not been observed by geodetic method. The slip deficit rate of this SSE source region is about $3 \mathrm{~cm} /$ year (Yokota and others, 2016), and the plate convergence rate is 5.0 to $6.5 \mathrm{~cm} /$ year (Heki and Miyazaki, 2001). Therefore, in addition to this case, there is a possibility that SSE is frequently occurred in this region.

Acknowledgment

Y. Asano kindly provided VLF catalog.

${ }^{1}$ Geological Survey of Japan, National Institute of Industrial Science and Technology.

${ }^{2}$ Department of Geosciences and Center for Geomechanics, Geofluids, and Geohazards, Pennsylvania State University. 

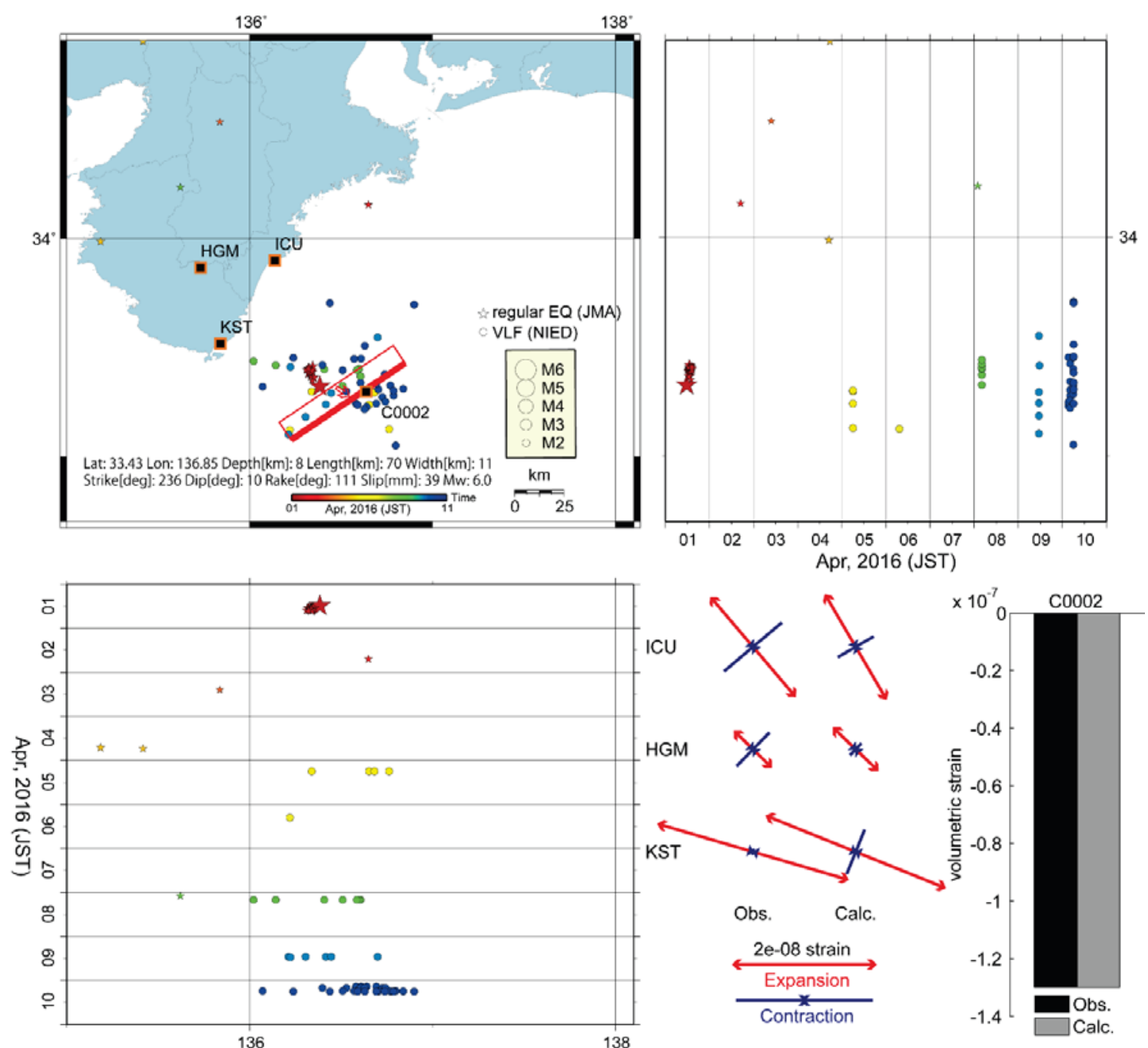

Figure 1. The fault plane of SSE and space-time distribution of VLF and regular earthquake.

\section{References Cited}

Heki, K. and S. Miyazaki, Plate Convergence and Long-Term Crustal Deformation in Central Japan,. Geophys. Res. Lett., 28, 2313-2316, 2001.

Yokota, Y., T. Ishikawa, S. Watanabe, T. Tashiro, and A. Asada, Seafloor geodetic constraints on interplate coupling of the Nankai Trough megathrust zone, Nature, 534, 374-377, doi:10.1038/nature17632, 2016. 


\title{
Fluid-faulting Evolution in High Definition: Connecting Fault Structure and Frequency-magnitude Variations During the 2014 Long Valley Caldera, California Earthquake Swarm
}

\author{
By David R. Shelly, ${ }^{1}$ William L. Ellsworth, ${ }^{1,2}$ David P. Hill, ${ }^{1}$ and Jeanne L. Hardebeck${ }^{1}$
}

An extended earthquake swarm occurred beneath southeastern Long Valley Caldera between May and November 2014, culminating in three magnitude 3.5 earthquakes and 1,145 cataloged events on 26 September alone. The swarm produced the most prolific seismicity in the caldera since a major unrest episode in 1997-1998. To gain insight into the physics controlling swarm evolution, we used large-scale cross-correlation between waveforms of cataloged earthquakes and continuous data, producing precise locations for 8,494 events, more than 2.5 times the routine catalog. We also estimated magnitudes for 18,634 events $(\sim 5.5$ times the routine catalog), using a principal component fit to measure waveform amplitudes relative to cataloged events.

This expanded and relocated catalog reveals multiple episodes of pronounced hypocenter expansion and migration on a collection of neighboring faults. Given the rapid migration and alignment of hypocenters on narrow faults, we infer that activity was initiated and sustained by an evolving fluid pressure transient with a low-viscosity fluid, likely composed primarily of water and $\mathrm{CO}_{2}$ exsolved from underlying magma. Although both updip and downdip migration were observed within the swarm, downdip activity ceased shortly after activation, while updip activity persisted for weeks at moderate levels. Strongly migrating, single-fault episodes within the larger swarm exhibited a higher proportion of larger earthquakes (lower Gutenberg-Richter b value), which may have been facilitated by fluid pressure confined in two dimensions within the fault zone. In contrast, the later swarm activity occurred on an increasingly diffuse collection of smaller faults, with a much higher b value. This swarm likely represents a natural analog to injectioninduced seismicity, with similarly strong interactions between fluid pressure changes and faulting in both circumstances and rapid fluid diffusion in the wake of faulting.

\footnotetext{
1U.S. Geological Survey.

2Stanford University.
} 

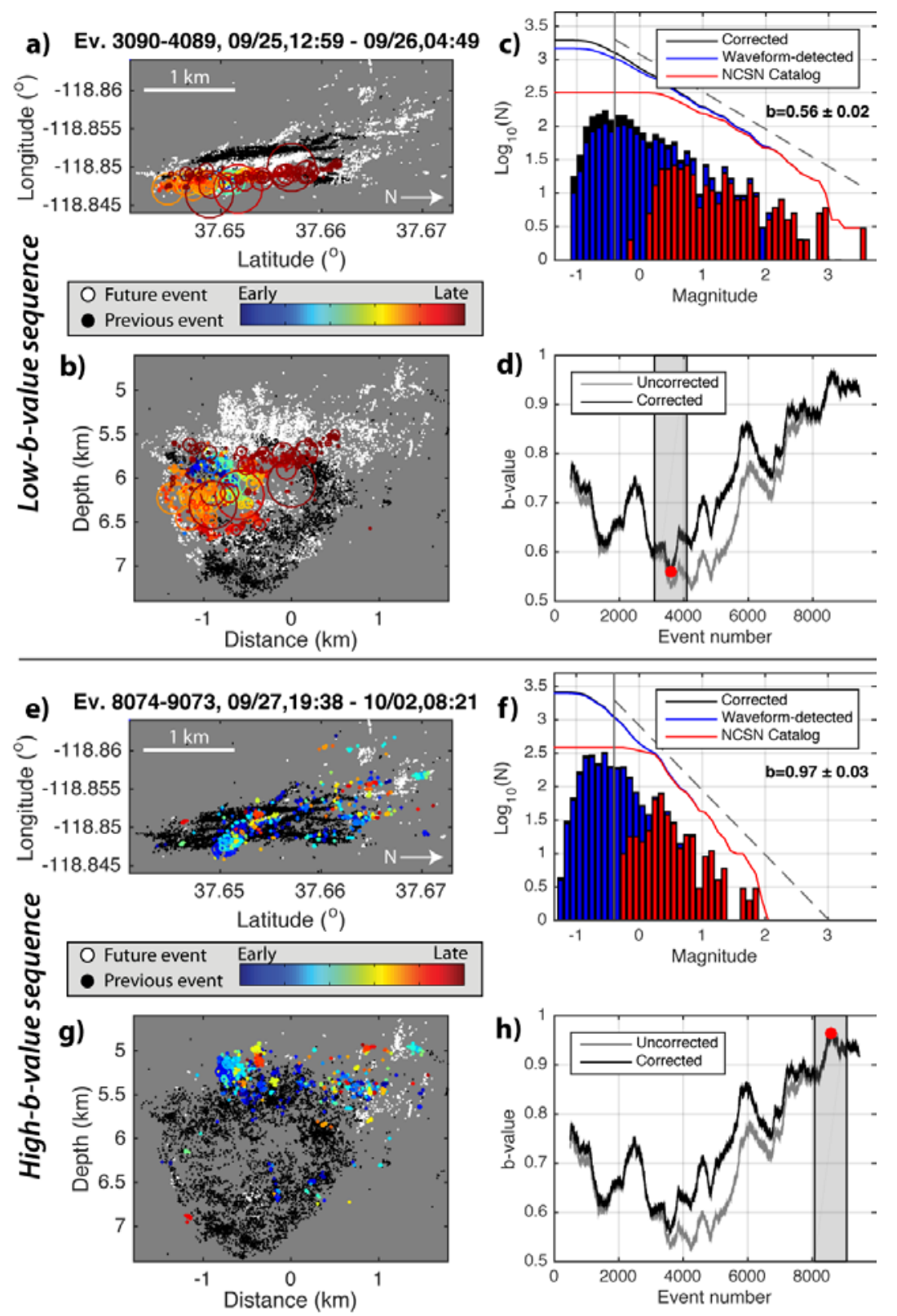

Figure 1. Comparison of a low-b-value sequence $(A-D)$ and a high-b-value sequence $(E-H)$, each containing 1,000 events $\geq M c=-0.4$. (A) Rotated map view. Colored events are those within the time period specified above the panel. Circles show estimated rupture dimensions for $M \geq 1$ earthquakes, assuming 3 MegaPascal (MPa) stress drop. (B) Corresponding south-north cross-section. (C) Frequency-magnitude distribution, showing Northern California Seismic Network catalog events (red), newly detected events (blue), and a correction for times when the detector is blind (black). Lines show corresponding cumulative distributions (all earthquakes $\geq$ a given magnitude); $b$-value (dashed line) is estimated using the corrected distribution. ( $D$ ) b-value evolution for a 1,000-event (above $M_{c}$ ) moving window. Black line shows $b$ value corrected for detector saturation time; gray is uncorrected. Red dot and gray shaded width show the $b$ value and window size corresponding to parts $A-C$. $(E-H)$ Same as $A-D$, but for high-b-value sequence late in the swarm. Figure from Shelly and others, 2016. 


\section{References Cited}

Shelly, D.R., Ellsworth, W.L., and Hill, D.P., 2016, Fluid-faulting evolution in high definitionConnecting fault structure and frequency-magnitude variations during the 2014 Long Valley Caldera, California earthquake swarm: Journal of Geophysical Research-Solid Earth, v. 121, no. 3, p. 1776-1795, https://doi.org/10.1002/2015JB012719. 


\title{
Interaction of SSE and Brittle Nucleation in Simulated Preseismic Slip
}

\author{
By Makiko Ohtani, ${ }^{1}$ Nobuki Kame, ${ }^{2}$ and Masao Nakatani ${ }^{2}$
}

At the subduction zone along the Nankai Trough, SW Japan, large earthquakes around $M 8$ had occurred repeatedly, and short-term aseismic slip were inferred from some observations before the recent 1946 event of Showa Nankai earthquake. They were observed within several days before the earthquakes, and could have been caused by $2 \mathrm{~m}$ slip on the plate interface at the deeper extension of the seismic region before the event (Linde and Sacks, 2002).

In this study, we conduct 2D quasi-dynamic earthquake cycle simulation to model such aseismic slip acceleration in the deeper extension of brittle seismic fault. Recently developed GNSS network systems have revealed that slow slip events constantly occur at the deeper extension of the seismic region along the Nankai Trough. These aseismic slip events are considered to occur at the brittle-to-ductile transition zone. The dominant deformation mechanism changes in the transition zone following the depth can be simply represented by the lower cut-off velocity $\left(\mathrm{V}_{\mathrm{cx}}\right)$, beyond which friction becomes velocity strengthening. Some studies model the SSEs successfully with this mechanism (Shibazaki and Iio, 2003; Kato 2003; Matsuzawa and others, 2010; Now we call the model as lower $V_{c x}$ model). However, the detailed behavior of lower $\mathrm{V}_{c x}$ model is not well investigated yet. In this study, we examine the effect of low cut-off velocity $\left(\mathrm{V}_{\mathrm{cx}}\right)$ under different brittle nucleation size $\left(\mathrm{L}_{\mathrm{cr}}\right)$ to investigate the interaction of SSEs at the transition zone and the brittle nucleation at the brittle zone.

We consider a flat plate interface with a dipping angle of 30 degrees for the depth 0-50 km. We assume constant frictional parameters through the fault, expect for $\mathrm{V}_{\mathrm{cx}}$ that is depth dependent (decreases from 10 to $10^{-9} \mathrm{~m} / \mathrm{s}$ at the transition zone). In this presentation, we show that this depth variation in $V_{c x}$ can possibly produce large preseismic slip.

In our model, large earthquake that ruptures the whole of the brittle region occurs with the recurrence time of 100-170 years, and large SSEs repeatedly occur at the transition zone. As the transition zone releases the accumulated stress by slip, the SSE spontaneously stops. However, when enough time has passed from the former earthquake and the brittle zone is enough stressed, the SSE induces the earthquake at brittle zone. When $\mathrm{L}_{\mathrm{cr}}$ is enough smaller than the size of transition zone, SSE plays the role of nucleation and SSE is observed as preseismic slip. With larger $\mathrm{L}_{\mathrm{cr}}$, SSE induces the brittle nucleation at the brittle zone, and the resultant preseismic slip is composed of the SSE at the transition zone and the brittle nucleation at the brittle zone. In both cases, the size of preseismic slip is much larger than that expected from $\mathrm{L}_{\mathrm{cr}}$. When the slip velocity is restricted to be smaller than $V_{c x}$, the slip and the stress drop at the point and the increase of energy release rate $G$ at the crack tip are also restricted. Then it becomes more difficult to achieve the condition of the rupture initiation, $G=G_{c}$ (fracture energy), at the crack tip and the preseismic slip becomes larger than the case without $\mathrm{V}_{\text {cx. }}$.

\footnotetext{
${ }^{1}$ Geography and Crustal Dynamics Research Center, Geospatial Information Authority of Japan. 2Earthquake Research Institute, The University of Tokyo.
} 


\section{References Cited}

Kato, N. (2003), A possible model for large preseismic slip on a deeper extension of a seismic rupture plane. Earth and Planet. Sci. Lett., 216(1-2), 17-25.

Linde, A. T., and I. S. Sacks (2002), Slow earthquakes and great earthquakes along the Nankai trough. Earth and Planet. Sci. Lett., 203(1), 265-275.

Matsuzawa, T., H. Hirose, B. Shibazaki, and K. Obara (2010), Modeling short-and long-term slow slip events in the seismic cycles of large subduction earthquakes, J. Geophys. Res., 115, B123016. Shibazaki, B., and Y. Iio (2003), On the physical mechanism of silent slip events along the deeper part of the seismogenic zone, Geophys. Res. Lett., 30(9), 1489. 


\title{
Operational Forecasting and Early Warning Systems of Earthquakes and Tsunamis
}

\author{
Global Navigation Satellite System Tsunami Early Warning Project
}

By John B. Rundle, ${ }^{1}$ LaBrecque, ${ }^{2}$ Attila Komjathy, ${ }^{3}$ and Tony Song ${ }^{3}$

The past decade has witnessed a terrible loss of life related to large earthquakes and resultant tsunamis in the Indo-Pacific region. Algorithms based on GNSS data and science now exist to rapidly determine the likelihood that a tsunami will be generated from a large earthquake, to predict their extent, inundation, and runup, and to track the tsunami as it propagates through the ocean basins. The algorithms use GNSS in combination with other sensors to measure ground displacements generated by large earthquakes and to measure disturbances in the ionosphere generated by the propagating tsunamis. An experimental prototype GNSS-based tsunami early warning system could be developed that would initially incorporate real-time data from existing networks in economies around the circum- and intra- Pacific and Indian Ocean basins. This prototype requires access to real-time GNSS data distributed throughout earthquake and tsunami prone regions. GNSS networks can provide tsunami predictions to communities nearest to a large earthquake's epicenter where the loss of life and damage to infrastructure is most severe. This capability is not currently available through existing tsunami warning systems and would be unique.

Beginning with the M9.3 earthquake and tsunami in Sumatra on December 26, 2004, and continuing to the more recent past with the M8.8 2010 Maule, Chile earthquake, and the March 11, 2011 M9.1 Tohoku-Oki earthquake and tsunami off the coast of north eastern Japan, it has been recognized that great tsunamis represent a significant threat to many regions around the Pacific Rim. In the United States, the M 9 Cascadia earthquake of January 26, $1700 \mathrm{AD}$ is now recognized to have been in this category of great earthquakes and tsunamis that threaten all coastal areas around the Pacific Rim.

To deal with this problem, very significant work has been done in the development of cost effective and efficient GNSS-based data systems to rapidly estimate a number of vital earthquake parameters that are necessary to predict the likelihood of resulting tsunamis and to track tsunami waves for communities nearest the earthquake's epicenter and as they propagate to distant coastlines around the world.

Published results using retrospective real-time analysis of GNSS networks have shown that the moments and slip displacement patterns of large magnitude earthquakes can be calculated within 3-5 minutes. Furthermore, algorithms now exist to use these earthquake source models to assess the likelihood of tsunamis and to predict the extent, inundation and runup of tsunami waves. Recently, a joint NOAA/NASA effort has further demonstrated the consistent estimates of tsunami energy using GNSS for improved early warning.

\footnotetext{
1University of California, Davis.

${ }^{2}$ Center for Space Research, University of Texas, Affiliated Research Fellow.

${ }^{3}$ Jet Propulsion Laboratory.
} 
A complementary approach is to use the GNSS networks to track the tsunamis using disturbances in the ionosphere. It has also been shown that augmenting these GNSS stations with relatively inexpensive accelerometers will improve the accuracy and timeliness of our ability to determine if an earthquake will produce a tsunami. Studies have also shown the benefit of supplementing the land- and atmosphere-based data with ocean surface and ocean bottom sensors. In short, we can now demonstrate that the existence of a real-time GNSS network of stations in the Pacific could have provided sufficient early warning of tsunamis to save tens of thousands of lives. For the great earthquakes and tsunamis mentioned above, the hardest hit were those closest to the earthquake source, a scenario for which there exists no adequate early warning system available today.

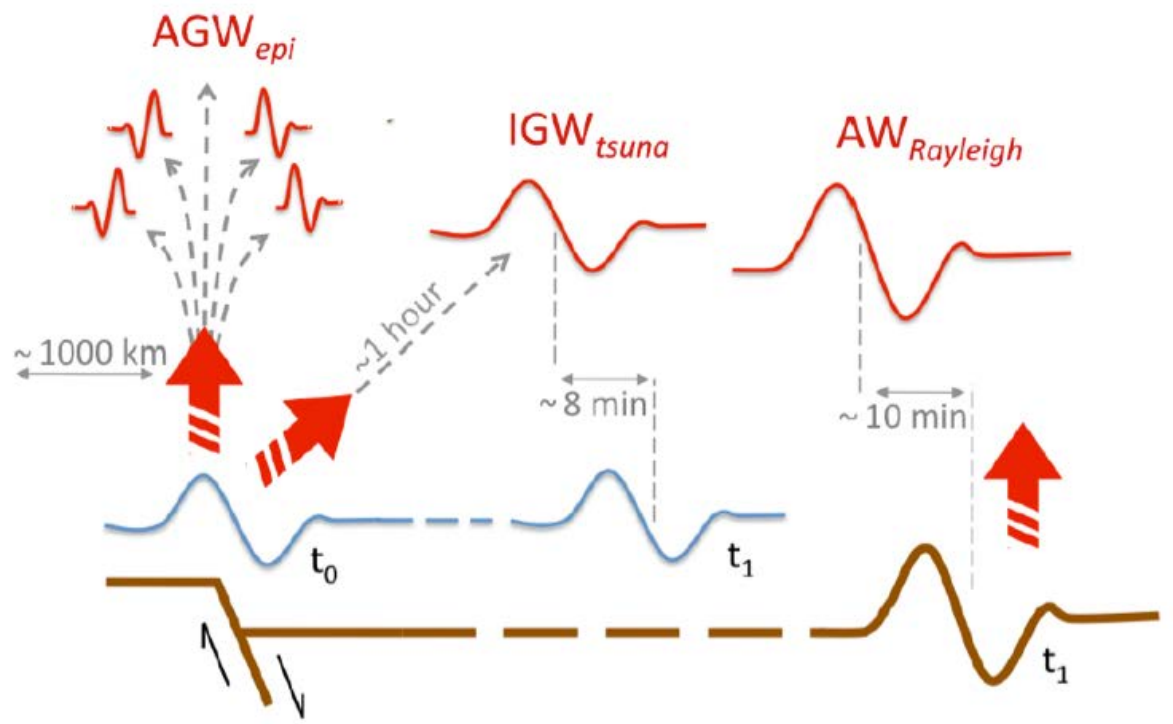

Figure 1. Illustration for coupling mechanism for solid Earth, ocean and ionosphere (after Occhipinti, 2015).

We plan to coordinate efforts with the Asia Pacific Economic Cooperation (APEC) group, and the Association of Pacific Rim Universities (APRU). We thus plan to take full advantage of this existing science collaboration of Pacific Rim institutions, in a geographic region where tsunamis are frequent. We have already begun collaborations with the APRU Multi-Hazards (MH) program (https://apru.org/partnering-on-solutions/multi-hazards-program) with hub at Tohoku University in Sendai, Japan. J. Rundle is a member of the Core Group (advisory committee) for the APRU/MH hub, and is a senior advisor to the APRU (http://apru.org/about/senior-advisorsresearch-associates). We have also begun collaborations with the APEC Policy Partnership for Science Technology and Innovation (PPSTI), and in particular, the Emergency Preparedness Working Group (EPWG). As a part of the proposed work, we will continue to build on the collaborations begun previously. This requires regular and frequent interactions with the APEC and APRU groups. We are also coordinating our activities with the GGOS Geohazards monitoring focus area, the IUGG GeoRisk commission, and other appropriate federal agencies including NOAA, the USGS, and the US Department of State. 


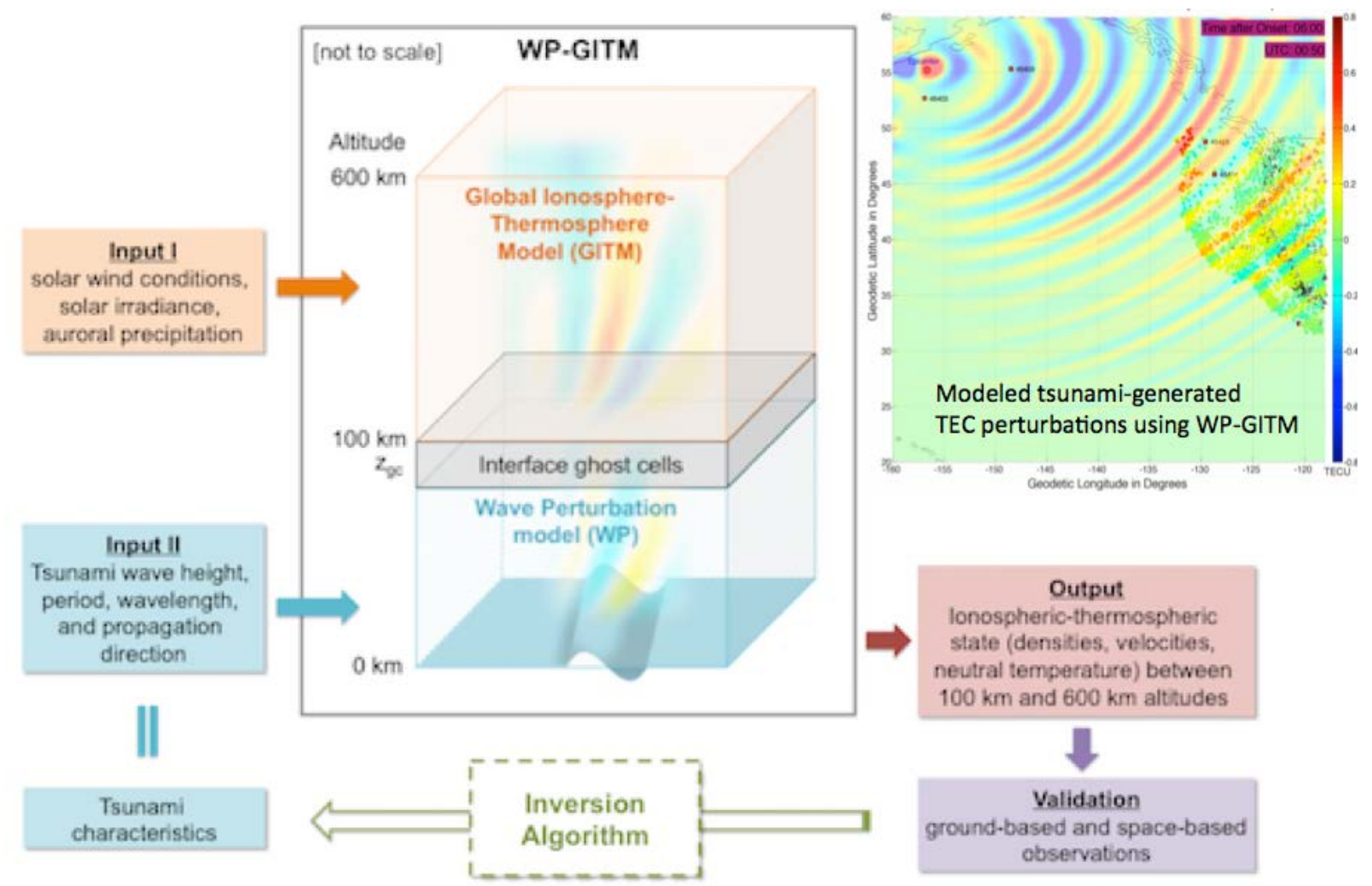

Figure 2. The JPL Wave Perturbation Global lonosphere-Thermosphere Model (WP-GITM) flowchart.

A tsunami early warning system also embodies the cooperation envisioned by the February 26, 2015 UN General Assembly resolution calling for increased data sharing and cooperation in developing geodetic infrastructure and its applications. The GNSS Tsunami Early Warning System (GTEWS) project also supports the 2014 APEC Leaders Declaration [3] to "foster a pragmatic, efficient and vigorous partnership on science, technology, and innovation" and to "encourage further cooperation of member economies in disaster preparedness, risk reduction, response and post-disaster recovery, and cooperation in search and rescue, including through...increased data sharing; and application of science and technologies."

Finally, a recent Concept Note to APEC and its committee PPSTI, states that the technology to develop a GNSS Tsunami Early Warning System should lead to the rapid design of an early warning system. GNSS technologies can provide an opportunity to enhance existing warning systems with more timely, accurate, and informative warnings while insuring a robust, cost effective and sustainable framework. This GNSS capability complements the existing Tsunami Early Warning System based upon seismic monitoring and DART buoys. Up to 90 minutes of advanced warning of an approaching tsunami might be achieved with this system (J. LaBrecque, personal communication, 2016). For the GTEWS to be effective, nations around the Indo-Pacific Basin should establish a framework for the sharing of data and analysis software because the impacts of large earthquakes and tsunamis transcend national boundaries and land area.

In this talk, I will summarize this project and its current state of activity. We plan to convene a workshop in May, 2017 in Sendai, Japan to begin planning this project with the aid of the Japanese scientific community. At the appropriate time, we will solicit participation in this meeting for interested parties. 


\section{Real-time Prediction of Ground Shaking Without Source Information: Data Assimilation and Simulation of Seismic Wave Propagation for Earthquake Early Warning}

By Mitsuyuki Hoshiba, ${ }^{1}$ and Masashi Ogiso ${ }^{1}$

Many of the present Earthquake Early Warning (EEW) systems quickly determine the hypocenter and magnitude, and then predict strength of ground motions. The $M_{\mathrm{w}} 9.0$ Tohoku earthquake, however, revealed some technical issues with such methods: under-prediction at large distances due to the large extent of the fault rupture, and over-prediction because the system was confused by multiple aftershocks that occurred simultaneously. To address these issues, we have proposed a new concept for EEW (Hoshiba and Aoki, 2015; fig. 1), in which the distribution of the present wavefield is estimated precisely in real time (real-time shake mapping) by applying a data assimilation technique, and then the future wavefield is predicted timeevolutionally by simulation of seismic wave propagation. Information on the hypocenter location and magnitude are not necessarily required. We call this method, in which physical processes are simulated from the precisely estimated present condition, "numerical shake prediction" by analogy to "numerical weather prediction" in meteorology.

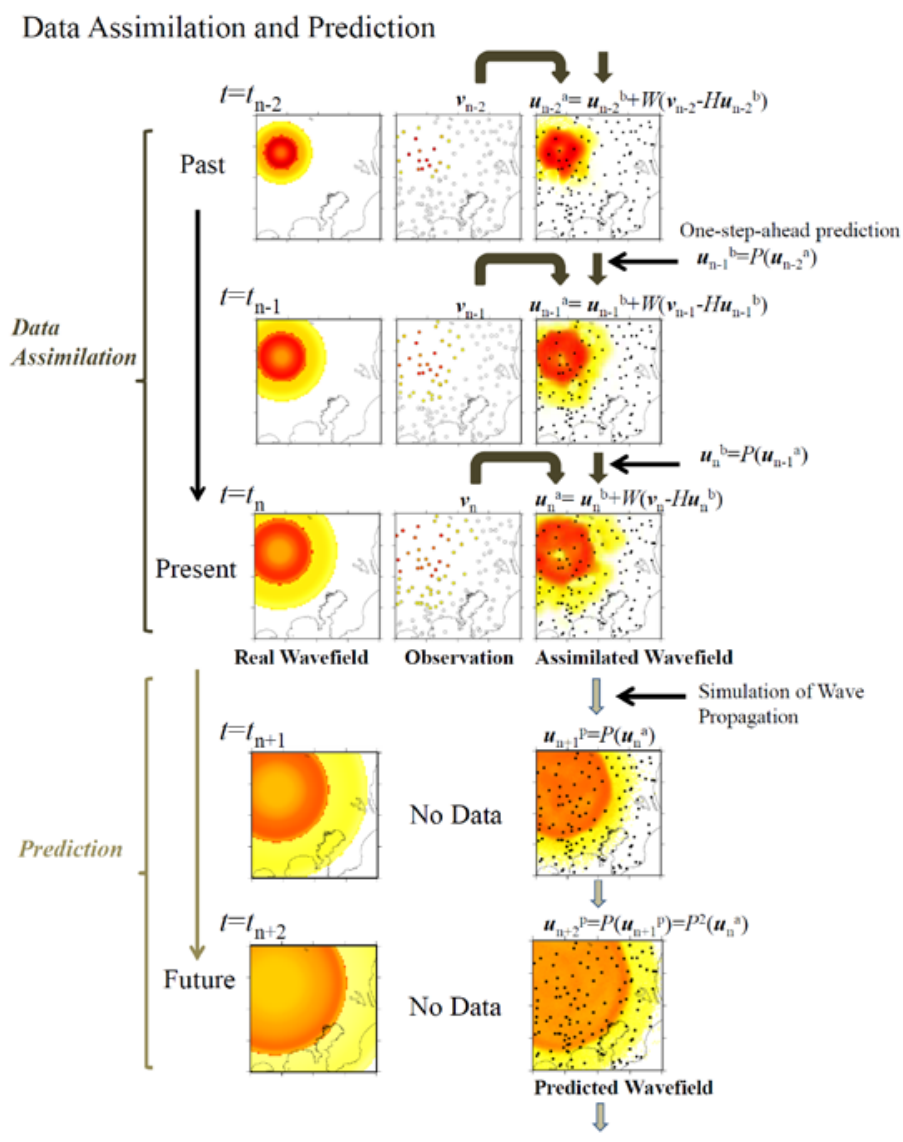

Figure 1. Flow from estimation of wavefield using data-assimilation to prediction of ground motion.

${ }^{1}$ Meteorological Research Institute, the Japan Meteorological Agency (JMA). 
In many methods of the present EEW systems of rapid determination of hypocenter and magnitude, the strength of ground motions (PGA, PGV, seismic intensity) are predicted using the hypocentral distance and magnitude based on a ground motion prediction equation (GMPE), which usually leads the prediction of concentric distribution. However, actual ground shaking is not always concentric, even when site amplification is corrected. The strength of shaking may be much different among earthquakes even when their hypocentral distances and magnitudes are almost the same. For some cases, PGA differs more than 10 times, which leads to imprecise prediction in EEW.

In numerical shake prediction method, because future is predicted from the present condition, it is possible to address the issue of the non-concentric distribution. Once the heterogeneous distribution is actually observed in ongoing wavefield, future distribution is predicted accordingly to be non-concentric. We will indicate examples of $M 6$ crustal earthquakes occurred at central Japan, in which strength of shaking were observed to non-concentrically distribute. We will also show the case of the numerical shake prediction for the 2016 Kumamoto earthquake $\left(M_{\mathrm{w}} 7.0\right)$, during which $M 6$ class earthquake was remotely triggered apart from $70 \mathrm{~km}$ from the epicenter (fig. 2).

(a) Present Wavefield
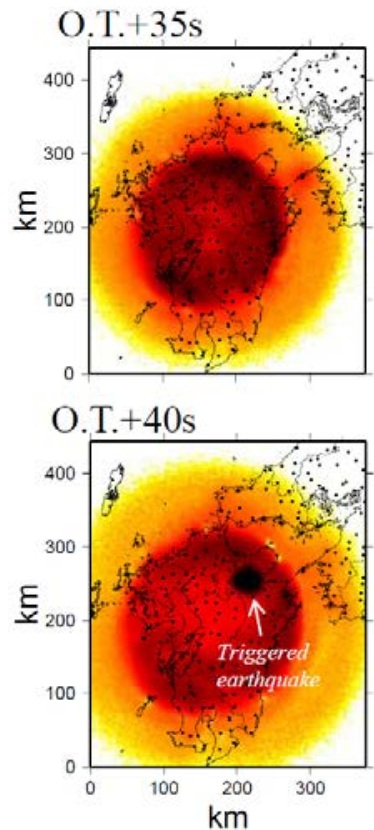

(b) Prediction of $10 \mathrm{~s}$ ahead
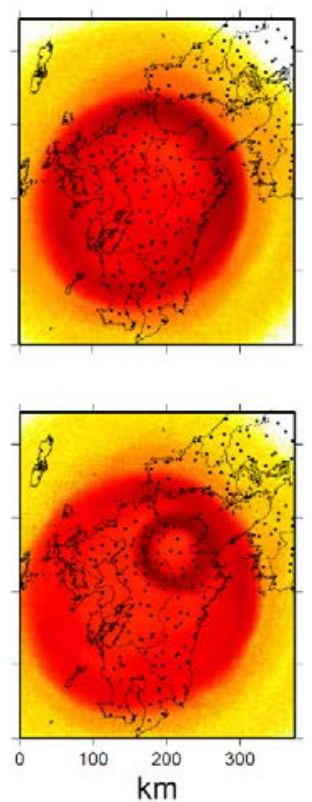

(c) Actual wavefield of $10 \mathrm{~s}$ ahead

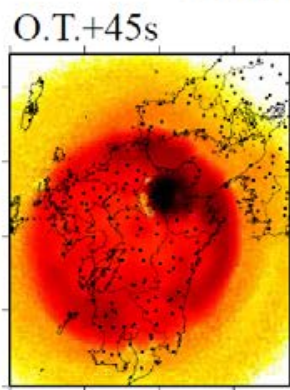

O.T. $+50 \mathrm{~s}$

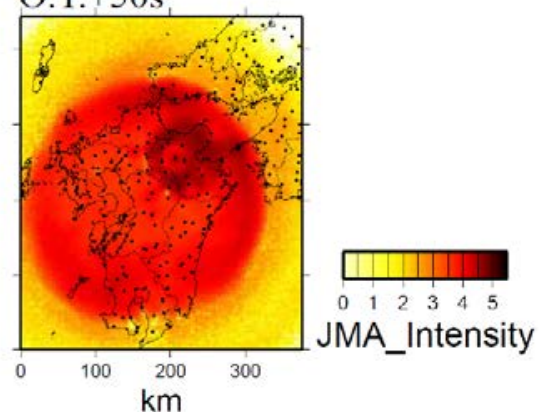

Figure 2. Numerical shake prediction for the 2016 Kumamoto earthquake $\left(M_{\mathrm{w}} 7.0\right)$. (A) Wavefield at O.T. $+35 \mathrm{~s}$ and 40 s from the origin time, $(B)$ prediction of 10 s ahead, $(C)$ Actual wavefield of 10 s ahead. The triggered earthquake occurred at around O.T. $+35 \mathrm{~s}$.

Acknowledgment

We used waveform data from K-NET and KiK-net (NIED), and from JMA. 


\section{References Cited}

Hoshiba, M. and S. Aoki, 2015: Numerical Shake Prediction for Earthquake Early Warning: Data Assimilation, Real-Time Shake Mapping, and Simulation of Wave Propagation, BSSA, 105, 1324 1338, doi: 10.1785/0120140280. 


\title{
Constructing Better Communication for Operational Earthquake Forecasting of Aftershocks
}

\author{
By Anne Wein, ${ }^{1}$ J.B. Becker, ${ }^{2}$ S. McBride, ${ }^{2,3}$ S.H. Potter, ${ }^{2}$ and E.E.H. Doyle ${ }^{3}$
}

GNS Science (GNS) and the U.S. Geological Survey (USGS) are investigating how communication and use of aftershock forecasts can be improved to reduce earthquake risk. Using a study of the communication of aftershock information during the Canterbury sequence, we describe communication gaps between the delivery of information by scientists and the use of it by various audiences. We summarize the results of two independent workshops to close those gaps. The workshops complemented each other: the GNS workshop surveyed user needs and identified communication issues; the USGS workshop designed solutions in the form of communication product concepts.

Introduction

The USGS is collaborating with GNS on how communication and use of aftershock forecasts can be improved to reduce earthquake risk. Aftershocks occur after a large earthquake (mainshock), creating an earthquake sequence. Aftershock forecasts provide frequencies and probabilities of particular earthquake magnitudes or shaking intensities that can be expected in future time periods for the area. For example, a text version of the forecast issued by GNS during the Canterbury New Zealand 2010-present earthquake sequence on 1 August 2015 states: "Within the next 1 year, there is a 51 percent probability of one or more earthquakes of Magnitude 5.0 to 5.9 occurring in the [aftershock zone]... It is expected that there will be between 0 and 3 events of this magnitude during the coming year". A study of the communication of aftershock information during the Canterbury sequence is used to examine the communication gaps between knowledge and use of aftershock forecasts. To close these gaps, each agency conducted a workshop to better attend to user needs for earthquake forecasts.

\section{Communication Gaps Between Knowledge and Use}

Our research on the communication of aftershock information during the Canterbury sequence used focus groups and interviews to gather data on people's experiences with earthquake and aftershock information and feedback on various forecast products. Thirty-five study participants included scientists, emergency managers and responders, people from critical infrastructure agencies, businesses, elected officials, and members of the public. A qualitative analysis of the data for gaps between knowledge and use in practice was undertaken with thematic coding framed by a message-centered approach: (1) information is available, needed but not used; (2) information is needed, but not available; and (3) information is available, but not needed. Reasons for gaps between available aftershock information and use of aftershock information are summarized with examples in table 1.

\footnotetext{
1U.S. Geological Survey.

${ }^{2}$ GNS Science.

${ }^{3}$ Massey University.
} 
Table 1. Examples of of gaps between aftershock information and audience needs.

Gaps for Audiences

Not knowing

information is available

Not seeking the

information or

reluctance to request it.

Not knowing how to use

information

Needing additional information

Not receiving in time for

decision-making

Needing information

that is not available

Not needing provided

information
Example from Canterbury Study

Website design made it hard to find a table of sequential earthquake forecasts and

occurrences that was later praised for conveying uncertainty and validating the science.

After the February 22 aftershock, only one organization in Christchurch city requested aftershock forecast information from GNS Science. One reason expressed by some emergency managers was not wanting to bother busy scientists.

Communicators were unfamiliar with aftershock forecasts and unprepared (in terms of how) to communicate low-probability-high-consequence events. An elected official shared that he believed a M6 or larger earthquake was not going to happen, despite a

$70 \%$ chance, as he wanted to be optimistic.

Urban Search \& Rescue (USAR) engineers also needed ground motion information for the recent and future earthquakes in order to make decisions.

Lack of technology (e.g., Smartphone) and USAR camp being separate from the Emergency Operation Centre interfered with delivery of information.

People were missing a view of risk (e.g., translation of earthquake forecasts into potential impacts such as building damages)

24 hour shaking intensity forecast map published daily in the newspaper did not match decision-making time frames.

The findings of this research suggest the use of aftershock information in risk management decisions can be improved if; (1) potential users have experience with aftershock forecasts beforehand; they are informed about aftershock forecasts, where to find or receive them, and how to use them; and (2) Scientists understand the specific needs for information by the various audiences. To these points, participatory processes help to get and keep attention, engage an audience, and tailor the products to the intended audience.

\section{Understanding Audience Needs}

To close the communication gaps, science agencies recently conducted two independent workshops with critical infrastructure and emergency management participants. Both workshops contained presentations by scientists to inform participants about the science of aftershock forecasting. The GNS Science workshop in October 2015 was structured around questions about (1) the content and format of aftershock forecasts, (2) the uses for forecasts, and (3) communication issues. Participants completed a feedback form. The USGS workshop in February 2016 was facilitated for scientists and participants to develop solutions to communicating earthquake forecasts together. A creative process called design thinking generated lots of ideas; clustered related ideas; and developed the more popular solutions into communication product concepts. An independent evaluation of the workshop was conducted.

\section{Diverse Preferences for Aftershock Forecast Content and Format}

In both workshops, participants recognized the usefulness of aftershock forecasts in decisions across the four phases of disaster management: (1) preparedness (making plans, resource staging); (2) response (situational awareness, safety/risk management); (3) recovery (when to repair and rebuild); and (4) mitigation (building and foundation design standards, land use, insurance). The GNS Science workshop gathered diverse needs for information, differentiated by roles and levels of technical capability. Across workshop participants: (1) Shaking intensity is the most popular measure of the hazard, and earthquake magnitude is the least popular measure 
(despite being the current practice), while the engineers preferred peak ground acceleration. (2) The forecast time window of 24 hours had the most disagreement on usefulness: those concerned with infrastructure considered it useful; insurers and emergency managers did not. All participants scored the month forecast as at least somewhat useful. (3) Shaking of at least intensity V or VI is most useful, but insurers are also interested in lower levels of shaking. (4) Translation of the forecasted hazard into impacts is most wanted by those concerned with public safety (for example, emergency managers) and insurers.

The USGS workshop revealed a similarly diverse list of audience needs for content and technical detail. The participants sketched and described an aftershock information-living hazards'-portal that provides direct, centralized, and standardized access to information for various audiences and coordination among audiences. The portal enables users to customize forecasts that can be tailored for hazard measure and level, forecast time window, and format (text, table, map, figure). Lifeline engineers, trained to use hazard curves (probability of levels of shaking at a location) can access hazard curves adjusted for changes in seismicity (by scientists) and apply them in the repair or rebuild designs of their systems. Meanwhile, emergency managers and responders can access succinct, essential, and actionable messages in real-time. The portal also provides documentation of the forecast models and methods

GNS workshop participants responded favorably to information about changes to forecasted earthquake probabilities and frequencies. USGS participants conceptualized retrospective aftershock information products: (1) maps and figures that reveal the evolution, patterns, and trends of the earthquake sequence epicenters and shaking, and (2) 'cumulative ShakeMaps' for emergency managers to visualize the repeat or maximum shaking that building types have been subjected to, in lieu of a cumulative damage assessment tool that can update building fragility after each earthquake in a sequence.

USGS workshop participants also conceptually designed earthquake early warning boxes for repair crews that are restoring damage and disruption from the mainshock while at risk of injury from aftershocks. Another cluster of ideas pertained to training for different user groups.

\section{Communication Challenges}

During the GNS workshop, Emergency Managers expressed concern about translating forecasts into advice for the public. Similarly, lifelines operators are primarily concerned about communication with the public rather than internal use of the information. The reported public communication challenges pertain to forecast changes, desensitized populations, and explaining when earthquakes do not occur despite high probability in the forecast, and vice versa. There is uneasiness with how some people (such as politicians and specific sectors) use aftershock forecasts and how others (such as businesses and tourism) are affected by them. Similarly, USGS workshop participants are comfortable with their ability to use forecast data, but need to be able to craft simple, short and appropriate messages for their customers and constituents.

\section{Workshop Evaluations}

Both workshops received positive feedback for skilled facilitation and informative science presentations. The opportunities to network, interact with scientists, and hear a range of perspectives was valued, but absences of some roles were noted. In comparison to the more familiar GNS workshop structure, the USGS design thinking approach and more fluid agenda caused some confusion about what to expect and the two-day commitment for the creative 
process was demanding. However, the open mindedness of scientists and the brainstorm activities were acclaimed for enabling productive discussion and creation of new ideas that participants believed would not have formed otherwise.

\section{Conclusion}

Using a message-centered framework, we identified various gaps between scientific knowledge and use of aftershock information during the Canterbury earthquake sequence. GNS and USGS workshops aimed to close communication gaps by informing participants about aftershock forecasts. Two workshops complemented each other: the GNS workshop surveyed diverse forecast information needs and identified communication issues; the USGS workshop developed solutions in the form of conceptual communication products. Continued development and evaluation of communication plans will help to ensure our communications are effective, and gaps between information provision and use are minimized.

\section{Acknowledgments}

Many thanks to participants in the Canterbury focus groups and workshops. Matt Gerstenberger and Annemarie Christophersen assisted with the GNS Science workshop. Sue Perry, Sherry Hoffman (facilitator), Phillippe Enzler, Dale Cox, Andrew Michael, and Jeanne Hardebeck contributed to the USGS workshop. Reviews by Nicholas van der Elst and Maureen Coomer helped to improve the abstract. The effort has been funded by the Hazard Platform and USGS SAFRR and Land Change Science.

\section{References Cited}

GeoNet, Canterbury aftershocks, 2015, GeoNet web page, accessed August 10, 2015 at http://info.geonet.org.nz/display/home/Canterbury+Aftershocks.

Wein, A., Potter, S., Becker, J., Ratliff, J., Hudson-Doyle, and E., 2014, Communication of aftershock forecasts for risk reduction in urban areas: Third International Conference on Urban Disaster Reduction (3ICUDR), available at http://3icudr.org/images/Extended_Abstracts/Breakout_3/Track_2/4AftershockForecastCommunicationforRiskReductioninUrbanAreas.pdf.

Sellnow, T.L., Ulmer, R.R., Seeger, M.W., and Littlefield, R.S., 2009, Effective risk communication-A message-centered approach: New York, Springer Science \& Business Media.

Becker, J.S., McBride, S.K., Potter, S.H., Gerstenberger, M., and Christophersen, A., in press, Effective communication of operational earthquake forecasts (OEF)-Findings from a New Zealand workshop: GNS Science Report 2016/45. p.

Perry, S.C., Blanpied, M.L., Burkett, E.R., Campbell, N.M., Carlson, A., Cox, D.A., Driedger, C.L., Eisenman, D.P., Fox-Glassman, K.T., Hoffman, S, Hoffman, S.M., Jaiswal, K.S., Jones, L.M., Luco, N., Marx, S.M., McGowan, S.M., Mileti, D.S., Moschetti, M.P., Ozman, D., Pastor, E., Petersen, M.D., Porter, K., Ramsey, D.W., Ritchie, L.A., Fitzpatrick, J.K., Rukstales, K.S., Sellnow, T.S., Vaughon, W.L., Wald, D.J., Wald, L.A., Wein, A, and Zarcadoolas, C., 2016, Get your science used-Six guidelines to improve your products: U.S. Geological Survey Circular 1419, 37 p., http://dx.doi.org/10.3133/cir1419. 


\section{Warning When it Matters: Earthquakes and Tsunamis Around the Globe}

By Richard Allen, ${ }^{1}$ Angela Chung, ${ }^{1}$ Qingkai Kong, ${ }^{1}$ Diego Melgar, ${ }^{1}$ and Christine Ruhl${ }^{1}$

With our improved understanding of earthquake processes, new dense geophysical deployments, and rapid pervasive communication systems, we can now deliver targeted warning of forthcoming ground shaking and tsunami inundation around the world. The Berkeley Seismological Laboratory has developed and is implementing a range of tools for this purpose. ElarmS rapidly detects the beginnings of earthquakes to generate a rapid first alert. G-larmS uses geodetic observations to determine the finite extent and magnitude of the largest earthquakes. TlarmS can then provide an estimate of local tsunami height in minutes. These algorithms are now being tested in the US, Israel, Chile and Korea. The most recent addition to the effort is MyShake which harnesses personal smartphones to detect earthquakes (myshake.berkeley.edu). MyShake is currently deployed on 40,000 smartphones around the globe and 10,000 provide data to the system every day. In the future we hope to be able to provide warnings from the MyShake network around the world.

${ }^{1}$ University of California, Berkeley, Seismological Laboratory. 


\section{The Theoretical and Observational Limits of Earthquake Early Warning}

By Sarah E Minson, ${ }^{1}$ Annemarie Baltay, ${ }^{1}$ Thomas $\mathrm{C}$ Hanks, ${ }^{1}$ Men-Andrin Meier, ${ }^{2}$ and Elizabeth S Cochran ${ }^{1}$

In this study we assume that the goal of earthquake warning is ground-motion early warning: to predict expected ground shaking intensity so that action can be taken at various locations to prepare for the imminent ground motion. The usefulness of early warning depends both on the accuracy of the ground motion prediction and the timeliness of the warning. We take timeliness to be the time difference between when the warning is received and when the expected ground motion arrives at the user's location, minus the time needed for users to take precautionary measures. The time required to issue a warning depends on several factors including the telemetry latency associated with receiving real-time data, the computational time needed to analyze those data, and, most crucially, the time needed to characterize the earthquake source in order to make accurate ground motion predictions. In this study we explore, both theoretically and observationally, the conditions necessary to make an accurate ground motion prediction and the temporal evaluation of the expected accuracy of early warning systems. We consider the limits of rapid magnitude estimation given the non-deterministic nature of earthquake rupture, and the band-limited Gaussian white noise properties of high-frequency (for example, Peak Ground Acceleration) ground motion. We also study the best-case warning time scenario given the limits on magnitude estimation and the finiteness of large faults. Finally, we consider the accuracy and effectiveness of real-time ground-motion prediction given the uncertainties and limitations in magnitude estimation and the range of potential warning times.

\footnotetext{
${ }^{1}$ U.S. Geological Survey.

${ }^{2}$ California Institute of Technology.
} 


\title{
Probabilistic Earthquake and Tsunami Hazard Estimation
}

\section{Inferring seafloor displacements during the 2011 Tohoku-Oki earthquake with minimal prior information}

By Junle Jiang, ${ }^{1,2}$ and Mark Simons ${ }^{1}$

\begin{abstract}
Diverse observations from the $2011 M_{\mathrm{w}} 9.0$ Tohoku-oki earthquake suggest large coseismic fault slip proximal to the Japan Trench, challenging the conventional assumption that the outer fore-arc is stable and aseismic. However, the nature of near-trench fault slip during this event remains debated, without consensus on whether slip peaked at the trench or at greater depths. Here we use a probabilistic imaging approach to resolve the coseismic seafloor displacement that produced the near-field tsunami. Our models indicate that the seafloor is broadly uplifted and tilted seaward approaching the trench, with a $\sim 5-\mathrm{m}$ peak uplift bordering the outer fore-arc decreasing to $\sim 2-\mathrm{m}$ at the trench-axis over a $50-\mathrm{km}$ distance. Mechanical models that reproduce such tapered displacement require a deficit of near-trench fault slip. With shallower earthquakes undocumented in the region, aseismic deformation is the most likely mode for satisfying the longterm slip, suggesting a metastable frictional behavior for the shallowest megathrust.
\end{abstract}

${ }^{1}$ Seismological Laboratory, California Institute of Technology.

${ }^{2}$ Institute of Geophysics and Planetary Physics, Scripps Institution of Oceanography, University of California San Diego. 


\section{A Seafloor geodetic measurements}

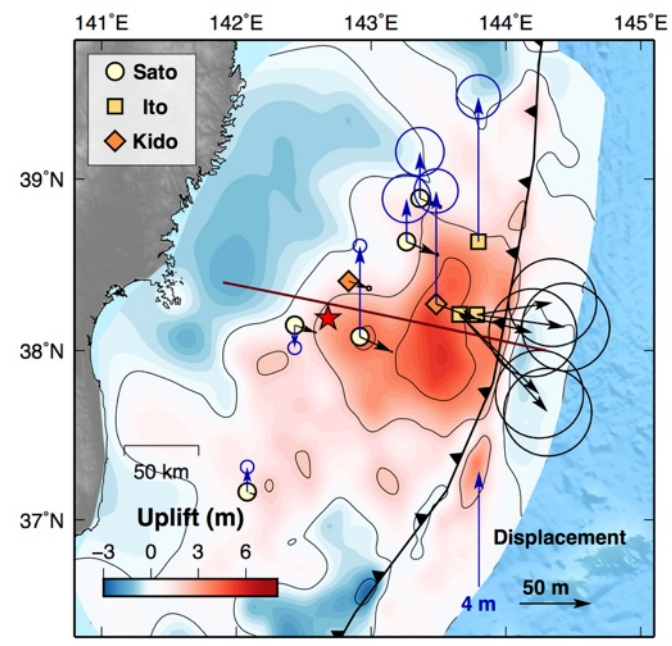

\section{Large-scale seafloor tilt}

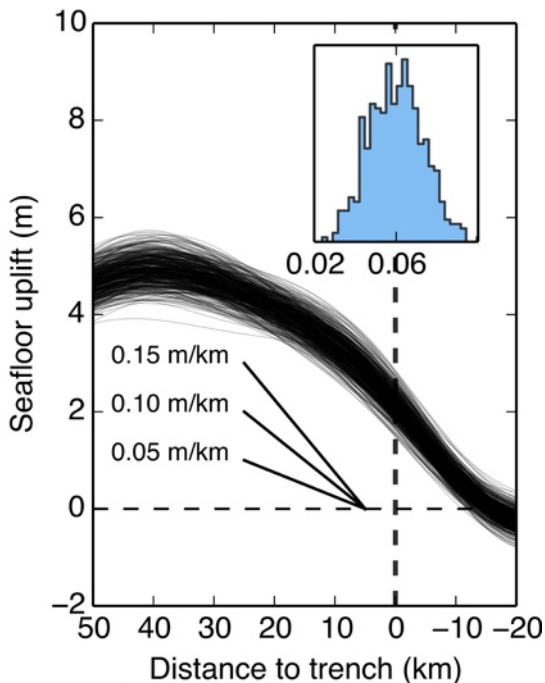

B Trench-normal profile of seafloor deformation

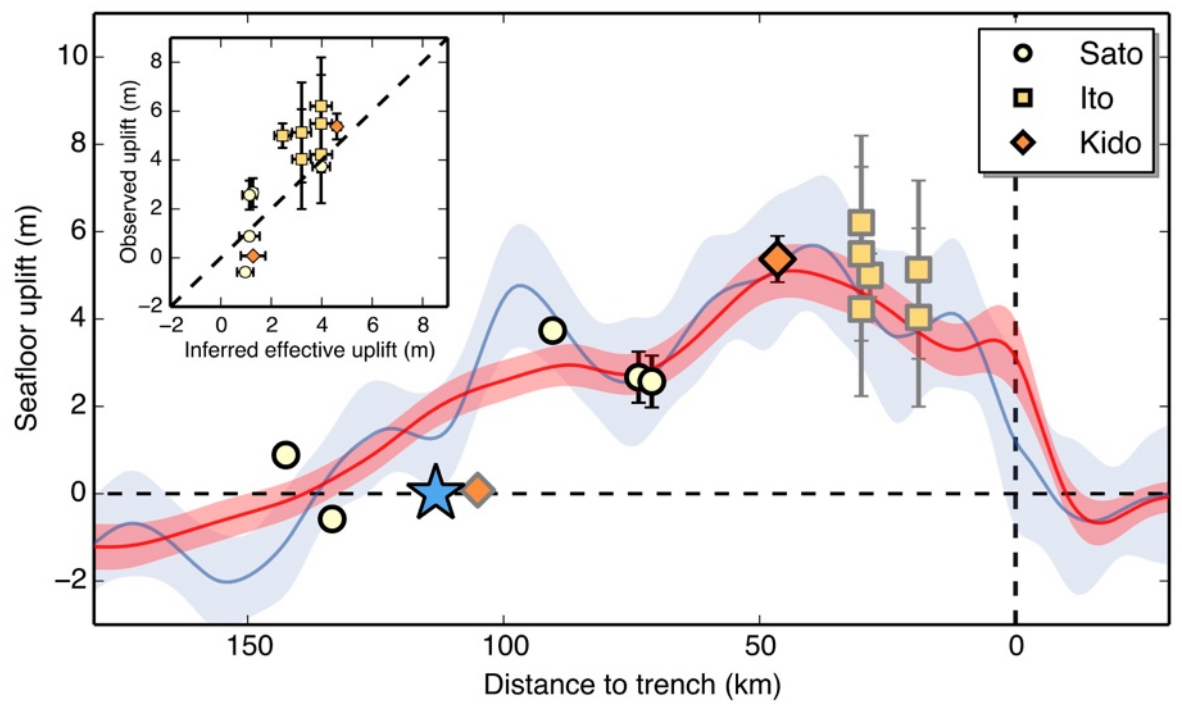

Figure 1. Seafloor uplift near the Japan Trench. (A) Seafloor displacement model and available seafloor geodetic measurements. Blue and black arrows represent the vertical and horizontal components, respectively. $(B)$ The trench-normal profile of the inferred effective seafloor displacements. Seafloor geodetic measurements are shown as symbols, with their associated uncertainties represented by vertical error bars. The effective displacement comprises both vertical and horizontal displacements (black-outlined symbols) or only the horizontal displacement (gray-outlined symbols). The blue and red lines represent the mean of stacked trench-normal profiles of seafloor displacements in using less and more spatial averaging, and blue and red regions indicate the uncertainty range (68 percent). The figure inset shows comparisons between the inverted and observed effective uplift at coinciding locations. The dashed line corresponds to an exact match between data and model. (C) Larger-scale $(\sim 40 \mathrm{~km})$ uplift profiles from 200 random realizations of model $M 2$ are shown in black. The figure inset shows the histogram for the seafloor tilt. Vertical dashed lines indicate the location of the trench. 


\title{
Self-consistent Source Model for the 2011 Tohoku Earthquake and Tsunami: Evaluating the Northern Extent of Coseismic Slip
}

\author{
By Yoshiki Yamazaki, ${ }^{1}$ Kwok Fai Cheung, ${ }^{1}$ and Thorne Lay ${ }^{2}$
}

The 2011 Tohoku great earthquake and tsunami produced unprecedented geophysical and hydrographic datasets for investigation of the rupture processes and coastal wave impacts. Numerous analyses of the diverse data have resulted in a suite of models for coseismic slip during the earthquake that account for specific data well, but may not be consistent with all observations. Joint modeling or inversion methods allow the discrepancies to be reconciled to a certain extent, but present challenges in model parameterization and data weighting. The current state of understanding of the 2011 event remains murky with respect to (a) the magnitude of near-trench coseismic slip up-dip from the hypocenter, (b) the northward extent of near-trench slip, and (c) possible contribution from a conjectured submarine slump in the trench north of the rupture zone. Most, but not all, source investigations that utilize tsunami buoy and run-up observations with or without seismic and geodetic data favor occurrence of large magnitude slip (>30 m) on the shallow megathrust, compatible with observed offsets from repeat seismic reflection imaging of the sedimentary wedge. This appears to be quite compelling, combined with the fact that the models lacking large near-trench slip tend to utilize data that have very limited sensitivity to neartrench slip. We focus on outstanding issues (b) and (c), as these seem to be more unresolved in our opinion. Of particular importance is the magnitude of any slip near the trench extending north of $38.5^{\circ} \mathrm{N}$, overlapping the estimated slip zone for the 1896 tsunami earthquake. Even among the subset of rupture models with strong slip to the trench up-dip from the hypocenter, there are large differences in inferred slip north of $38.5^{\circ} \mathrm{N}$, ranging from zero to more than $20 \mathrm{~m}$. This leaves great uncertainty regarding the current potential for a tsunami earthquake in the 1896 zone.

The similarity of run-up observations for the 1896 and 2011 events along the coasts of Sanriku and Hokkaido immediately raises the possibility that the 1896 zone re-ruptured in its entirety during the recent earthquake. However, it is clear that the down-dip region of the megathrust along the 1896 zone did not have large coseismic slip in 2011, apparently due to a high percentage of aseismic deformation in this region. Offshore geodetic measurements are not available along the 1896 zone to help constrain any shallow slip, and on-shore geodetic data do not require slip near the trench in the 1896 zone, but have very limited sensitivity to any slip that may have occurred. Efforts to model the offshore tsunami recordings along Sanriku have been successful for variable placements of shallow slip (it can be further south at earlier time or further north at later time and still match the timing and large peak pulse of the tsunami waveforms). One issue is that models that have late slip in the north to match the tsunami timing have not been reconciled with seismic data that constrain the main source process to about 150 s duration. More challenging has been to model the run-up observations; almost all existing source models, even those that satisfactorily fit the offshore waveform data as well as offshore geodetic data, fall short in matching the peak tsunami run-up along the Sanriku coast. This has motivated the speculation that a secondary source, such as a submarine slump, to which the seismic and geodetic data are

\footnotetext{
${ }^{1}$ Department of Ocean and Resources Engineering, University of Hawaii at Manoa.

2Department of Earth and Planetary Sciences, University of California Santa Cruz.
} 
essentially blind, is needed to account for the run-up. No direct evidence for a sufficiently large slump has been reported, but the possibility continues to be discussed. Such an interpretation of course raises similar questions about the nature of the1896 event, which was weakly detected based on ground shaking but had such similar run-up along northern Honshu.

Our approach to this issue is to evaluate whether rupture models obtained from seismic observations and tsunami recordings and run-up observations can be reconciled with a selfconsistent model that is also compatible with geodetic observations. Essentially, we are testing whether it is necessary to invoke an additional exotic source to account for the tsunami or whether a single fault displacement model can adequately match all observations. We begin with a finite-fault model obtained from inversion of global seismic records, in which the poorly resolved model parameters such as rupture velocity and source grid dimensions are iteratively constrained by forward modeling of the tsunami at near-field stations. This earlier approach depends on the resolution of seismic data over the source region as the tsunami records do not play a role in directly modifying the fault slip. A linear elastic model reconstructs the land and seafloor displacement from fault-slip distributions, while the shock-capturing non-hydrostatic NEOWAVE code computes the near-field tsunami waveforms and runup heights for comparison with the records. NEOWAVE can describe tsunamis generation from time-varying seafloor deformation, local dispersion on steep continental slopes, and bore formation near the shore to accurately model near-field tsunamis. The modeled tsunami from the initial iterative finite-fault model has good overall agreement with the observations, but underestimates the initial arrival at a coastal buoy adjacent to the southwest portion of the rupture where the seismic signals do not constrain the rupture model well, and significantly underfit the runup along the Sanriku coast. Direct adjustment of the fault-slip distribution through an extensive forward modeling procedure improves the fit of the tsunami and geodetic observations that are not well explained by the initial tsunami-constrained seismic wave inversion. The forward modeling at $5-\mathrm{m}$ resolution is able to reproduce the recorded runup heights of close to $40 \mathrm{~m}$ on the rugged Sanriku coasts. The finitefault model that fits all of the tsunami observations (fig. 1) is then used to formulate a final subfault moment and rake-constrained inversion of the global seismic records (fig. $2 B$ ), recognizing that attributes of the slip distribution required by the tsunami data may be poorly resolved by the seismic data. The good agreement between the synthetics and recorded seismic waves found for this final iteration provides validation of the source model, allowing us to satisfactorily account for the seismic, geodetic, and tsunami observations without needing to invoke any additional exotic source.

The fault model found by this approach gives large shallow, near-trench slip relative to the initial tsunami-constrained solutions (fig. $2 A$ ) in the region from $38.5^{\circ} \mathrm{N}$ to $39.7^{\circ} \mathrm{N}$, where the 1896 rupture is thought to have occurred. Peak slip of $\sim 25-30$ m near the trench is inferred, accounting for the huge run-up along the Sanriku coast. At face value, this modeling indicates that the 2011 rupture extended significantly northward with large slip near the trench in addition to having large slip near the trench up-dip of the hypocenter. The large slip indicates that the potential for another 1896-style tsunami earthquake is now reduced and further emphasizes the compound nature of the 2011 Tohoku earthquake as a combined rupture of Domain B (main megathrust region) and Domain A (tsunami earthquake region). While one cannot uniquely demonstrate that this model is the only way to satisfactorily reconcile all of the seismic, geodetic, and tsunami observations, it does demonstrate that there is no requirement that an exotic source not sensed by some of the geophysical measurements has to be invoked. 

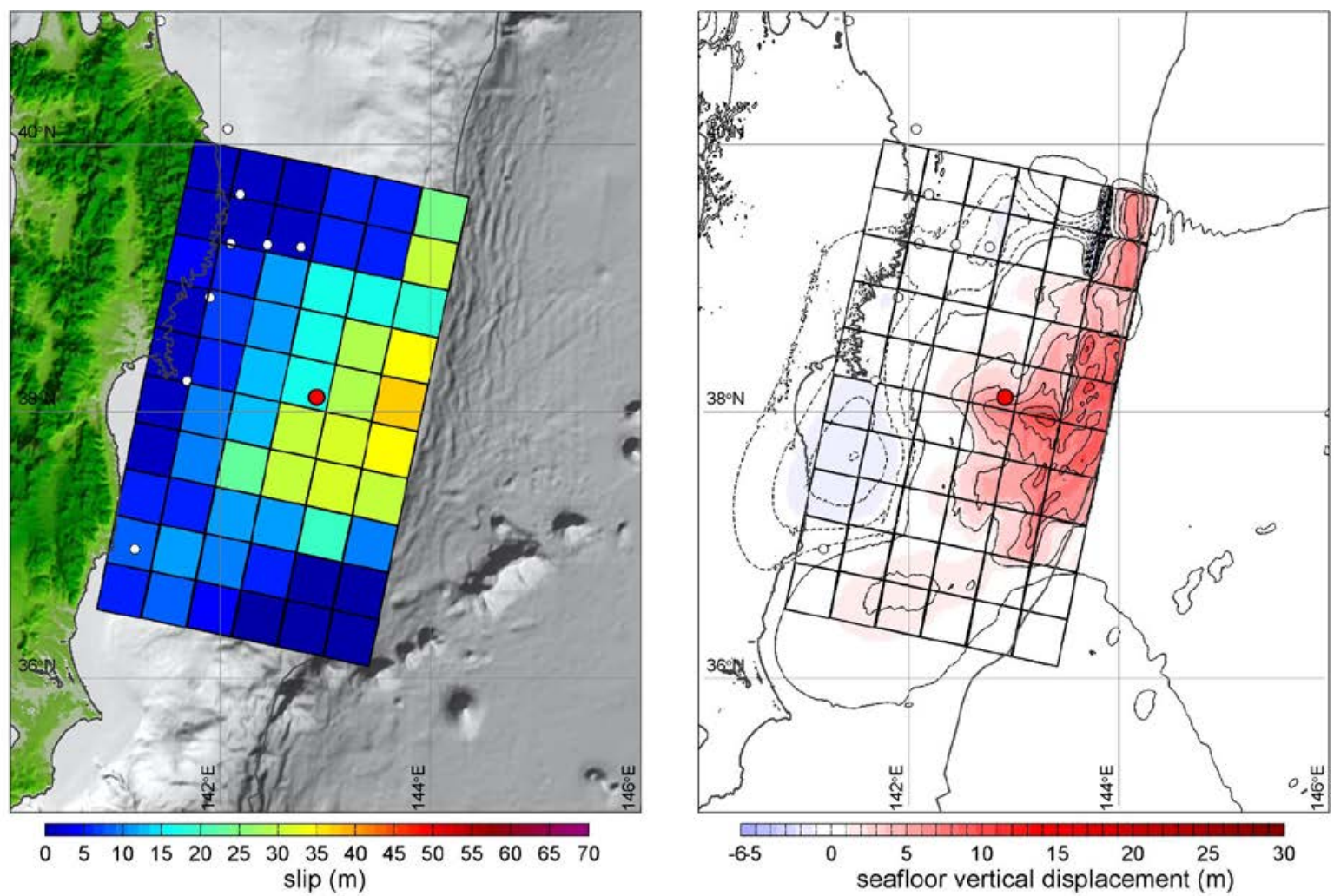

Figure 1. Slip model inferred from forward modeling of near-field tsunami recordings and run-up measurements along with on-shore and off-shore geodetic observations (left) with seafloor vertical displacement produced by combined vertical and horizontal motion of the seafloor (right). Note the neartrench large-slip patch north of $39^{\circ} \mathrm{N}$. This is within the estimated 1896 tsunami earthquake rupture zone. 

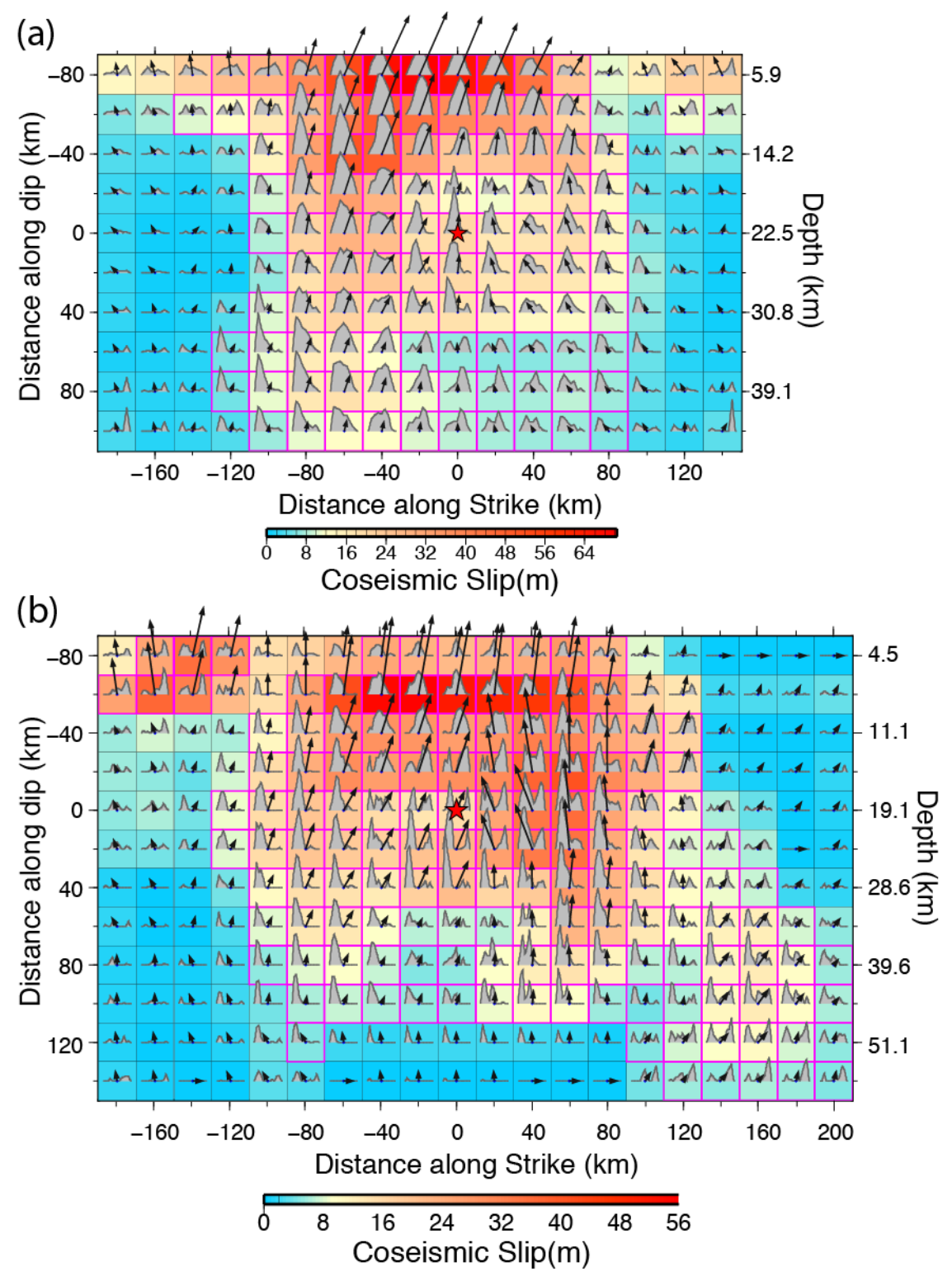

Figure 2. (A) Initial co-seismic slip model from iterative tsunami-constrained seismic inversion for the 2011 Tohoku rupture used as the starting model for detailed forward modeling of run-up and geodetic observations that resulting in the model in figure 1 . The slip in each subfault is indicated by the color pallet and by the length of the vector showing the direction of rake of each subfault. The subfault source time functions are shown within each subfault, with total durations of $32 \mathrm{~s}$. (B) Final slip model from inversion of seismic waves with $2 \times 2$ subfault groups having total moment and rake from the tsunami-constrained model in figure 1 . This model fits the seismic data to within 1 percent of the unconstrained model in $(A)$, and produces almost identical fits to the tsunami data as the coarser model in figure 1. Note the large increase in slip at shallow depth on the left side (NNE end) of the fault model. This is the region of the 1896 tsunami earthquake. The increase in deeper slip $50 \mathrm{~km}$ along strike improves fits to tsunami observations south of the hypocenter relative to the model in $(A)$. Subfault source time function durations are $48 \mathrm{~s}$. 


\title{
Modeling Deformation Processes of the Island Arc Crust and Mantle During the Interseismic and Postseismic Periods of the Tohoku-oki Earthquake
}

\author{
By Bunichiro Shibazaki, ${ }^{1}$ Takumi Matsumoto, ${ }^{2}$ Satoshi Miura, ${ }^{3}$ Jun Muto, ${ }^{3}$ Takeshi linuma, ${ }^{4}$ and Takuya \\ Nishimura ${ }^{5}$
}

We developed a heterogeneous rheological structure model and modeled the deformation field due to the generation of the Tohoku-oki earthquake over the entire island arc. We calculated the effective viscosity of the Japanese island arc crust and upper mantle, considering the thermal structure obtained by dense geothermal observations from Hi-net boreholes (Matsumoto, 2007) and by Tanaka and others, (2004). We reproduced several elongated low-viscosity regions, striking transverse to the arc, in the crust and upper mantle of the northeastern Japan arc, which correspond to hot fingers. Then, we investigated the viscoelastic deformation processes of the Japan island arc during the postseismic period of the Tohoku-oki earthquake considering the heterogeneous rheological structure of the island arc crust and mantle. Miura and others, (2014) found a postseismic strain anomaly (decreases in areal strain) along the volcanic front after the 2011 Tohoku-oki earthquake. We examined several cases with different coseismic slip distributions to find a solution that could reproduce the postseismic strain anomaly along the volcanic front. In our numerical results, significant extensional viscous deformation occurs in the low-viscosity regions in the crust and upper mantle. Extensional strain occurs along the EW direction, but the amount of the EW strain is small along the volcanic front. Contraction strain occurs along the NS direction. As a result, decreases in areal strain that are consistent with the observed ones occur along the volcanic front.

We also investigated the viscoelastic deformation processes of the Japan island arc during the interseismic period of the Tohoku-oki earthquake. Vertical deformation data for a 100-year period indicates uplift in the backarc region but subsidence in the forearc region (Nishimura, 2012). To explain the uplift from the volcanic front to the backarc and the subsidence in the forearc, we needed to consider back-slips at the deeper subduction plate interface. Compared with the model with only elastic structures, a smaller amount of deep back-slip is necessary for the model with heterogeneous viscoelastic structure to reproduce the observed uplift. Our model, which considers the heterogeneous rheological structure of the island arc, may explain both the observed postseismic and interseismic deformation of the island arc better than the model with a uniform rheological structure of the island arc.

\footnotetext{
1International Institute of Seismology and Earthquake Engineering, Building Research Institute. ${ }^{2}$ National Research Institute for Earth Science and Disaster Resilience.

${ }^{3}$ Tohoku University.

4Japan Agency for Marine-Earth Science and Technology.

5yoto University.
} 


\section{References Cited}

Matsumoto, T. (2007), Terrestrial heat flow distribution in Japan area based on the temperature logging in the borehole of NIED Hi-net, Am. Geophys. Union, Fall Meeting 2007, abstract T23A1217.

Miura, S., Y. Ohta, T. Iinuma, T. Demachi, K. Tachibana, T. Sato, and M. Ohzono (2014), Postseismic strain anomaly along volcanic front after the 2011 Tohoku Earthquake, Programme and abstracts the Volcanological Society of Japan 2014, B1-05 (in Japanese).

Nishimura T. (2014), Pre-, co-, and post-seismic deformation of the 2011 Tohoku-Oki earthquake and its implication to a paradox in short-term and long-term deformation, J Disaster Res, 9, 294-302

Tanaka, A., M. Yamano, Y. Yano, and M. Sasada (2004), Geothermal gradient and heat flow data in and around Japan, Digital Geoscience Map DGM P5, Geological Survey of Japan. 


\section{Using Tsunami Deposits to Interpret Tsunami Wave and Seafloor Rupture Characteristics: Lessons from Japan Applied to the Aleutians}

By Guy Gelfenbaum, ${ }^{1}$ SeanPaul La Selle, ${ }^{1}$ Daisuke Sugawara, ${ }^{2}$ Rob Witter, ${ }^{1}$ Bruce Jaffe, ${ }^{1}$

A challenge in assessing tsunami hazard from sandy coastal deposits is inferring the relative magnitude of past tsunamis from characteristics of the deposits. Empirical data from a laboratory flume experiment and field data from the 2011 Tohoku-oki earthquake and tsunami reveal a high correlation between the volume of onshore sandy tsunami deposits, tsunami magnitude, and seafloor deformation. We use a Delft3D hydrodynamic and sediment transport model to test how well we can replicate the relationships between onshore tsunami deposit volume and offshore slip from the 2011 Tohoku-oki earthquake and tsunami. An initial waterlevel condition was obtained from a published tsunami source model based on waveform inversion method (Satake and others, 2013) and was used to derive the hydrodynamic boundary conditions for the sediment transport simulations. The model uses sediment transport formulations and coefficients from van Rijn (2007) and a two-dimensional vertical grid in order to include the affect of suspended-sediment induced density stratification on the vertical turbulent mixing. This test explores how variation in offshore slip affects tsunami deposit volume for a wide range of sediment sources, offshore and onshore slopes, and boundary roughness conditions. Model results show a strong correlation between onshore tsunami deposit volume and adjacent offshore coseismic slip, so long as ample sediment is available in the model to be eroded and transported (fig. 1). These results are consistent with data from the 2011 Tohoku tsunami at sites with sufficiently wide beaches and without shoreline armoring.

\footnotetext{
${ }^{1}$ U.S. Geological Survey.

2Museum of Natural and Environmental History, Shizuoka, Japan.
} 


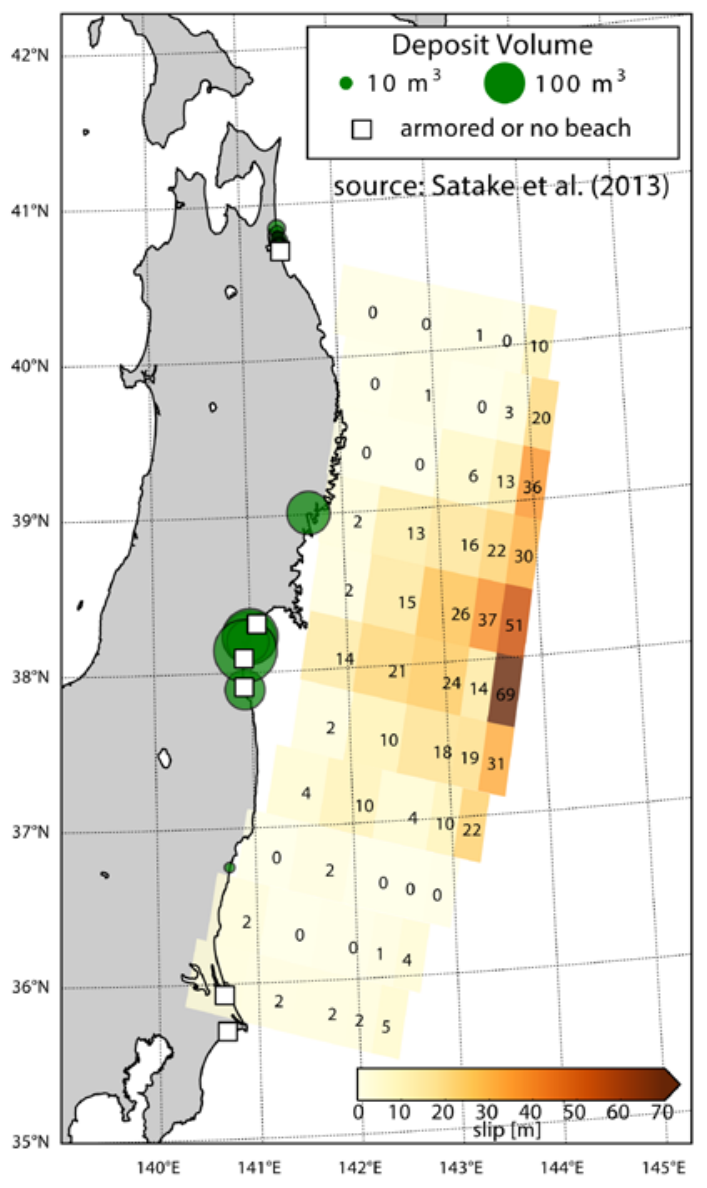

Figure 1. Map showing tsunami deposit volume and offshore slip. Slip from Satake and others, (2013).

We are applying the model to newly discovered tsunami deposits in the Aleutian Islands. Field studies in the eastern Alaska-Aleutian subduction zone have identified sequences of tsunami deposits from the 1957 Andreanof Islands earthquake $\left(M_{\mathrm{w}} 8.6\right)$ and at least five other pre-historic tsunami events from the last $\sim 2,000$ years (Witter and others, 2015). At Stardust Bay on the Pacific Coast of Sedanka Island, a sand-rich deposit attributed to the 1957 tsunami is 1-13 centimeters $(\mathrm{cm})$ thick and is found at elevations up to 18.5 meters above mean sea level. Older sand units are 6-50 cm thick and sometimes have rounded gravel at the base of multiple, normally graded sand beds (fig. 2). At Driftwood Bay on the south side of Umnak Island, about 200 kilometers to the southeast of Stardust Bay, the 1957 deposit is 1-5.5 cm thick, underlain by a sequence of peat with up to 8 sandy deposits, some of which exhibit normally graded beds up to $14 \mathrm{~cm}$ thick. 


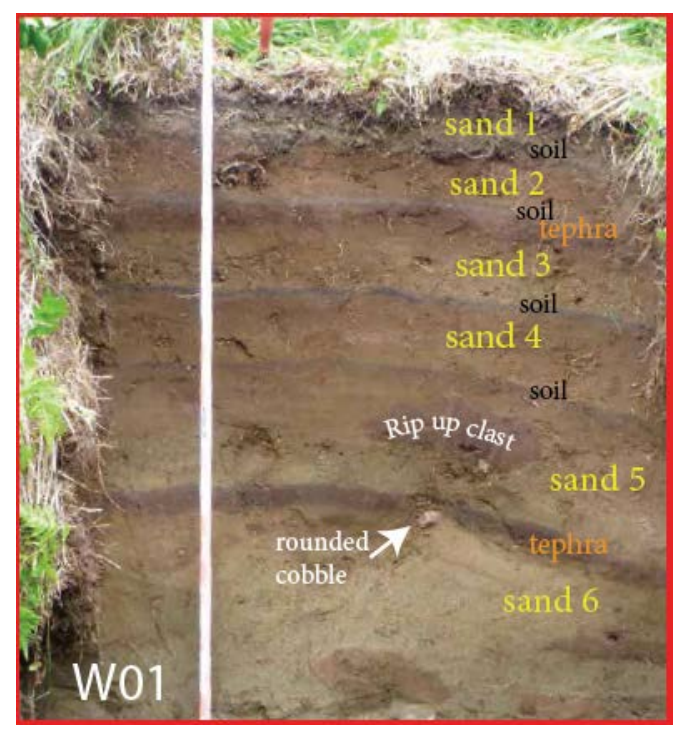

Figure 2. Photo from Stardust Bay on Sedanka Island shows a sequence of thin soils interbedded with thicker sand layers and tephra. Some sandy units (5 and 6) contain rounded cobbles and rip-up clasts of soil.

We will continue to test the model to evaluate sensitivity to parameters that may not be well known for paleotsunamis such as width of fault rupture and roughness of inundated terrain.

\section{References Cited}

Satake K., Fujii, Y., Harada, T., and Namegaya, Y., 2013, Time and space distribution of coseismic slip of the 2011 Tohoku Earthquake as inferred from tsunami waveform data: Bulletin of the Seismological Society of America, v. 103, no. 2B, p. 1473-1492.

van Rijn, L.C., Walstra, D.J.R., and van Ormondt, M., 2007, Unified view of sediment transport by currents and waves. IV-Application of morphodynamic model: Journal of Hydraulic Engineering, v. 133, no. 7, p. 776-793.

Witter, R.C., Engelhart, S.E., Nelson, A.R., Milker, Y., Hawkes, A.D., Gao, D., Horton, B., and Wang, K., 2015, Megathrust slip varied during past Cascadia subduction zone earthquakes at Siletz Bay, central Oregon: American Geophysical Union Fall Meeting, December, 2015. 


\title{
Evaluation of Variety in Earthquake Rupture Along the Nankai Trough Deduced from Paleoseismological Data
}

\author{
By Masanobu Shishikura ${ }^{1}$
}

Coastal paleoseismological data is very important to evaluate long-term occurrence potentials of infrequent giant earthquakes such as the 2011 Tohoku earthquake. Especially the information of tsunami inundation history based on the tsunami deposit survey is useful to mitigate tsunami risk. Therefore a plenty of paleoseismological data has been collected from the coastal area along the Nankai Trough. However some issues on studying paleoearthquakes of the Nankai Trough appear recently, which are summarized as various rupture and maximum class earthquake.

Regarding the various rupture, the Headquarters of Earthquake Research Promotion (HERP) of the Japanese government recently reevaluated long-term occurrence potentials of subduction-zone earthquakes along the Nankai Trough (HERP, 2013). The former evaluation was that the Nankai Trough could be simply divided into three earthquake segments as Nankai, Tonankai and Tokai based on the rupture areas of the historical earthquakes (HERP, 2001). Recent interpretation of paleoseismological data for the events of 1707 Hoei, 1854 Ansei series and 1944/1946 Showa series suggest that the rupture extent was partially overlapped but different and complementary each other (Seno, 2012). Compiling the ages of tsunami deposit in each coastal area, Shishikura (2013) pointed out that geologically preserved records indicate longer recurrence of 400-500 years, and those timings are different between Nankai and Tokai. This imply that the large slip area also has been various at each event.

The Japanese government's cabinet office (2012) has assumed the maximum class model of potential earthquake along the Nankai Trough, which are based on a series of theoretical hypotheses without any evidence that such megaquakes and tsunamis had actually occurred in the past and failing to take paleoseismological information into consideration. Therefore paleoseismologists must confirm the existence of such megaquakes and tsunamis in the past. Tanigawa and others, (2015) evaluated the past maximum tsunami inundation in the Tochi lowland, Kochi Prefecture, from 5000 years geological record. Whole of this lowland would be inundated for the assumption of the maximum class, but the inundation area based on tsunami deposit is smaller and limited to coastal side. This kind of survey should be conducted at multiple locations along the trough to evaluate the lateral rupture extent initiated by the occurrence of a maximum class event.

\section{References Cited}

HERP (2001, 2013) http://www.jishin.go.jp/evaluation/long_term_evaluation/subduction_fault/; Cabinet Office (2012) http://www.bousai.go.jp/jishin/nankai/nankaitrough_info.html; Seno (2012) zishin, 64, 97-116; Shishikura (2013) GSJ Geological News, 2, 201-204, Tanigawa and others, (2015) JpGU2015 abstract, MIS25-P06.

\footnotetext{
${ }^{1}$ Geological Survey of Japan/AIST.
} 


\section{Smooth Megathrusts Are More Prone to Mega-earthquakes}

By Quentin Bletery, ${ }^{1}$ Amanda M. Thomas, ${ }^{1}$ Alan W. Rempel, ${ }^{1}$ Leif Karlstrom,,${ }^{1}$ Anthony Sladen, ${ }^{2}$ and Louis De Barros $^{2}$

Today, forecasts of potential large earthquakes focus mainly on imaging the slip deficit with respect to the relative plate motion, as such deficits are thought to result in stress loading that is ultimately released in earthquakes. We follow a complementary approach by analyzing large-scale geometrical features of subduction faults and assessing their possible influence on the physical conditions favoring large earthquake ruptures. Seismic moment M0 $\alpha \Delta \sigma S^{3 / 2}$ (1) depends mainly on the surface area $S$ over which an earthquake ruptures, as stress drop $\Delta \sigma$ is roughly constant among earthquakes over a large range of magnitudes (2). Here, we demonstrate that slab interface curvature exerts a leading-order control on the spatial extent of potential ruptures in subduction zones and hence on the magnitude of the largest earthquakes.

Data sets from active source and passive seismology have been combined to constrain the slab1.0 model for the geometry of the major worldwide subduction zones (3). We computed maps of the along-dip interface curvature $K_{s}=d \theta / d s-$ hereafter referred to as curvature - (where $\theta$ is the dip angle and $\mathrm{s}$ is the tangent to the interface pointing in the down-dip direction) using the slab1.0 models of global subduction zone geometries (3) (fig. 1). Comparison with a catalog of historical events reveals a tendency for mega-earthquakes to occur on relatively flat (low-K $\mathrm{K}_{\mathrm{s}}$ megathrusts (fig. 1). The curvature is particularly small in the Japan - Kuriles - Kamchatka, Alaska - Aleutians, Sumatra - Java, South America and Cascadia subduction zones, which are known to produce $M_{-} 9.0$ earthquakes. Subduction zones with large curvature, such as the Philippines, Solomon islands, Izu - Bonin, Santa Cruz - Vanuatu - Loyalty and Tonga - Kermadec lack historic mega-earthquakes. At a smaller scale, we also observe that the down-dip limit of megaearthquakes offshore Sumatra-and to a lesser extent, in the Aleutians, Alaska, Nankai and Kamchatka-coincides with an abrupt change in the slope, suggesting that the conditions required to generate large earthquakes are directly related to the local curvature along the megathrust interface. To further explore the role of subduction geometry, we calculated the average curvature $\mathrm{K}_{\mathrm{s}}$ from the trench to $60 \mathrm{~km}$ depth, and compared these values with the magnitude of the largest megathrust earthquake $\mathrm{M}_{\max }$ recorded in each subduction zone. We found that $\mathrm{M}_{\max }$ anti-correlates strongly $(\mathrm{r}=-0.80)$ with $\mathrm{K}_{\mathrm{s}}$. We suggest, based on our observations, that planar slab interfaces are prone to hosting larger earthquakes.

We considered a simple 2D fault model: a fault interface subjected to the pressure of the upper plate mass and an unknown horizontal tectonic stress. Within this framework, the shear strength - defined as the critical shear stress required to slip at a given location — can be expressed as a function of the crustal density $\rho$, the friction $\mu$, the depth $h$, the dip angle $\theta$ and the angle $\psi$ between the maximum principal component of stress and the horizontal:

$$
\frac{g h \mu\left(\rho-\rho_{w}\right)(\sin 2 \theta+\tan 2 \psi \cos 2 \theta)}{\sin 2 \theta-\mu(1-\cos 2 \theta)+\tan 2 \psi(\cos 2 \theta-\mu \sin 2 \theta)},
$$

${ }^{1}$ Department of Earth Sciences, University of Oregon.

2Universit'e C^ote d'Azur, CNRS, OCA, IRD, G'eoazur. 
As the magnitude of earthquakes is primary controlled by the area of rupture, homogeneous distributions of shear strength over large fault areas may favor the occurrence of mega-earthquakes. In this framework, the shear strength gradient $\mathrm{dT}^{\mathrm{c}} / \mathrm{ds}$ is a critical parameter. Treating $\mu, \rho, \rho w$ and $g$ as constants, spatial variations of $\mathrm{r}^{\mathrm{c}}$ obtained by differentiation of equation (1) satisfy:

$$
\mathrm{dT} c / \mathrm{ds}=g \mu\left(\rho-\rho_{\mathrm{w}}\right) A_{\mu}(\theta, \psi) \sin \theta+B_{\mu}(\theta, \psi) h K_{\mathrm{s}}+C_{\mu}(\theta, \psi) h d \psi / d s
$$

where $\rho>\rho_{\mathrm{w}}$ and the functions $A_{\mu}(\theta, \psi), B_{\mu}(\theta, \psi)$ and $C_{\mu}(\theta, \psi)$ are positive for $\mu=0.6$ and values of $\theta$ and $\psi$ typically encountered in subduction zones (4). Therefore, $|\mathrm{dTc} / \mathrm{ds}|$ increases with $\mathrm{K}_{\mathrm{s}}$. Shear-strength heterogeneity increases with curvature: the flatter the megathrust interface (lower $\mathrm{K}_{\mathrm{s}}$ ), the more homogeneous the shear-strength distribution. Stress accumulation along faults is complex and heterogeneities in driving stress can result from the effect of stress concentrations inherited from past events or changes in coupling associated with variations in the friction coefficient or pore fluid pressure. However, dynamic stress perturbations induced by earthquake propagation are more likely to overstep the resistance to failure over broad areas if shear strength is homogeneously distributed along a large fault surface. In contrast, barriers to earthquake propagation are more likely for heterogeneous shearstrength distributions, as the dynamic stress perturbations required to reach local values of shear strength will tend to be larger in some regions. Therefore, smooth megathrusts and the absence of geometrical asperities along them may counter-intuitively be a source of higher hazard.

\section{References Cited}

Madariaga, R. (1979), On the relation between seismic moment and stress drop in the presence of stress and strength heterogeneity, J. Geophys. Res., 84(B5), 2243-2250, doi:10.1029/JB084iB05p02243.

Kanamori, H., and D. L. Anderson (1975), Amplitude of the Earth's free oscillations and longperiod characteristics of the earthquake source, J. Geophys. Res., 80(8), 1075-1078Hayes, G. P., D. J. Wald, and R. L. Johnson (2012), Slab1.0: A three-dimensional model of global subduction zone geometries, J. Geophys. Res., 117, B01302, doi:10.1029/2011JB008524.

Hardebeck, J. L., (2015). "Stress orientations in subduction zones and the strength of subduction megathrust faults," Science 349, Issue 6253, pp. 1213-1216 DOI: 10.1126/science.aac5625 


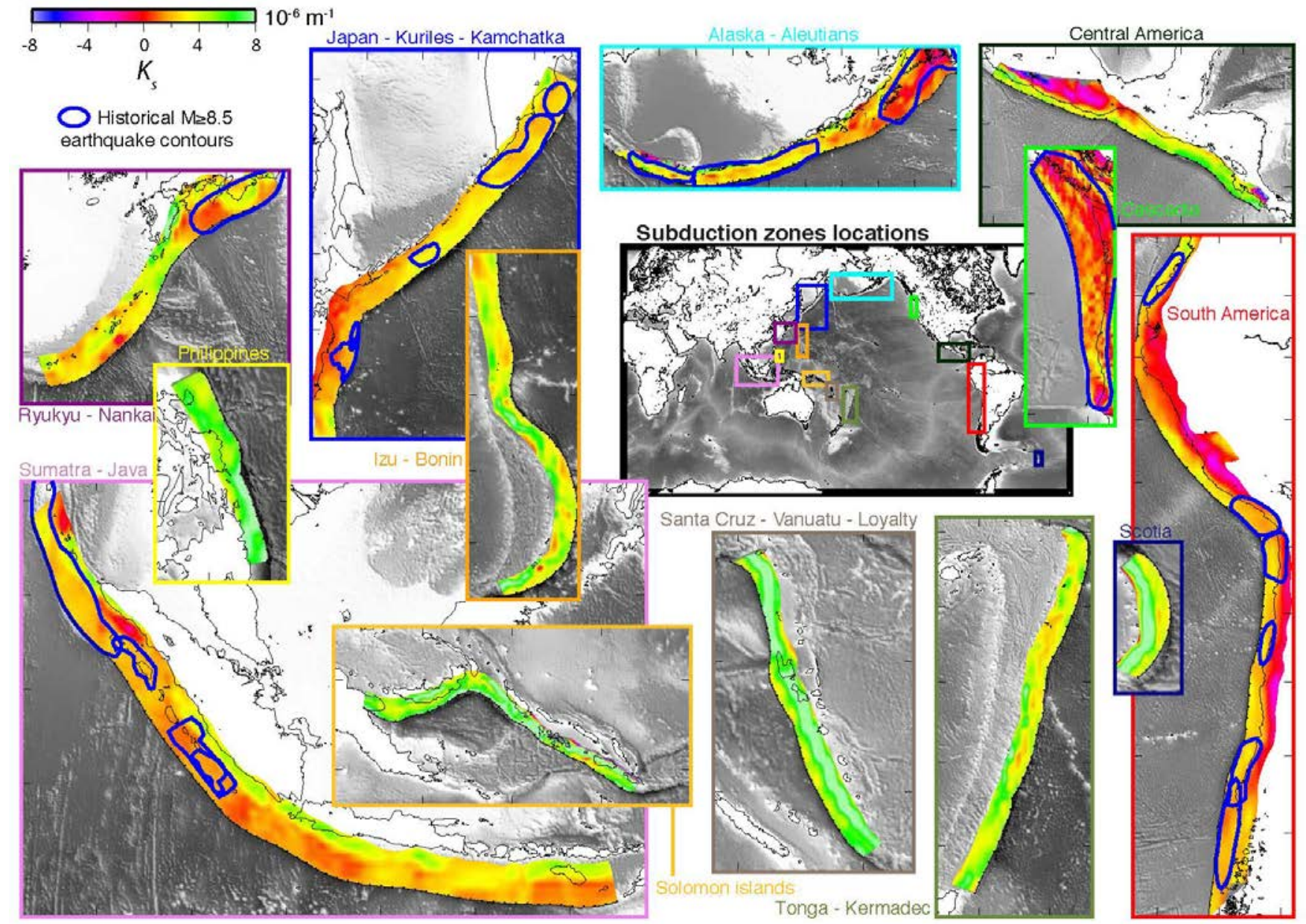

Figure 1. Variations of curvature and distribution of historical mega-earthquakes. Along-dip curvature $\mathrm{K}_{\mathrm{s}}=$ $\mathrm{d} \theta / \mathrm{ds}$ on the megathrust of the 13 main subduction zones of the world compared to the estimated slip contours of the known historical mega-earthquakes $(M \geq 8.5)$. Tick marks in sub-figures are spaced at $5^{\circ}$ increments. 


\title{
Modeling Researches Toward Earthquake Disaster Mitigation by using Japanese High Performance Computing Systems
}

\author{
By Keisuke Ariyoshi, ${ }^{1}$ Ryoko Nakata, ${ }^{1}$ Hyodo Mamoru, ${ }^{1}$ and Takane Hori ${ }^{1}$
}

Introduction

Due to the development of high performance computing (HPC) such as Earth simulator (at JAMSTEC in Yokohama) and K-computer (at RIKEN in Kobe), earthquake cycle simulations based on the rate- and state- friction laws have been performed by many seismological researches. In JAMSTEC, we have focused on modeling interplate earthquakes on the subduction plate boundaries around Japan in order to estimate the plate motion, crustal deformation and occurrence of the next earthquakes.

Modeling of repeating earthquake off Kamaishi

After the 2011 Tohoku earthquake, we modeled two large and small earthquakes off Tohoku region. One is repeating earthquake off Kamaishi, which is suitable to understand temporal earthquake aperiodicity perturbed by the great postseismic slip because of short spatiotemporal scale about $M \sim 4$ and 5 years recurrence interval. If the repeater is composed of single asperity, our results show that, (1) a mixture of partial and whole rupturing of a single asperity can explain some of the observed variability in timing and size of the repeating earthquakes off Kamaishi; (2) the partial rupturing can be reproduced with moderate frictional instability with the aging-law and not the slip or Nagata laws; (3) the perturbation of the activated earthquake hypocenters observed mostly in the ESE-WNW direction may reflect the fact that the large postseismic slip of the 2011 Tohoku earthquake propagated from ESE to WNW off Kamaishi; (4) the observed region of repeating earthquake quiescence may reflect the strong plate coupling of megathrust earthquakes.

1Japan Agency for Marine-Earth Science and Technology (JAMSTEC). 


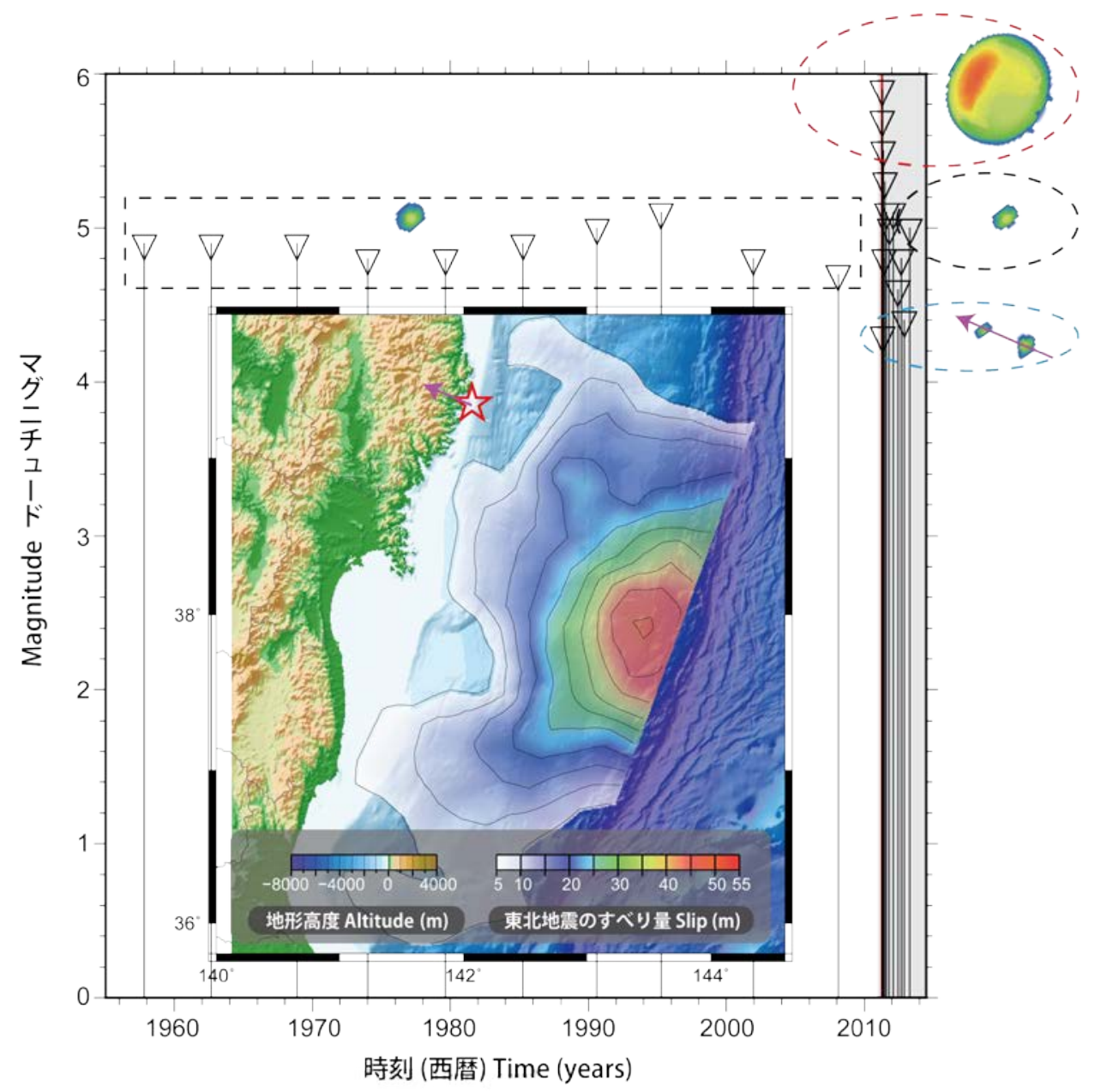

Figure 1. Map view and time history of repeating earthquakes off Kamaishi. Small color regions outside the map show slip velocity field in the small asperity with propagation direction (WNW) indicated by arrows.

Modeling of Miyagi-ken-Oki earthquake

Applying those results of the repeating earthquake off Kamaishi to larger interplate earthquakes, we show possible scenarios for the occurrence of $M \sim 7$ interplate earthquakes prior to and following the $M \sim 9$ earthquake along the Japan Trench, such as the 2011 Tohoku-Oki earthquake. We conducted numerical simulations of earthquake generation cycles by using realistic three-dimensional (3D) geometry of the subducting Pacific Plate. We obtained a number of scenarios, which successfully reproduced important characteristics such as the recurrence of $M \sim 7$ Miyagi-ken-oki earthquakes, coseismic slip distribution and afterslip distribution of the 2011 earthquake. In these scenarios, the time interval between the $M \sim 9$ earthquake and the subsequent $M \sim 7$ Miyagi-ken-Oki earthquake was equal to or shorter than the average recurrence interval during the later stage of the $M \sim 9$ earthquake cycle. Thus, these results suggest that we should prepare for future $M \sim 7$ earthquakes in the Miyagi-ken-Oki segment even though this segment recently experienced large coseismic slip in 2011. 

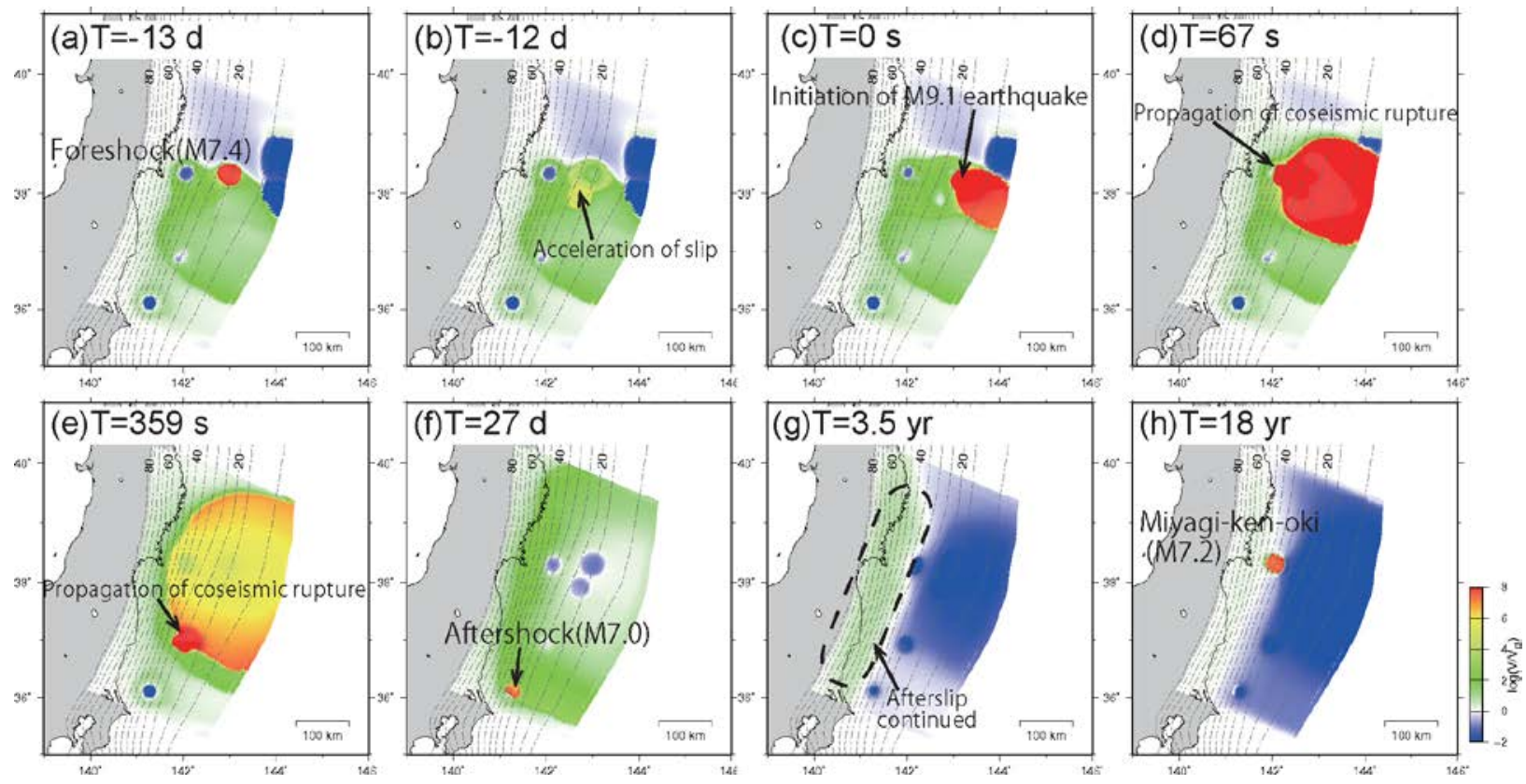

Figure 2. Simulated slip velocity distribution normalized to the plate convergence rate prior to and following the M 9 earthquake along the Japan Trench.

\section{Modeling of megathrust earthquakes along Nankai Trough}

Several recent large-scale earthquakes including the 2011 Tohoku earthquake $\left(M_{\mathrm{w}} 9.0\right)$ in northeastern Japan and the 2014 Iquique earthquake $\left(M_{\mathrm{w}} 8.1\right)$ in northern Chile were associated with foreshock activities $\left(M_{\mathrm{w}}>6\right)$. The detailed mechanisms between these large earthquakes and the preceding smaller earthquakes are still unknown; however, to plan for disaster mitigation against the anticipated great Nankai Trough earthquakes, in this study, possible scenarios after $M_{\mathrm{w}}$ 7-class earthquakes that frequently occur near the focal region of the Nankai Trough are examined through quasi-dynamic modeling of seismic cycles. By assuming that simulated Nankai Trough earthquakes recur as two alternative earthquakes with variations in magnitudes $\left(M_{\mathrm{w}} 8.7-\right.$ 8.4) and recurrence intervals (178-143 years), we systematically examine the effect of the occurrence timing of the $M_{\mathrm{w}} 7$ Hyuga-nada earthquake on the western extension of the source region of Nankai Trough earthquakes on the assumed Nankai Trough seismic cycles. We find that in the latter half of a seismic cycle preceding a large Nankai Trough earthquake, an immature Nankai earthquake tends to be triggered within several years after the occurrence of a Hyuganada earthquake, then Tokai (Tonankai) earthquakes occur with maximum time lags of several years. The combined magnitudes of the triggered Nankai and subsequent Tokai (Tonankai) earthquakes become gradually larger with later occurrence of the Hyuga-nada earthquake, while the rupture timings between the Nankai and Tokai (Tonankai) earthquakes become smaller. The triggered occurrence of an immature Nankai Trough earthquake could delay the expected larger Nankai Trough earthquake to the next seismic cycle. Our results indicate that triggering can explain the variety and complexity of historical Nankai Trough earthquakes. Moreover, for the next anticipated event, countermeasures should include the possibility of a triggered occurrence of a Nankai Trough earthquake by an $M_{\mathrm{w}} 7$ Hyuga-nada earthquake. 


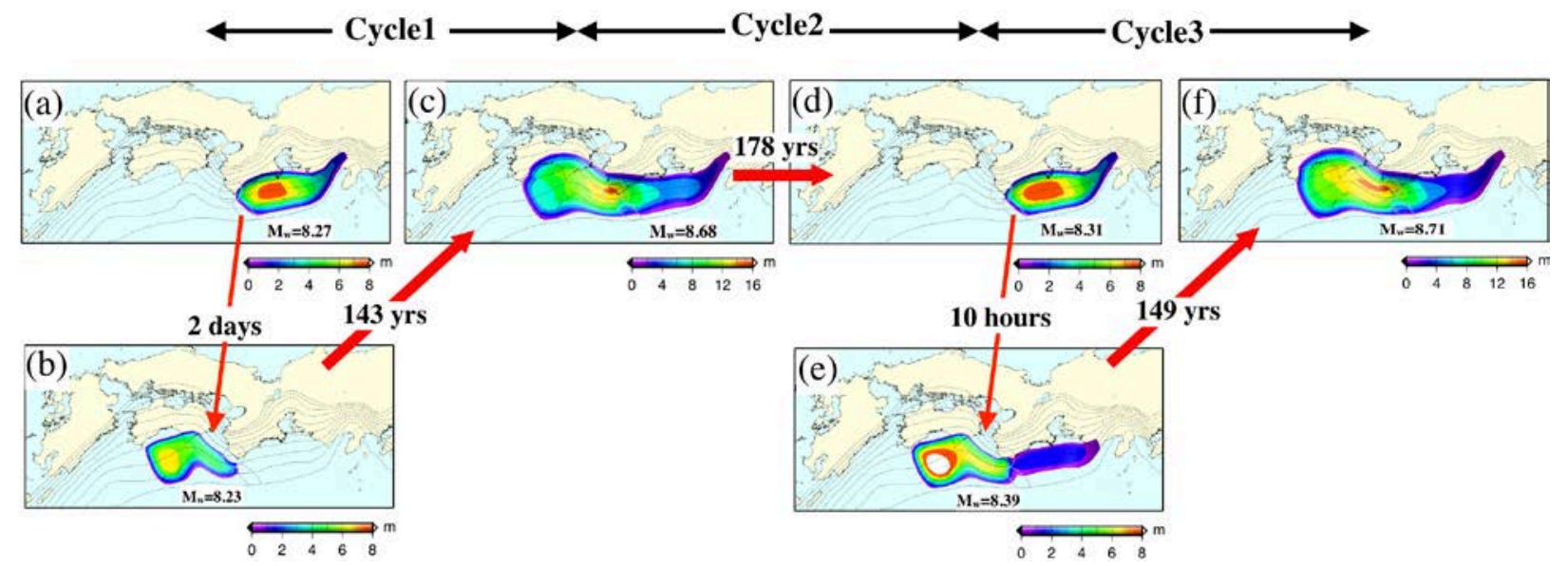

Figure 3. An example of earthquake cycles along Nankai Trough with coseismic slip distributions. Large and small Nankai Trough earthquakes occur alternately, and the interval of the seismic cycle preceding the larger Nankai Trough earthquake is shorter than that preceding the smaller earthquake. In small earthquakes at the beginning of the first cycle (i.e., $(A)$ and $(B)$ ) and the end of the second cycle (i.e., $(D)$ and $(E)$ ), the eastern and western segments of the Nankai Trough rupture separately with time lags of about 2 days and 10 hours, respectively. In contrast, large earthquakes in $(C)$ and $(F)$ break the entire region from western Shikoku to the Tokai region almost simultaneously.

\section{References Cited}

Ariyoshi, K., N. Uchida, T. Matsuzawa, R. Hino, A. Hasegawa, T. Hori, and Y. Kaneda (2015), A trial estimation of frictional properties, focusing on aperiodicity off Kamaishi just after the 2011 Tohoku earthquake, Geophys. Res. Lett., 41, 8325-8334, doi:10.1002/2014GL061872. Nakata, R., T. Hori, M. Hyodo, and K. Ariyoshi (2016), Possible scenarios for occurrence of $M \sim 7$ interplate earthquakes prior to and following the 2011 Tohoku-Oki earthquake based on numerical simulation, Scientific Reports, 6, 25704, doi:10.1038/srep25704 Hyodo, M., T. Hori, and Y. Kaneda (2016), A possible scenario for earlier occurrence of the next Nankai earthquake due to triggering by an earthquake at Hyuga-nada, off southwest Japan, Earth Planets and Space, 68(6), doi:10.1186/s40623-016-0384-6. 


\title{
Real-time Seismic and Geodetic Monitoring and Seafloor Observations
}

\section{Transient Deformation and Stress From Enduring Postseismic Deformation of the 2011 Tohoku-Oki Earthquake}

By Roland Bürgmann, ${ }^{1}$ Yan $\mathrm{Hu}^{2}{ }^{2}$ and Naoko Uchida ${ }^{3}$

\begin{abstract}
Great megathrust earthquakes produce far-reaching and enduring postseismic deformation transients that affect crustal stress, seismicity and earthquake hazard for many decades. Here we draw on insights gained from modeling postseismic deformation of several recent global subduction zone earthquakes to consider the effects of three dimensional (3D) rheology structure and contributions from multiple relaxation mechanisms on the predicted evolution of deformation and stress in the aftermath of the 2011 M9.0 Tohoku earthquake in Japan. We have developed a three-dimensional, spherical viscoelastic finite element model to study the postseismic deformation of the Tohoku earthquake that has been recorded at unprecedented resolution in space and time (Hu and others, 2014; Hu and others, 2016). We integrate geodetic observations and constraints on afterslip from small repeating earthquakes on the megathrust to better distinguish contributions from the different postseismic processes. We model stress-driven afterslip in a 2-km-thick weak shear zone away from historic rupture zones on the megathrust. We model both the viscoelastic relaxation of the upper mantle and shear-zone deformation with a transient Burgers body rheology. Viscoelastic relaxation of the mantle wedge alone causes postseismic uplift and seaward motion in the upper plate, opposite to the pattern from relaxation of just the oceanic upper mantle. Afterslip of the fault produces uplift up-dip of the afterslip zone and subsidence over its downdip edge, and mostly seaward motion above the afterslip zone. The optimal steady-state viscosities of the deep weak shear zone, continental mantle wedge and oceanic upper mantle are determined to be $5 \times 10^{17} \mathrm{~Pa} \mathrm{~s}, 3 \times 10^{19} \mathrm{~Pa}$ s, and $5 \times 10^{19} \mathrm{~Pa}$ s, respectively (Hu and others, 2016). The stress-driven afterslip in the shear zone is up to $\sim 3.5$ meters in the first two years after the earthquake, equivalent to a $M_{\mathrm{w}} 8.4$. Our model reproduces the first-order pattern of the land-based and seafloor GPS observations both in horizontal and in vertical directions.

We compute Coulomb stress changes on faults in Japan from both coseismic and transient postseismic deformation. Figure 1 shows predicted stress changes on intra-plate faults with the fault locations and geometry previously used in coseismic stress-change models by Toda and others, (2011). Stress on continental thrust faults in NE Japan were generally relaxed by the Tohoku earthquake, whereas substantial stress increases are predicted on the adjacent sections of the Japan subduction zone, normal faults of the outer rise, and a number of strike-slip faults in continental Japan. Seismicity rates across Japan have substantially changed since the Tohoku earthquake including enduring accelerations in the Kanto region. The enduring nature of these rate changes suggests that in addition to the initial static and dynamic stress changes due to the
\end{abstract}

\footnotetext{
${ }^{1}$ University of California, Berkeley.

${ }^{2}$ School of Earth and Space Sciences, University of Science and Technology of China.

${ }^{3}$ Tohoku University
} 
Tohoku rupture, postseismic deformation rate changes are affecting the seismicity across the region. We compare seismicity-rate changes with the time-dependent stressing rates from the postseismic relaxation model.

Using insights gained from our study of the postseismic deformation and stress evolution of the Tohoku earthquake, we develop models of the postseismic relaxation following great earthquakes in the Cascadia subduction zone. The average recurrence interval of great megathrust earthquakes is about 500 years and the last M9 event occurred in 1700 . There is evidence for events that ruptured the whole Cascadia margin and smaller events that represent partial ruptures of the megathrust (Goldfinger and others, 2008). We aim to better constrain the role of time-dependent deformation associated with megathrust earthquake cycles in the timing of earthquakes on various crustal fault zones in Washington, Oregon and the northern San Andreas fault system in California, as well as intermediate depth intra-slab events. For this purpose we draw on a new spherical finite element model that uses bi-viscous transient rheology and accounts for the 3D rheological structure in the plate boundary of the western US informed by seismic tomography, seismicity and geodetic constraints. Goldfinger and others, (2008) examined the relationship between the Holocene earthquake history along the San Andreas fault zone in northern California and the times of megathrust ruptures along the Cascadia margin. They found that thirteen of the fifteen San Andreas events occurred within about 50 years of Cascadia megathrust events. We will present new models illuminating the possible stress linkage of earthquakes along the San Andreas fault system and other continental fault zones in the Pacific Northwest to the earthquake cycle deformation of Cascadia using our 3D spherical FEM model.

(a) Coseismic

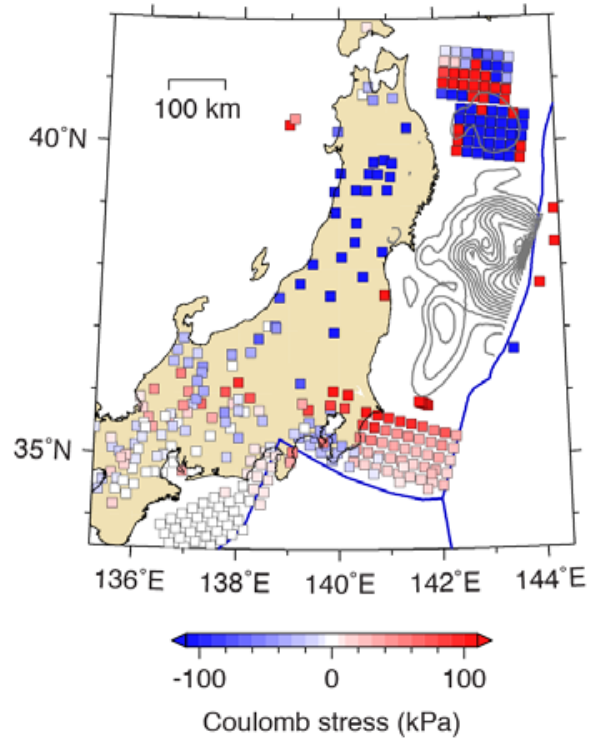

(b) Postseismic (5 yr)

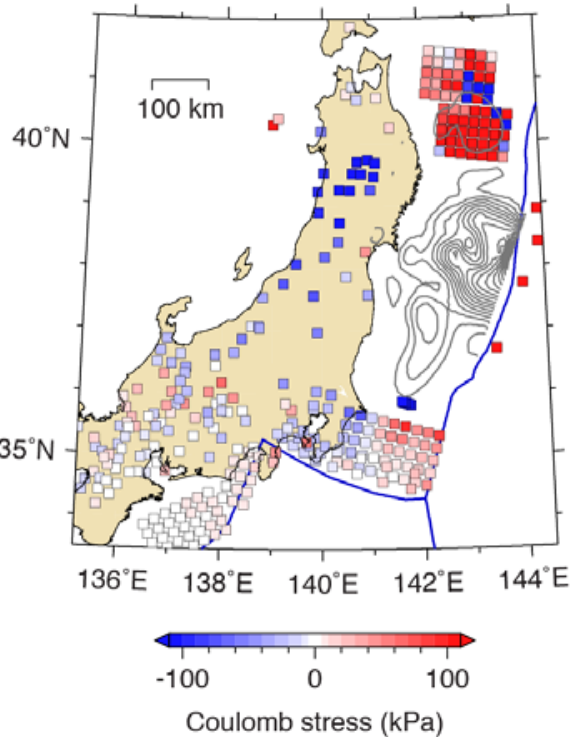

(c) Postseismic (50 yr)

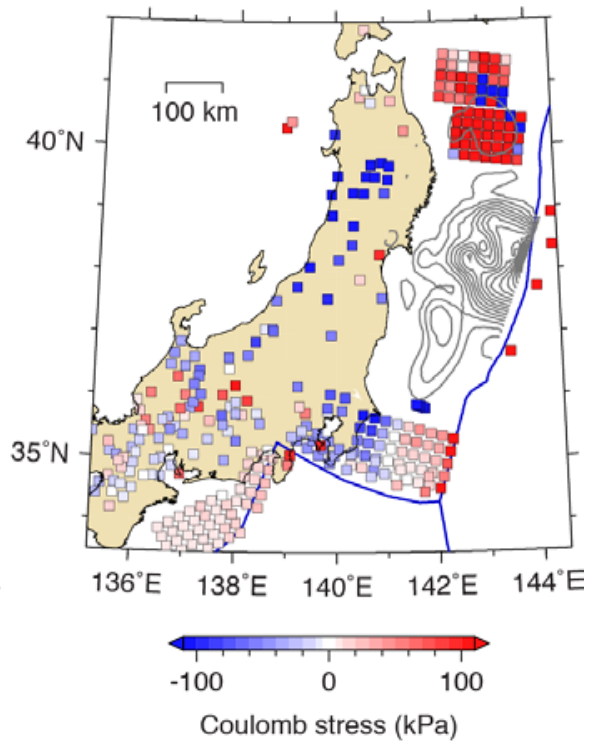

Figure 1. Coulomb stress changes $\left(\mu^{\prime}=0.4\right)$ on nearby faults from coseismic and postseismic deformation of the 2011 Tohoku earthquake. Fault geometry and slip vectors are from Toda and others, (2011), the deformation models are from Hu and others, (2016).

\section{References Cited}

Goldfinger, C., and others, (2008), Late Holocene rupture of the Northern San Andreas fault and possible stress linkage to the Cascadia subduction zone, Bull. Seis. Soc. Am., 98(2), 861-889, doi: doi:10.1785/0120060411. 
Hu, Y., R. Bürgmann, J.T. Freymueller, P. Banerjee, and K. Wang (2014), Contributions of poroelastic rebound and a weak volcanic arc to the postseismic deformation of the 2011 Tohoku earthquake, Earth Planet. Space, 66(106), doi:doi:10.1186/1880-5981-66-106.

Hu, Y., R. Bürgmann, N. Uchida, P. Banerjee, and J.T. Freymueller (2016), Stress-driven Relaxation of Heterogeneous Upper Mantle and Time-dependent Afterslip Following the 2011 Tohoku Earthquake, J. Geophys. Res., 121, doi:10.1002:2015JB012508.

Toda, S., and R.S. Stein (2011), Using the $2011 M=9.0$ Tohoku earthquake to test the Coulomb stress triggering hypothesis and to calculate faults brought closer to failure, Earth, Planets and Space, 63, 1-6, doi:10.5047/eps.2011.05.010. 


\section{Subduction Zone Geodesy and UNAVCO Community Science Results}

\section{By Meghan Miller ${ }^{1}$}

UNAVCO serves the research community to advance earthquake and tsunami science, around the world and in collaborations between the academic community and government agencies. Through efficient maintenance and operation of significant permanent geodetic networks, repair, data rescue and installation of sites in key seismic regions, and critical integration of geodesy and seismology, UNAVCO helps researchers further their understanding of earthquake processes and related hazards, such as tsunamis. UNAVCO's geodetic tools and data services advance research on specific earthquakes and the topics of this meeting from earthquake early warning to operational forecasting. Since the last UJNR meeting in 2014, UNAVCO has supported event responses for more than 15 earthquakes around the world. Our support varies from rapid field deployments to reoccupy campaign sites to repair/data rescue from permanent sites affected by an event. Where UNAVCO operates permanent GPS networks, largely within the Americas, we provide custom data sets for earthquakes or other geophysical events.

Geodetic tools continue to advance and expand our understanding of Earth processes from the solid Earth to the uppermost atmosphere. Here I provide some recent examples of community research focused on understanding earthquake and tsunami hazards. These examples include using the Plate Boundary Observatory to assess coseismic and post-seismic deformation from the Craig, Alaska earthquake; using COCONet to determine Caribbean plate motion and estimate large earthquake recurrence rates; using rescued geodetic data to determine the amount of slip caused by the Gorkha, Nepal earthquake; combining geodetic and seismic data to improve tsunami early warning; and using dense geodetic network to track tsunamis in the ionosphere.

EarthScope's Plate Boundary Observatory, the largest and densest geodetic network that UNAVCO maintains in the United States has provided a wealth of information about earthquakes in California and the Pacific Northwest that other speakers may cover. Here I discuss one example from the Aleutian Arc of Alaska from a paper by Ding and others. Analysis of GPS observations before, during and after the 5 January $2013 M_{\mathrm{w}} 7.5$ Craig earthquake show that slip during the earthquake averaged about 6 meters and that substantial post-earthquake deformation may be related to slip on an adjacent segment of the fault. The results show that the Craig earthquake fills a gap between a 1949 and a 1972 event, improving earthquake forecasting and accounting for plate motion between the North American and the Pacific plates.

UNAVCO with 38 other entities operates and maintains a circum-Caribbean geodetic network called COCONet to understand the complex tectonics of this region. A paper by Symithe and others (2015), determines the present-day motion of the Caribbean Plate. The authors show that the subduction edge of the Caribbean plate transitions from fully locked near Hispaniola to partially locked under Puerto Rico and the Lesser Antilles. This behavior implies about one magnitude 8 earthquake every 2000 years along the subduction zone.

The 25 April $2015 M_{\mathrm{w}} 7.8$ Gorkha Nepal earthquake was captured with unprecedented clarity by a geodetic array. Access to the sites and the data was a significant issue after the damaging event, however, UNAVCO Field Engineer John Galetzka was able to work with many

1UNAVCO. 
partners to recover the data and repair sites throughout Nepal. A paper by Galetzka et al. combined high rate GPS measurements with accelerometer and satellite radar data to show that the earthquake ruptured a 20-kilometer wide segment of the fault at depth. The rupture propagated toward the Kathmandu basin and the smooth slip onset caused only moderate ground shaking in the city. Greater damage, especially to taller structures in Kathmandu, was caused by whole basin resonance of the seismic waves. The resonance was captured by GPS station, NAST, in Kathmandu.

\section{References Cited}

Slip pulse and resonance of the Kathmandu basin during the 2015 Gorkha earthquake, Nepal, J. Galetzka, D. Melgar, J. F. Genrich, J. Geng, S. Owen, E. O. Lindsey, X. Xu, Y. Bock, J.-P. Avouac, L. B. Adhikari, B. N. Upreti, B. Pratt-Sitaula, T. N. Bhattarai, B. P. Sitaula, A. Moore, K. W. Hudnut, W. Szeliga, J. Normandeau, M. Fend, M. Flouzat, L. Bollinger, P. Shrestha, B. Koirala, U. Gautam, M. Bhatterai,. R. Gupta, T. Kandel, C. Timsina, S. N. Sapkota, S. Rajaure and N. Maharjan, Science 349 (6252), 1091-1095. doi:10.1126/science.aac6383.

Kaihua Ding, Jeffrey T. Freymueller, Qi Wang, and Rong Zou, Coseismic and Early Postseismic Deformation of the 5 January $2013 \mathrm{Mw}$ 7.5 Craig Earthquake from Static and Kinematic GPS Solutions, Bulletin of the Seismological Society of America, Vol. 105, No. 2B, pp. 1153-1164, May 2015, doi:10.1785/012014017.

Symithe, S., E. Calais, J. B. de Chabalier, R. Robertson, and M. Higgins (2015), Current block motions and strain accumulation on active faults in the Caribbean, J. Geophys. Res. Solid Earth, 120, doi:10.1002/2014JB011779. 


\section{New Ways to Look at Active Tectonic Deformation of the Western United States}

By Wayne Thatcher ${ }^{1}$ and Robert Simpson ${ }^{1}$

Abstract

We describe some tools for exploring and organizing global positioning system (GPS) observations collected to reveal regional deformation patterns. One tool, inherited from potential field studies, searches for steep gradients in an anomaly field of interest. In potential fields such gradients commonly overlie the boundaries of the underground bodies that produce the anomalies. In regional GPS velocity fields, steep gradients can be equally revealing, because changes in GPS velocities often overlie active tectonic features such as faults. Instead of a scalar anomaly field, as in the case of gravitational attraction, we search for gradients in a twodimensional (2D) or three-dimensional (3D) velocity field. We propose to use the maximum magnitude of the directional derivative (MMDD) at each location as the scalar field of interest. This quantity encapsulates both changes in direction and magnitude of the velocities; the direction in which the maximum occurs is perpendicular to the direction in which the least amount of change is occurring. The method is particularly suited for applications in regions where the tectonic deformation is complex and poorly understood, and we illustrate its utility using the GPS velocity field in northeastern California, where subduction, strike-slip faulting, back arc extension and volcanism all occur.

1U.S. Geological Survey. 


\section{Session 6: The South Napa Earthquake}

\section{Fault Afterslip Forecast for the August 24, 2014, South Napa Earthquake}

\section{By Ken Hudnut ${ }^{1}$}

An update will be provided on the USGS forecast and assessment of ongoing fault afterslip (Hudnut and others, 2014), especially in the Browns Valley residential neighborhood of the City of Napa. At the time of the M6.0 South Napa earthquake, the fault ruptured the ground surface right away, as is typical. However, it became clear in the days afterwards that parts of the fault were continuing to move. This is a known phenomenon called "afterslip" but in this case was observed adjacent to, and possibly going right through, a residential area for the first time. This necessitated a first-of-its kind official forecast for use by homeowners in designing their repairs. To fill this need, FEMA supported USGS to innovate and turn their afterslip science into a simple map product, which indicates hazard with red, yellow and green lines that could be easily understood and used by the City of Napa and residents of Browns Valley. A public meeting was held to explain the product and answer peoples' questions. The USGS fault afterslip forecast has stayed within range so far.

\section{References Cited}

Hudnut, K.W., Brocher, T.M., Prentice, C.S., Boatwright, J., Brooks, B.A., Aagaard, B.T., Blair, J.L., Fletcher, J.B.,Erdem, J.E., Wicks, C.W., Murray, J.R., Pollitz, F.F., Langbein, J., Svarc, J., Schwartz, D.P., Ponti, D.J., Hecker, S., DeLong, S., Rosa, C., Jones, B., Lamb, R., Rosinski, A., McCrink, T.P., Dawson, T.E., Seitz, G., Rubin, R.S., Glennie, C., Hauser, D., Ericksen, T., Mardock, D., Hoirup, D.F., and Bray, J.D., 2014, Key recovery factors for the August 24, 2014, South Napa earthquake: U.S. Geological Survey Open-File Report 2014-1249, 51 p., https://doi.org/10.3133/ofr20141249.

1U.S. Geological Survey. 


\title{
Ground-Motion Attenuation in the Sacramento-San Joaquin Delta, California from Seven Bay Area Earthquakes, Including the 2014 M6.0 South Napa Earthquake
}

\author{
By Jem Erdem, ${ }^{1}$ J. Boatwright, ${ }^{1}$ and J.B. Fletcher ${ }^{1}$
}

The August 24, 2014 M6.0 South Napa earthquake was recorded by an extensive network of accelerometers. Baltay and Boatwright (2015) compiled and analyzed strong motion records obtained at 134 stations within 50 kilometers $(\mathrm{km})$ and 292 stations within $100 \mathrm{~km}$ of the epicenter. They found that peak ground acceleration (PGA) and velocity (PGV) fall off significantly faster with distance than the NGA-West2 ground motion prediction equations (GMPEs) published in Bozorgnia and others, (2014). In a subsequent study, Erdem and others (2016), showed that this variant attenuation was pronounced for ground motions within the Sacramento-San Joaquin Delta, situated approximately 50-75 km East-Southeast of the earthquake. In this study, we evaluate the attenuation for multiple paths into the Delta with the intent of improving attenuation models by regionalization. In addition to the South Napa recordings, the dataset includes six earthquakes, $4 \leq M<7$, located near Yountville, El Cerrito, Fremont, Alum Rock, Loma Prieta, and Tres Pinos. We select stations within azimuthal ranges of $60^{\circ}$ to $120^{\circ}$ into the Delta, and fit the residuals to the Boore and Atkinson (2008) GMPEs for each earthquake to the function a $-k^{\mathrm{g}}$. Here, $\mathrm{a}$ is the event term (the ratio of the observed ground motion for a specific event to the predicted ground motion for an event with the same magnitude) and $\mathrm{k}$ is the differential attenuation (the difference between the observed and predicted attenuation). The exponent $g$ modifies the falloff of the attenuation with distance: $\mathrm{g}=0.24$ fits the seven-earthquake dataset. The differential attenuations range from 0.16 to 0.72 , with no clear dependence on magnitude and location, but exhibit some tradeoff with the event terms. While there is a large variation in differential attenuation values, the ground motions from all of these events attenuate faster than predicted by the Boore-Atkinson GMPEs. Overall, these results suggest that attenuation models can be improved by regionalization, but with significant epistemic uncertainty.

\section{References Cited}

Baltay, A.S., and Boatwright, J., 2015, Ground-motion observations of the 2014 South Napa Earthquake: Seismological Research Letters, v. 86, no. 2A, p. 355-360, https://doi.org/10.1785/0220140232.

Boore, D.M., and Atkinson, G.M., 2008, Ground-motion prediction equations for the average horizontal component of PGA, PGV, and 5\%-damped PSA at spectral periods between $0.01 \mathrm{~s}$ and 10.0 s: Earthquake Spectra, v. 24, no. 1, p. 99-138.

Bozorgnia, Y., Abrahamson, N.A., Atik, L.A., Ancheta, T.D., Atkinson, G.M., Baker, J.W., Baltay, A., Boore, D.M., Campbell, K.W., Chiou, B.S.-J., Darragh, R., Day, S., Donahue, J., Graves, R.W., Gregor, N., Hanks, T., Idriss, I.M., Kamai, R., Kishida, T., Kottke, A., Mahin, S.A., Rezaeian, S., Rowshandel, B., Seyhan, E., Shahi, S., Shantz, T., Silva, W., Spudich, P., Stewart, J.P., Watson-Lamprey, J., Wooddell, K., and Youngs, R., 2014, NGA-West2 Research Project, Earthquake Spectra, v. 30, no. 3, p. 973-987.

1U.S. Geological Survey. 
Erdem, J.E., Boatwright J., and Fletcher, J.B., 2016, Ground-motion attenuation for the South Napa Earthquake in the Sacramento-San Joaquin Delta, California [abstract]: Seismological Research Letters, v. 87, no. 2B, p. 401-589, https://doi.org/10.1785/0220160046 


\section{Regional Attenuation Parameters in Ground-motion Predictions: An Example from the 2014 South Napa Earthquake}

By Annemarie Baltay, ${ }^{1}$ Valerie Sahakian, ${ }^{1}$ Donna Eberhart-Phillips, ${ }^{1}$ and Tom Hanks ${ }^{1}$

Ground motions of the 2014 M6.0 South Napa, California, earthquake were recorded at 19 stations within 20 kilometers $(\mathrm{km})$ and 292 stations within $100 \mathrm{~km}$ of the rupture surface trace, generating peak ground motions in excess of 50 percent of gravitational acceleration $(g)$ and 50 $\mathrm{cm} / \mathrm{s}$ at a few sites in and near Napa Valley. Baltay and Boatwright (2015) compared the ground motion from the earthquake to existing ground-motion prediction equations (GMPEs) in considerable detail, finding that the NGA-West2 GMPEs overestimate the observed ground motions at all frequencies, for distances greater than $\sim 20 \mathrm{~km}$. This indicates that the actual wholepath attenuation is stronger than the models predict, which is not astonishing given that those GMPEs are regressed with one average attenuation function (per frequency) for the entire state of California. Currently, the path component of GMPEs are dependent on only the source-site distance, and do not incorporate any path-specific information.

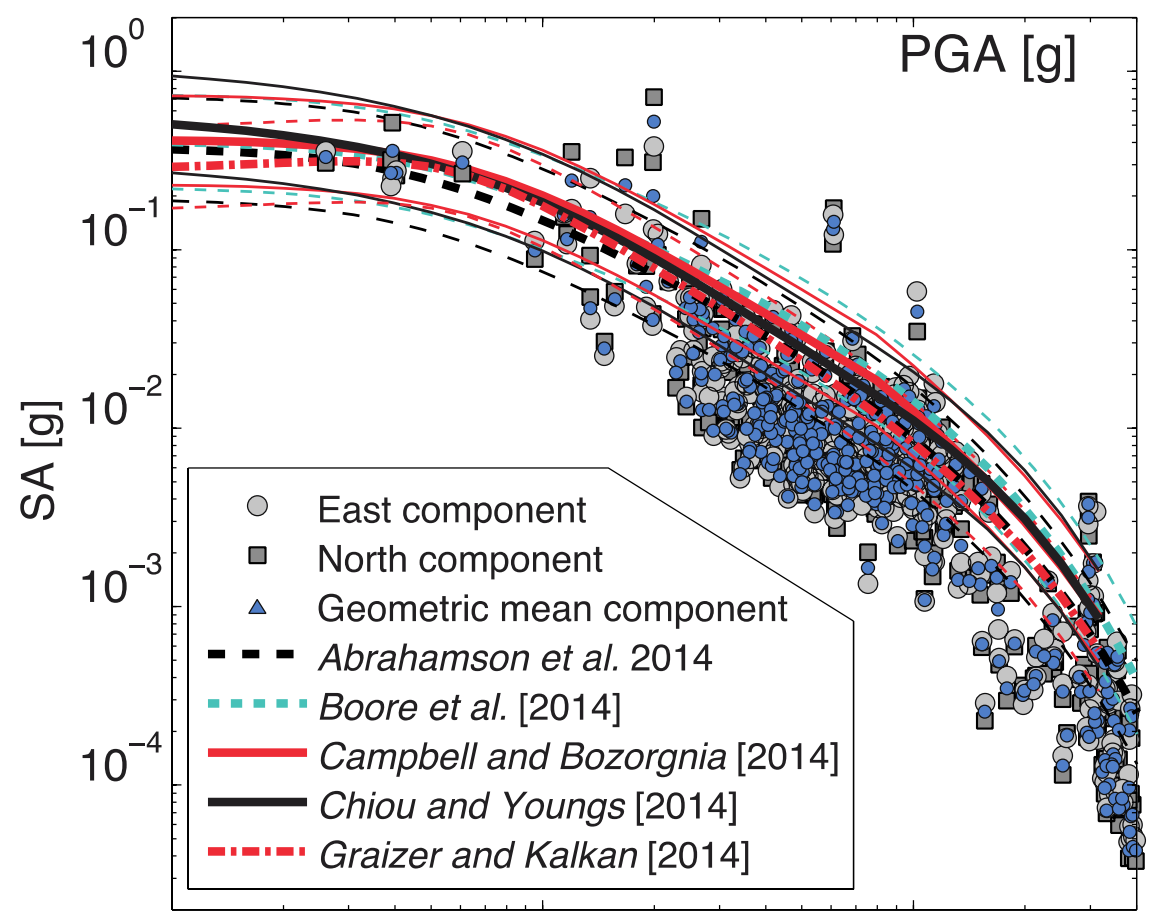

Figure 1. Ground-motion observations from the 2014 M6.0 South Napa, California, earthquake compared with four NGA-West2 GMPEs and that of Graizer and Kalkan (2014). Although the GMPEs match the data well at close distances, the observed attenuation is stronger than predicted at distances greater than $\sim 20$ kilometers. From figure 2 of Baltay and Boatwright (2015).

1U.S. Geological Survey. 
To improve GMPEs in a forward sense, we move from the uniform, ergodic model, in which all of California (for example) has the same attenuation properties; to a regional or path-specific, non-ergodic model. To do so, we need to incorporate geophysical knowledge into specific sourceto-site paths. We demonstrate a framework for our method and show examples of how material velocity and attenuation, determined from independent geophysical models, can be correlated with the observed path residuals.

In the Anza region of Southern California, we first fit a robust GMPE to a large database of small-to-moderate magnitude earthquakes spanning 30+ years. We then perform residual analysis to deconstruct the data into contributions from source, site, and path. Individual paths between the sources and sites are raytraced through a local velocity model, and we compare the integral of the material to the observed path residuals. With an initial database using only short hypocentral distances, we find that the site components dominate the residual decomposition and thus correlate more closely with the velocity model than do the path residuals, demonstrating the nuance between the definitions of and delineations between "path" and "site" effects.

In northern California, we consider the three-dimensional (3D) Qp and Qs models of Eberhart-Phillips (2016). For every ray path between the South Napa earthquake and the recording stations, we correlate the path attenuation from the Q model with the observed GMPE residuals and find a small, but positive, correlation between the observations and predicted attenuation. Thus, we demonstrate an improvement in GMPEs by incorporating a priori physical information. Thus, adopting path specific attenuation would not only yield better predictions, but could reduce the uncertainty in the GMPEs, which in turn can result in lowered hazard for very low probability ground motion, for example, with long return periods.

\section{References Cited}

Abrahamson, N.A., Silva, W.J., and Kamai, R., 2014, Summary of the ASK14 ground-motion relation for active crustal regions: Earthquake Spectra, v. 30, no. 3, p. 1025-1055, https://doi.org/10.1193/070913EQS198M.

Baltay, A.S., and Boatwright, J., 2015, Ground-motion observations of the 2014 South Napa Earthquake: Seismological Research Letters, v. 86, no. 2A, p. 355-360, https://doi.org/10.1785/0220140232.

Boore, D.M, Stewart, J.P., Seyhan, E., and Atkinson, G.M., 2014, NGA-West2 equations for predicting PGA, PGV, and 5\%-damped PSA for shallow crustal earthquakes: Earthquake Spectra, v. 30, no. 3, 1057-1085, https://doi.org/10.1193/070113EQS184M.

Campbell, K.W., and Bozorgnia, Y., 2014, NGA-West2 ground motion model for the average horizontal components of PGA, PGV, and 5\% damped linear acceleration response spectra: Earthquake Spectra, v. 30, no. 3, p. 1087-1115, https://doi.org/10.1193/062913EQS175M. Chiou, B.S.J., and Youngs, R.R., 2014, Update of the Chiou and Youngs NGA model for the average horizontal component of peak ground motion and response spectra, Earthquake Spectra, v. 30, no. 3, p. 1117-1153, https://doi.org/10.1193/072813EQS219M.

Eberhart-Phillips, D., Thurber, C., and Fletcher, J.B., 2014, Imaging P and S attenuation in the Sacramento-San Joaquin Delta region, northern California: Bulletin of the Seismological Society of America, v. 104, no. 5, p. 2322-2336.

Graizer, V., and Kalkan, E., 2015, Update of the Graizer-Kalkan ground-motion prediction equations for shallow crustal continental earthquakes: U.S. Geological Survey Open-File Report 2015-1009, 98 pp., https://doi.org/10.3133/ofr20151009. 


\section{Using Numerical Models to Investigate Distributed Deformation - The South Napa Earthquake as a Case Study}

By Margaret Glasscoe,,${ }^{1}$ Jay Parker, ${ }^{1}$ Gregory Lyzenga,${ }^{1}$ Andrea Donnellan,,${ }^{1}$ and Christopher Milliner ${ }^{2}$

Constraining the spatial distribution of slip and determining the behavior of fault interactions is a complex problem. Field and remotely sensed data often lack the necessary coverage to fully resolve fault behavior. However, realistic physical models may be used to more accurately characterize the complex behavior of faults constrained with observed data, such as GPS, InSAR, and SfM. These results will improve the utility of using combined models and data to understand fault interactions, estimate earthquake potential and characterize plate boundary behavior.

Slip on multiple fault strands was observed during the South Napa earthquake [Brocher, and others, 2015, Hudnut, and others, 2014; see figure below]. Simulations of earthquakes using viscoelastic models may help us understand how faults root at depth and how this is reflected at the surface, particularly in complex events such as the South Napa earthquake.

We model fault segments and slip distributions using the JPL GeoFEST software. GeoFEST (Geophysical Finite Element Simulation Tool) is a two- and three-dimensional finite element software package for modeling solid stress and strain in geophysical and other continuum domain applications [Lyzenga, and others, 2000; Glasscoe, and others, 2004; Parker, and others, $2008,2010]$.

Our preliminary simulation results show distributed deformation in a damage zone containing multiple fault strands with varying lateral rigidity, consistent with the observed geologic and geodetic deformation. Both field and remotely sensed data are extremely helpful in constructing and constraining models, and the South Napa earthquake provides an excellent case study to examine this problem.

New methods to advance geohazards research using computer simulations and remotely sensed observations for model validation are required to understand fault slip, the complex nature of fault interaction and plate boundary deformation. These models help enhance our understanding of the underlying processes, such as transient deformation and fault creep, and can aid in developing observation strategies for SUAV, airborne, and upcoming satellite missions seeking to determine how faults behave and interact and assess their associated hazard.

\footnotetext{
${ }^{1}$ Jet Propulsion Laboratory, California Institute of Technology. ${ }^{2}$ University of California, Berkeley.
} 


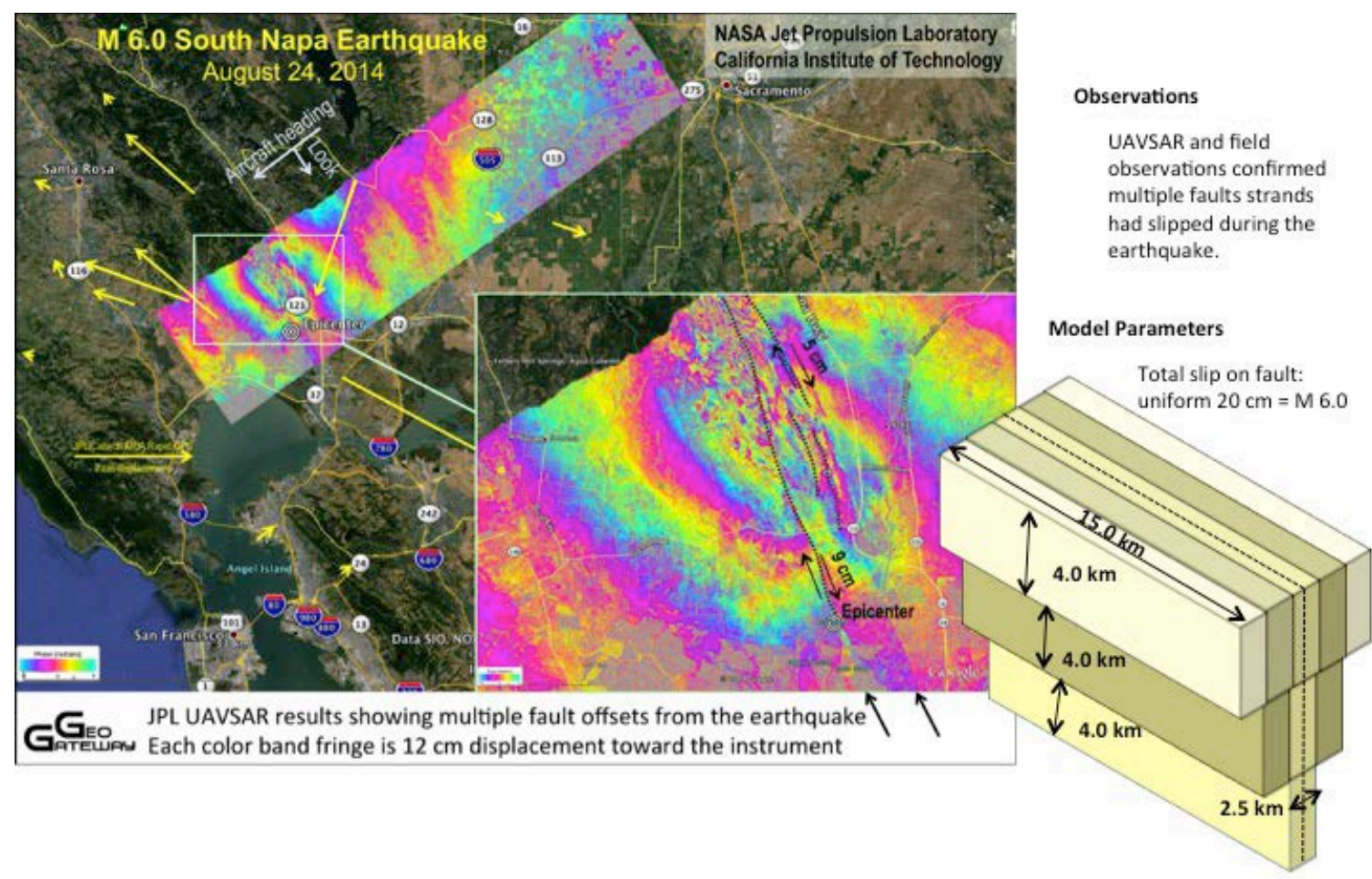

Figure 1. (Left): An interferogram created from UAVSAR data collected May 29, 2014, three months before the South Napa earthquake, and August 29, 2014, five days following the event, indicates that slip occurred on several strands of the fault. The initial GPS analyses (yellow arrows), indicated an average slip of nearly $60 \mathrm{~cm}$ along a $15 \mathrm{~km}$ fault, which is equivalent to a magnitude 6.1 earthquake, which is consistent with the observed afterslip. GPS data inversion and analyses of the UAVSAR data were carried out under NASA's GeoGateway project with rapid GPS solutions provided by the JPL/Caltech ARIA team. Image courtesy NASA JPL/Caltech (http://www.jpl.nasa.gov/spaceimages/details.php?id=PIA18801). (Lower right): The numerical model used to simulate the South Napa earthquake features a main fault embedded in a damage zone that narrows with depth in which rigidity may be varied laterally, with ancillary fault strands that will be allowed to slip in order to compare results to observed fault behavior during the South Napa event.

\section{References Cited}

Brocher, T.M., Baltay, A.S., Hardebeck, J.L., Pollitz, F.F., Murray, J.R., Llenos, A.L., Schwartz, D.P., Blair, J.L., Ponti, D.J., Lienkaemper, J.J., Langenheim, V.E., Dawson, T.E., Hudnut, K.W., Shelly, D.R., Dreger, D.S., Boatwright, J., Aagaard, B.T., Wald, D.J., Allen, R.M., Barnhart, W.D., Knudsen, K.L., Brooks, B.A., and Scharer, K.M., 2015, The Mw 6.024 August 2014 South Napa Earthquake, Seismological Research Letters, v. 86, pp. 309-326, doi: 10.1785/0220150004.

Glasscoe, M.T., Donnellan, A., Kellogg, L.H., and Lyzenga, G.A., 2004, Evidence of strain partitioning between the Sierra Madre fault and the Los Angeles Basin, southern California from numerical models, Pure and Applied Geophysics, v. 161, pp. 2343-2357.

Hudnut, K. W., Brocher, T.M., Prentice, C.S., Boatwright, J., Brooks, B.A., Aagaard, B.T., Blair, J.L., Fletcher, J., Erdem, J.E., and Wicks, C.W., and others, (2014), Key recovery factors for the August 24, 2014, South Napa earthquake, U.S. Geological Survey Open-File Report 2014-1249, 51 pp., doi: $10.3133 /$ ofr20141249. 
Lyzenga, G. A., W. R. Panero, and A. Donnellan, 2000, Influence of anelastic surface layers on postseismic thrust fault deformation, Journal of Geophysical Research, 105, 3151-3157.

Parker, J., Lyzenga, G., Norton, C., Zuffada, C., Glasscoe, M., Lou, J., and Donnellan, A., 2008, Geophysical Finite Element Simulation tool (GeoFEST): algorithms and validation for quasistatic regional faulted crust problems, Pure and Applied Geophysics, v. 165, pp. 497-521.

Parker, J., Norton, C., and Lyzenga, G., 2010, Parallel GeoFEST for regional faulted deformation, Concurrency and Computation: Practice and Experience, Special Issue: Proceedings of the 6th ACES Symposium, May 11-16, 2008, Cairns, Australia, 22, 1604-1625, DOI: 10.1002/cpe.1511. 


\section{Poster Session Abstracts}

\section{Low Frequency Tremor Near the Nankai Trough Axis, Japan}

By Satoshi Annoura, ${ }^{1}$ Tetsuo Hashimoto, ${ }^{1}$ and Noriko Kamaya ${ }^{1}$

We analyzed long-term continuous seismic records (from September, 2015 to April, 2016) of DONET which is an ocean-floor observation system deployed around shallower part of Nankai subduction zone and we investigated low frequency tremor near the trough axis (shallow tremor). We found that activity of shallow tremor is concentrated in two time periods in October, 2015 and in April, 2016 and their durations are about 6 days and 2 weeks respectively. In episode of April, 2016, migration and triggering properties were observed. These characteristics are similar to those of tremor in the deeper part of subduction zone. Because tremor activity is very sensitive to nearby stress perturbation and shallow tremor analyzed by this study was located near the initiation point of past large earthquakes along Nankai trough, it is very important to keep monitoring them to chase stress accumulation process of megathrust earthquake.

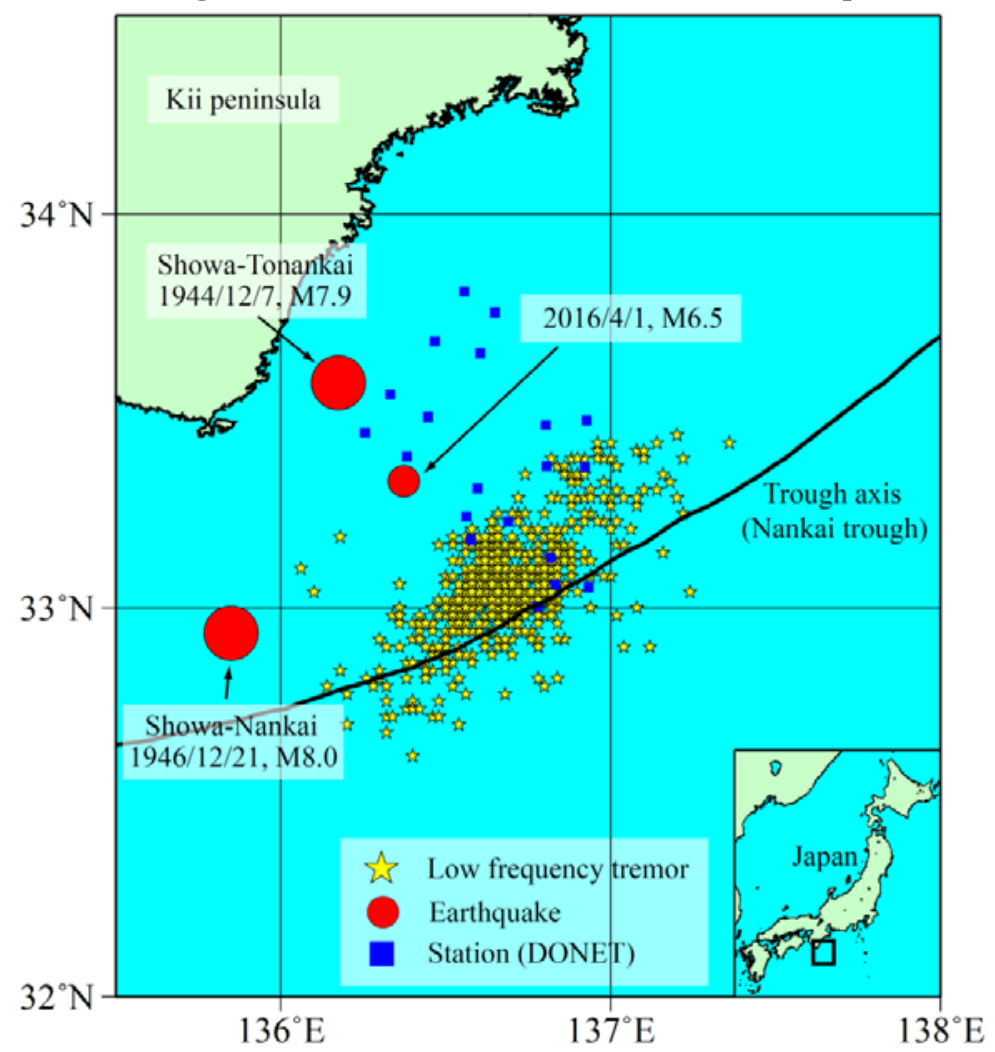

Fig. Distribution of shallow tremor (2015 09/01-2016 04/30)

Figure 1. Distribution of shallow tremor (09/01/2015-04/30/2016).

1Seismology and Volcanology Department, Japan Meteorological Agency. 


\title{
Bayesian Combination of Models for a Data-driven Approach to Earthquake Recurrence, for Crustal or Subduction Sources
}

\author{
By Delphine D. Fitzenz, ${ }^{1}$ Deborah Kane, ${ }^{1}$ and Marleen Nyst ${ }^{1}$
}

Often times, specific ruptures on mature faults are integrated in hazard or risk models by defining a set of magnitudes the fault can generate and assuming some temporal model. When nothing is known of the history of past events, a constant hazard rate is usually assumed (with its corresponding exponential model for interevent times). The only parameter is a mean recurrence time. When dates of past events are known, even with uncertainties, quasi-periodic models are often assumed. One model, together with one set of parameters are thought to be true, but there are several candidates, which leads to a representation of uncertainties in the form of a logic-tree. The weights for the different model functional forms are usually set by expert opinion, while the weights for various values of model parameters may come from more data-driven approaches.

Of particular relevance to risk models is the potential for early repeats of a damaging earthquake even when the mean recurrence over a large time period is large. When only one recurrence model can be right, then this possibility has to come from a large value of the coefficient of variation (or aperiodicity). However another possibility not considered in logic-tree approaches is that no one model is true and that past faulting behaviors may reflect the interplay of various mechanisms, best represented by a mixture of models.

This contribution presents an overview of situations in which this type of approach seems relevant: first the mature fault, "simple" ruptures, then the complex ruptures, and finally an example of subduction zone earthquakes. Discussion on the impact of model choices on risk metrics will also be included.

Fitzenz and Nyst, 2015 argue that even simple geometry ruptures can have complex underlying faulting mechanisms and should not be expected to behave according to only one recurrence model all the time. Significant changes related to fluid migration, nearby major earthquakes, or slow slip events might be of orders of magnitude and type not compatible with the random walk perturbations to a steady fault loading assumed in a Brownian Passage Time model, for example. They have proposed an empirical method to characterize recurrence that uses geomorphological data and trench data in addition to catalog data in a Bayesian framework to test the relative performance of various recurrence models at explaining the data. They propose to use a mixture of all the models that yield behaviors compatible with the data. This is a very different approach compared to the usual logic-tree approach that assumes that one and only one of the proposed models is true. The resulting probability density function for interevent time and the hazard rate functions then may reflect the potential for early repeats of a rupture as well as the main mode of recurrence. This is a feature identified as necessary by UCERF3 (timedependent, Field and others, 2016) even though this project approximated it by using a logic-tree approach and branches with BPT models and a branch with a Poisson model, with arbitrary weights given to each. To preserve the intent of the authors, it is necessary to first combine the recurrence logic-tree branches and then go on to following the other paths in the logic-tree.

${ }^{1}$ Risk Management Solutions. 
Complex ruptures (for example, involving several segments mapped as distinct features) happen and should definitely be incorporated into hazard and risk studies. Those ruptures typically jump across geometrical complexities, for example, from strike-slip to dipping faults, across compressive or extensive step-overs. There are two difficulties related to incorporating these ruptures: 1) quantify how often they might happen on average, and 2) estimate how regular they might be. While slip rate information and magnitude-frequency distribution on the fault system might help constrain the mean recurrence time (as in UCERF3), the aperiodicity needs other input. Recent studies have shown that the less mature the fault at a certain location, the less localized surface and near-surface slip is, and the larger the discrepancy between slip at depth and slip at the surface trace (Dolan and Haravitch, 2014). Also, step-overs are thought to be regions of increased fluid flow. So not only is the stress level on the fault less likely to be homogeneous, but also healing mechanisms involving both friction and cohesion might be very spatially variable. Paleoseismological compilations in California (Biasi and Scharer 2015) show larger aperiodicities near fault complexities. This can come from seeing different size events going through one point on a fault, so enough information to sort through event sizes are necessary. When not enough data is available to resolve an issue because of short observation window, it is customary to turn to earthquake simulators. In simulated faults that are defined as frictional interfaces only, UCERF3 compiled aperiodicities and found a trend with magnitude, with values as low as 0.1 or 0.2 for events larger than $M_{\mathrm{w}}=7.7$. These low values have spectacular effects on both the average annual loss (basis for insurance premiums) and on the reserves needed to keep a company in business with a good rating. It is therefore important to further study the regularity of very large earthquakes in the context of complex geometries, localized vs broad deformation, and friction and cohesion healing. It is likely that rupturing through segment boundaries, as well as the interplay between the single-segment or sub-segment events and those complex ruptures result in complex time-histories, best characterized by mixtures of models.

Kane and others, (personal communication 2016, ms in prep) also developed an empirical mixture of models to characterize the recurrence of $M 7+$ events on the subduction zone in Mexico. Since the subduction is very active, they could use catalog data (1900 to 2013 compiled primarily from SSN (Servicio Sismológico Nacional) and IRIS catalogs) to perform their analysis. Interevent times by segment were collected and stacked as a single histogram for the whole subduction zone between latitude $14^{\circ}$ and latitude $21^{\circ}$. The histogram clearly shows a peak of early repeats as well as a mode at longer interevent times, consistent with a quasi-periodic model. Examples of early repeats on a segment include a pair of earthquakes near Guerrero in $1950\left(M_{\mathrm{w}} 7.3\right)$ and $1957\left(M_{\mathrm{w}}\right.$ 7.8) and a pair of earthquakes near Colima in $1995\left(M_{\mathrm{w}} 8.0\right)$ and $2003\left(M_{\mathrm{w}} 7.5\right)$. The causal relationships between the events are not simple to determine and while some events might be flagged as aftershocks/foreshocks by some methods, others would not due to the large temporal scale of the clustering. It therefore seems very important to not only capture in risk models the common mode of recurrence but also the potential for early repeats in the first 10-15 years after an event.

Kane and others, (personal communication 2016, ms in prep) fitted this empirical bimodal distribution with a mixture of Weibull, Poisson and BPT models to reflect multiple possibilities. As time since last event on a section of the subduction zone increases, the hazard rate reflects the new conditional probability. In other words, if this possibility for early repeats is not realized, then probability transfers onto the mode of the quasi-periodic model. 
Finally, other cases not presented here include sets of faults that define a broader deformation zone. In those cases, it seems important to in the future be able to infer both the individual behavior of each fault but also the group behavior.

\section{References Cited}

Biasi and Scharer, 2015, AGU Fall Meeting, Coefficient of Variation Estimates for the Plate Boundary Fault System of California, S23A-2696

(accessible at https://agu.confex.com/agu/fm15/webprogram/Paper77616.html)

Dolan, J.F., Haravitch, B.D., 2014. How well do surface slip measurements track slip at depth in large strike-slip earthquakes? The importance of fault structural maturity in controlling on-fault slip versus off-fault surface deformation. Earth Planet. Sci. Lett. 388, 38-47.

Field and others, 2015, Long-Term Time-Dependent Probabilities for the Third Uniform California Earthquake Rupture Forecast (UCERF3), doi: 10.1785/0120140093, Bulletin of the Seismological Society of America April 2015 vol. 105 no. 2A 511-543.

Fitzenz and Nyst, 2015, Building Time-Dependent Earthquake Recurrence Models for Probabilistic Risk Computations, doi: 10.1785/0120140055.

Bulletin of the Seismological Society of America February 2015 vol. 105 no. 1, 120-133. 


\section{The GEONET Real-time Analysis System for Rapid Finite Fault Modeling}

By Satoshi Kawamoto, ${ }^{1}$ Yohei Hiyama, ${ }^{1}$ Naofumi Takamatsu,${ }^{1}$ and Hiroshi Yarai ${ }^{1}$

Geospatial Information Authority of Japan, which operates Japan's national GNSS network GEONET including 1300 sites, has developed a system that estimates earthquake fault model rapidly using GNSS data in collaboration with the Tohoku University. The system is named REGARD: Real-time GEONET Analysis system for Rapid Deformation monitoring. The displacement data produced by GNSS observations have a great advantage over a seismometer for large earthquakes because seismometer data have a limitation of instrument saturation.

The REGARD system consists of three subsystems: the real-time positioning subsystem, the event detection subsystem, and the fault model inversion subsystem. The real-time data stream from the GEONET stations are processed by the real-time positioning subsystem using RTKLIB 2.4.2 software (Takasu, 2013), and 1-Hz station positions are estimated using dual-frequency phase and pseudo-range data in real time. Earthquake events are detected by the event detection subsystem if the JMA EEW with $M>7.0$ and/or the displacement over $10 \mathrm{~cm}$ at three neighboring GEONET stations are observed. Then, the latest static displacements are modeled by a single rectangular fault and slip distribution along an assumed plate boundary.

In this paper, we show the overview of REGARD and assess the performance of REGARD for the previous large earthquakes. We used the data of three previous large earthquakes occurred on plate boundaries around Japan: 2003 Tokachi-oki earthquake, 2011 Tohoku earthquake. The simulation data of the 1707 Hoei type Nankai trough earthquake (Todoriki, 2013) was also used. The Mw estimates with high variance reductions $>90$ percent were derived for all the earthquakes within 3 minutes. It is noteworthy that the $M_{\mathrm{w}} 8.83$ was estimated for the 2011 Tohoku earthquake by 3 minutes without saturations. The performance assessment of REGARD confirmed that the real-time GNSS analysis is very powerful to estimate reliable Mw for large earthquakes with $M>8$ rapidly.

We also show the real-time results of REGARD system during the 2016 Kumamoto earthquakes (April 16 mainshock [M7.3] and two large foreshocks occurred on April 14 [M6.5], 15 [M6.4]). The REGARD system successfully estimated a finite fault model with $M_{\mathrm{w}} 6.85$ within 1 min, which converged to $M_{\mathrm{w}} 6.96$ within $5 \mathrm{~min}$ of the origin time. The finite fault model estimate showed right-lateral strike-slip fault along the Futagawa fault that is evaluated to be the main fault of the 2016 Kumamoto earthquake. This demonstrates the potential of a GNSS-based EEW system for inland earthquakes.

\section{References Cited}

Takasu, T. (2013), RTKLIB: An Open Source Program Package for GNSS, http://www.rtklib.com/ Todoriki M., Furumura, T., and Maeda, T. 2013 “3D FDM simulation of seismic wave propagation forNankai Trough earthquake; effects of topography and seawater," American Geophysical Union Fall Meeting, 9-13 December, San Francisco, USA.

${ }^{1}$ Geospatial Information Authority of Japan. 


\title{
Earthquake Rupture Properties of the 2016 Kumamoto Earthquake Foreshocks (Mj 6.5 and Mj 6.4) Revealed by Conventional and Multiple-aperture InSAR
}

\author{
By Tomokazu Kobayashi ${ }^{1}$
}

\section{Preface}

A large inland earthquake with a Japan Meteorological Agency (JMA) magnitude (Mj) of 7.3 occurred on April 16, 2016, mainly rupturing the Furtagawa fault zone (fig. 1). Prior to the event, Mj 6.5 and Mj 6.4 events occurred at 21:25 (Japan Standard Time: JST) on April 14 and 00:06 on April 15, 2016, respectively. The magnitudes of these events are, as yet, the second and third largest in this series of earthquakes. The foreshocks are thought to have ruptured the Hinagu fault zone, which connects with the Futagawa fault zone. It is further noted that a seismic intensity of 7, which is the highest rank in the JMA seismic intensity scale, was recorded at Mashiki town. Some reasons can be considered for why the damage was so major, reportedly leading to 9 fatalities and over 800 injuries in spite of the magnitude of Mj $6.5\left(M_{\mathrm{w}} 6.2\right)$, but to date, no evidence has definitively shown which factors are dominantly responsible.

Analysis and Result

I used ALOS-2 data acquired on November 14, 2014 and April 15, 2016. This is the unique data pair that can observe the crustal deformation caused by the foreshocks alone. I applied not only InSAR but also MAI to derive further information on crustal deformation.

${ }^{1}$ Geospatial Information Authority of Japan. 

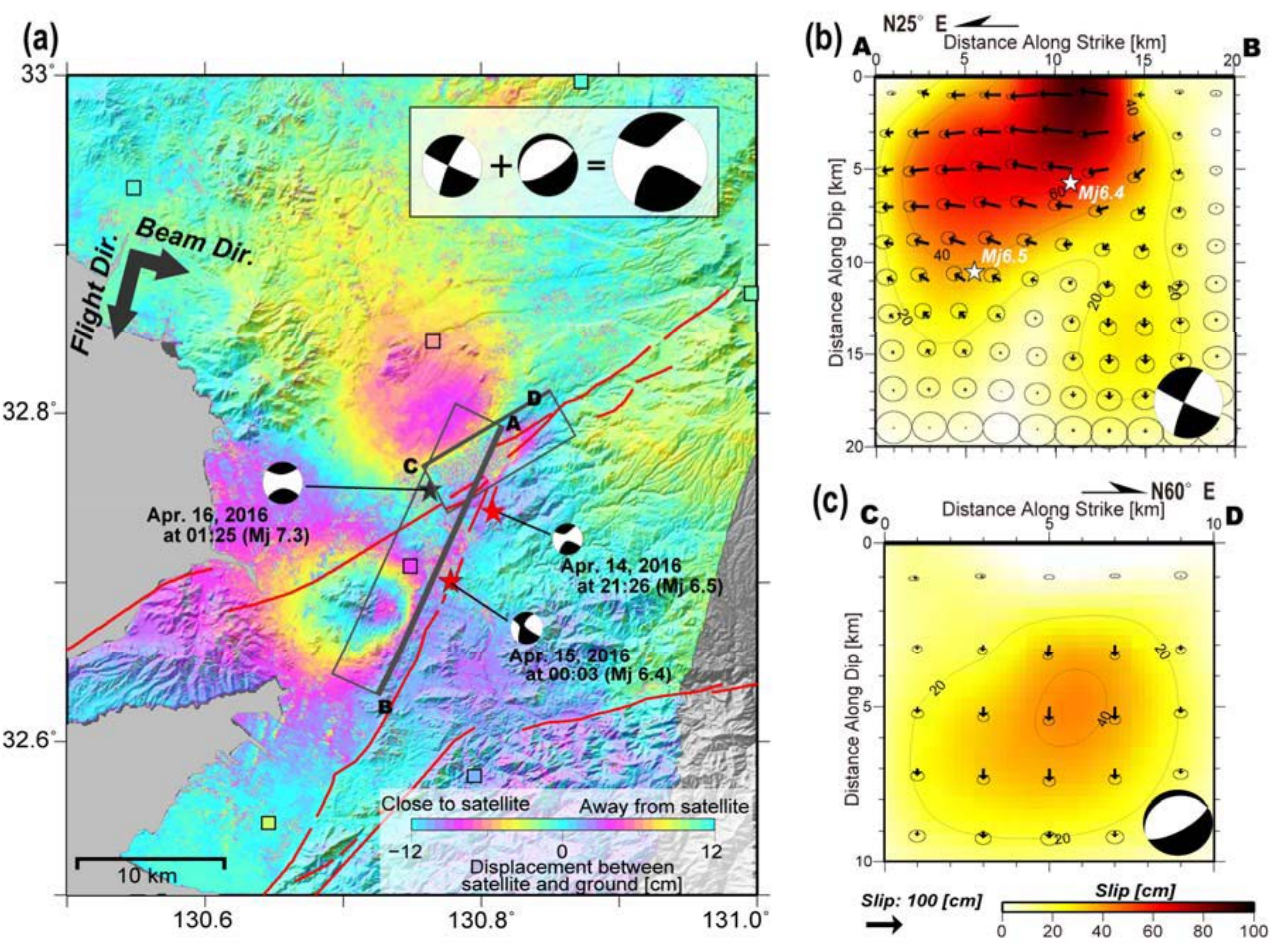

Figure 1. (A) InSAR image using ALOS-2 data acquired on November 14, 2014 and April 15, 2016. Squares indicate GEONET sites, and their colors represent the estimated line-of-sight displacements. Focal mechanisms estimated from distributed slip models of both the Hinagu fault and the local fault beneath Mashiki town are shown in the inset. $(B)$ Slip distribution model for the Hinagu fault. The arrows show slip vectors of the hanging wall. $(C)$ Same as $(B)$ but for the local fault beneath Mashiki town.

Acknowledgments

ALOS-2 data were provided from the Earthquake Working Group under a cooperative research contract with JAXA (Japan Aerospace Exploration Agency). The ownership of ALOS-2 data belongs to JAXA. 


\section{Estimation of Fluid Volumes Necessary for the Fracturing Around the Seismogenic Zone: Insights from the Formation of Mineral Veins}

By Makoto Otsubo, ${ }^{1}$ Hanae Saishu,,${ }^{1}$ Atsushi Okamoto, ${ }^{2}$ Kohtaro Ujiie,,${ }^{3}$ Ayumu Miyakawa, ${ }^{1}$ Asuka Yamaguchi, ${ }^{4}$ and Gaku Kimura ${ }^{5}$

Mineral veins are ancient fluid pass ways ("fossils of fluid pass ways"). The mineral veins in various depths of the subduction zones are keys to understand the interaction among the stress, fracturing and fluid migration in subduction zones. In this study, we focus the fluid volume for formation of veins filling the cracks generated in the seismogenic zone of the subduction zones. The fluid volume for the fracturing is an important factor on the fluid circulation during slow earthquakes (for example, ETS). We employed the silica precipitation model to estimate the fluid volumes for the formation of the veins in this study. The silica precipitation depends on the thermal and pressure conditions of the fluid (Okamoto and others, 2010; Saishu and others, 2012; 2014). In this study, we make the assumption that a tension crack is simplified as a parallel fracture in a host rock as a reservoir of the silica-saturated solution. The quartz solubility ( $\mathrm{mg} / \mathrm{kg}\left(\mathrm{H}_{2} \mathrm{O}\right)$ ) in pure water calculated by using Loner AP (Akinfiev and Diamond, 2009).

In this study, we estimated the fluid volumes for the formation of quartz veins in the two cases: (1) the extension veins of mode I around Nobeoka Thrust, Kyushu, SW Japan (Otsubo and others, 2016) and (2) en echelon cracks (arrays) in the Kodiak accretionary complex, Alaska (Fisher and Brantley, 2014). In the coastal region of the Nobeoka Thrust (ancient megathrust as the boundary between northern and southern Shimanto Belts, depth: $\sim 10 \mathrm{~km}$, pore fluid pressure: $260 \mathrm{MPa}$, temperature: $250{ }^{\circ} \mathrm{C}$, Kondo and others, 2005), the fluid volume for formation of a vein is equal to the fluid volume within radius 0.15 to $0.5 \mathrm{~m}$ of a crack (in case of porosity $=3$ percent). The space $(<0.1 \mathrm{~m})$ between the veins that we can observe is shorter than the radius of reservoir of silica-saturated solution estimated by this study. The results indicate that the dense veins are the cumulative during seismic cycles. In the Kodiak accretionary complex (Kodiak Formation, depth: $\sim 10 \mathrm{~km}$, pore fluid pressure: $260 \mathrm{MPa}$, temperature: $280{ }^{\circ} \mathrm{C}$, porosity: 3 percent, Fisher and Brantley, 2014), the fluid volume for formation of veins on a array is equal to the fluid volume within radius 0.6 to $1.5 \mathrm{~m}$ of a array. The results indicate that the fluid volume within the distance $(\sim 0.5 \mathrm{~m})$ estimated by Fisher and Brantley (2014) may be insufficient for precipitation of quartz in cracks.

\section{References Cited}

Akinfiev and Diamond (2009) GCA, 73, 1597-1608; Fisher and Brantley (2014) Journal of Structural Geology, 69, 395-414; Kondo and others, (2005) Tectonic, 24, TC6008; Okamoto and others, (2010) GCA, 74, 3692-3706; Otsubo and others, (2016) Island Arc,

\footnotetext{
${ }^{1}$ Geological Survey of Japan/AIST.

2Tohoku University.

${ }^{3}$ Tsukuba University.

4The University of Tokyo.

5Tokyo University of Marine Science and Technology.
} 
doi:10.1111/iar.12155; Saishu and others, (2012) Am. Min., 97, 2060-2063; Saishu et al. (2014) Terra Nova, 26, 253-259. 


\section{Alternative Segmentation Methods for Subduction Zones: An Alaskan-Aleutian Megathrust Model}

\section{By Natanya Porto ${ }^{1}$}

To model hazard or risk on a subduction zone, we must know the slab geometry, the rate or reoccurrence of earthquakes on the interface, and maximum magnitude. Subduction zones are usually modeled by breaking up the interface in to individual segments. These segments can each have their own rates, reoccurrence time, and maximum magnitudes. Typically, segments can also rupture independently, or together, depend on the prescribed model parameters. Segment boundaries are usually defined by changes in geometry, historic earthquakes, and by areas that are locked vs creeping. However, as a region experiences new earthquakes, our knowledge of historic events grows, and often the segmented subduction zone models become outdated. In Porto \& Fitzenz (2016) we used a Bayesian approach to determine the location of segment boundaries along the Alaskan-Aleutian subduction zone. The approach examines the seismic activity rate and finds the marginal probability density function (pdf) to determine the location of the limit between two zones, i.e. potential segment boundary. In our study we proposed 2 segment boundaries for seismic hazard and risk modeling in Central and Eastern AlaskanAleutian subduction zone. In contract, the USGS uses 4 segment boundaries in this region (Wesson, 2007), which we believe underestimates the potential for large magnitude (8+) events in the Semidi and Shumagin segments. Our methods also have the advantage of being repeatable, as additional earthquake data becomes available. This approach has potential applications to the Japan subduction zone. In the Japan hazard maps, segment boundaries are used over several sections of the subduction zone to model various interface sources. The methodology outlined in Porto \& Fitzenz (2016) could also be applied to the Japan subduction zone to examine the segment boundaries, and search for confirmation, or variation, to the defined source geometry. This would also create a repeatable approach for future hazard model updates.

\section{References Cited}

Porto, Natanya M. and Fitzenz, Delphine D., 2016, An Alternative Segmentation Model for the Alaskan Aleutian Megathrust, Bulletin of the Seismological Society of America Jun 2016, 106 (3) 1125-1132; DOI: 10.1785/0120150235

Wesson, Robert L., Boyd, Oliver S., Mueller, Charles S., Bufe, Charles G., Frankel, Arthur D., Petersen, Mark D., 2007, Revision of time-Independent probabilistic seismic hazard maps for Alaska: U.S. Geological Survey Open-File Report 2007-1043.

${ }^{1}$ Risk Management Solutions. 


\title{
Regional and Stress Drop Effects on Aftershock Productivity of Large Megathrust Earthquakes
}

\author{
By Nadav Wetzler, ${ }^{1,2}$ Emily E. Brodsky, ${ }^{1}$ and Thorne Lay ${ }^{1}$
}

Presented by Susan Schwartz

Almost all earthquakes produce aftershocks. Aftershocks are commonly defined as an earthquake sequence superimposed on a background level of activity bounded by temporal and/or spatial windowing with respect to a mainshock. In general, aftershock productivity, $N_{\text {aft, }}$ is well established to be a function of mainshock magnitude following a power law:

$$
N_{\text {aft }}=K 10^{\alpha\left(M_{m}-M_{C}\right)} \text {, }
$$

where $\alpha$ is a constant commonly measured to be $\sim 1, M_{\mathrm{m}}$ is the mainshock magnitude, $M_{\mathrm{c}}$ is the lower limit on measured aftershock magnitude, and the prefactor $K$ is usually assumed to be a constant. Observed variations from this trend prompt questions regarding influences of regional environment and individual mainshock rupture characteristics.

We investigate how aftershock productivity varies regionally and with mainshock source parameters for large $\left(M_{\mathrm{W}} \geq 7.0\right)$ circum-Pacific megathrust earthquakes within the past 25 years, drawing on extant finite-fault rupture models. For this purpose we count aftershock with about one rupture length from the mainshock. The temporal time window is kept fixed (7 days) for all mainshock, and spatial window was adjusted by the spatial cutoff of the calculated seismic density of annuli of fixed width (25 km) centered at the mainshock epicenter.

Aftershock productivity is found to be higher for subduction zones of the western circumPacific than for subduction zones in the eastern circum-Pacific (fig. 1). This appears to be a manifestation of differences in faulting susceptibility between island arcs and continental arcs. Surprisingly, events with relatively large static stress drop tend to produce fewer aftershocks than comparable magnitude events with lower stress drop. Studies of aftershock productivity have documented that variations in the state of stress after an earthquake control the aftershock behavior on a variety of scales, with an increase of aftershocks associated with increased Coulomb stress change for individual events. But in general, we expect high stress drop $(\Delta \sigma)$ events to tend to have smaller rupture dimensions $(A)$ for mainshocks of the same size $\left(\mathrm{M}_{0}\right)$ following

$$
M_{0}=\mu A D \approx C A^{2 / 3} \Lambda \sigma,
$$

so that a smaller adjacent region will be perturbed.

However, for events with similar co-seismic rupture area $(A)$, aftershock productivity increases with stress drop (fig. 2) and radiated energy, indicating a significant impact of source rupture process on productivity.

These results demonstrate the influence of source physics on the ensuing aftershock sequence and the value of quantitative source parameter estimation for predicting aftershock productivity.

\footnotetext{
1University of California, Santa Cruz.

${ }^{2}$ Geological Survey of Israel.
} 
(a)

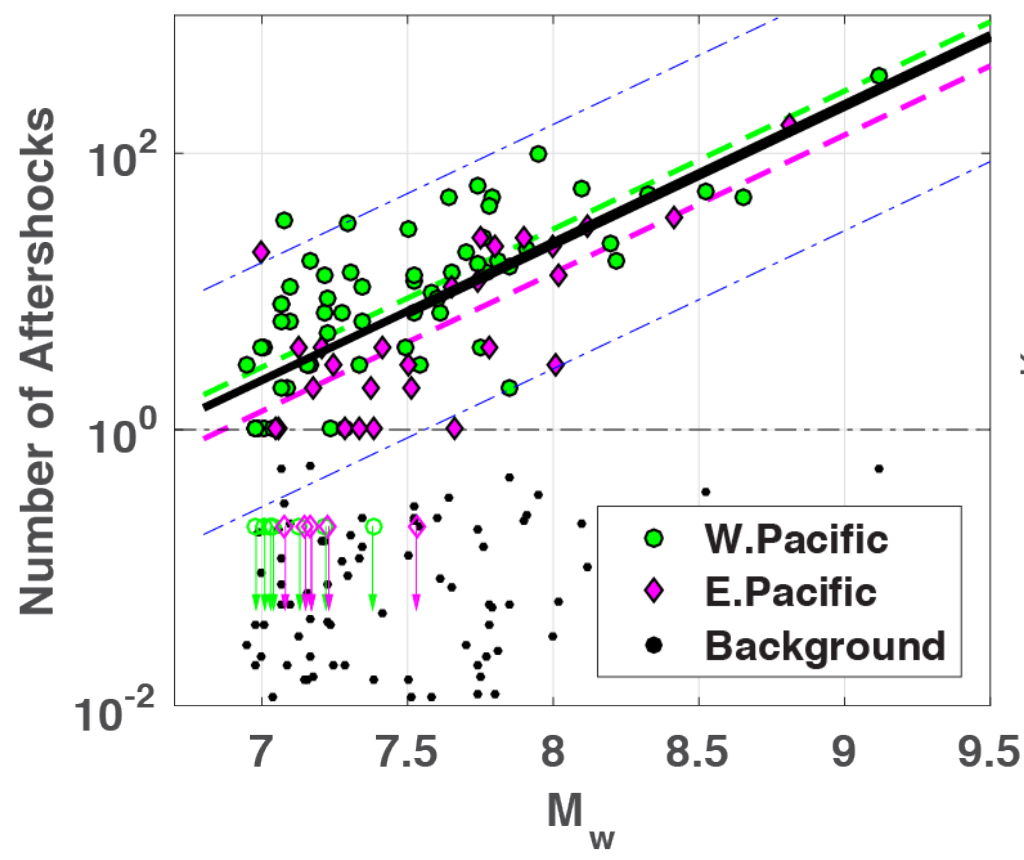

(b)

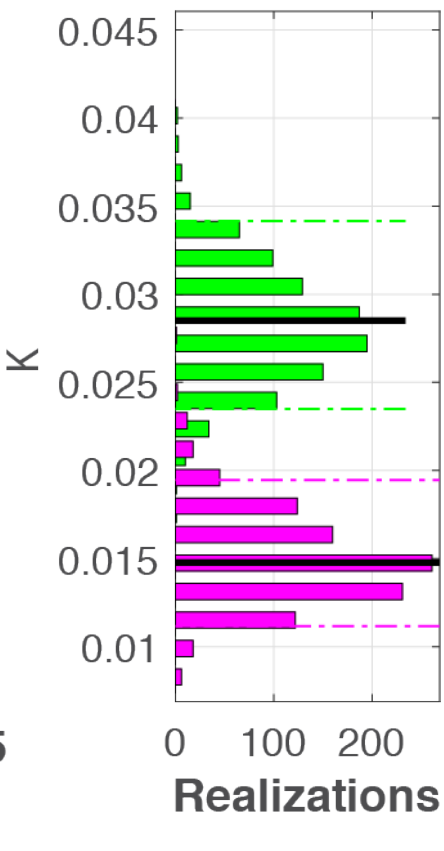

Figure 1. (A) Aftershock productivity (magenta-Eastern Pacific, green-Western Pacific) plotted with respect to mainshock magnitude. The power law fit with a slope of 1 is shown by the black line, and separately for eastern and western Pacific populations by the magenta and green dashed lines, respectively. The thin dashed blue lines represent the 95 percent interval. Unfilled symbols with down pointing arrows mark maishocks with zero aftershock count. (B) Histograms show the distribution of the prefactor ' $K$ ' (eq. 1) with the number of realizations from the bootstrap trials of each group (green and magenta). Dashed lines represent the 5 percent and 95 percent confidence levels, and solid black lines indicate the mean of each group. 
(a)

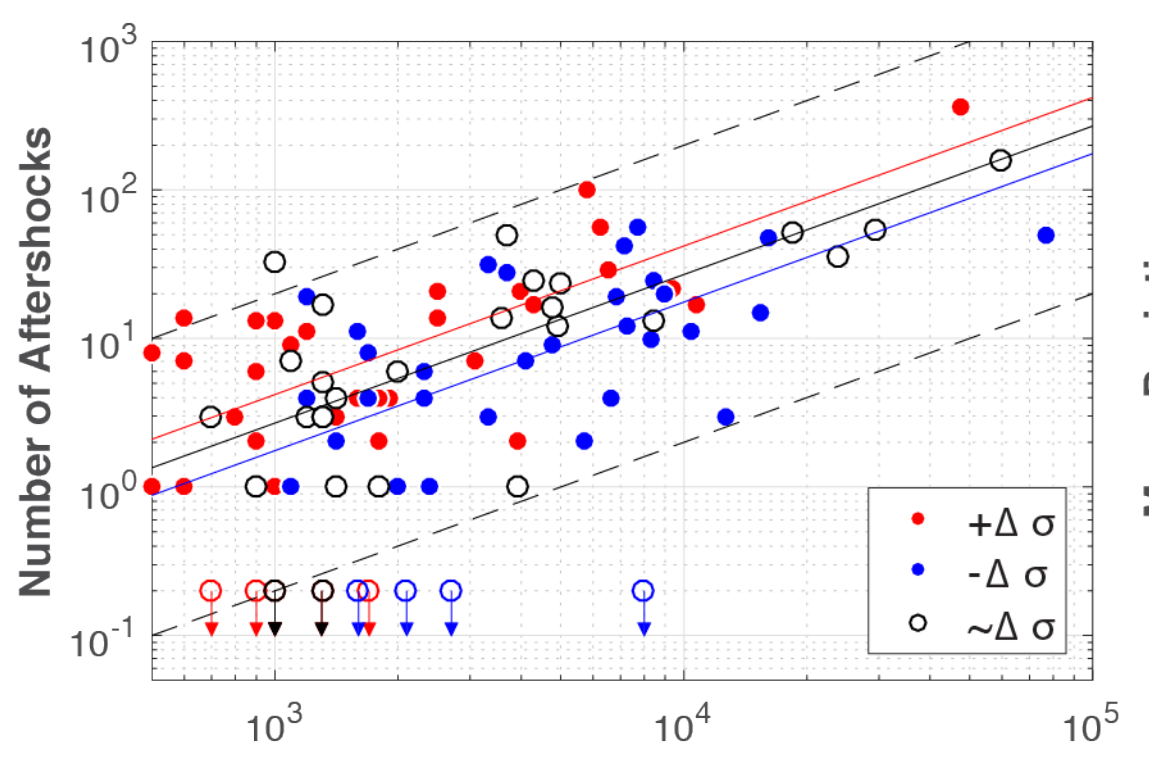

$\mathrm{A}_{\mathrm{S}}\left[\mathrm{KM}^{2}\right]$ (b)

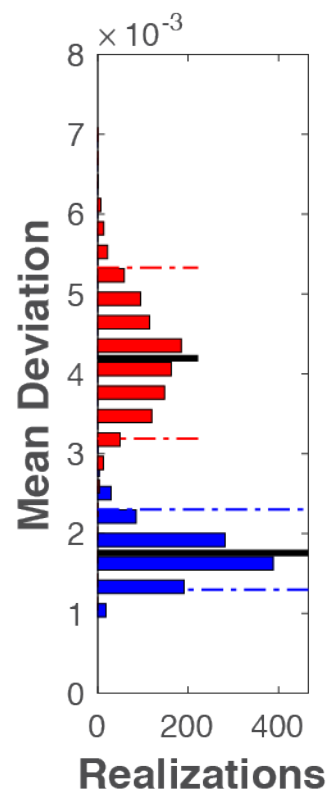

Figure 2. (A) Aftershock number $N_{\text {aft }}$ versus mainshock rupture area color-coded by the mainshock static stressdrop. Blue and red dots indicate relatively low or high (respectively) values of the calculated static stress drop with respect to the median of each group. Unfilled symbols represent mainshocks with zero aftershock count. Solid black lines indicate the power law fit for a slope of 1 , dashed black lines represent constant trends of $2 \times 10^{-2}$ and $2 \times 10^{-4}$. Solid blue and red lines represent the power law fit for each group of low or high stress drop (respectively) from the bootstrap method. (B) Histograms show the distribution of the deviations from the trends for number of realizations for each group (red and blue). Dashed lines represent the 5 percent and 95 percent confidence levels, and solid black lines indicate the mean of each group. 


\section{Basin Edge And Depth Effects On Ground Motion Amplifications In The Kanto Basin, Japan}

By Emel Seyhan ${ }^{1}$, and Byungmin Kim²

The Kanto basin, the largest basin in Japan, lies underneath metropolitan Tokyo and the greater Kanto area in Japan. It has a unique sedimentary basin geometry with the sediment thickness approaching up to $4 \mathrm{~km}$ (similar to Po Plain in Italy, Los Angeles basin) which corresponds to a site period of approximately $7 \mathrm{sec}$. It is acknowledged that deep, soft soil deposits within basins tend to amplify the long-period ground motions, causing damages specifically to high-rise buildings. Many ground motion prediction equations (GMPEs) [for example, Next Generation Attenuation relationships for Western United States (NGA-West2)] have considered the basin depth effects. However, the basin edge effect, the phenomenon of ground motion amplifications due to the angle of incidence of the wave field and interference of reflected/refracted motions within the steeper dipping edges of deep basins, has not been studied well, and is not considered in the existing GMPEs. In this study, we aim to quantify the basin edge effects using the recordings in Japan. We collected strong ground motion recordings at stations located at the edge and center of the Kanto basin from NIED KiK-net network. We used a conventional approach to compute the amplification by taking the ratio of the pseudo-spectral acceleration at the surface to those within borehole. Using the database by Dawood (2015), we developed a simple ground motion amplification model to represent the ground motion amplification characteristics for non-basin sites. At the basin edge sites, the amplifications for short periods are larger than those at non-basin sites, while the amplification for long periods is similar for both basin edge sites and non-basin sites. The larger amplification at short periods in the basin edge sites is caused by the fact that the short period components are predominant in the basin edge where site period is relatively short. We observed large amplifications for long periods in the center of the basin, as expected.

\footnotetext{
${ }^{1}$ Risk Management Solutions.

2Texas Tech University.
} 


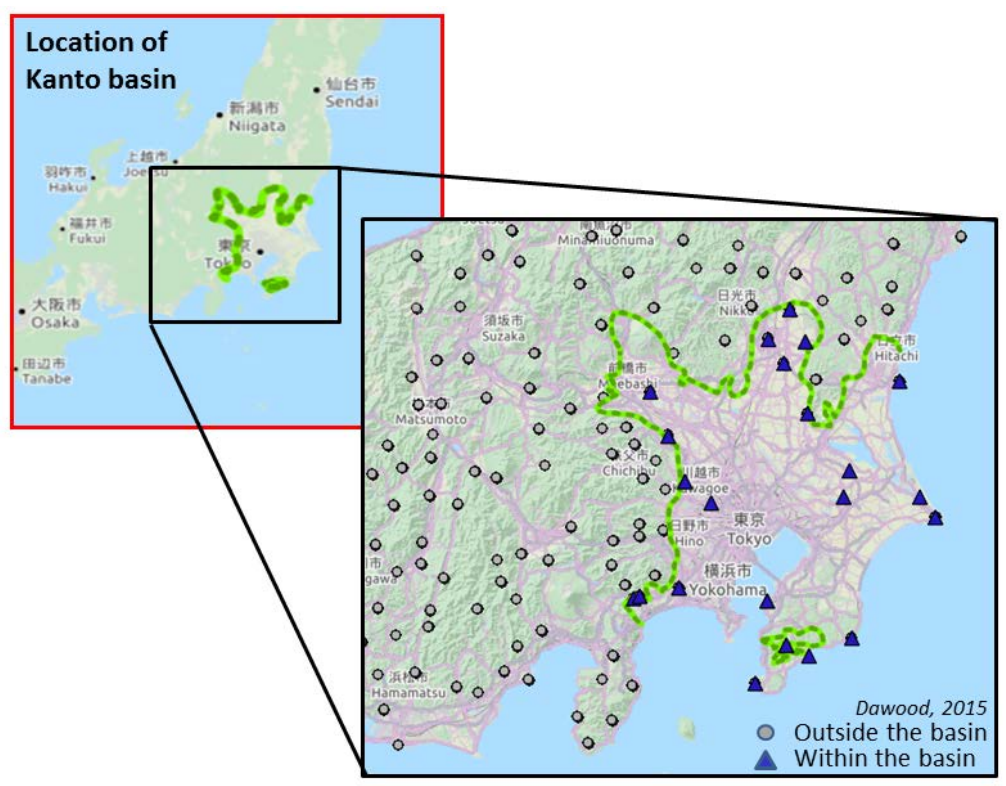

Figure 1. Location of Kanto basin and the data extent.

\section{References Cited}

Haitham M. Dawood, Adrian Rodriguez-Marek, Jeff Bayless, Christine Goulet, and Eric Thompson (2016) A Flatfile for the KiK-net Database Processed Using an Automated Protocol. Earthquake Spectra: May 2016, Vol. 32, No. 2, pp. 1281-1302. 


\section{Surface ruptures associated with the 2016 Kumamoto earthquake sequence, central Kyushu, Japan}

By Yoshiki Shirahama, ${ }^{1}$ Masayuki Yoshimi, ${ }^{1}$ Yasuo Awata,,${ }^{1}$ Tadashi Maruyama, ${ }^{1}$ Takashi Azuma, ${ }^{1}$ Yukari Miyashita, ${ }^{1}$ Hiroshi Mori, ${ }^{2}$ Kazutoshi Imanishi, ${ }^{1}$ Naoto Takeda, ${ }^{1}$ Tadafumi Ochi, ${ }^{1}$ Makoto Otsubo, ${ }^{1}$ Daisuke Asahina, ${ }^{1}$ and Ayumu Miyakawa ${ }^{1}$

The 2016 Kumamoto earthquake sequence started with a $M_{\mathrm{J}}$ (Japan Meteorological Agency magnitude) 6.5 event on April 14, and culminated in a $M_{\mathrm{J}} 7.3$ event on April 16. Associated with the sequence, approximately $34 \mathrm{~km}$ of surface ruptures appeared along the eastern part of the Futagawa fault zone and the northernmost part of the Hinagu fault zone. We carried out an urgent field investigation soon after the earthquake to map the extent and displacement of surface ruptures with the following results. (1) The rupture zone generally consisted of a series of leftstepping en echelon arrays of discontinuous fault traces of various lengths (fig. 1). (2) Slip exceeding $100 \mathrm{~cm}$ occurred on previously unrecognized fault traces in the alluvial lowland of the Kiyama plain and on the western limb of the Aso volcano caldera (fig. 2). (3) The maximum dextral slip of $220 \mathrm{~cm}$ was measured throughout the central section of the rupture zone along the Futagawa segment, and the slip gradually decreased bilaterally on the adjoining northeastern and southwestern sections (fig. 2). (4) The surface rupture mostly occurred along fault traces mapped in previous paleoseismological and active fault investigations (fig. 1). (5) Most of the surface ruptures were produced by the mainshock, and significant postseismic slip occurred after the mainshock.

\footnotetext{
${ }^{1}$ Geological Survey of Japan, Advanced Industrial Science and Technology.

${ }^{2}$ Faculty of Science, Shinshu University.
} 


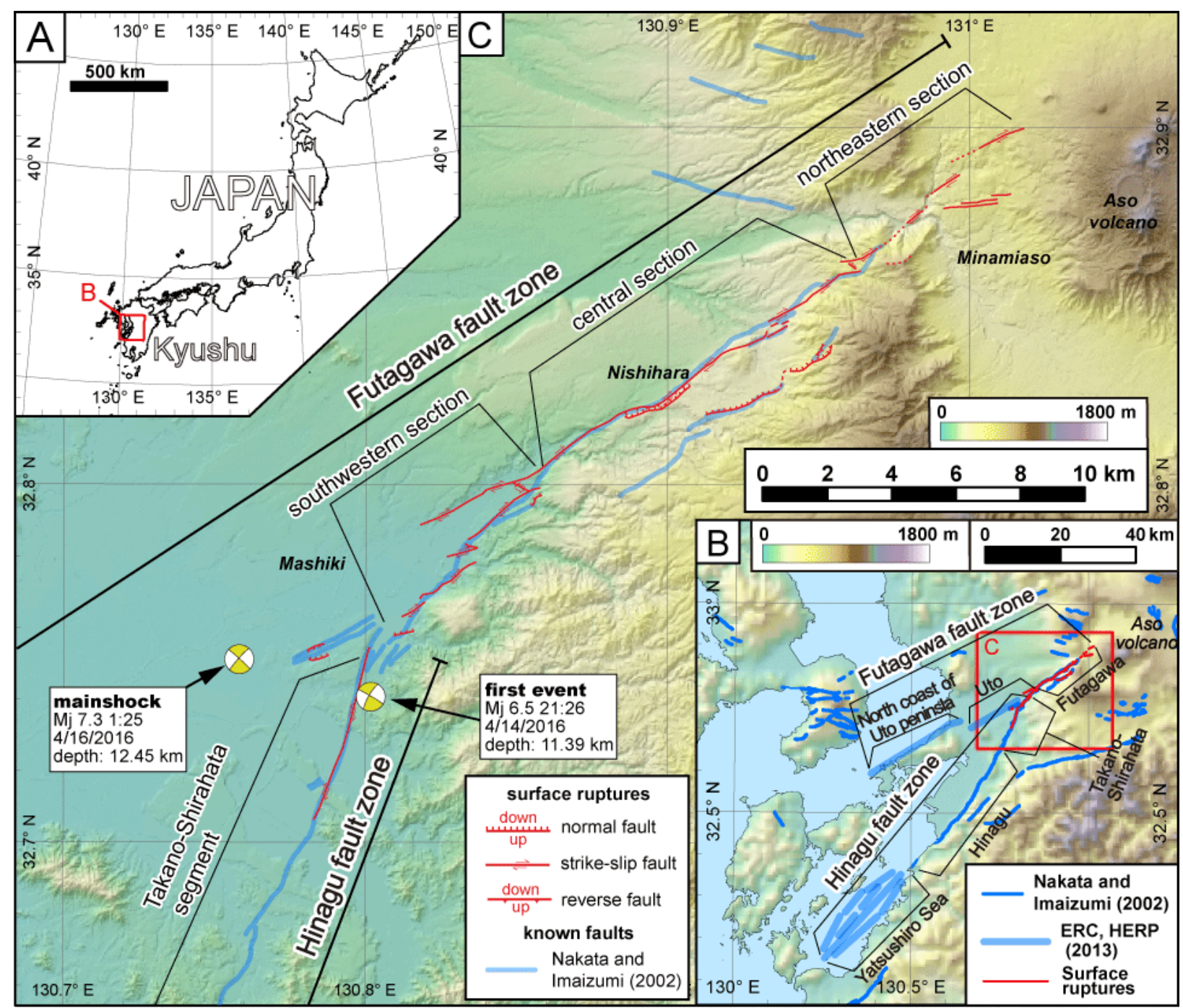

Figure 1. (A) Location of the study area in Kyushu, southwestern Japan. (B) Active faults in the western part of central Kyushu (blue lines after Nakata and Imaizumi 2002, light blue lines after ERC, HERP 2013) and the 2016 surface ruptures (red lines). (C) Distribution of surface ruptures associated with the 2016 Kumamoto earthquake sequence observed during our survey (red lines), previously mapped active faults (blue lines) and the best double-couple solution of centroid moment tensor diagrams for the mainshock and the initial MJ 6.5 event (yellow beach balls) determined by the Japan Meteorological Agency, and unconfirmed ruptures interpreted from aerial photos (GSI 2016) (dashed red lines). 


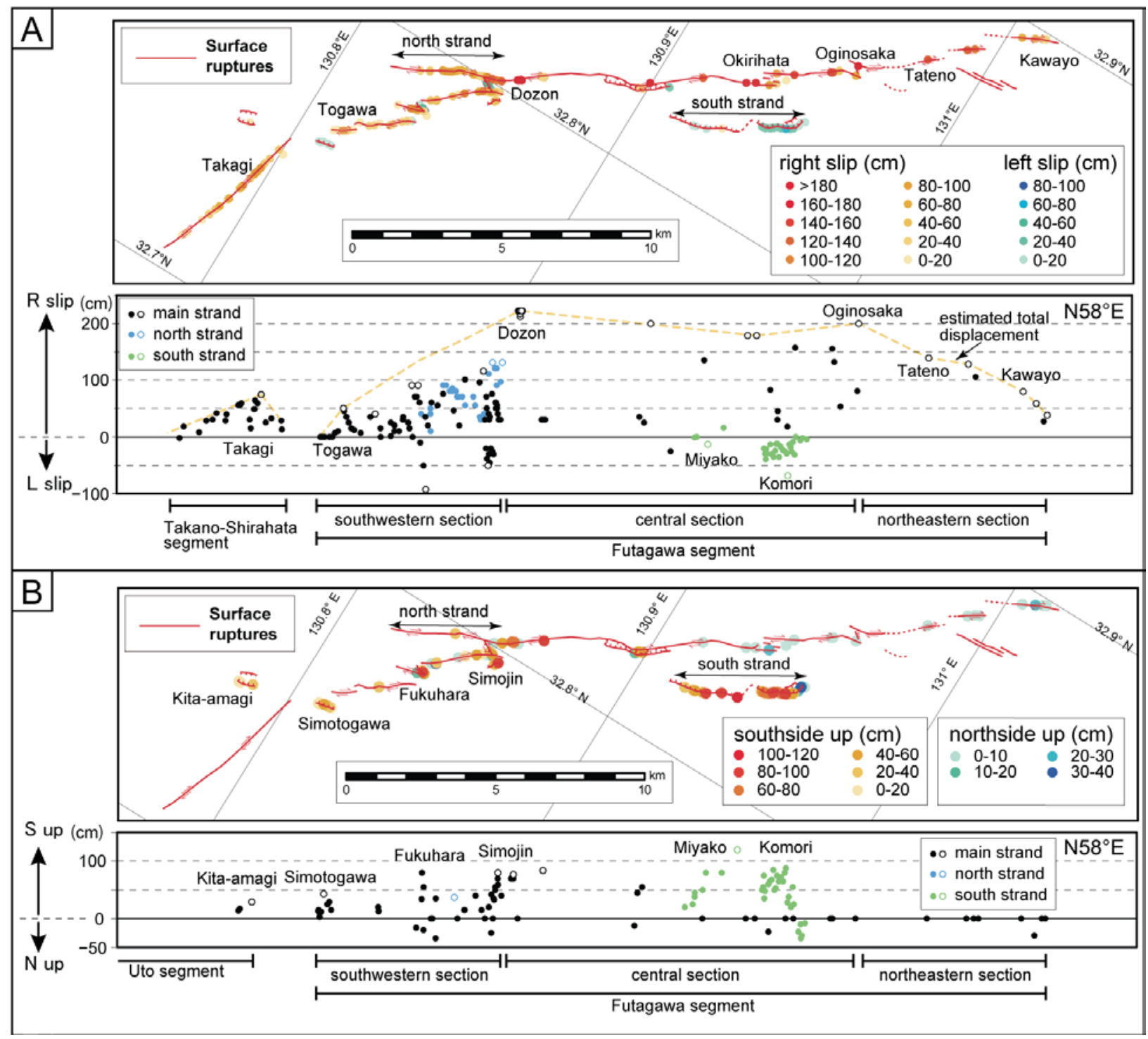

Figure 2. (A) Distribution of the strike-slip component of surface ruptures (red lines) at measured locations (colored dots with the amount of displacement represented by their shade) along the Futagawa and Hinagu fault zones (top); explanation of surface ruptures in fig. 1C. Diagram of slip distribution along the fault zone (bottom). Open dots show the representative displacement at each substrand. Dashed yellow line shows the estimated total displacement. $(B)$ Distribution of the vertical component of surface ruptures along the Futagawa fault zone.

\section{References Cited}

Earthquake Research Committee, Headquarters for Earthquake Research Promotion (2013) Longterm evaluation of the Futagawa and Hinagu fault zones (2013 revision).

Geospatial Information Authority of Japan (2016) Orthoimages at Nishihara area, taken on 16 April.

Nakata T, Imaizumi T (2002) Digital active fault map of Japan. Univ Tokyo Press. 60. 


\section{Earthquake Fatalities Mapping for the Eastern Asia Earthquake and Volcanic Hazards Information Map}

By Masayuki Yoshimi, ${ }^{1}$ Shinji Takarada, ${ }^{1}$ Yuzo Ishikawa, ${ }^{1}$ Bandibas Joel, ${ }^{1}$ Tadashi Maruyama, ${ }^{1}$ Dan Matsumoto, ${ }^{1}$ Takashi Azuma, ${ }^{1}$ Ryuta Furukawa,${ }^{1}$ Akira Takada, ${ }^{1}$ Yasuto Kuwahara, ${ }^{1}$ and Eikichi Tsukuda ${ }^{1}$

The Eastern Asia Earthquake and Volcanic Hazards Information Map is published in May 2016. This map illustrates geology and tectonics, active faults, earthquakes hypocenters and source areas, fatalities of major earthquakes, tsunami hazards, distribution of volcanoes, calderas, pyroclastic falls and ignimbrites, and fatalities of major volcanic events. We believe that this hazards information map will provide useful information for earthquake, tsunami, and volcanic disaster mitigation efforts.

Earthquake fatalities map is one of the major contents, which has been compiled to facilitate visual understanding of earthquake disasters in terms of their number of fatalities (deaths) and the main causes of deaths. Major disastrous earthquakes in terms of number of fatalities are selected in each country or region: all the recent (after 1850) events with fatalities more than 1,000 (hereafter, F1000 event) are included; for a country with less than three F1000 events, two F100-F10 events are added; for a country with no F1000 events, up to two F100 events or one worst earthquake with fatalities are added. The number of fatalities is categorized by five causes; structure (building) damage, tsunami, landslide, fire, and others (related death), when possible. It is important to understand that an earthquake and ground motions do not directly kill people, but vulnerable structures, fire, landslide, or tsunami do. The number of fatalities is mainly based on the Significant Earthquake Database (NGDC/WDS) provided by NOAA, and individual reports of each earthquake, if any.

The contents of the Information Map are planning to be implemented on the online hazard information system (http://ccop-geoinfo.org/G-EVER). We are going to collect more data or reports to make the map more reliable.

${ }^{1}$ Geological Survey of Japan/AIST . 


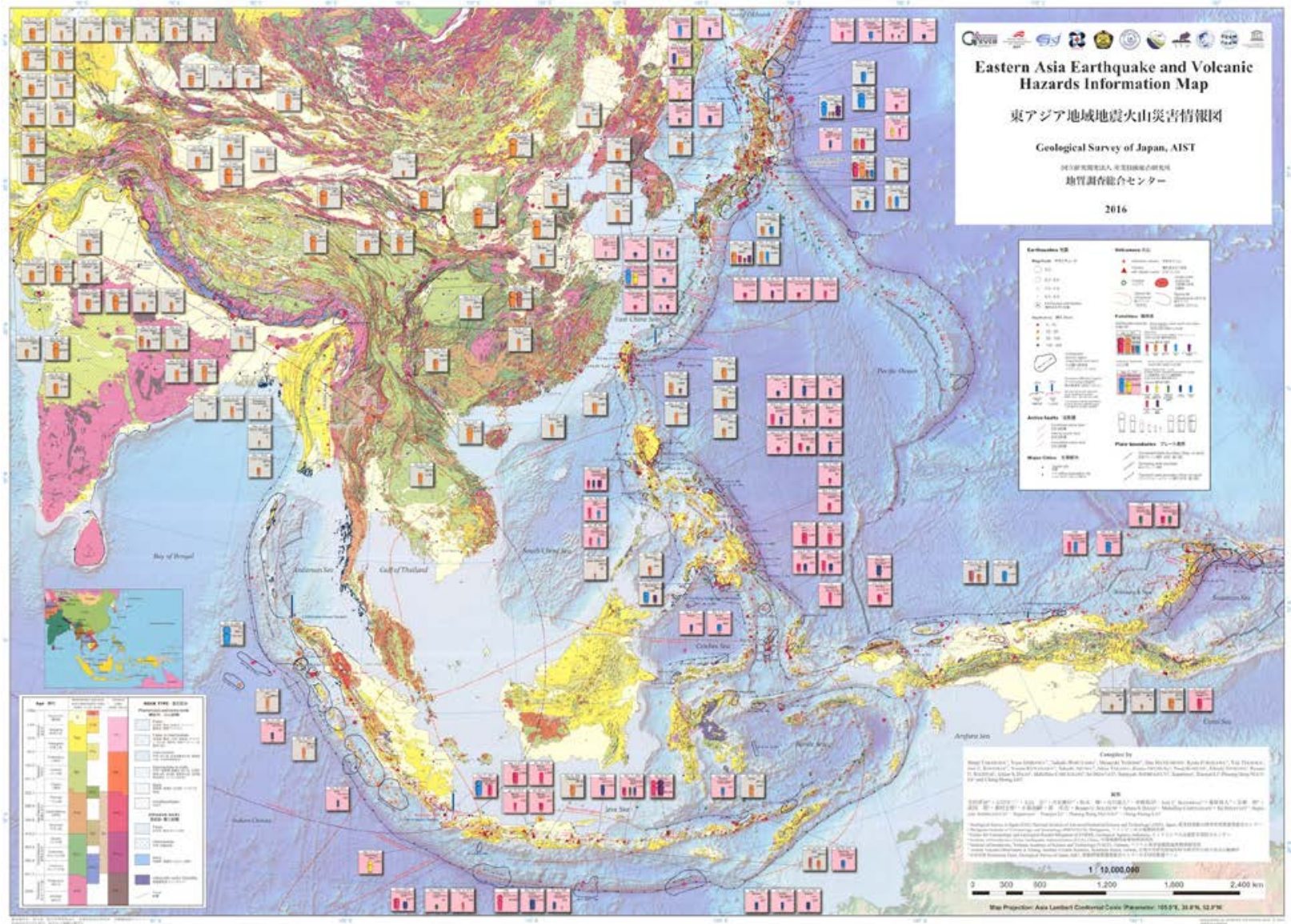

Figure 1. Eastern Asia Earthquake and Volcanic Hazards Information Map. 


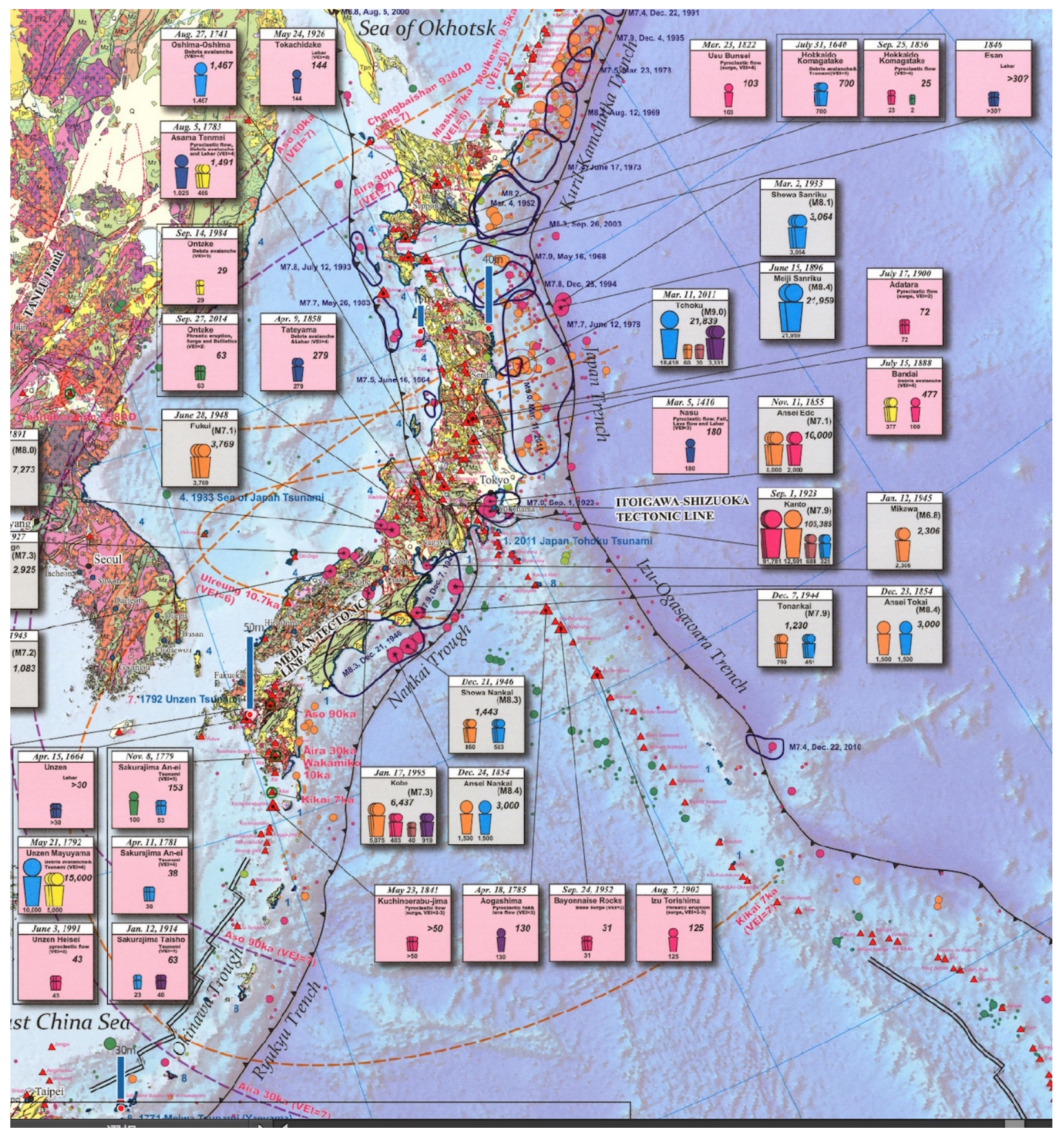

Figure 2. Blowup image around Japan from the map. 
ISSN 2331-1258 (online)

https://doi.org/10.3133/ofr20171133 